MARIA FERNANDA QUINTANA YTZA

MÉTODOS CONSTRUTIVOS DE PONTES ESTAIADAS ESTUDO DA DISTRIBUIÇÃO DE FORÇAS NOS ESTAIS

São Paulo

2009 


\section{MÉTODOS CONSTRUTIVOS DE PONTES ESTAIADAS - ESTUDO DA DISTRIBUIÇÃO DE FORÇAS NOS ESTAIS}

Dissertação apresentada à Escola Politécnica da Universidade de São Paulo como parte dos requisitos para a obtenção do título de Mestre em Engenharia de Estruturas

Área de Concentração:

Engenharia de Estruturas

Orientador:

Prof. Titular Fernando Rebouças Stucchi 
Este exemplar foi revisado e alterado em relação à versão original, sob responsabilidade única do ator e com a anuência de seu orientador.

São Paulo, 16 de março de 2009

Assinatura do autor

Assinatura do orientador

FICHA CATALOGRÁFICA

Ytza, Maria Fernanda Quintana

Métodos construtivos de pontes estaiadas : estudo da distribuição de forças nos estais /Maria Fernanda Quintana Ytza. -- São Paulo, 2009.

$151 \mathrm{p}$.

Dissertação (Mestrado) - Escola Politécnica da Universidade de São Paulo. Departamento de Engenharia de Estruturas e Geotécnica.

1. Pontes estaiadas (Comportamento estrutural) 2. Sistemas e processos construtivos 3. Forças de instalação dos Estais I. Universiade de São Paulo. Escola Politécnica. Departamento de Engenharia de Estruturas e Geotécnica II. t. 
À minha mãe, fundação da minha vida... 
"O mais importante é conseguir sacrificar o que somos pelo que poderíamos chegar a ser." Anônimo 


\section{AGRADECIMENTOS}

A minha mãe por ter me apoiado incondicionalmente nesta e em todas as etapas da minha vida, por ter iluminado os caminhos obscuros com amor e dedicação, por terme dado tudo e ainda mais.

Ao meu orientador Fernando Rebouças Stucchi, pela orientação paciência e motivação demonstradas ao longo deste trabalho.

Ao Prof. Hideki Ishitani e o Eng. Daniel Berguer pelos importantes aportes feitos para a conclusão deste trabalho.

Aos amigos do Laboratório de Estruturas e Materiais (LEM), Carol, Luciana, Marcelo e Renato por ter compartilhado esta etapa da minha vida.

Às pessoas que me orientaram na redação deste trabalho: Carol, Luciana, Marcelo e Sandro.

Aos meus primeiros orientadores no Uruguai Eng. Alberto Ponce e Dr. Eng. Eduardo Pedoja por ter me introduzido neste maravilhosa profissão.

À Conselho Nacional de Desenvolvimento Cientifico e Tecnológico (CNPq) pelo apoio financeiro 


\section{RESUMO}

As pontes estaiadas consistem de um tabuleiro suportado por cabos retos e inclinados (estais) fixados nos mastros. Este tipo de estrutura é altamente hiperestática, bastante sensível à seqüência construtiva, mas mesmo assim aceitando, por conta a flexibilidade do tabuleiro, uma considerável gama de esforços de instalação dos estais. É importante escolher uma distribuição inicial apropriada para esses esforços sob carregamento permanente tal que a flexão no tabuleiro seja limitada. A presente pesquisa tem como objetivo estudar diferentes métodos para a obtenção de uma boa distribuição de esforços nos estais em pontes estaiadas. Os métodos estudados nesta pesquisa são: o método do tabuleiro articulado (uma articulação em cada cruzamento com os estais - MTA), o método de anulação dos deslocamentos (MAD), o método de anulação das reações em apoios fictícios (MAR) e o método de anulação dos deslocamentos ao longo do processo construtivo. A idéia final de todos eles é obter para o tabuleiro uma resposta próxima à de uma viga continua. Porém, se for necessário, pode-se controlar também os deslocamentos do mastro. Os três primeiros métodos são estudados para a configuração final da ponte, mas também foram verificados seus resultados considerando o processo construtivo, já que durante esta etapa ocorrem variações nos esforços internos da ponte alterando assim o resultado final. Todos os resultados são comparados com a finalidade de escolher um método que além de controlar a configuração final da ponte apresente uma distribuição aceitável de esforços ao final da construção. Desta forma, pode-se obter uma boa estimativa dos esforços de instalação dos estais. 


\begin{abstract}
Cable-stayed bridges consists of a deck supported by inclined and straight cables anchored to the pylons. This type of structure is highly hyperestatic and quite sensitive to the construction sequence, but yet supporting a considerable range of loadings from the cable installation due to the deck flexibility. Nevertheless, due to the deck flexibility the cables can accept a considerable range of loadings. It is important to choose an appropriate initial distribution for those loadings under permanent load, so that the bending moment on the bridge deck is limited. The main goal of this research is to study the different methods for obtaining a good load distribution in cables in cable-stayed bridges. The methods that are studied in this research are: The articulated deck method (there is a joint in every cable-deck junction - MTA), the zero displacement method (MAD), the ficticious support force equilibrium method (MAR), and the construction process zero displacement method. The objective of them all is to obtain a deck bending moment similar to that of a continuous beam. However, if necessary, the displacements of the pylon can be controlled. The first three methods are studied for the bridge final configuration. However, their results for the initial configuration during the construction process are also verified, since there are significant bridge internal loading variations which may change the final outcome. All the results are evaluated in order to choose a method that not also controls the bridge final configuration, but also presents an acceptable cable loading distribution at the end of the construction. This way, a good estimative of the loadings from the pylons installation can be obtained.
\end{abstract}




\section{SUMÁRIO}

FICHA CATALOGRÁFICA .......................................................................... II

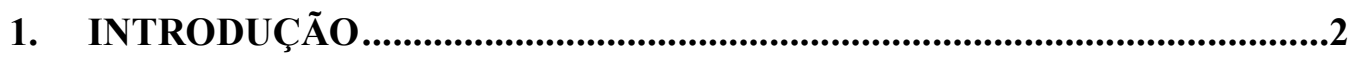

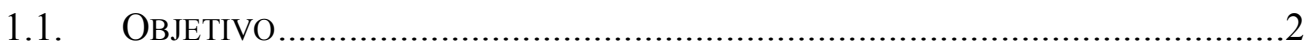

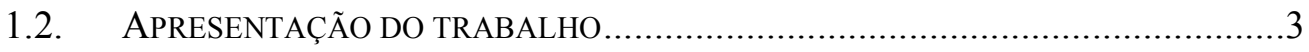

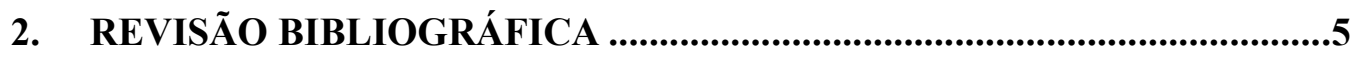

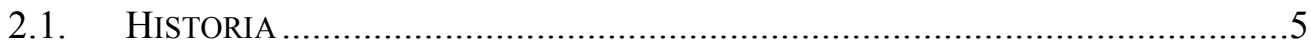

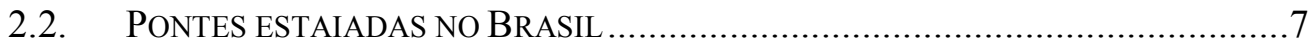

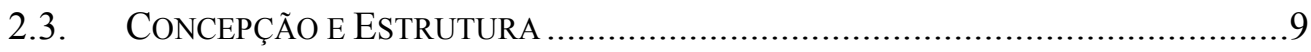

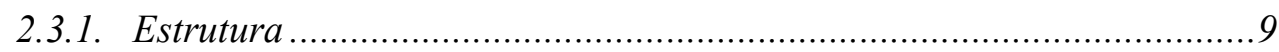

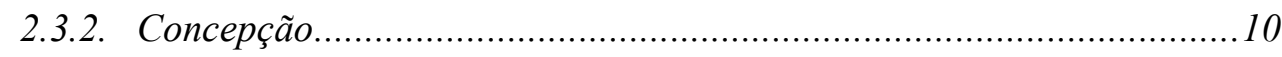

2.4. MÉTodos Construtivos nas Pontes EstaiAdas ..................................12

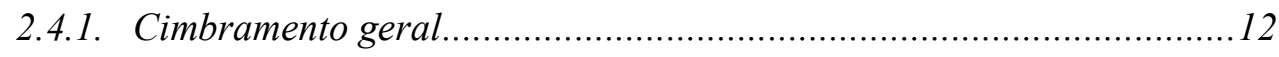

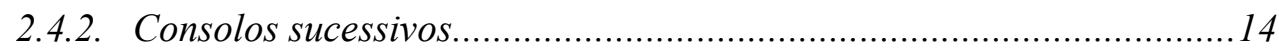

2.4.3. Lançamentos progressivos.............................................................21

3. EXEMPLO DE APLICAÇÃ̃ .......................................................................25

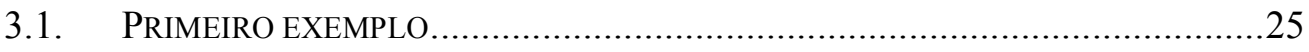

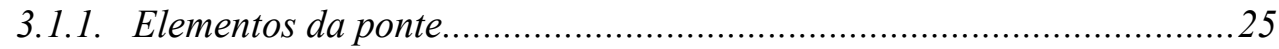

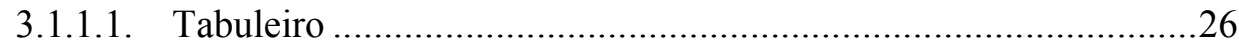

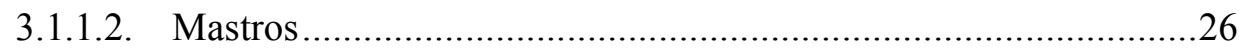

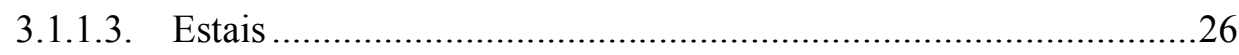

3.2. Segundo EXEMPlo: Ponte Construtor João Alves SObRe o Rio

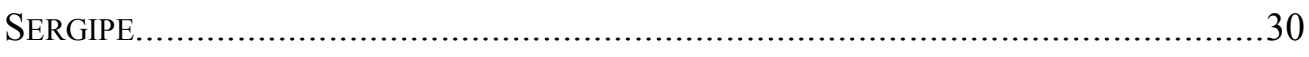

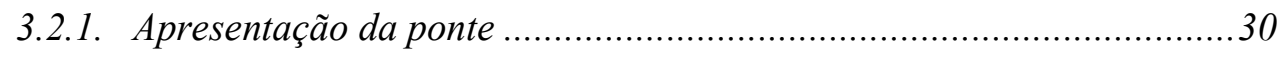

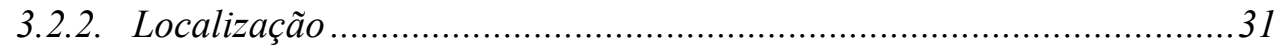

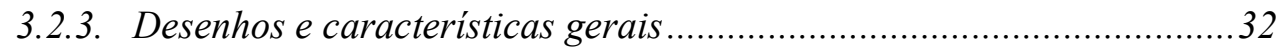

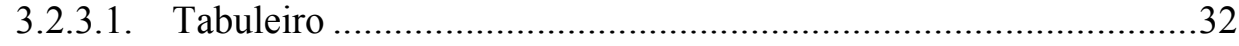

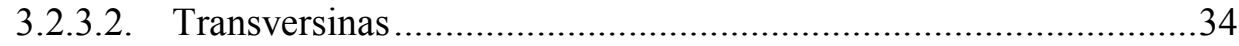

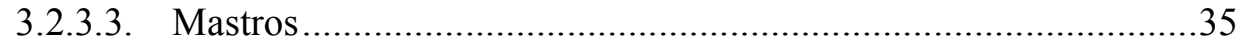

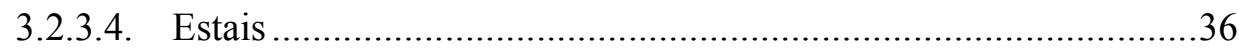

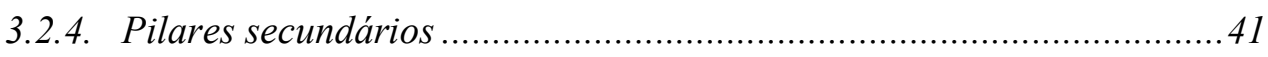


4. MODELAGEM DOS EXEMPLOS....................................................47

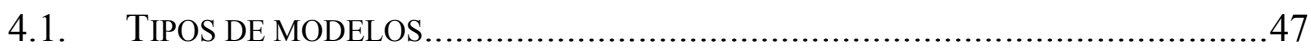

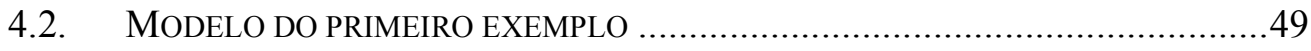

4.3. Modelo PARA A Ponte CONSTRUtOR JoÃo AlVES..................................51

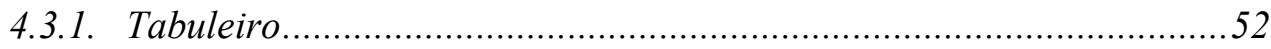

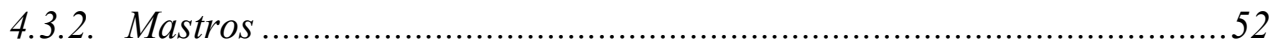

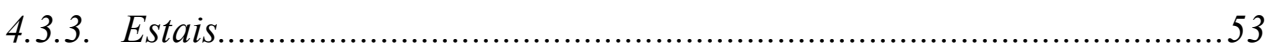

\section{DETERMINAÇÃO DAS FORÇAS DE INSTALAÇÃO DOS ESTAIS .....55}

5.1. MÉtodo do tabUleiro ARTiculado EM todos os ESTAis (MTA) ...........55

5.2. MÉTOdO DE ANULAÇÃO DOS DESLOCAMENTOS (MAD) ..............................57

5.3. MÉTOdO DE ANULAÇÃO DAS REAÇÕES EM APOIOS FICTÍCIOS (MAR) ..........61

5.4. MÉTOdo DE ANULAÇÃo DOS DESLOCAMENTOS AO LONGO DO PROCESSO

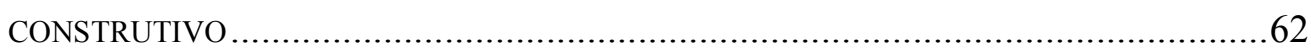

6. RESULTADOS DOS MÉTODOS ......................................................66

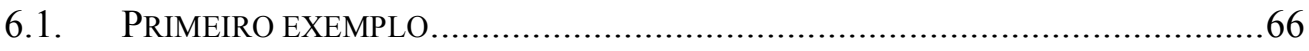

6.1.1. Método do tabuleiro articulado em todos os estais (MTA) ..................66

6.1.2. Método de anulação dos deslocamentos (MAD)............................... 70

6.1.3. Método de anulação das reações em apoios fictícios (MAR) ................75

6.1.4. Método de anulação dos deslocamentos no processo construtivo (MAD

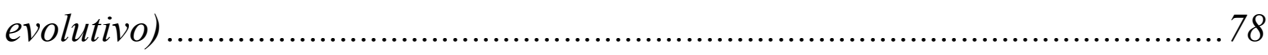

6.1.5. Comparação dos métodos........................................................... 82

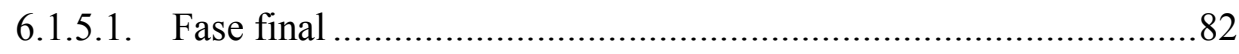

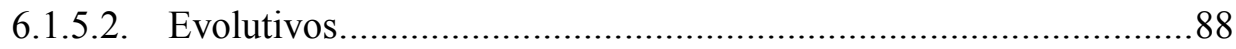

6.2. Segundo eXemplo: Ponte Construtor JoÃo Alves .............................96

6.2.1. Método do tabuleiro articulado em todos os estais (MTA) ..................96

6.2.2. Método de anulação dos deslocamentos (MAD)............................... 100

6.2.3. Método de anulação das reações em apoios fictícios (MAR) .............. 104

6.2.4. Método de anulação dos deslocamentos no processo construtivo (MAD

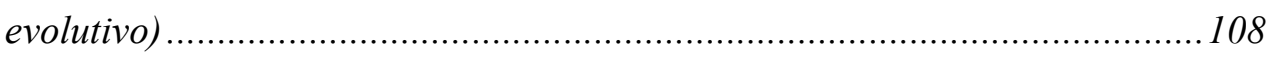

6.2.5. Comparação dos métodos......................................................... 112 


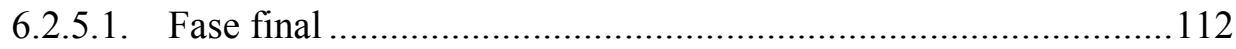

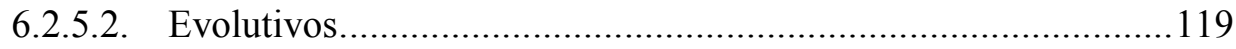

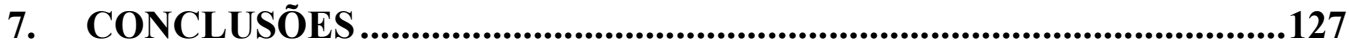

7.1. CONCLUSÕES E CONSIDERAÇÕES GERAIS ...............................................127

7.2. CONCLUSÕES DOS ESTUDOS NA CONFIGURAÇÃO FINAL ............................127

7.3. CONCLUSÕES DOS ESTUDOS EVOLUTIVOS .............................................129

7.4. CONCLUSÕES FINAIS SOBRE OS RESULTADOS .......................................130

7.5. SUGESTÕES PARA TRABALHOS FUTUROS............................................... 130

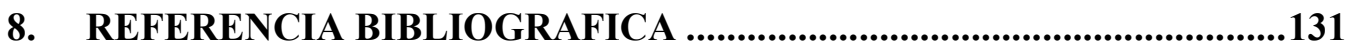




\section{LISTA DE FIGURAS}

Figura 2.1: Barco egípcio com cordas suportando a vela (TROITSKY, 1977)..........5

Figura 2.2: Ponte estaiada em madeira C.J.Löscher (1784) (TROITSKY, 1977) ......6

Figura 2.3: Sistema de pontes estaiadas com correntes proposto por Navier (TROITSKY, 1977).

Figura 2.4: A) Ponte de Porto Alencastro sobre o Rio Paranaíba (www.transportes.gov.br), B) Ponte estação metroviária Engenheiro Jamil Sabino sobre o Rio Pinheiros, São Paulo(www.panoramio.com), C) Ponte sobre o Rio Guamá, Belém do Pará (www.abcp.org.br) .................................................... 8

Figura 2.5: Componentes de uma ponte estaiada ..................................................

Figura 2.6: Arranjo transversal e longitudinal dos cabos .................................... 9

Figura 2.7: Fluxograma simplificado do projeto e uma ponte estaiada a partir do estabelecido por WALTHER (1985) .11

Figura 2.8: Exemplo de ponte moldada "in loco" sobre cimbramento fixo (PODOLNY, 1976) .13

Figura 2.9: Processo construtivo da ponte sobre o Rio Rin, Maxau (Alemanha)

(PODOLNY, 1976) 14

Figura 2.10: A) e B) Vistas do Pilar e Aduelas da Ponte Libertador General San Martín (PUENTE LIBERTADOR GENERAL SAN MARTIN, 1992)......................17

Figura 2.11: Esquema da Ponte de Porto Alencastro sobre o Rio Paranaíba (GOLEBIEWSKI, 2008) .18

Figura 2.12: Processo construtivo da ponte sobre o Rio Paranaíba (GOLEBIEWSKI, 2008)

Figura 2.13: Esquema do sistema de lançamento progressivo...............................21

Figura 2.14: Viaduto de Millau, França ...........................................................22

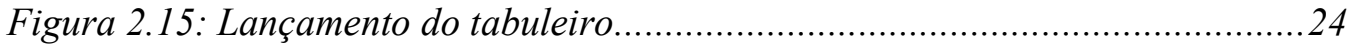

Figura 2.16: Processo de montagem dos mastros ..............................................24

Figura 3.1: Ponte estaiada, primeiro exemplo ..................................................25

Figura 3.2: Seção do tabuleiro e transversina (medidas em metros) .......................26

Figura 3.3: Numeração dos estais .....................................................................2

Figura 3.4: Esquema de forças para dimensionamento do estai de estabilidade.......30

Figura 3.5: Localização de Aracaju no Estado de Sergipe (pt.wikipedia.org) ..........32 
Figura 3.6: Foto da Ponte Construtor João Alves sobre o Rio Sergipe

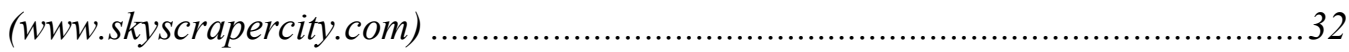

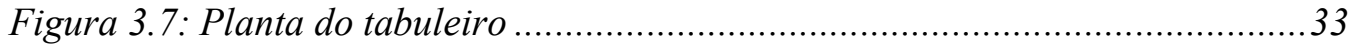

Figura 3.8: Detalhe das Transversinas (medidas: $\mathrm{cm}$ ) ........................................... 34

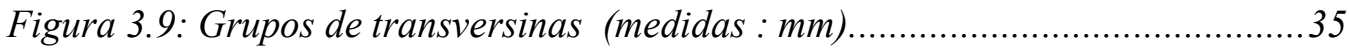

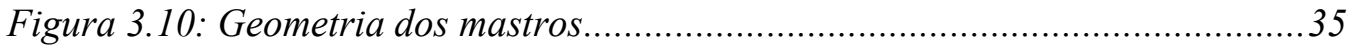

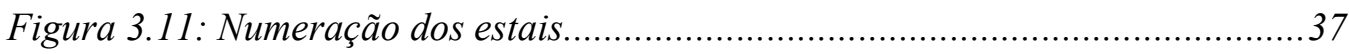

Figura 3.12: Esquema dos encontros dos estais ................................................ 37

Figura 3.13: Esquema de elementos de um estai sistema "TSR" (Catalogo Protende) 39

Figura 3.14: Primeira fase construtiva .......................................................... 42

Figura 3.15: Segunda fase construtiva .......................................................... 42

Figura 3.16: Terceira fase construtiva ........................................................... 43

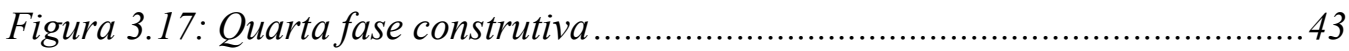

Figura 3.18: Quinta fase construtiva .......................................................... 44

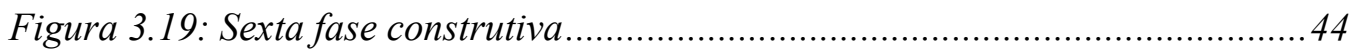

Figura 3.20: Sétima fase construtiva ........................................................... 45

Figura 3.21: Oitava fase construtiva ........................................................... 45

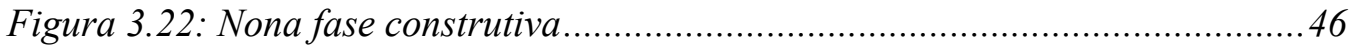

Figura 4.1: A) Ponte Düsseldorf-Flehe sobre o Rio Rhin na Alemanha (http://en.structurae.de), B) Modelo da Ponte (WALTHER, 1999)........................47

Figura 4.2:A) Ponte Diepoldsau sobre o Rio Alpenrhein na Suiça (http://en.structurae.de), B) Modelo da Ponte (WALTHER, 1999)..........................48

Figura 4.3:Modelo plano do primeiro exemplo ......................................................49

Figura 4.4: Segundo modelo da Ponte Constritor João Alves- modelo plano ...........51

Figura 4.5: Seção do tabuleiro (medidas em centímetros)......................................52

Figura 5.1: Fluxograma do Método de anulação dos deslocamentos .......................60

Figura 5.2: Fluxograma do Método de anulação das reações em apoios ficticios ...62

Figura 5.3: Diagrama de esforços no estai i na fase construtiva ............................63

Figura 5.4: Solução de contrapeso para processo construtivo ...............................64

Figura 5.5: Solução de cabos de protensão para processo construtivo ...................65

Figura 6.1: Distribuição de esforços dos estais do primeiro exemplo(MTA) ...........67 
Figura 6.2: A) Deformada da ponte devida ao peso-próprio sem protensão dos estais, B) Deformada da ponte com forças do MTA ...............................................67

Figura 6.3: Deformada da ponte do primeiro exemplo (MTA) ..............................68

Figura 6.4: A)Forma do mastro, B) Momento no mastro devido ao peso-próprio sem protensão nos estais, C) Momento no mastro com forças do MTA..........................68

Figura 6.5: A)Forma do tabuleiro (metade), B) Momento no tabuleiro devido ao peso-próprio sem protensão nos estais, C) Momento no tabuleiro com forças do MTA

Figura 6.6: Distribuição de esforços dos estais do primeiro exemplo (MAD)..........72

Figura 6.7: Deformada do tabuleiro do primeiro exemplo (MAD) ........................ 73

Figura 6.8: A) Deformada da ponte devida ao peso-próprio sem protensão dos

estais, B) Deformada da ponte com forças do MAD ............................................ 73

Figura 6.9: A)Forma do mastro, B) Momento no mastro devido ao peso-próprio sem protensão dos estais, C) Momento no mastro com forças do MAD ......................... 74

Figura 6.10: A)Forma do tabuleiro (metade), B) Momento no tabuleiro devido ao peso-próprio sem protensão dos estais, C) Momento no tabuleiro com forças do

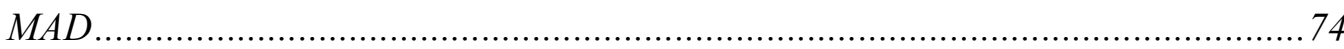

Figura 6.11: Distribuição de esforços dos estais do primeiro exemplo (MAR) ........76 Figura 6.12: A) Deformada da ponte sem protensão dos estais, B) Deformada da ponte com forças do MAR 76

Figura 6.13: A)Forma do tabuleiro (metade), B) Momento no tabuleiro devido ao peso-próprio sem protensão dos estais, C) Momento no tabuleiro com forças do $M A R$ 77

Figura 6.14: A)Forma do mastro, B) Momento no mastro devido ao peso-próprio sem protensão dos estais, C) Momento no mastro com forças do MAR

Figura 6.15: Distribuição de esforços dos estais do primeiro exemplo (MAD evolutivo)

Figura 6.16: A) Deformada da ponte sob carregamento de peso próprio sem protensão dos estais, B) Deformada da ponte com forças do MAD evolutivo .80 Figura 6.17: A)Forma do mastro, B) Momento no mastro devido ao peso-próprio sem protensão dos estais, C) Momento do mastro com forças do MAD evolutivo....80 
Figura 6.18: A)Forma do tabuleiro (metade), B) Momento no tabuleiro devido ao peso-próprio sem protensão dos estais, C) Momento do tabuleiro com forças do MAD evolutivo .81

Figura 6.19: Comparação dos esforços do MTA, MAD e MAR para o primeiro exemplo .84

Figura 6.20: Comparação dos deslocamentos do MTA, MAD e MAR para o primeiro exemplo

Figura 6.21: A)Forma do mastro, B) Momento no mastro devido ao peso-próprio sem protensão dos estais, C) Momento no mastro para o MTA, D) Momento no mastro para o MAD, E) Momento no mastro para o MAR.

Figura 6.22: A) Forma do tabuleiro (metade), B) Momento do tabuleiro para o pesopróprio sem protensão dos estais, C) Momento no tabuleiro para o MTA, D) Momento no tabuleiro para o MAD, E) Momento no tabuleiro para o MAR .87

Figura 6.23: Comparação dos esforços dos evolutivos dos métodos e o processo construtivo para o primeiro exemplo

Figura 6.24: A) Deformada da ponte ao final do evolutivo sem protensão dos estais, B) Deformada da ponte com forças do MTA, C) Deformada da ponte com forças do $M A D, D)$ Deformada da ponte com forças do MAR, E) Deformada da ponte com forças do MAD evolutivo .92

Figura 6.25: Diagrama dos deslocamentos dos evolutivos dos métodos e o processo construtivo para o primeiro exemplo. 93

Figura 6.26: A) Forma do mastro, B) Momento no mastro devido ao peso-próprio sem protensão dos estais(fase final), C) Momento no mastro com forças do MTA, D) Momento no mastro com forças do MAD, E) Momento no mastro com forças do MAR, F) Momento do mastro com forças do MAD evolutivo.

Figura 6.27: A) Forma do tabuleiro (metade), B) Momento do tabuleiro devido ao peso-próprio sem protensão dos estais, C) Momento no tabuleiro com forças do $M T A, D)$ Momento no tabuleiro com forçaso do MAD, E) Momento no tabuleiro com forças do MAR, F) Momento do tabuleiro com forças do MAD evolutivorutivo......95 Figura 6.28: Distribuição de esforços dos estais do segundo exemplo (MTA) .........97 Figura 6.29: A) Deformada da ponte sem protensão dos estais, B) Deformada da ponte com forças do MTA 
Figura 6.30: A) Forma do tabuleiro (metade), B) Momento no tabuleiro devido ao peso próprio sem protensão dos estais, C)Momento no tabuleiro com forças do MTA

Figura 6.31: A) Forma do mastro, B) Momento no mastro devido ao peso-próprio sem protensão dos estais, C) Momento no mastro com forças do MTA. .99

Figura 6.32: Distribuição de esforços dos estais da Ponte Construtor João Alves (MAD) 101

Figura 6.33: A) Deformada da ponte sem porotensão dos estais, B) Deformada da ponte com forças do MAD. 101

Figura 6.34: A) Forma do tabuleiro (metade), B) Momento no tabuleiro devido ao peso próprio sem protensão dos estais, C)Momento no tabuleiro com forças do MAD

Figura 6.35: A) Forma do mastro, B) Momento no mastro devido ao peso-próprio sem protensão dos estais, C) Momento no mastro com forças do MAD. 103

Figura 6.36: Distribuição de esforços dos estais da Ponte Construtor João Alves $(M A R)$

Figura 6.37: A) Deformada da ponte sem protensão dos estais, B) Deformada da ponte com forças do MAR. 105

Figura 6.38: A) Forma do tabuleiro (metade), B) Momento no tabuleiro devido ao peso próprio sem protensão dos estais, C)Momento no tabuleiro com forças do MAR 106

Figura 6.39: A) Forma do mastro, B) Momento no mastro devido ao peso-próprio sem protensão dos estais, C) Momento no mastro com forças do MAR 107

Figura 6.40: Distribuição de esforços dos estais da Ponte Construtor João Alves (Processo Construtivo) 109

Figura 6.41: A) Deformada da ponte sem protesão dos estais, B) Deformada da ponte com forças do MAD evolutivo. 109

Figura 6.42: A) Forma do tabuleiro (metade), B) Momento no tabuleiro devido ao peso próprio sem protensão dos estais, C)Momento no tabuleiro com forças do MAD evolutivo 110

Figura 6.43: A) Forma do mastro, B) Momento no mastro devido ao peso-próprio sem protensão dos estais, C) Momento no mastro com forças do MAD evolutivo.. 111 Figura 6.44: Comparação da distribuição de esforços do segundo exemplo .........114 
Figura 6.45: Comparação dos deslocamentos. 116

Figura 6.46: A) Forma do tabuleiro (metade), B) Momento no tabuleiro devido ao peso próprio sem protensão dos estais, C)Momento no tabuleiro com forças do MTA, D) Momento no tabuleiro com forças do MAD, E) Momento no tabuleiro com forças do MAR 117

Figura 6.47: A) Forma do mastro, B) Momento no mastro devido ao peso-próprio sem protensão dos estais, C) Momento no mastro com forças do MTA,D) Momento no mastro com forças do MAD,E) Momento no mastro com forças do MAR ......... 118 Figura 6.48: A) Momento no tabuleiro para o MTA, B) Momento no tabuleiro para o MAD, C) Momento no tabuleiro para o MAR ............................................... 121

Figura 6.49: Comparação dos deslocamentos.................................................... 123 Figura 6.50: A) Deformada da ponte na fase final, B) Deformada da ponte com forças do MTA, C) Deformada da ponte com forças do MAD, D) Deformada a ponte com forças do MAR, E) Deformada da ponte com forças do MAD evolutivo .......... 124 Figura 6.51: A) Forma do tabuleiro (metade) na fase final, B) Momento no tabuleiro devido ao peso próprio sem protensão dos estais, C)Momento no tabuleiro com forças do MTA, D) Momento no tabuleiro com forças do MAD, E) Momento no tabuleiro com forças do MAR, F) Momento no tabuleiro com forças do MAD evolutivo 125

Figura 6.52: A) Forma do mastro, B) Momento no mastro devido ao peso-próprio sem protensão dos estais, C) Momento no mastro com forças do MTA,D) momento no mastro com forças do MAD, E) Momento no mastro com forças do MAR, F) Momento no mastro com forças do MAD evolutivo 126 


\section{LISTA DE TABELAS}

Tabela 2.1: Seqüencia construtiva das aduelas da ponte sobre o Rio Paranaíba

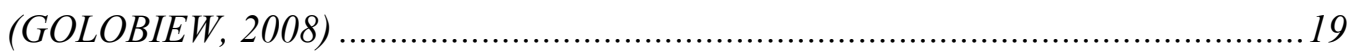

Tabela 3.1: Propriedades geométricas dos estais do primeiro exemplo...................29

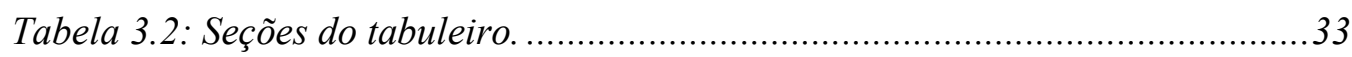

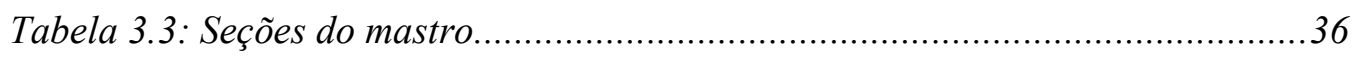

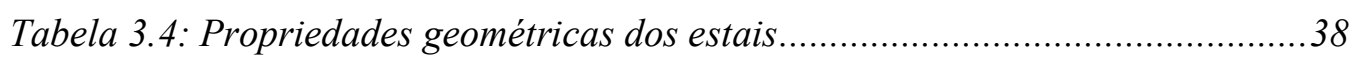

Tabela 3.5: Seções detalhadas ..........................................................................41

Tabela 4.1: Determinação do módulo de elasticidade corrigido (Módulo de

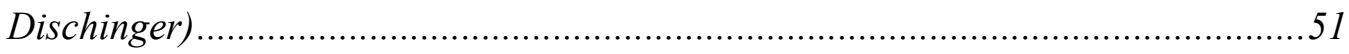

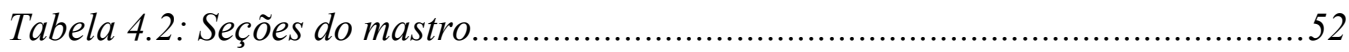

Tabela 4.3: Determinação do módulo de elasticidade corrigido (Módulo de

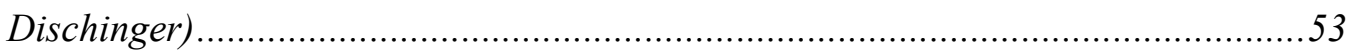

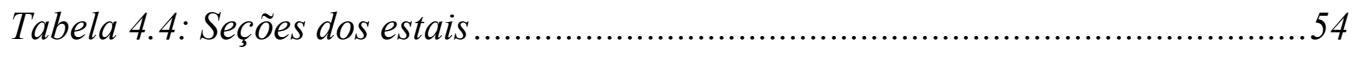

Tabela 6.1: Avaliação isostática do primeiro exemplo(MTA) .................................66

Tabela 6.2: Distribuição de temperaturas dos estais do primeiro exemplo (MAD)

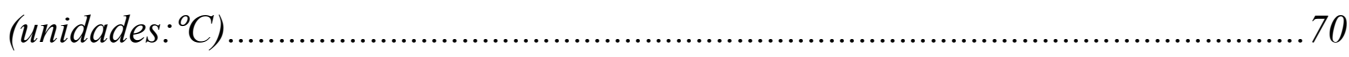

Tabela 6.3: Distribuição de esforços dos estais do primeiro exemplo (MAD)

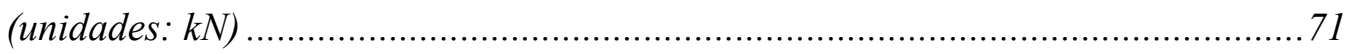

Tabela 6.4: Distribuição de esforços e temperaturas dos estais e deslocamentos dos

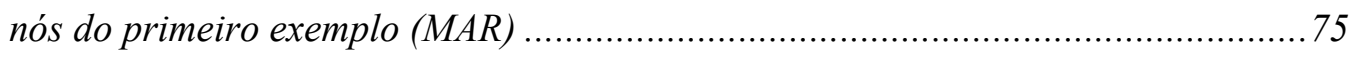

Tabela 6.5: Distribuição de esforços e temperaturas dos estais e deslocamentos dos

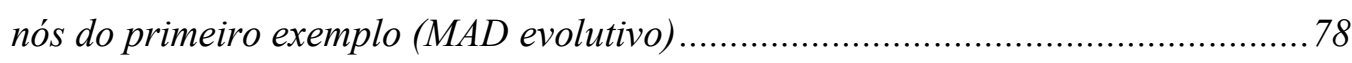

Tabela 6.6: Comparação das temperaturas do MTA, MAD e MAR para o primeiro

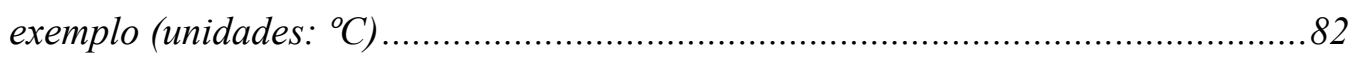

Tabela 6.7: Comparação dos esforços do MTA, MAD e MAR para o primeiro

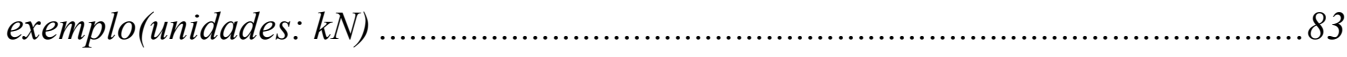

Tabela 6.8: Comparação das deslocamentos do MTA, MAD e MAR para o primeiro

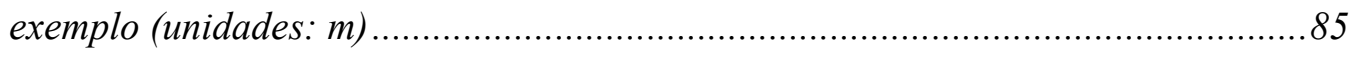

Tabela 6.9: Comparação das temperaturas nos estais dos evolutivos dos métodos

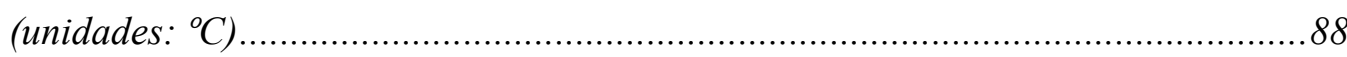


Tabela 6.10: Comparação dos esforços nos estais para dos evolutivos dos métodos (unidades: $k N$ )

Tabela 6.11: Comparação dos deslocamentos nos estais para dos evolutivos dos métodos (unidades: tf)...... .91

Tabela 6.12: Avaliação isostática das forças nos estais para a Ponte Construtor João Alves .96

Tabela 6.13: Distribuição de esforços e temperaturas dos estais e deslocamentos da Ponte Construtor João Alves (MAD) 100

Tabela 6.14: Distribuição de esforços e temperaturas dos estais da Ponte Construtor João Alves (MAR) 104

Tabela 6.15: Distribuição de esforços e temperaturas dos estais da Ponte Construtor

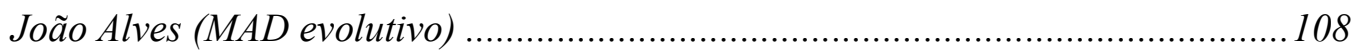

Tabela 6.16: Comparação das temperaturas dos métodos (unidades: ${ }^{\circ} \mathrm{C}$ ) .............. 112

Tabela 6.17: Comparação dos esforços dos métodos (unidades:kN) .....................113

Tabela 6.18: Comparação dos deslocamentos dos métodos (unidades: m) ............115

Tabela 6.19: Comparação das temperaturas dos métodos (unidades: ${ }^{\circ} \mathrm{C}$ ) .............. 119

Tabela 6.20: Comparação dos esforços dos métodos (unidades:kN) ..................... 120

Tabela 6.21: Comparação dos deslocamentos dos métodos (unidades:m) .............. 122 


\section{INTRODUÇÃO}

\subsection{Objetivo}

As pontes estaiadas consistem de um tabuleiro suportado por cabos retos e inclinados (estais) fixados nos mastros. Elas têm se tornado mais comuns devido à sua economia e estabilidade para vãos grandes (200 a 1000m) mas principalmente pela aparência atrativa. Têm três partes principais: o tabuleiro, os mastros e os estais. $\mathrm{O}$ tabuleiro é suportado elasticamente em vários pontos ao longo do seu comprimento por cabos inclinados (estais) fixados no mastro. Os carregamentos permanente e móvel são transmitidos ao mastro mediante esses estais como numa treliça em balanço, com estais tracionados enquanto o mastro e o tabuleiro ficam comprimidos.

Este tipo de estrutura é altamente hiperestática, bastante sensível à seqüência construtiva, mas mesmo assim aceitando, por conta a flexibilidade do tabuleiro uma considerável gama de esforços de instalação dos estais. É importante escolher uma distribuição inicial apropriada para esses esforços sob carregamento permanente tal que a flexão no tabuleiro seja limitada. A ponte é construída por fases e é mista, tem peças de concreto como mastro e tabuleiro conectados por estais metálicos. Os elementos de concreto sofrem retração e fluência, enquanto os elementos metálicos não sofrem retração e fluência (no nível de tensão usual). Esses efeitos alteram as deformações e os esforços internos nessas pontes, fazendo os esforços tenderem, ou ao menos se aproximarem daqueles da obra moldada in loco. Por essa razão uma boa distribuição de esforços na configuração final é importante. Vale também lembrar que os inevitáveis desvios de construção alteram esses valores. Assim, é sempre conveniente ter o tabuleiro e sua protensão dimensionados com uma certa folga que tolere esses desvios.

A presente pesquisa tem como objetivo estudar diferentes métodos para a obtenção de uma boa distribuição de esforços nos estais de pontes estaiadas. Desde a década do 1970 autores como BEHIN,1992; CHEN, 2000; JANIC, 2003; WANG, 1993; etc., tem estudado diferentes tipos de métodos para a obtenção das forças de instalação nos estais.

Teoricamente é possível achar uma distribuição dessas forças de modo que o tabuleiro se comporte como uma viga continua. 
Os métodos estudados nesta pesquisa são: o método do tabuleiro articulado (uma articulação em cada cruzamento com os estais - MTA), o método de anulação dos deslocamentos (MAD), o método de anulação das reações em apoios fictícios (MAR) e o método de anulação dos deslocamentos ao longo do processo construtivo. A idéia final de todos eles é obter para o tabuleiro uma resposta próxima à de uma viga continua. Porém, se for necessário, pode-se controlar também os deslocamentos do mastro. Os três primeiros métodos são estudados para a configuração final da ponte, mas também foram verificados os resultados deles no processo construtivo, já que durante esta etapa ocorrem variações nos esforços internos da ponte alterando assim o resultado final. Por exemplo, se a ponte for construída por consolos sucessivos, essa seqüência executiva alterara os esforços.

O estudo da retração e fluência está fora do escopo deste trabalho. No entanto, a consideração destes na determinação das forças de instalação dos estais pode ser levada em consideração tendo em conta seus efeitos sobre as flechas do tabuleiro ou sobre os esforços nos apoios fictícios do tabuleiro.

\subsection{Apresentação do trabalho}

Este trabalho está dividido em 8 capítulos, incluindo este introdutório.

O capítulo 2 apresenta uma breve introdução das pontes estaiadas ao longo da história, assim como uma resenha dessas pontes no Brasil. Explica-se a concepção e a estrutura desse tipo de pontes e os métodos construtivos empregados, incluindo as descrições de cimbramento geral, consolos sucessivos e lançamento progressivo.

No capítulo 3, são detalhados os exemplos de aplicação. Escolheram-se dois exemplos: o primeiro é um modelo de uma ponte estaiada simples com estais arranjados em formato de semi-harpa, o segundo exemplo é uma ponte estaiada localizada na cidade de Aracaju, no estado de Sergipe, chamada Ponte Construtor João Alves. Nesse capítulo, são explicadas as características estruturais de cada um dos exemplos.

O capítulo 4 se refere aos modelos que foram desenvolvidos para a análise dos exemplos. No caso do primeiro exemplo, foi realizado um modelo plano simples, enquanto que, para o segundo exemplo, a Ponte Construtor João Alves, foram feitos 
dois modelos: um modelo plano simplificado e o um modelo espacial, respeitando as características do projeto.

O capítulo 5 descreve os 4 métodos que foram utilizados para a obtenção das tensões nos estais. Esses métodos são: avaliação isostática dos esforços nos estais (MTA), método de anulação dos deslocamentos (MAD), método de anulação das reações em apoios fictícios (MAR) e o método de anulação dos deslocamentos no processo construtivo.

No capítulo 6, são apresentados os resultados dos métodos estudados e a comparação entre eles.

Finalmente, no capítulo 7, são apresentadas as conclusões. 


\section{REVISÃo BIBLIOGRÁFICA}

\subsection{Historia}

A história das pontes estaiadas nos indica que a idéia de suportar uma viga mediante cordas inclinadas ou correntes suspensas de mastros tem sido conhecida desde a Antigüidade. Os egípcios já utilizavam essa idéia em seus barcos a vela (Figura 2.1). As primeiras pontes estaiadas primitivas foram construídas em algumas regiões tropicais. É provável que as primeiras pontes tenham sido feitas colocando um ou mais troncos para cruzar um córrego, ou amarrando troncos com cipó para atravessar vales estreitos (TROITSKY, 1977). O próprio Leonardo da Vinci sugeriu em seus esboços a utilização dessa idéia (SCHMID, 2008).

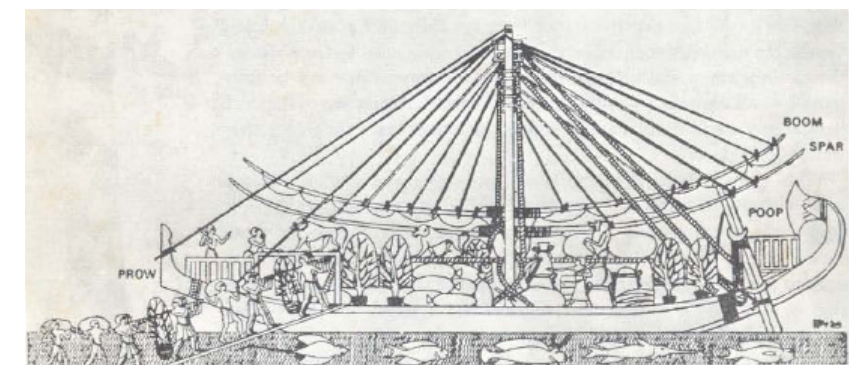

Figura 2.1: Barco egípcio com cordas suportando a vela (TROITSKY, 1977)

O primeiro registro da utilização de um tipo de ponte estaiada como uma forma regular de transposição de obstáculos é do ano 1617, quando Faustus Verantius propôs um sistema de pontes que consistia em um tabuleiro de madeira suportado por barras de aço inclinadas (TROITSKY, 1977).

O conceito de uma ponte suspensa por estais inclinados foi originado em Veneza, Itália. Entretanto, esse conceito é atribuído a C.J. Löscher, carpinteiro de Friburgo, Suíça, que em 1784 construiu uma ponte inteiramente em madeira, com $32 \mathrm{~m}$ de vão (Figura 2.2). 


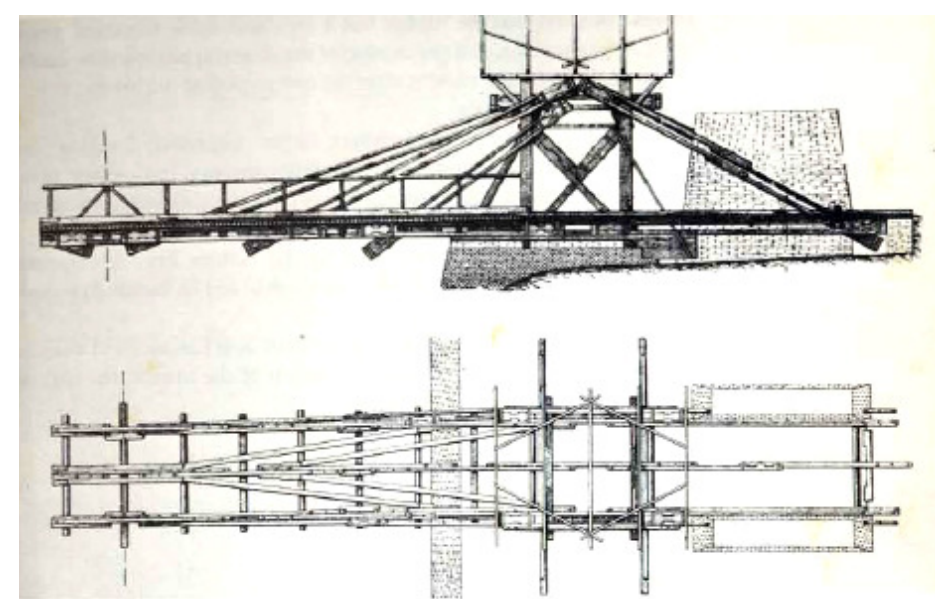

Figura 2.2: Ponte estaiada em madeira C.J.Löscher (1784) (TROITSKY, 1977)

Aparentemente, esse conceito não foi novamente usado até 1817, quando dois engenheiros britânicos projetaram a Ponte King's Meadows, uma passarela estaiada com um vão de 33,6m, usando estais de arame e mastro de ferro em forma celular.

As pontes estaiadas poderiam ter sido uma forma usual de construção, mas uma série de acidentes ocorridos na Inglaterra, França e Alemanha, em 1823, suscitaram uma manifestação de C.L. Navier, no artigo Mémoires sur les Ponts Suspendus. Nessa publicação, ele propôs um sistema de pontes sustentadas por correntes inclinadas e comparou dois modelos. O primeiro apresentava os cabos ancorados no topo, e o segundo exemplo apresentava os cabos ancorados ao longo do comprimento do mastro (Figura 2.3). A conclusão de Navier foi que, para um determinado vão e altura do mastro, o custo dos dois modelos era, aproximadamente, igual. No entanto, esse tipo de estrutura não foi bem compreendida. Tratando-se dos cabos, por exemplo, a área transversal era insuficiente e estes não eram protendidos durante a construção. Conseqüentemente, os estais tinham um bom rendimento somente quando atingiam uma deformação considerável. Esse aspecto das pontes estaiadas e os acidentes ocorridos até aquele momento levaram Navier a considerar as pontes pênseis mais confiáveis que as estaiadas (TROITSKY, 1977). 

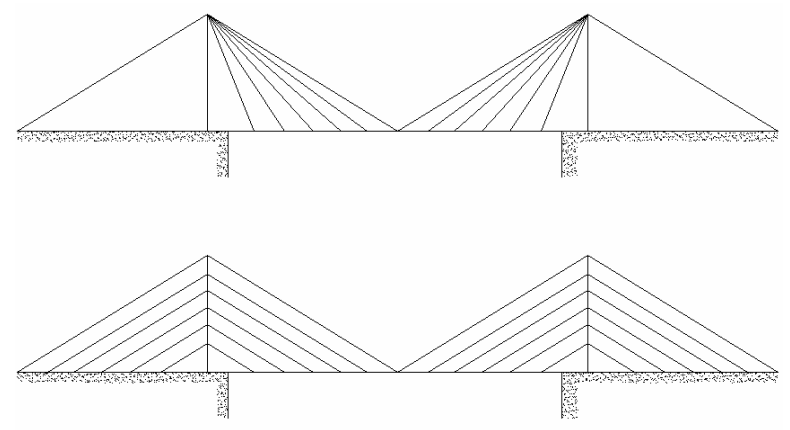

Figura 2.3: Sistema de pontes estaiadas com correntes proposto por Navier (TROITSKY,1977)

O conceito de pontes sustentadas por cabos foi retomado no século XX. A falta de aço na Alemanha, depois da Segunda Guerra Mundial, conduziu a sua máxima utilização e, portanto, deveria ser feita uma redução no peso das estruturas. A reconstrução das pontes destruídas após a Segunda Guerra Mundial na Europa proporcionou aos engenheiros a oportunidade de aplicar novas tecnologias a um conceito antigo: as pontes estaiadas.

\subsection{Pontes estaiadas no Brasil}

No Brasil, a primeira ponte estaiada projetada foi a Ponte de Porto Alencastro, localizada sobre o Rio Paranaíba, na divisa entre Minas Gerais e Mato Grosso do Sul. Esse projeto foi encomendado pelo atual DNTI (Direção Nacional de Transporte e Infraestrutura) ao consórcio formado pela Noronha Engenharia e Fritz Leonhardt. $\mathrm{O}$ início da construção dessa ponte foi concomitante à Ponte Estação Metroviária Engenheiro Jamil Sabino, localizada sobre o Rio Pinheiros, em São Paulo, com uma extensão de 126m (Figura 2.4); mas esta última foi a primeira a ser inaugurada, no ano 2000. Em seguida, foi inauguradaa Ponte Sergio Mota, localizada sobre o Rio Cuiabá, na cidade de Cuiabá, Mato Grosso do Sul. Em 2003, foi inaugurada a Ponte sobre o Rio Guamá, em Belém do Pará (Figura 2.4). Trata-se de uma ponte sustentada por cabos dispostos no formato de leque, que liga a região metropolitana da capital Belém à parte nordeste do Estado do Pará, possui uma extensão total de $2000 \mathrm{~m}$ e vão estaiado central de 320m (Figura 2.4). No mesmo ano, inaugurou-se a Ponte JK, em Brasília, e a Ponte da Amizade, construída sobre o Rio Acre, na fronteira entre Brasil e Bolívia. Em 2004, foi a vez da Ponte Irineu Bornhausen ser inaugurada, na cidade de Brusque, Santa Catarina. Em 2006, foi 
inaugurada a maior passarela estaiada do Brasil (200m de comprimento). em Rio Branco, Acre. E, no mesmo ano, inaugurou-se a Ponte Construtor João Alves, localizada sobre o Rio Sergipe, em Aracaju, Sergipe. A última ponte estaiada a ser inaugurada foi a Ponte Octavio Frias de Oliveira, construída sobre o Rio Pinheiros, em São Paulo, essa ponte se caracteriza por ter dois vão curvos.

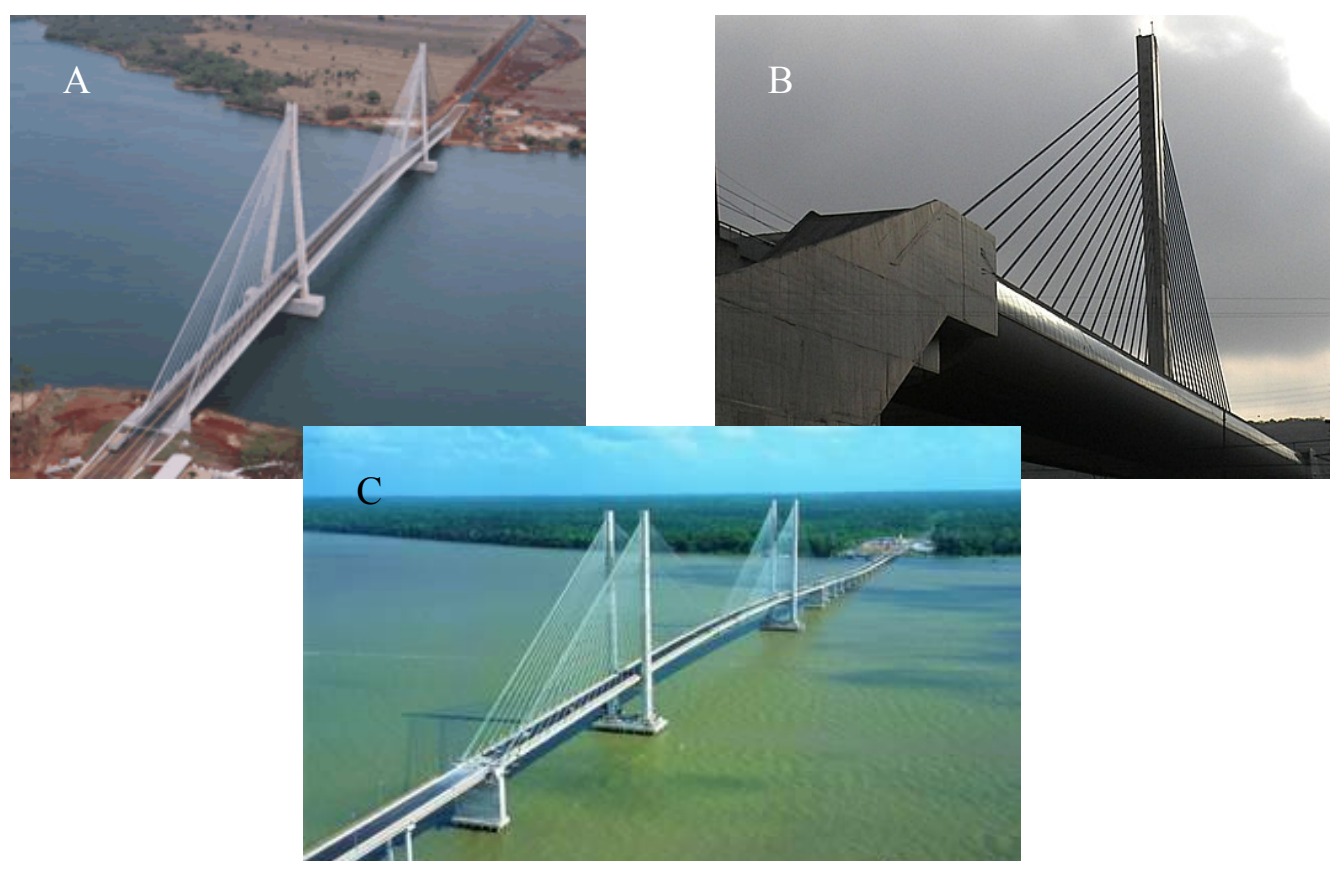

Figura 2.4: A) Ponte de Porto Alencastro sobre o Rio Paranaiba (www.transportes.gov.br), B) Ponte estação metroviária Engenheiro Jamil Sabino sobre o Rio Pinheiros, São Paulo(www.panoramio.com), C) Ponte sobre o Rio Guamá, Belém do Pará (www.abcp.org.br)

Atualmente, o maior emprego das pontes estaiadas deve-se aos tabuleiros inteiramente metálicos, ao desenvolvimento da tecnologia, tanto do aço como do concreto, dos estais, suas ancoragens e sua execução, ao custo competitivo (comparado a outras soluções), à facilidade de construção, ao apelo estético, assim como também da evolução da análise estrutural. Os computadores, mediante a implementação de softwares, permitiram uma velocidade de processamento maior para a obtenção da solução, levando em conta a alta hiperestaticidade que apresentam esse tipo de estrutura. Entretanto, é importante destacar que ainda hoje as soluções aproximadas são feitas mediante pré-dimensionamento. 


\subsection{Concepção e Estrutura}

\subsubsection{Estrutura}

Nos últimos anos, as pontes estaiadas têm se desenvolvido rapidamente, obtendo sucesso devido ao fato de cobrirem grandes vãos de forma econômica, além de possuírem um forte apelo estético. Os componentes existentes nesse tipo de pontes estão apresentados na (Figura 2.5):

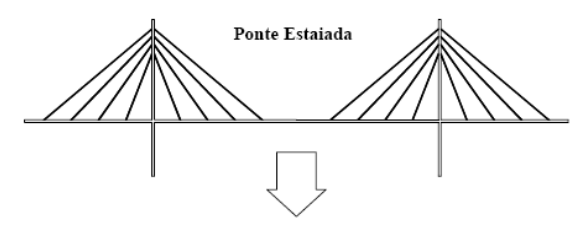

Tabuleiro

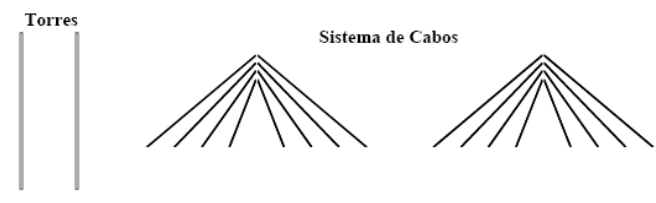

Figura 2.5: Componentes de uma ponte estaiada

Existem vários tipos de sistemas estruturais associados, principalmente, ao arranjo dos cabos da ponte: arranjo em leque, semi-harpa e harpa. Os arranjos usuais de cabos variam tanto na direção transversal como na longitudinal (Figura 2.6).

Também existem sistemas estruturais diferenciados segundo o tipo de mastro: de plano simples (mastro central ou lateral) ou de plano duplo (mastro vertical ou inclinado) (Figura 2.6).
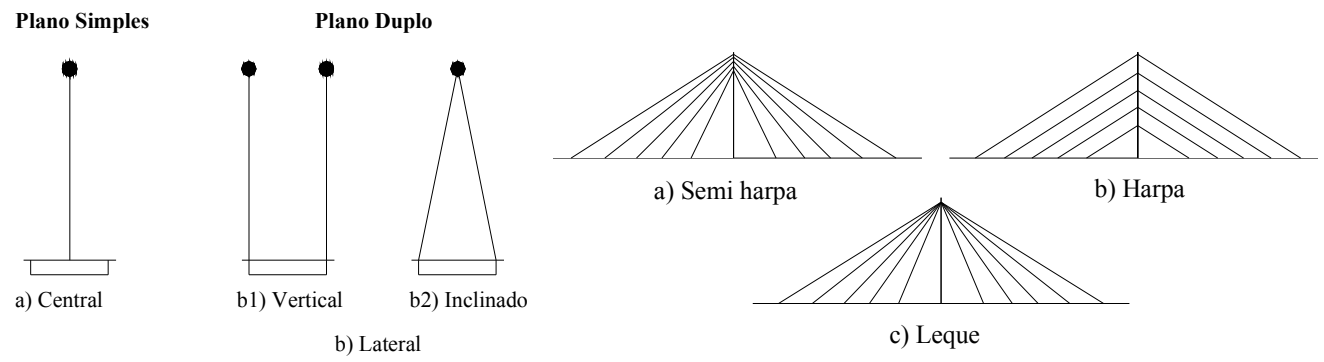

Figura 2.6: Arranjo transversal e longitudinal dos cabos 


\subsubsection{Concepção}

O desafio representado pelas pontes estaiadas surge desde o momento da concepção do seu projeto e permanece em toda a sua fase de construção.

O projeto preliminar de uma ponte estaiada consiste, basicamente, em determinar para certo arranjo estrutural escolhido as dimensões iniciais dos vãos com suas respectivas propriedades seccionais, a altura da torre e o nível de tensão inicial nos estais.

Existem muitas formas de se chegar ao modelo preliminar de projeto, mas todas essas formas constam de diversas etapas, além de um entendimento estrutural do problema. Uma delas, a mais conhecida, é a metodologia de espiral. Nessa metodologia, o projetista parte de um conjunto de requisitos de projeto a serem cumpridos e utiliza sua experiência prévia em projetos semelhantes. Em passos seqüenciais de cálculo, o projetista refina o modelo estrutural em busca de um projeto final considerado aceitável (aquele projeto que satisfaz todas as necessidades físicas e estruturais). Uma forma mais explícita é adotada por WALTHER (1985); uma modificação do fluxograma estabelecido por esse autor é apresentado na Figura 2.7 .

Uma das formas de se chegar ao modelo preliminar de projeto é mediante o prédimensionamento da estrutura. Esse estudo não se vê altamente alterado em comparação com o pré-dimensionamento de pontes regulares. É importante ressaltar que as características iniciais adotadas para os elementos estruturais influem em toda a distribuição de esforços, já que a estrutura possui grau de hiperestaticidade elevado. A determinação da área da seção transversal das cordoalhas dos estais, por exemplo, influi muito no comportamento de toda a estrutura e é uma tarefa que requer a adoção de diversas hipóteses. (TORNERI, 2002).

O desafio é achar uma distribuição de esforços nos estais que anule os deslocamentos no tabuleiro para as cargas permanentes e, posteriormente, alcançar o ajuste das forças finais. É importante destacar que, anulando esses deslocamentos, os momentos também serão diminuídos.

A complexidade do problema aumenta no caso de surgirem estais inclinados em relação ao plano dos mastros como, por exemplo, a Ponte Roberto Marinho, no Rio Pinheiros, em São Paulo, Brasil. São utilizados softwares para solucionar esses tipos 
de sistemas altamente hiperestáticos, mediante análises estáticas exatas, levando em consideração seu comportamento em três dimensões.

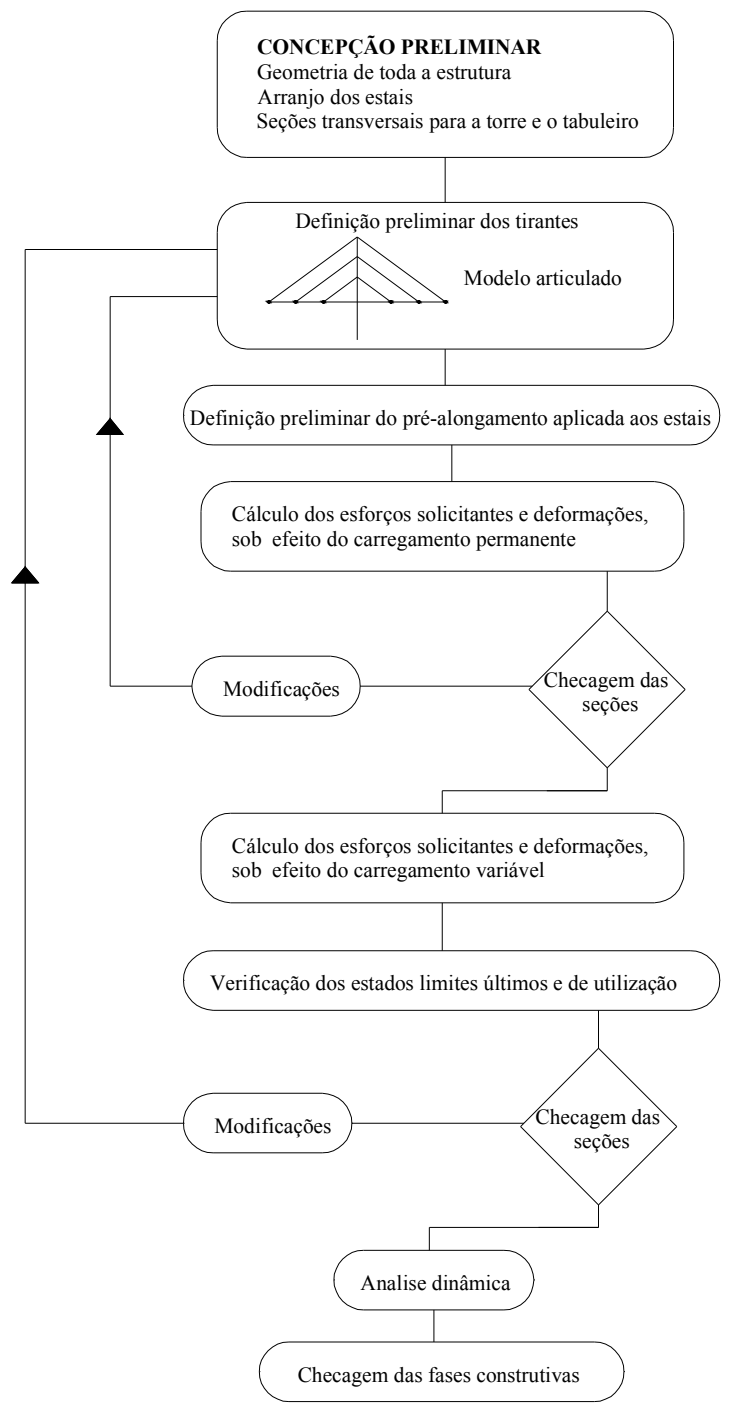

Figura 2.7: Fluxograma simplificado do projeto e uma ponte estaiada a partir do estabelecido por WALTHER (1985)

Considerando-se todos os problemas que podem ocorrer em etapas posteriores, o presente trabalho explica, estuda e analisa o processo construtivo de pontes estaiadas, utilizando os métodos mais modernos de fabricação e modelagem.

A idéia central desta pesquisa é fazer um estudo da questão, modelando o processo construtivo nas etapas mais importantes e estudando seu comportamento. 


\subsection{Métodos Construtivos nas Pontes Estaiadas}

O conceito de uma ponte deve ser selecionado levando em conta o número de parâmetros específicos relacionados com as características da nova ligação que será construída. Geralmente, esses parâmetros são especificados pelo proprietário, que na maioria dos casos é o Estado, a concessionária ou alguma relevante organização privada. Essas características são, geralmente, a localização da ponte, o propósito da ponte (autopista, ferrovia), a importância da ponte e a durabilidade desejada, o cronograma de execução da obra e a economia. Cada uma dessas características leva ao estudo de outros problemas particulares. No caso da localização, as condições geográficas e geotécnicas (capacidade de resistência do terreno de fundação), características do cruzamento (a altura do escoramento, regime, profundidade e velocidade do rio) e possíveis perigos naturais ou humanos (terremotos, vento ou impactos). O propósito da ponte geralmente leva ao estudo de dimensões e detalhes apropriados. A importância da ponte e a durabilidade desejada levam ao estudo de materiais a serem utilizados e a forma que estes deverão ser preparados e implementados. (COMBAULT, 2008).

Pela importância, tanto como processo construtivo, como pela influência no arranjo estrutural e na avaliação dos esforços solicitantes durante a fase construtiva, o assunto recebe um tratamento de destaque dentro da tecnologia da construção das pontes (EL DEBS et all, 2007).

Os principais métodos construtivos das pontes e viadutos estaiados são:

- cimbramento geral;

- consolos sucessivos;

- lançamentos progressivos.

\subsubsection{Cimbramento geral}

Esse método é geralmente usado quando a ponte está localizada em uma zona de baixo gabarito e solo com boa capacidade resistente. O cruzamento não está congestionado com estradas ou ferrovias, e a ponte não tem que atravessar uma corrente de água.

Há dois tipos de cimbramento: 
- cimbramento fixo;

- cimbramento móvel.

O cimbramento é considerado fixo quando ele deve ser desmontado após sua utilização, podendo ou não ser reutilizado em outras partes da ponte. No cimbramento fixo, os tipos mais comuns são: cimbramento de madeira, de treliças ou vigas metálicas e cimbramento metálico. Consiste na montagem de apoios temporários que, após a construção, são retirados (Figura 2.8).

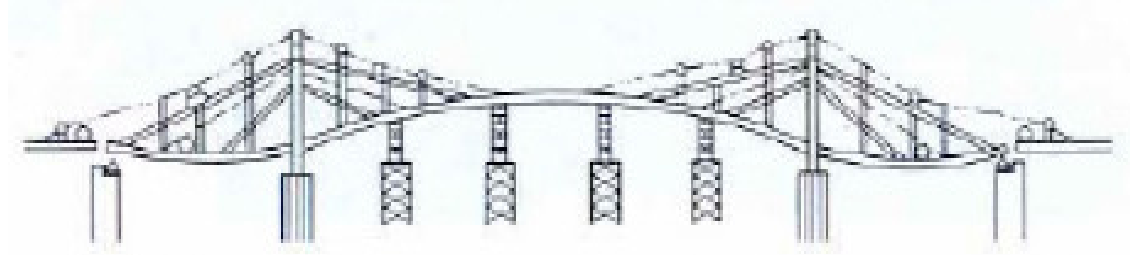

Figura 2.8: Exemplo de ponte moldada "in loco" sobre cimbramento fixo (PODOLNY, 1976)

Conforme (STUCCHI 1999) os cuidados que se devem ter na utilização do cimbramento fixo são:

- fundação e contraventamento do cimbramento;

- contra-flechas para compensar recalques ou deformações de vigas e treliças;

- cuidados na concretagem - os recalques e as deformações devem ocorrer antes do final da concretagem, também deve-se tratar as juntas;

- cuidados na desforma - desencunhar do centro para os apoios de todos os vão e só após desmontar o cimbramento;

- vistoria antes, durante e depois da concretagem.

O cimbramento é considerado móvel quando existem dispositivos que permitem deslocar o cimbramento, sem desmontá-lo, após a desmoldagem de um segmento ou tramo da ponte. Esse sistema consiste na execução vão por vão da ponte, por meio da treliça de escoramento deslizante sobre rolos dispostos em vigas transversais.

Conforme (STUCCHI 1999) os cuidados que se devem ter na utilização do cimbramento móvel são:

- escolher a posição da junta e seu tratamento;

- influência do método construtivo no cálculo;

- interferências que podem impedir o movimento das formas ou da treliça;

- levar em conta os cinco cuidados do cimbramento fixo. 
Um exemplo de aplicação de cimbramento móvel é a construção da ponte sobre o Rio Rin, em Maxau, na Alemanha (Figura 2.9). O método empregado foi construir toda a superestrutura sobre pilares temporários, seguidos pela montagem da torre e as conexões dos cabos. Finalmente, as partes superiores da torre foram içadas, os estais protendidos até a tensão desejada e os pilares temporários removidos.

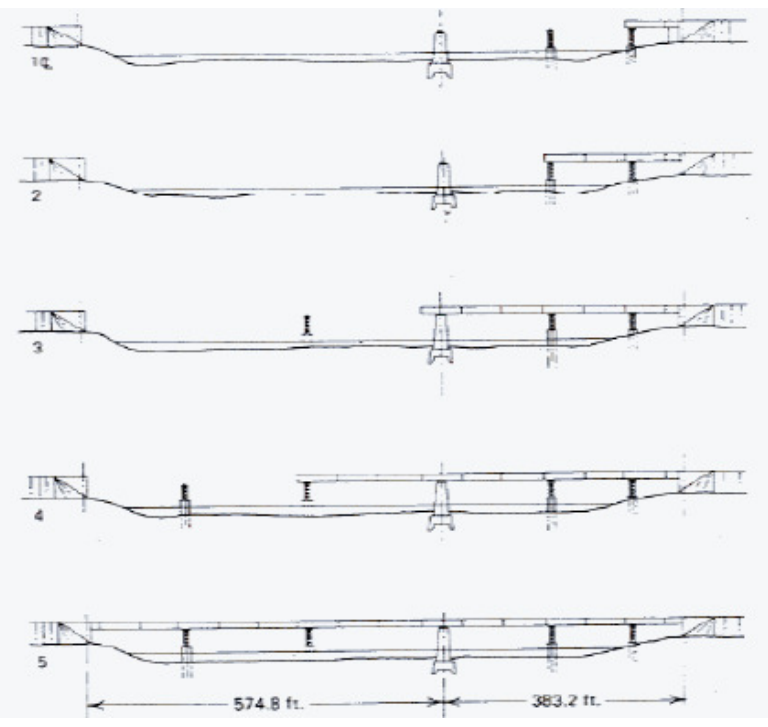

Figura 2.9: Processo construtivo da ponte sobre o Rio Rin, Maxau (Alemanha) (PODOLNY, 1976)

É importante ressaltar que esse tipo de solução construtiva provoca uma elevada dificuldade na hora da resolução da estrutura. As pontes estaiadas apresentam uma alta hiperestaticidade e se além desse problema se adiciona a dificuldade do cimbramento, a solução estrutural torna-se muito complexa.

\subsubsection{Consolos sucessivos}

Esse sistema construtivo foi criado em 1930 pelo engenheiro brasileiro Emílio Baumgart, para a construção do vão central da Ponte de Herval, localizada sobre o Rio Peixe, em Santa Catarina.

É o método construtivo que melhor se adapta às obras estaiadas, sendo então o método mais utilizado (STUCCHI, 1999).

O processo é particularmente indicado para as seguintes situações:

- quando a altura da ponte em relação ao terreno é grande;

- em rios com correnteza violenta e súbita; 
- em rios e canais onde é necessário obedecer gabaritos de navegação durante a construção.

O método consiste na construção da obra em segmentos (aduelas), formando consolos que avançam sobre o vão a ser vencido. Existem duas técnicas básicas para a construção de pontes mediante o sistema de balanços sucessivos; uma delas emprega aduelas pré-moldadas, as quais se levantam mediante guinchos e outros equipamentos e a outra técnica consiste em construir as aduelas in loco.

Quando as aduelas são moldadas in loco, a concretagem é executada com o auxílio de formas deslizantes escoradas nos trechos já construídos e, quando é atingida a resistência de projeto estabelecida, as aduelas são protendidas.

As aduelas pré-moldadas são fabricadas no canteiro e transportadas por meio de treliças metálicas até a extremidade do balanço, onde são protendidas longitudinalmente. Entre as aduelas pode-se usar ou não usar cola à base de resina epóxi, que serve para lubrificar a superfície, diminuir os efeitos das imperfeições das juntas entre as mesmas, impermeabilizar a junta e contribuir para a transmissão das tensões cisalhantes.

A execução em aduelas pré-moldadas pode ser feita por dois processos distintos: o sistema SHORT-LINE e o sistema LONG-LINE. No sistema SHORT-LINE as aduelas são fabricadas com o uso de apenas uma forma metálica, para atender a todas as diferenças e mudanças entre as seções transversais das aduelas, assim como as conformações em planta e perfil do projeto geométrico da estrutura. Essa forma é muito sofisticada e de custo elevado. Cada aduela serve de forma e de referencia topográfica para a aduela seguinte. No sistema $L O N G-L I N E$, é fabricada a forma que abrange todo o vão, podendo ser reaproveitada para outros vãos das mesmas dimensões. Disse-se que este sistema é mais conservador, já que pode-se construir a n-esima aduela com a referencia topográfica da primeira. A forma e a armação são montadas sobre um escoramento metálico ou sobre uma pista de concreto que poderá servir de forma de fundo. As aduelas são concretadas de maneira a garantir a perfeita acoplagem entre si, onde cada aduela concretada na etapa anterior serve de forma para a próxima (ALMEIDA, 2000).

Também nos dois processos, a construção do tabuleiro é feita através do deslocamento das treliças simetricamente desde os apoios até os centros do vão, onde é feito o fechamento central. Cada treliça está apoiada na borda do balanço já 
construído e suporta as futuras aduelas. Para contrabalancear o peso do concreto fresco, as formas e o peso dos equipamentos, por exemplo, a treliça utiliza um contrapeso. $\mathrm{O}$ mesmo representa um aumento de carregamento que deve sustentar o balanço durante a etapa construtiva. Atualmente, ancora-se a parte posterior da treliça ao balanço já construído mediante barras metálicas. $\mathrm{O}$ avanço da treliça é feito apoiado em perfis metálicos que servem de trilho para movimentação de todo o sistema.

Uma vez ancorada a treliça, são feitas as armações do reforço e a concretagem. Quando o concreto da aduela atinge a resistência desejada, procede-se a protensão. A execução de uma aduela depende do avanço da treliça, do ajuste da forma, da armação do reforço, dos cabos e ancoragens, da concretagem e, por último, da protensão. Geralmente, as vigas longitudinais possuem uma distribuição de cabos protendidos para resistir aos momentos fletores que atuam em todas as fases da estrutura.

A execução deve ser muito bem controlada, principalmente com relação às deformações, para que os trechos cheguem ao centro do vão de forma simultânea e coincidentemente. Normalmente, a concretagem do trecho central é realizada nos períodos com menor variação de temperatura, para que os efeitos térmicos não provoquem esforços no trecho até o endurecimento do concreto.

Sempre que possível, projeta-se a obra para que os balanços sejam feitos simetricamente em relação ao apoio, evitando grandes desequilíbrios entre as cargas. Quando os balanços são desiguais ou há balanço em apenas um vão, pode-se utilizar lastro no vão anterior ao balanço ou até mesmo estais ajustáveis ao desenvolvimento do vão, suportados por torres provisórias e ancorados no apoio anterior.

As vantagens que esse sistema construtivo oferece são várias, uma das mais importantes é permitir vencer vãos livres que podem atingir aproximadamente $300 \mathrm{~m}$. Portanto, essa solução é atrativa para vales profundos, rios com correntes intensas, vias de trânsito intenso e vias com pouco espaço de circulação. A construção sucessiva é um processo cíclico, que permite uma redução de custo das formas, devido à possibilidade de sua reutilização. Esse processo também favorece a redução da mão-de-obra, já que se pode atingir uma maior rapidez de execução.

A construção de pontes mediante esse tipo de método sofre a influência de alguns problemas relacionados à fluência e a retração do concreto. O fator principal desse 
fenômeno é a diferença de níveis das aduelas no fechamento da estrutura. O pesopróprio, a protensão longitudinal, o peso dos equipamentos de construção e as variações térmicas causam deformações não só elásticas, mas, também, deformações plásticas, produto da fluência, retração e relaxação do aço. Assim, antes da construção devem ser determinados os deslocamentos para permitir a definição das cotas de concretagem durante a construção (controle de flechas).

Um exemplo desse procedimento é a Ponte Libertador General San Martín (Figura 2.10) localizada no Rio Uruguay, que liga a cidade de Fray Bentos, no Uruguai, e a cidade Puerto Unzué, na Argentina. Essa ponte não é estaiada, mas é um bom exemplo desse método.

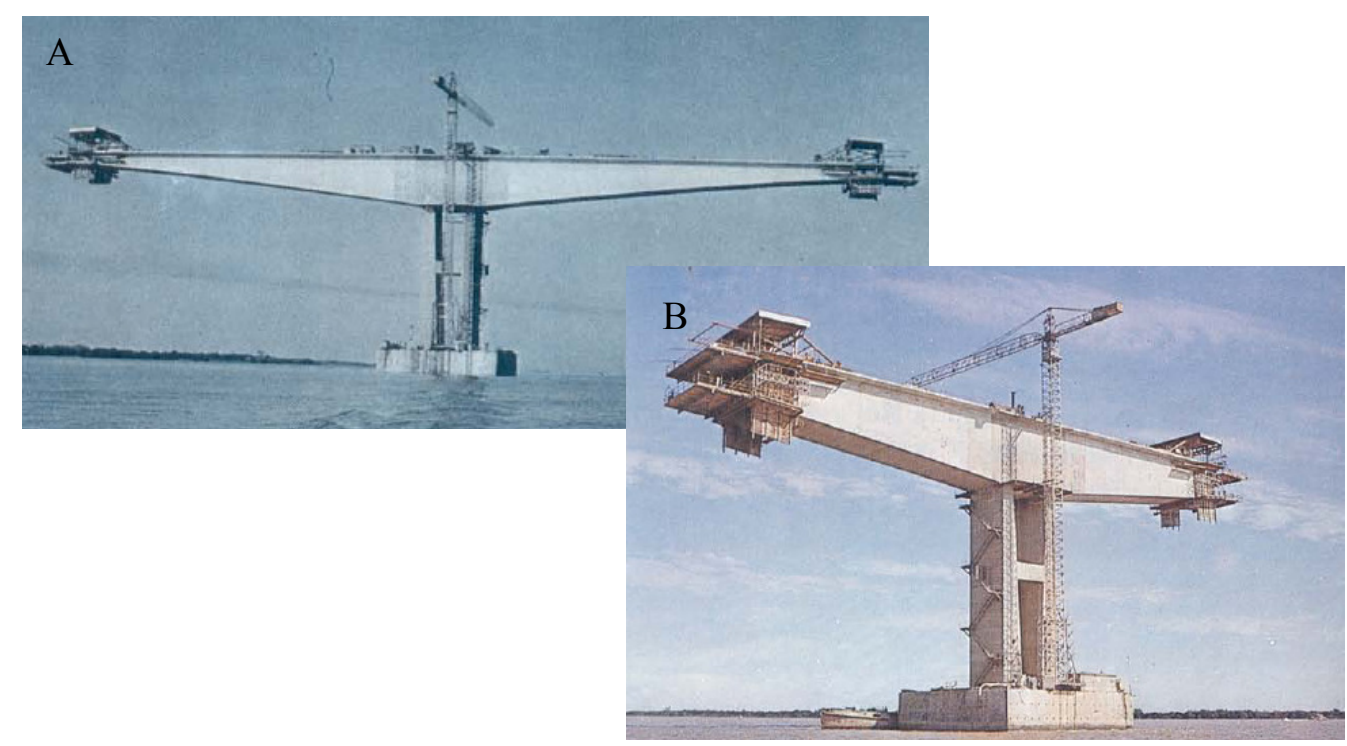

Figura 2.10: A) e B) Vistas do Pilar e Aduelas da Ponte Libertador General San Martín (PUENTE LIBERTADOR GENERAL SAN MARTIN, 1992)

Logo após a construção do pilar, foram colocadas no topo duas treliças que deslizavam sobre trilhos e sustentavam ambos os lados do pilar e as formas das duas primeiras aduelas. Ajustada a posição das formas, distribuiu-se a armadura e as bainhas para o aço de protensão, concretando-se em seguida. $\mathrm{O}$ avanço na construção das aduelas foi programado na razão de duas aduelas por semana, uma de cada lado do balanço. Para atingir essa meta, efetuou-se a cura do concreto a vapor. Uma vez verificada a resistência estipulada, protendeu-se o aço, que foi ancorado no extremo da aduela anteriormente construída. Por fim, as aduelas estavam em condição de 
resistir às solicitações provocadas pelo deslizamento da treliça com a forma e o peso das duas aduelas seguintes.

Um exemplo do mesmo procedimento, utilizado para uma ponte estaiada, é o da Ponte de Porto Alencastro, construída sobre o Rio Paranaíba, na divisa de Mato Grosso do Sul e Minas Gerais. A ponte possui um vão de 350m com um total de 136 estais (Figura 2.11). O tabuleiro possui uma largura de $16 \mathrm{~m}$ e os mastros têm uma altura de $95 \mathrm{~m}$, aproximadamente.

LADO MATO GROSSO DO SUI

LADO WINAS GERAIS

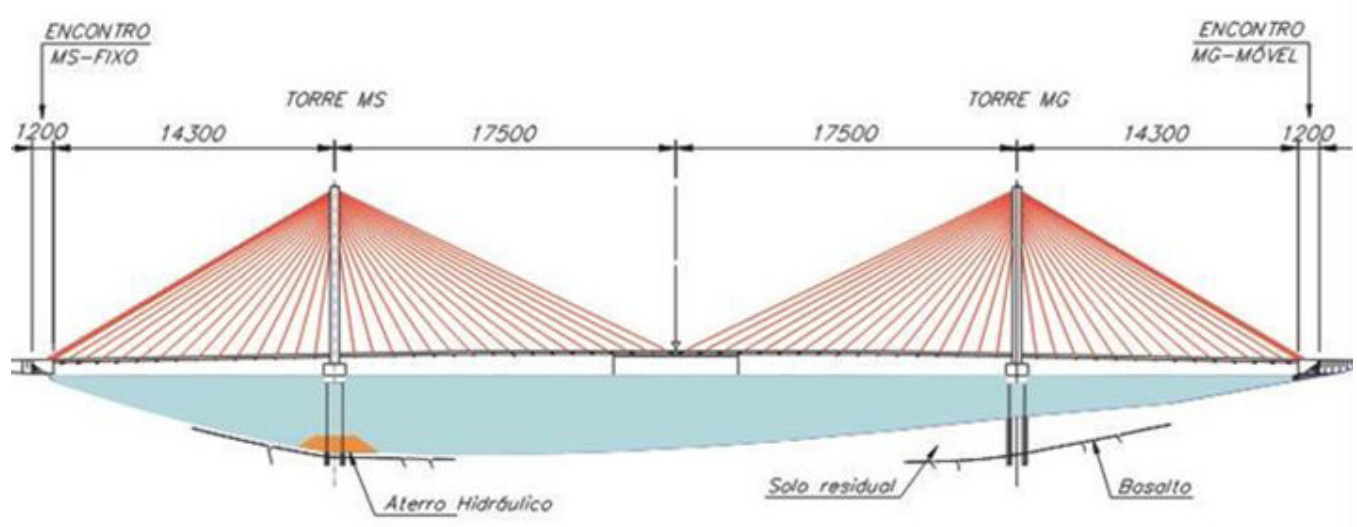

Figura 2.11: Esquema da Ponte de Porto Alencastro sobre o Rio Paranaiba (GOLEBIEWSKI, 2008)

Para o processo construtivo, foi utilizada uma treliça metálica, como apresentado na Figura 2.12. A cada nova aduela, os estais correspondentes foram protendidos de forma a suportar todo o seu peso. Assim, ao final da construção e sob cargas permanentes, o tabuleiro permaneceu quase que exclusivamente submetido à compressão. (STUCCHI, 1999).

Conforme GOLEBIEWSKI, 2008; após a construção dos mastros, se instalou o cabo de montagem (Figura 2.12-A), com a função de ancorar a estrutura nos apoios e formar parte dos estais de estabilidade da ponte final. Logo depois, foram construídas as aduelas mediante o procedimento de consolos sucessivos (Figura 2.12-B e C). Quando a construção chegou ao penúltimo estai, se desvinculou o cabo de montagem entre os mastros (Figura 2.12-D) e, por último, se realizou o fechamento com a aduela central (Figura 2.12-E). 

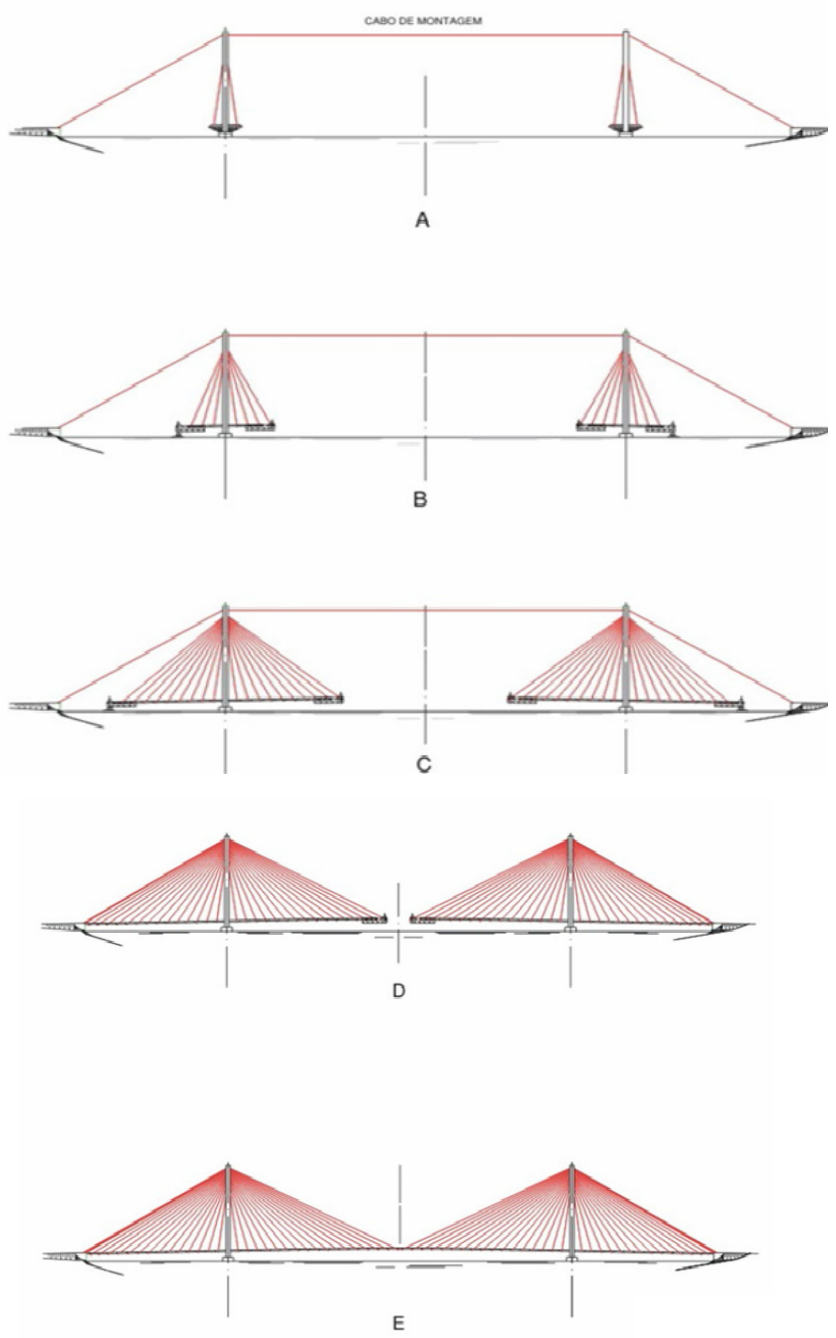

Figura 2.12: Processo construtivo da ponte sobre o Rio Paranaiba (GOLEBIEWSKI, 2008)

O procedimento da fabricação in loco das aduelas é apresentado na Tabela 2.1.

Tabela 2.1: Seqüência construtiva das aduelas da ponte sobre o Rio Paranaíba (GOLOBIEW, 2008) 


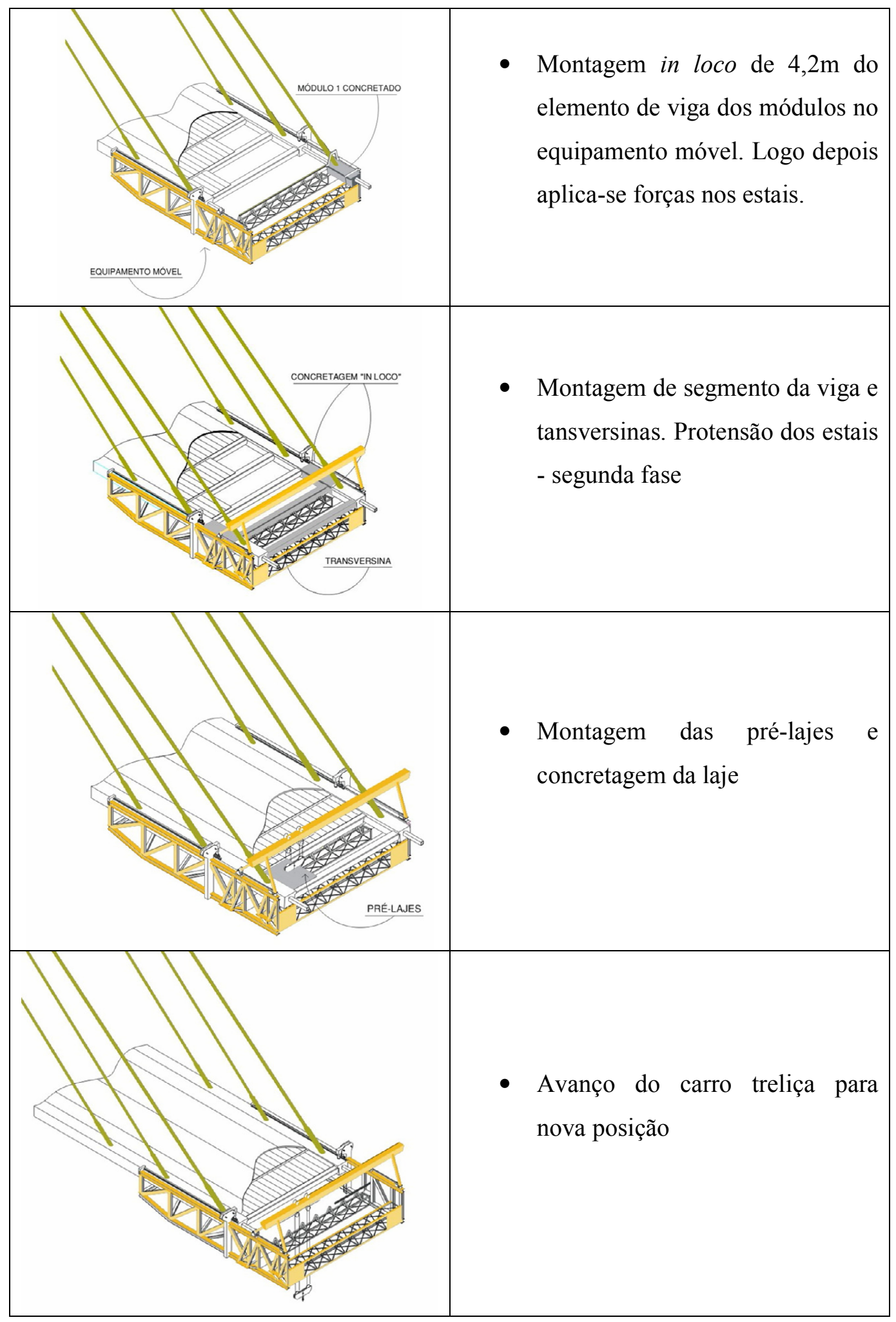




\subsubsection{Lançamentos progressivos}

A primeira aplicação desse método deu-se em 1950, na França, na construção da ponte Vauxsur-Seine, pela empresa Coignet. Em 1959, na construção de uma ponte sobre o Rio Agne, na Áustria, a empresa Auteried, com projeto do escritório do engenheiro Fritz Leonhardt, venceu os $280 \mathrm{~m}$ da obra, com quatro vãos de até $85 \mathrm{~m}$. Foi na ponte sobre o Rio Caroni, na Venezuela, projetada por Leonhardt, em 1961, e executada pela empresa Ed. Züblin AG entre 1962 e 1964, que se realizou pela primeira vez o lançamento do tabuleiro sem ajuda do cimbramento, pelo processo que foi denominado Taktschiebeverfahren (ou processo de lançamento cíclico) (WAIMBERG, 2002).

Nesse método, a superestrutura é fabricada nas margens da obra e empurrada para sua posição final ao longo dos vãos. Esta se comporta como um balanço à medida que vai avançando, até encontrar o próximo apoio. Cada segmento é executado sobre formas metálicas fixas, sendo concretado contra o anterior já concluído, permitindose a continuidade da armadura na região das juntas. A estrutura é empurrada por macacos hidráulicos e sobre aparelhos de apoios deslizantes de "Teflon" sobre os pilares que, dependendo do tamanho do vão, podem ser permanentes ou provisórios. Uma vez que o trecho dianteiro da estrutura fica em balanço até alcançar os apoios, utiliza-se uma treliça metálica fixada nesse lugar que alcança o apoio antes da estrutura, diminuindo o balanço e reduzindo o momento negativo durante a fase construtiva (Figura 2.13).

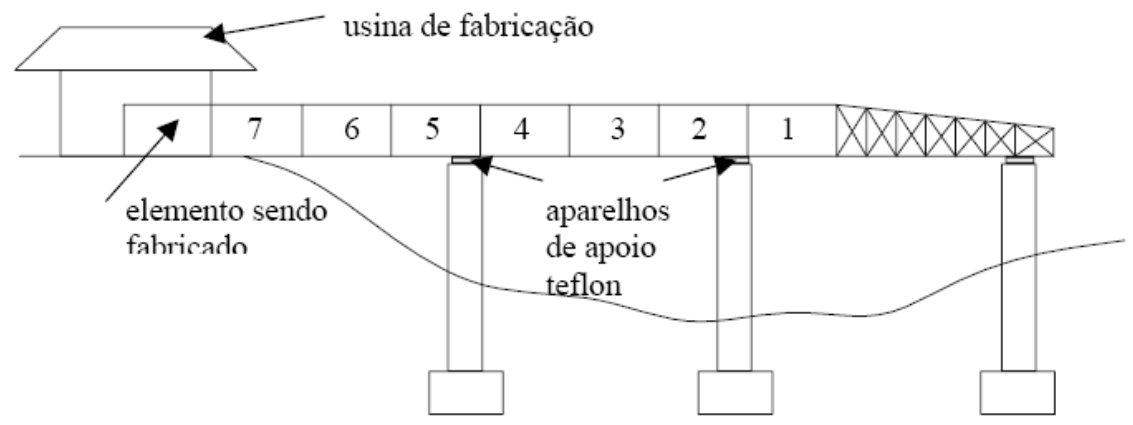

Figura 2.13: Esquema do sistema de lançamento progressivo

Esse método apresenta as seguintes vantagens:

- eliminação do cimbramento;

- redução das formas; 
- redução de mão-de-obra;

- rápida execução da superestrutura;

- industrialização da construção.

Essa é uma solução atrativa quando se está na presença de greides elevados, rios ou vales profundos e obras de grande extensão (vãos de até 50m para evitar a execução de pilares provisórios). Recomenda-se, para aplicação do método, modular os vãos intermediários com comprimentos iguais e os vãos extremos com 75\% do comprimento dos vãos intermediários. Esse procedimento e a adoção de segmentos com comprimentos iguais à metade do comprimento dos vãos intermediários asseguram que as emendas dos diversos segmentos coincidam com os quartos do vão, região em que os esforços internos são menores (SOUZA, 1983).

Nesse tipo de ponte, a protensão é aplicada em duas etapas. A primeira, na fase construtiva, devendo ser centrada em função da variação das solicitações devidas ao peso próprio durante a execução da obra. A segunda etapa é realizada após a execução do tabuleiro, para a complementação da primeira etapa, tendo em vista as solicitações de sobrecarga permanente e carga móvel (ALMEIDA, 2000).

Um exemplo mais recente desse método é o Viaduto de Millau, que cobre o vale do Rio Tarn (Aveyron), próximo de Millau, no sul da França (Figura 2.14). Antes do viaduto ser construído, o tráfego tinha que descer até o vale do Rio Tarn e passar pela estrada, nas proximidades da cidade de Millau. Isso causava pesados congestionamentos no início e no final de julho e agosto, que é o período de férias. Atualmente, o viaduto atravessa o vale de Tarn sobre o ponto mais baixo.

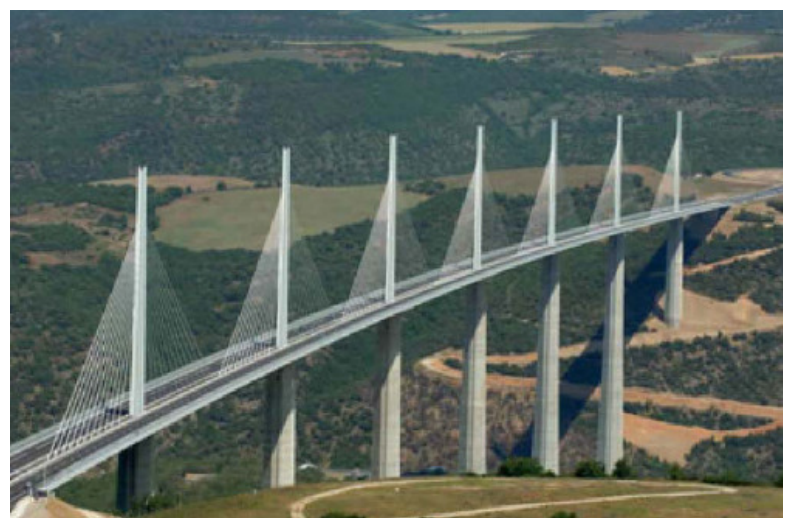

Figura 2.14: Viaduto de Millau, França 
O Viaduto de Millau possui oito vãos apoiados em sete pilares de concreto. Esse viaduto possui o maior tabuleiro estaiado até o momento, com uma extensão de $2.640 \mathrm{~m}$ e $32 \mathrm{~m}$ de largura. Este consta de duas faixas para o tráfego e dois encostamentos, um a cada lado das faixas. Os seis vãos centrais têm $342 \mathrm{~m}$ de comprimento, enquanto os dois laterais tem $204 \mathrm{~m}$ de extensão.

A altura dos pilares varia de $78 \mathrm{~m}$ até $245 \mathrm{~m}$, cada um deles é composto por 16 trechos que foram montados in loco. Os sete mastros estão localizados sobre os pilares e têm uma altura constante de $87 \mathrm{~m}$. Cada um deles possui um total de 12 estais que servem de suporte ao tabuleiro.

Nessa ponte, foi utilizado o método dos lançamentos progressivos e as principais etapas construtivas do viaduto foram:

- construção dos pilares e pilares provisórios;

- fabricação e lançamento do tabuleiro;

- ereção dos mastros.

Os pilares e alguns dos pilares provisórios foram os primeiros a serem montados. A velocidade de construção dos pilares permanentes foi elevada, a cada três dias os pilares aumentavam $4 \mathrm{~m}$ de altura. Esse desempenho ocorreu devido principalmente à forma deslizante. Os pilares provisórios foram treliças metálicas montadas in loco e reutilizadas conforme o avanço do tabuleiro. Foram construídos sete pilares e oito pilares provisórios.

A segunda etapa construtiva foi a etapa de fabricação do tabuleiro. Para que a estrutura não ficasse muito pesada e tivesse maior liberdade de movimento, optou-se por um tabuleiro de aço. Cada tramo foi construído na própria empresa e levado até o local da obra. Seu transporte foi cuidadosamente planejado e feito mediante transporte pesado. Os mastros eram conduzidos sobre o novo tabuleiro e eram erguidos. O conjunto foi empurrado desde ambas extremidades, e foi deslizado sobre os pilares mediante macacos hidráulicos (Figura 2.15). O movimento era monitorado por um sistema controlado por computador, que acionava atuadores hidráulicos que se moviam numa seqüência pré-determinada. 


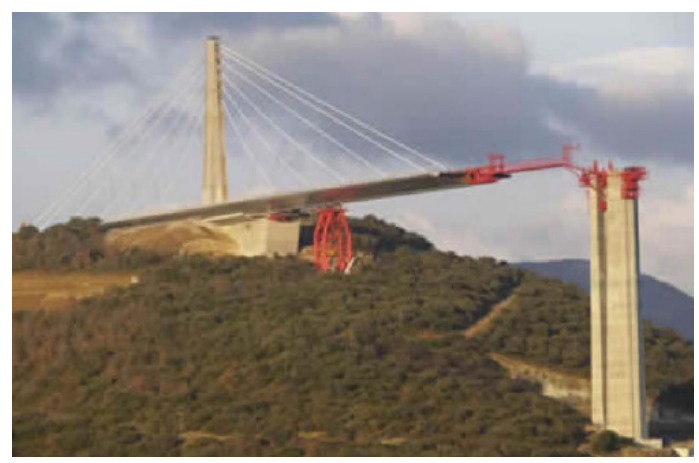

Figura 2.15: Lançamento do tabuleiro

Planejou-se que o fechamento central fosse no rio. Cada tramo avançou $60 \mathrm{~cm}$ a cada 4 minutos; essa tarefa era realizada somente durante o dia.

Finalmente, os mastros eram posicionados sobre os pilares e ancorados ao tabuleiro (Figura 2.16). Os estais que conectam os mastros com o tabuleiro eram instalados e os pilares provisórios retirados.

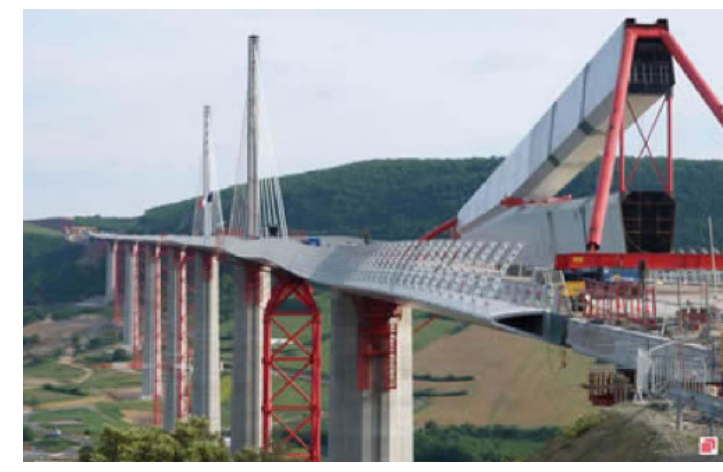

Figura 2.16: Processo de montagem dos mastros

A construção se iniciou no dia 10 de Outubro de 2001 e se destinava a ter três anos de duração, mas as condições meteorológicas atrasaram o cronograma. Embora o calendário revisado determinasse que o viaduto seria concluído em janeiro de 2005, o Viaduto de Millau foi inaugurado pelo Presidente Chirac em 14 de dezembro de 2004 e aberto para o tráfego no 16 de dezembro. 


\section{EXEMPLO DE APLICAÇÃO}

Para a aplicação dos métodos apresentados nesta pesquisa, foram estabelecidos dois exemplos. O primeiro é um modelo fictício que representa uma ponte estaiada típica. O segundo exemplo é a Ponte Construtor João Alves, construída sobre o Rio Sergipe. A seguir, detalham-se as características das duas pontes.

\subsection{Primeiro exemplo}

O primeiro exemplo consta de uma ponte estaiada de 346m de extensão, $186 \mathrm{~m}$ de vão central e $80 \mathrm{~m}$ de vão lateral. Possui quatro pilares de $70 \mathrm{~m}$ de altura e um total de 56 estais, arranjados em forma de semi-harpa. (Figura 3.1)

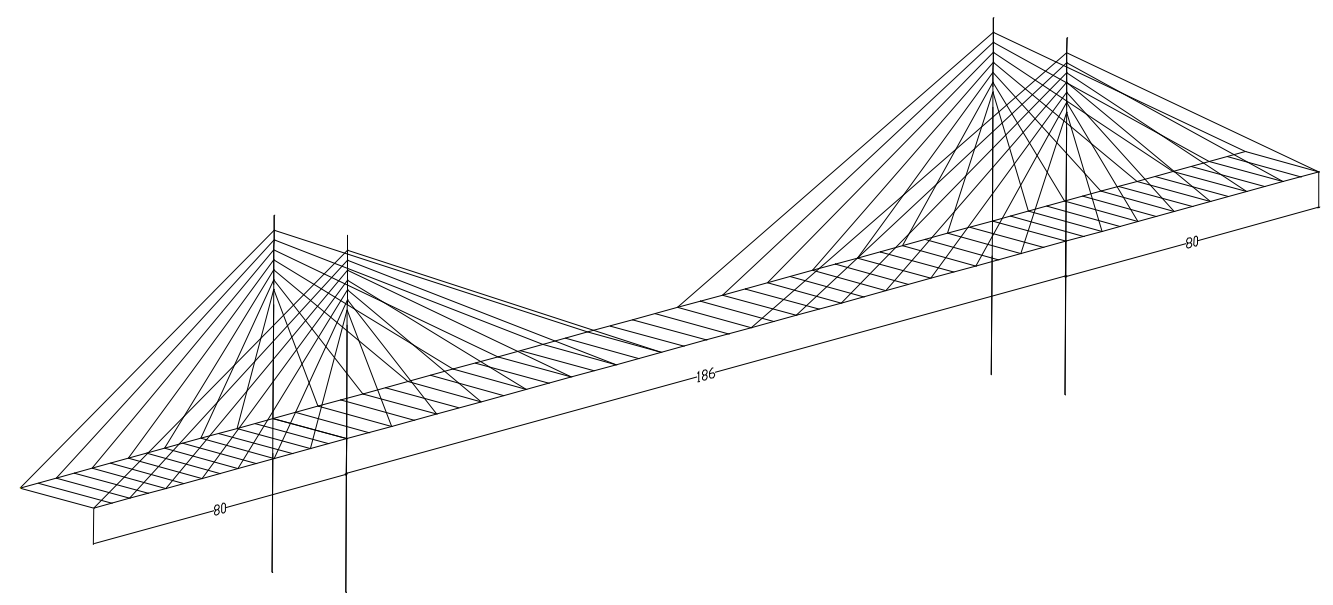

Figura 3.1: Ponte estaiada, primeiro exemplo

\subsubsection{Elementos da ponte}

Os elementos que formam a ponte são:

- tabuleiro: laje, longarinas e transversinas;

- mastro: pilares, viga de travamento;

- estais.

As características desses elementos estão explicadas a seguir. 


\subsubsection{Tabuleiro}

Estabeleceu-se que o tabuleiro é solidário aos pilares e está dividido em 15 aduelas de $12,4 \mathrm{~m}, 12$ aduelas de $11,4 \mathrm{~m}$ e duas aduelas de fechamento lateral de $5,7 \mathrm{~m}$.

A seção transversal do tabuleiro possui duas longarinas e apóiam a laje, além de mais 61 transversinas. As dimensões que foram escolhidas para o conjunto do tabuleiro estão apresentadas na Figura 3.2. Entretanto, as transversinas estão dispostas a cada $6,22 \mathrm{~m}$ e possuem $0,4 \mathrm{~m}$ de largura e altura de $1,5 \mathrm{~m}$.
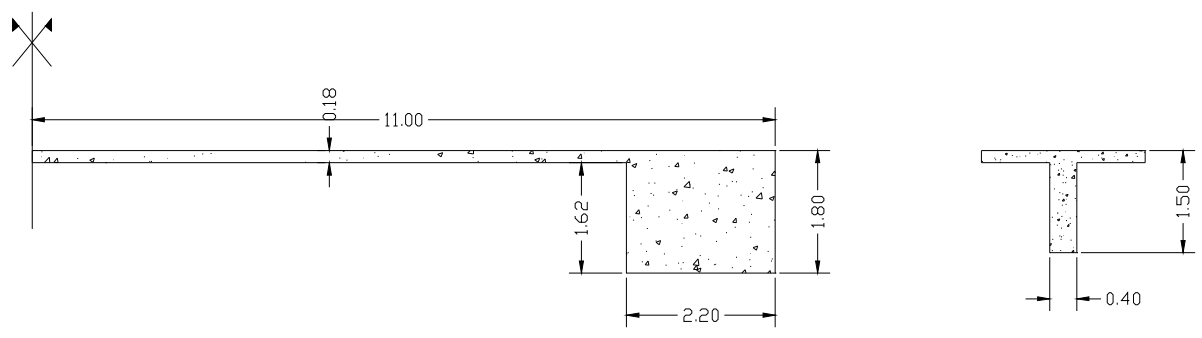

Figura 3.2: Seção do tabuleiro e transversina (medidas em metros)

\subsubsection{Mastros}

Os mastros têm uma altura aproximada de $45 \mathrm{~m}$ e cada um deles serve de suporte a 14 estais, 7 em cada um dos dois planos longitudinais. Foi proposta uma seção transversal retangular de $4,8 \mathrm{~m}$ por $2,1 \mathrm{~m}$.

\subsubsection{Estais}

A ponte tem 56 estais arranjados em forma de semi-harpa; estes foram numerados como mostra a Figura 3.3.

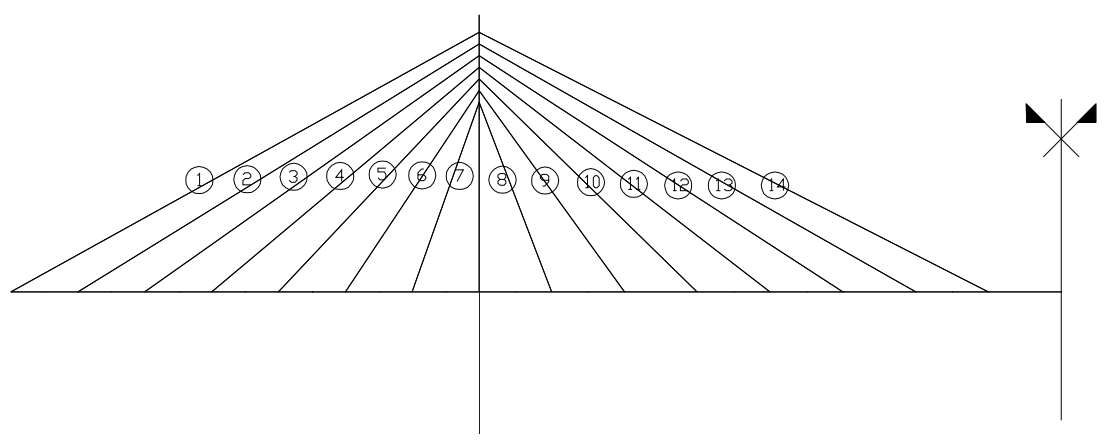




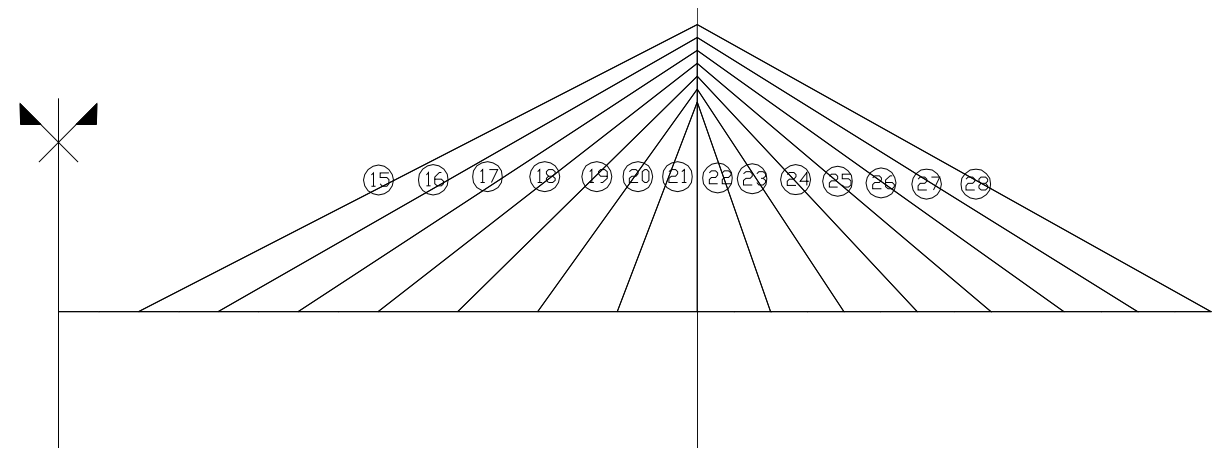

Figura 3.3: Numeração dos estais

O material utilizado nesse modelo é o aço CP 177 RB e as seções dos estais dependem da carga que cada um deve suportar, deste modo, todos têm um diâmetro diferente. Para a obtenção dessas áreas, foi realizado um pré-dimensionamento, admitindo-se que cada estai recebe a carga referente à largura de influência do tabuleiro, tendo-se, então, 3 larguras: de 12,4m, de 11,4m e de 5,7m. Dessa maneira, para um par de estais do tramo de $12,4 \mathrm{~m}$ :

a) peso-próprio $\left(\mathrm{g}_{1}\right)$

$\mathrm{g}_{1}=3437 \mathrm{kN}$

b) peso-próprio $\left(\mathrm{g}_{1 \mathrm{~T}}\right)$ das transversinas

$\mathrm{g}_{1 \mathrm{~T}}=528 \mathrm{kN}$

c) revestimento $\left(\mathrm{g}_{\mathrm{R}}\right)$ de $10 \mathrm{~cm}$ de altura, com $\gamma=24 \mathrm{kN} / \mathrm{m}^{3}$, aplicado no leito carroçável (de $21 \mathrm{~m}$ de largura)

$\mathrm{g}_{\mathrm{R}}=627 \mathrm{kN}$

d) dois guarda-rodas $\left(\mathrm{g}_{\mathrm{GR}}\right.$ ) cada um com peso aproximado de $20 \mathrm{kN} / \mathrm{m}$ $\mathrm{g}_{\mathrm{GR}}=498 \mathrm{kN}$

e) sobrecarga de multidão $\left(\mathrm{q}_{\mathrm{M}}\right)$ e $5 \mathrm{kN} / \mathrm{m}^{2}$, aplicada no leito carroçável, subtraindo-se a região ocupada pelo Trem-Tipo

$\mathrm{q}_{\mathrm{M}}=21 \times 12,4 \times 5-6 \times 3 \times 5=1216 \mathrm{kN}$

f) Trem-Tipo 45 (qtt)

$$
\mathrm{q}_{\mathrm{TT}}=450 \mathrm{kN}
$$

Conforme recomendado por (TORNERI 2003), admite-se que a carga distribuída será dividida igualmente entre os dois cabos da mesma seção transversal e que cada carga do trem-tipo atuará próxima a apenas um dos cabos, tem-se que a carga vertical total $\left(\mathrm{P}_{\text {tot }}\right)$ que solicita um estai será: 


$$
P_{t o t}=\frac{(3447+528+627+498+1216)}{2}+450=3608 k N
$$

A carga vertical permanente (peso-próprio, revestimento e guarda rodas) vale:

$$
P_{\text {perm }}=\frac{(3447+528+627+498)}{2}=2550 \mathrm{kN}
$$

Para o comprimento de aduela de $11,4 \mathrm{~m}$ :
a) $\mathrm{p}_{\mathrm{S}}=3160 \mathrm{kN}$
b) $\mathrm{p}_{\mathrm{T}}=528 \mathrm{kN}$
c) $\mathrm{g}_{\mathrm{R}}=575 \mathrm{~N}$
d) $\mathrm{g}_{\mathrm{GR}}=456 \mathrm{kN}$
e) $\mathrm{q}_{\mathrm{M}}=21 \times 11,4 \times 5-6 \times 3 \times 5=1107 \mathrm{kN}$
f) $\mathrm{q}_{\mathrm{TT}}=450 \mathrm{kN}$

Onde a carga vertical total $\left(\mathrm{P}_{\text {tot }}\right)$ que solicita um estai será:

$$
P_{t o t}=\frac{(3160+528+575+456+1107)}{2}+450=3363 \mathrm{kN}
$$

A carga vertical permanente (peso-próprio, revestimento e guarda rodas) vale:

$$
P_{\text {perm }}=\frac{(3160+528+575+456)}{2}=2360 \mathrm{kN}
$$

Conforme GIMSING (1993) a máxima tensão admissível para o cabo vale:

$$
\sigma_{g+q}=0,45 f_{p t k}
$$

Onde:

$f_{p t k}=$ valor característico da resistência à ruptura do aço de protensão $=1770 \mathrm{MPa}$

Assim, utilizando-se aço CP 190 RB, de 15,7 mm de diâmetro, tem-se:

$$
\begin{gathered}
T_{\text {total }}=\frac{P_{\text {total }}}{\operatorname{sen} \theta} \\
A=\frac{T_{\text {total }}}{\sigma_{g+q}}=n \cdot A_{1}
\end{gathered}
$$

Onde:

$\mathrm{T}=$ componente da carga vertical P na direção do eixo do cabo (esforço normal no estai);

$\theta=$ inclinação do estai analisado com relação ao eixo horizontal;

A = área de aço necessária para um estai; 
$\mathrm{n}=$ número de cordoalhas;

$\mathrm{A}_{1}=$ área da cordoalha de $15,7 \mathrm{~mm}$ de diâmetro.

Desse modo, a partir da formulação indicada, obteve-se a área de aço necessária para cada estai (Tabela 3.1).

Tabela 3.1: Propriedades geométricas dos estais do primeiro exemplo

\begin{tabular}{|c|c|c|c|c|}
\hline Estai & $\boldsymbol{\theta}\left({ }^{\circ}\right)$ & $\mathbf{T}(\mathbf{k N})$ & $\mathbf{n}$ & $\begin{array}{c}\mathbf{A}_{\text {efetiva }} \\
\left(\mathbf{m}^{\mathbf{2}} \mathbf{)}\right.\end{array}$ \\
\hline E2 & 32 & 6346 & 41 & 0,00797 \\
\hline E3 & 35 & 5863 & 38 & 0,00736 \\
\hline E4 & 40 & 5232 & 34 & 0,00657 \\
\hline E5 & 47 & 4598 & 30 & 0,00577 \\
\hline E6 & 56 & 4057 & 26 & 0,00509 \\
\hline E7 & 71 & 3557 & 23 & 0,00447 \\
\hline E8 & 69 & 3865 & 25 & 0,00485 \\
\hline E9 & 54 & 4460 & 29 & 0,00560 \\
\hline E10 & 44 & 5194 & 34 & 0,00652 \\
\hline E11 & 38 & 5860 & 38 & 0,00736 \\
\hline E12 & 33 & 6625 & 43 & 0,00832 \\
\hline E13 & 30 & 7216 & 47 & 0,00906 \\
\hline E14 & 27 & 7947 & 52 & 0,00998 \\
\hline
\end{tabular}

Os estais "E1" e "E28" são os estais de estabilidade, que, diferentemente dos demais, são aqueles que suportam o carregamento de todo o tabuleiro. Para seu dimensionamento, o esforço $\mathrm{H}$ que deve ser suportado pelo cabo é:

$$
H=\frac{M}{h}
$$

Sendo,

M: momento na base do mastro devido ao carregamento distribuído no tabuleiro;

$h$ : distancia entre o topo do estai e o tabuleiro.

Na Figura 3.4, apresenta-se o diagrama de esforços que devem ser considerados no dimensionamento. 


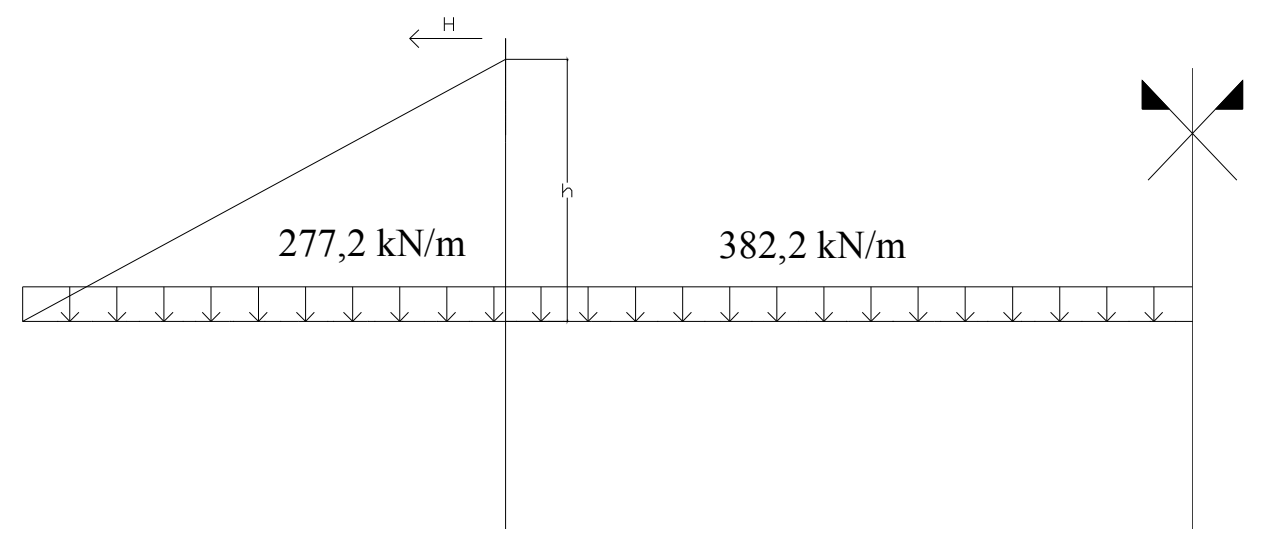

Figura 3.4: Esquema de forças para dimensionamento do estai de estabilidade

Por conseguinte, o momento M é:

$$
M=382,2 \times\left(\frac{93,3^{2}}{2}\right)-277,2 x\left(\frac{80^{2}}{2}\right)=776464,5 \mathrm{kNm}
$$

Considerando que $h$ é de $44,5 \mathrm{~m}$, então:

$H=\frac{M}{h}=\frac{776464,5}{44,5}=17448,6 \mathrm{kN}$

A projeção da força $\mathrm{H}$ na direção do tabuleiro é:

$$
T=\frac{H}{\cos \theta}
$$

Portanto,

$T=\frac{H}{\cos \theta}=\frac{17448,6}{\cos 29^{\circ}}=19950 \mathrm{kN} \quad \Rightarrow 129$ cordoalhas

\subsection{Segundo exemplo: Ponte Construtor João Alves sobre o Rio Sergipe}

\subsubsection{Apresentação da ponte}

As cidades de Aracaju e Barra dos Coqueiros estiveram separadas pelo Rio Sergipe durante anos até que, no dia 24 de setembro de 2006 as duas cidades do litoral do Estado de Sergipe foram ligadas pela Ponte Construtor João Alves. Seu propósito foi aproximar a capital Aracaju ao porto do estado, à beira do oceano Atlântico, dentro do Município da Barra dos Coqueiros. Com a obra, o litoral norte do Estado, que vai da foz do Rio Sergipe, até à foz do Rio São Francisco ficou mais acessível ao turismo em Aracaju. 
Os benefícios que essa ponte trouxe para as cidades de Aracaju, Barra dos Coqueiros, Pirambu, Santo Amaro das Brotas e Japaratuba foram, principalmente, ligados ao aumento de fluxo de pessoas e mercadorias entre elas. Assim como, o crescimento da economia e o turismo.

A ponte Aracaju - Barra dos Coqueiros tem uma extensão de $1.800 \mathrm{~m}$ com um vão central de 200m. Possui duas vias com quatro faixas para veículos, além de uma ciclovia e uma via exclusiva para pedestres.

\subsubsection{Localização}

Aracaju é a capital do menor estado do Brasil: Sergipe, localizado no litoral do Brasil a $345 \mathrm{Km}$ de Salvador (Figura 3.5). O povoado de Santo Antônio do Aracaju foi elevado à categoria de cidade no dia 17 de março de 1855. Essa cidade nasceu devido a um estreitamento das relações internacionais com países mais evoluídos e, entre outras características, foi o ponto da resistência contra os franceses no período colonial.

De acordo com o IBGE, no ano de 2008, a estimativa do número de habitantes na cidade era de 536.785 habitantes. Somando-se as populações dos municípios que formam a Grande Aracaju, Nossa Senhora do Socorro, Barra dos Coqueiros, Laranjeiras e São Cristóvão, o número passa para 900.000 habitantes aproximadamente.

A cidade foi construída numa área de charcos e pântanos, sendo, portanto, um desafio para a engenharia da época. O engenheiro Sebastião Basílio Pirro foi o responsável da comissão de engenheiros encarregados do desenho urbanístico da cidade. O centro do poder político-administrativo (atual Praça Fausto Cardoso) foi o ponto de partida para o crescimento da cidade. Todas as ruas foram localizadas geometricamente, como um tabuleiro de xadrez, para desembocarem no Rio Sergipe. Essa cidade foi um dos primeiros exemplos da tendência geométrica, já que até o momento as cidades eram adaptadas às condições topográficas naturais.

Aracaju está em comunicacão com resto do país por meio deduas importantes rodovias federais que cortam o estado. A BR 101 corta o estado de norte a sul, e a BR 235 no sentido leste-oeste. 


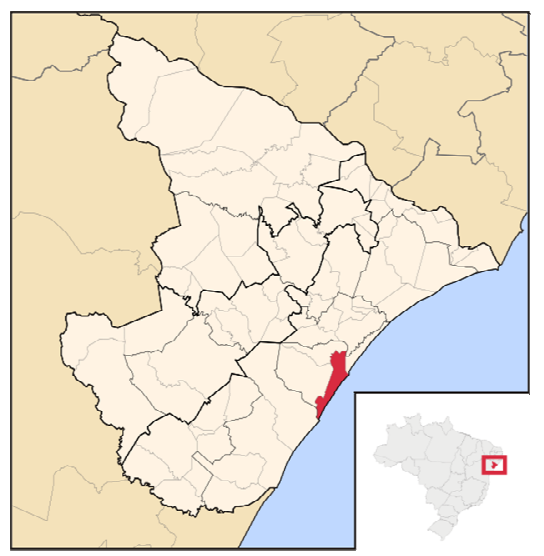

Figura 3.5: Localização de Aracaju no Estado de Sergipe (pt.wikipedia.org)

\subsubsection{Desenhos e características gerais}

A ponte possui uma extensão total de $440 \mathrm{~m}$, com um vão central de $200 \mathrm{~m}$ (Figura 3.6). O material empregado foi o concreto estrutural. Possui quatro pilares de $69 \mathrm{~m}$ de altura e um total de 112 estais arranjados em forma de leque. Além dos pilares principais, possui pilares secundários a $40 \mathrm{~m}$ dos pilares principais.

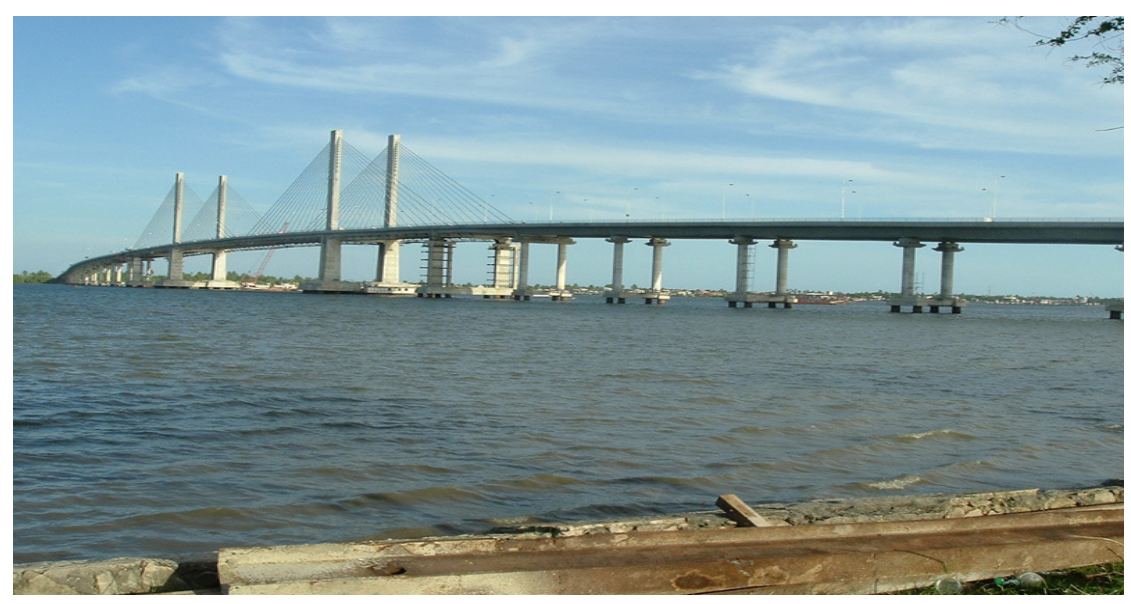

Figura 3.6: Foto da Ponte Construtor João Alves sobre o Rio Sergipe (www.skvscrapercity.com)

\subsubsection{Tabuleiro}

O tabuleiro é solidário aos pilares e está dividido em 52 aduelas de $6,5 \mathrm{~m}$; quatro aduelas de $12 \mathrm{~m}$; duas aduelas de $3,5 \mathrm{~m}$; duas aduelas de $20 \mathrm{~m}$ e uma aduela de fechamento central de 7,0m. O gabarito é de $28 \mathrm{~m}$, aproximadamente.

A seção do tabuleiro consta de duas vigas longitudinais ou longarinas e a laje (Figura 3.7). À medida que o tabuleiro se aproxima aos pilares principais, às seções deste variam e tornam-se maiores. Há cinco seções de propriedades diferentes. 


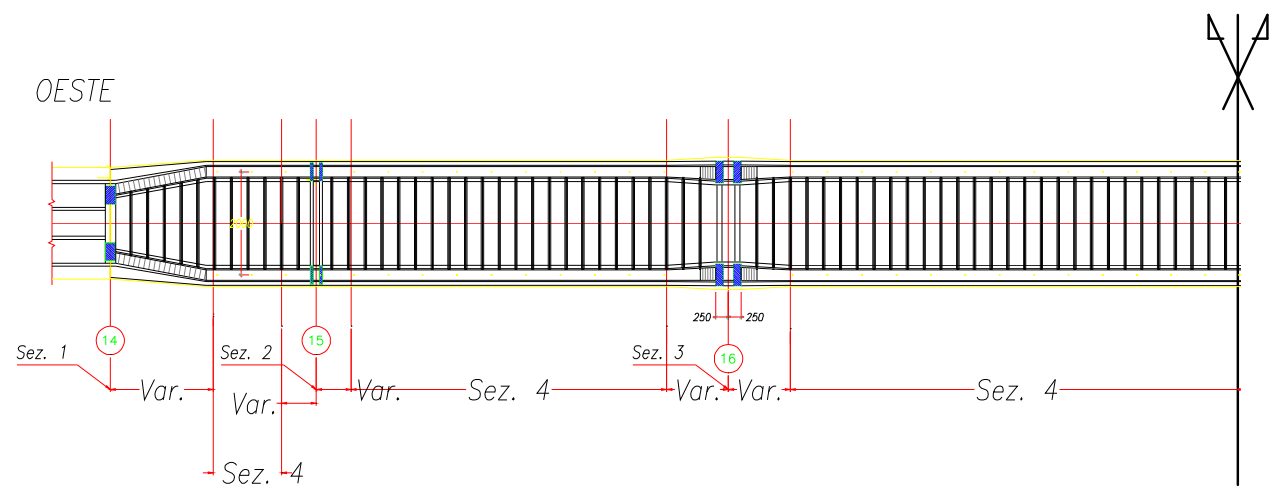

Figura 3.7: Planta do tabuleiro

Na figura anterior, apresenta-se a localização das seções no tabuleiro. Há três trechos variáveis e seis trechos de seção constante. Na Tabela 3.2 estão indicadas as quatro seções constantes que compõem o tabuleiro.

Tabela 3.2: Seções do tabuleiro (unidade: $\mathrm{cm}$ )

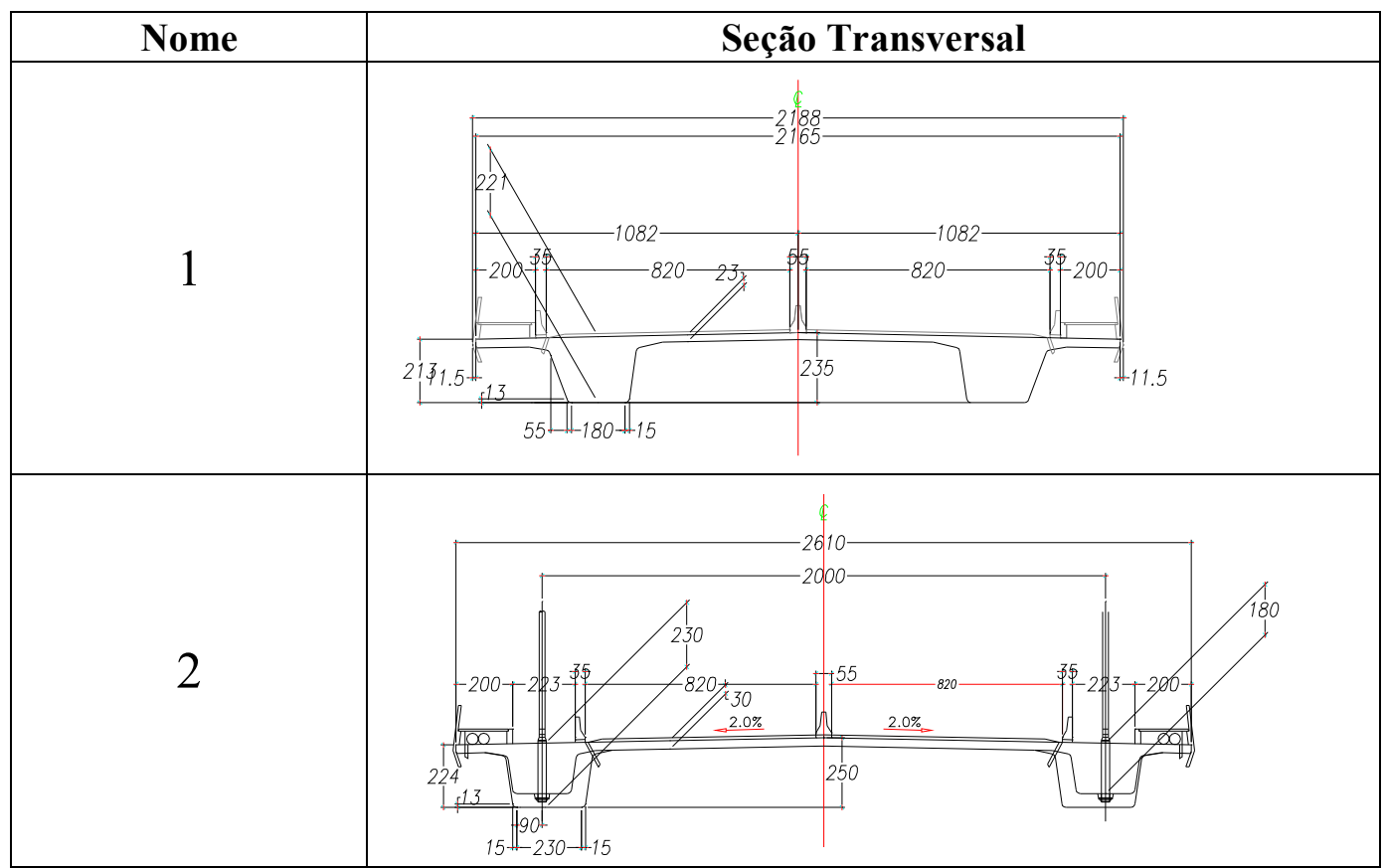




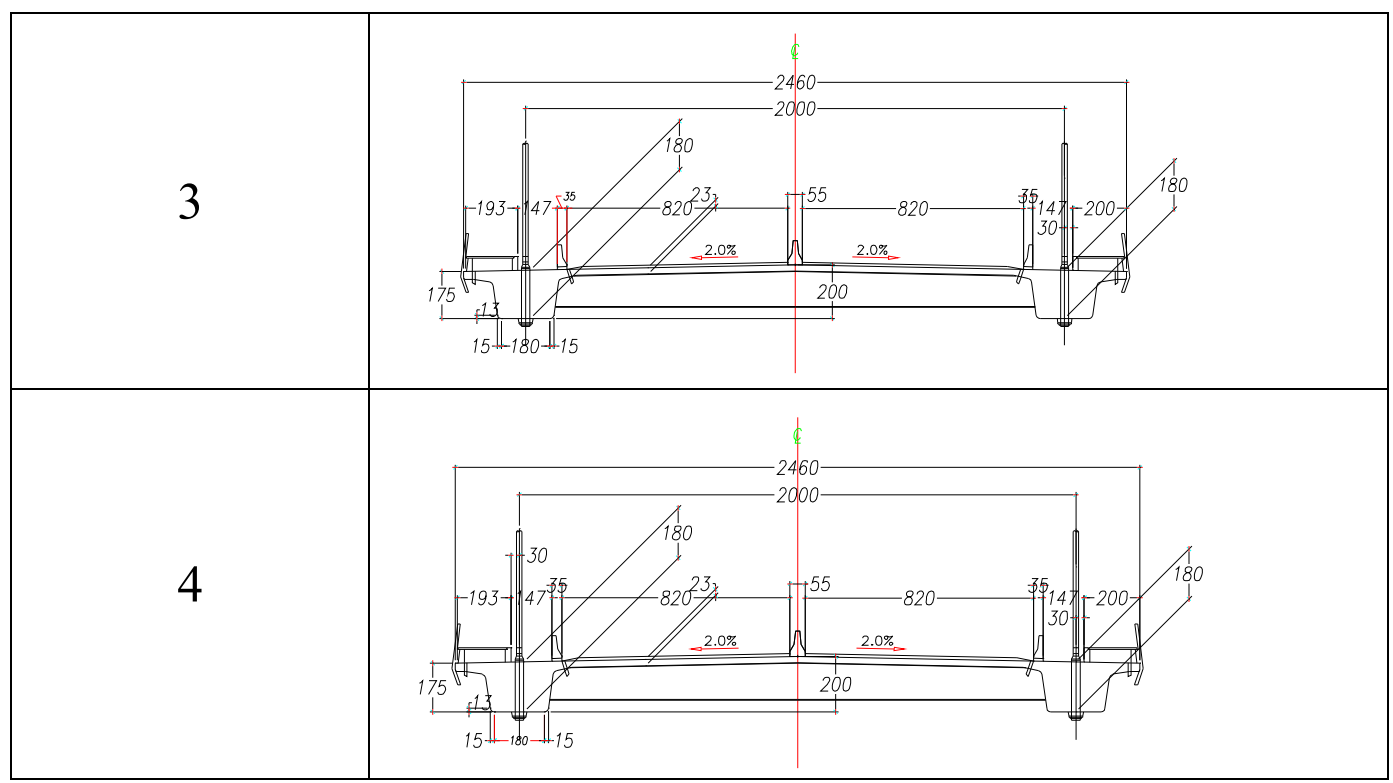

\subsubsection{Transversinas}

As vigas transversais estão localizadas a cada $3,25 \mathrm{~m}$. São perfis I e foram colocados no tabuleiro a cada 3,25m (Figura 3.8).

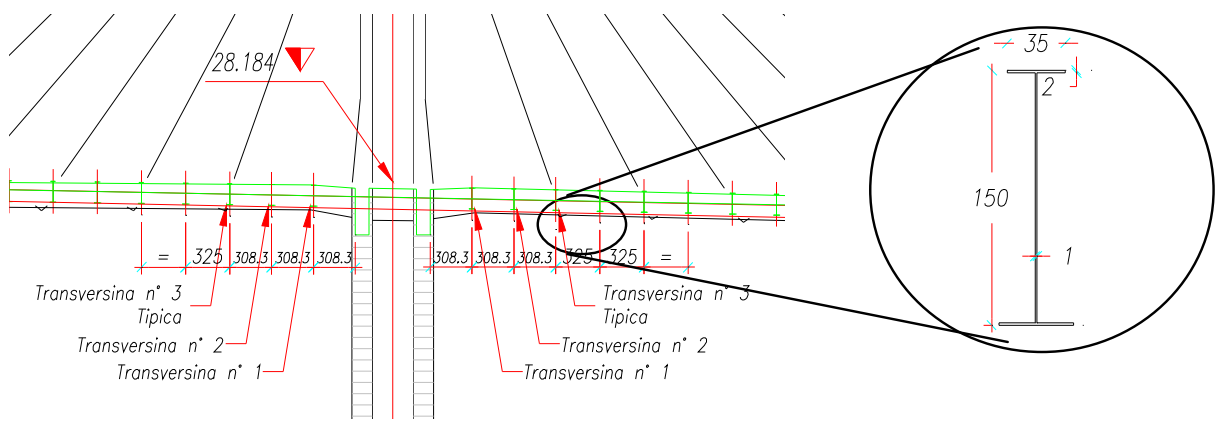

Figura 3.8: Detalhe das Transversinas (medidas: $\mathrm{cm}$ )

Estão divididas em oito grupos; dois deles estão localizados na região próxima ao mastro e os outros 5 estão nas proximidades do apoio. $\mathrm{O}$ oitavo grupo corresponde às transversinas típicas da ponte (Figura 3.9). No modelo, a geometria das transversinas está determinada pela própria geometria do tabuleiro. 

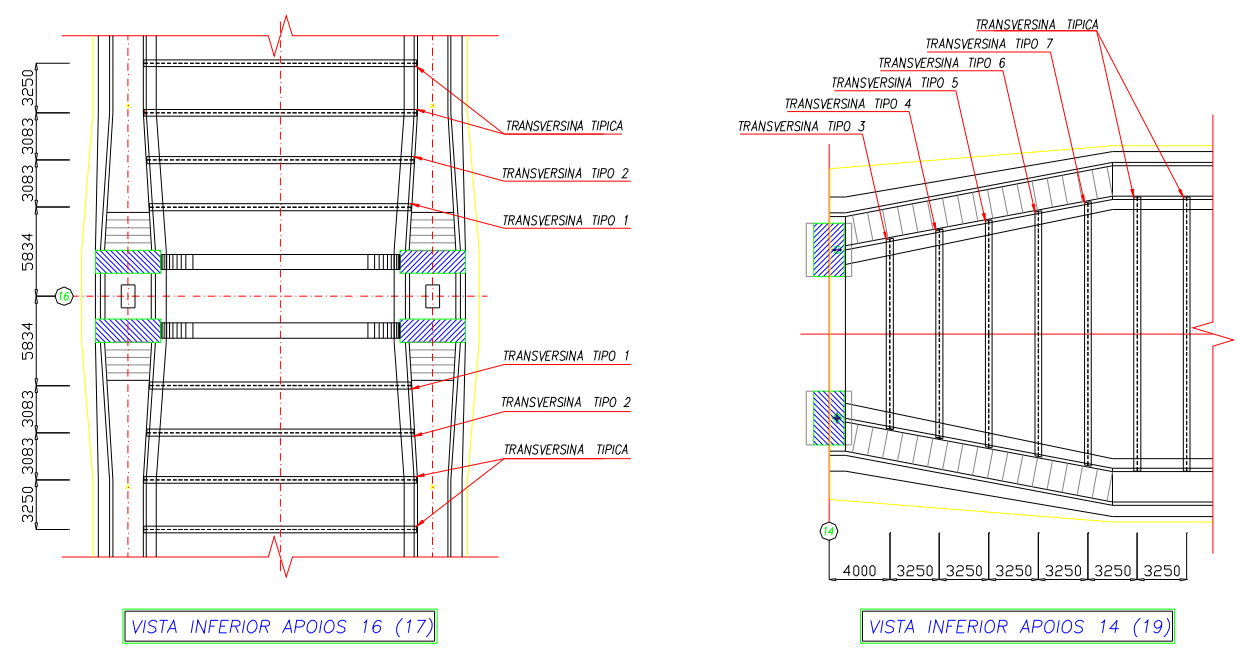

Figura 3.9: Grupos de transversinas (medidas: $\mathbf{m m}$ )

\subsubsection{Mastros}

Os mastros têm uma altura aproximada de 69 metros e cada um deles serve de suporte a 28 estais, 14 de cada lado do plano longitudinal. Estes têm quatro seções, duas delas fazem parte da área acima do tabuleiro e as outras duas da área abaixo (Figura 3.10).
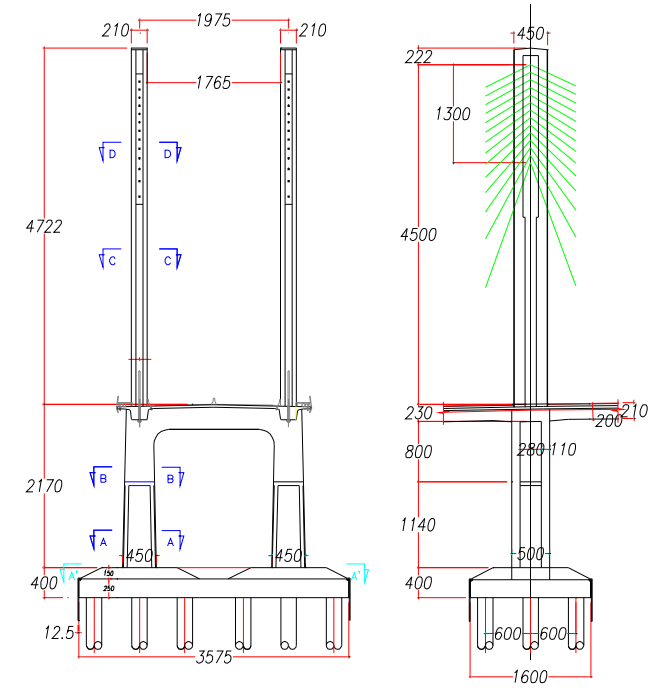

Figura 3.10: Geometria dos mastros (unidade: $\mathrm{cm}$ )

As seções do mastro estão apresentadas na Tabela 3.3. 
Tabela 3.3: Seções do mastro (unidade: $\mathrm{cm}$ )

\begin{tabular}{|c|c|}
\hline Corte & Seções \\
\hline$A-A$ & $\begin{array}{l}\text { DIIIIA } \frac{110}{110} \\
- \text { EIIIIIA } \frac{1}{110} \\
+350 \div 400+\end{array}$ \\
\hline B-B & $\begin{array}{l}10+5050+40 \\
+400 \div 450+\end{array}$ \\
\hline $\mathrm{C}-\mathrm{C}$ & 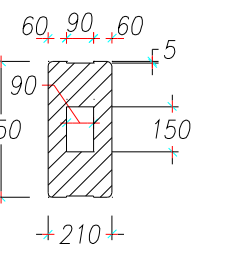 \\
\hline D-D & 200 \\
\hline
\end{tabular}

\subsubsection{Estais}

A ponte tem 112 estais arranjados em forma de leque. A seção destes é circular e varia de acordo com a força axial que tem que suportar. Para obter uma maior organização no momento de atribuir propriedades e processar dados, os estais foram numerados como mostra a Figura 3.11 


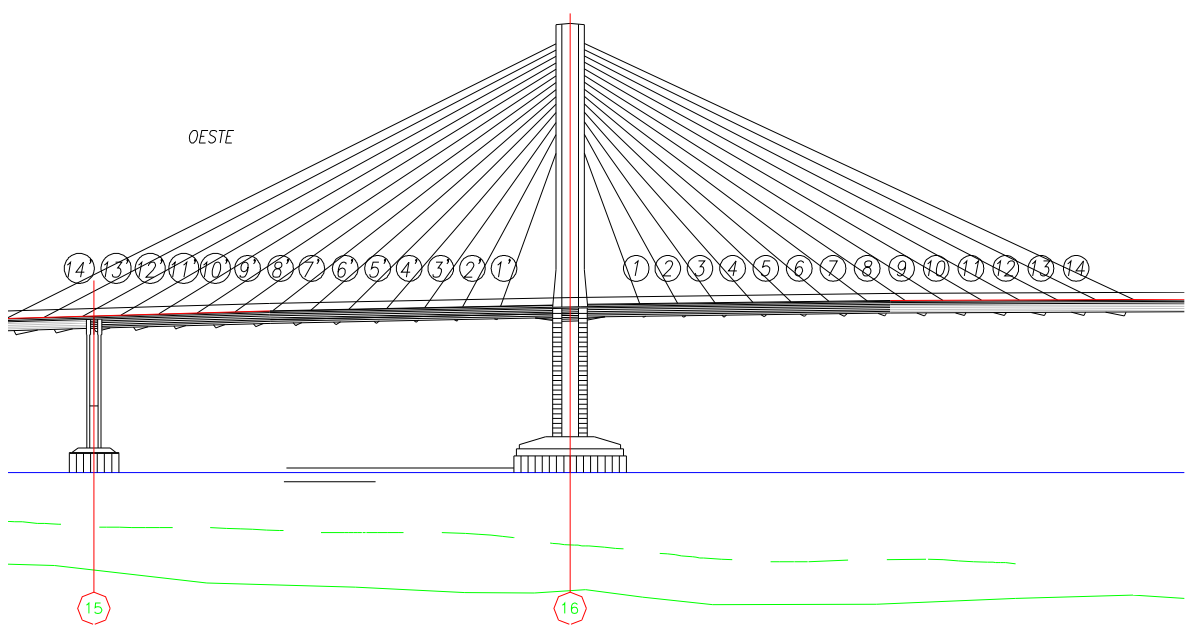

Figura 3.11: Numeração dos estais

O material utilizado é o aço $\mathrm{CP} 177 \mathrm{RB}$, cada cabo tem um número de cordoalhas que varia de 19 até 39, com um diâmetro de $15,7 \mathrm{~mm}$, e estão protegidos por um tubo antivandalismo. Na Figura 3.12 pode-se apreciar detalhes das ancoragens dos estais números 14', 13' e 14, 13 no mastro e no tabuleiro.

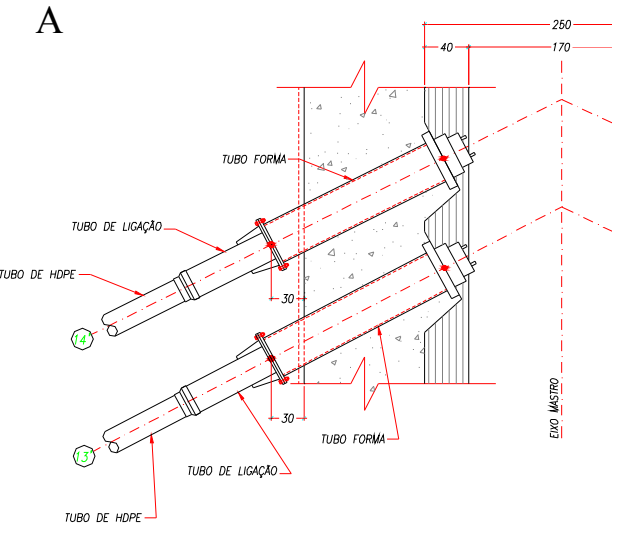

B

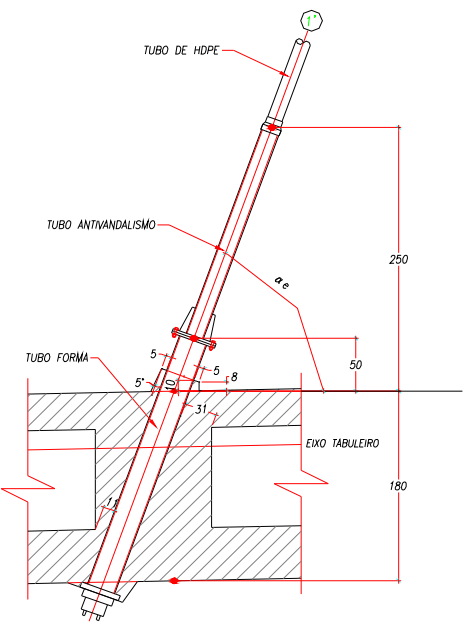

Figura 3.12: Esquema dos encontros dos estais (A: no mastro, B: no tabuleiro)

Na Tabela 3.4 apresentam-se as propriedades geométricas de todos os estais. 
Tabela 3.4: Propriedades geométricas dos estais

\begin{tabular}{|c|c|c|c|c|c|}
\hline Estai & $\mathbf{L}(\mathbf{m})$ & $\begin{array}{c}\text { Duct } \\
\text { Diam. } \\
\mathbf{( m )}\end{array}$ & $\begin{array}{c}\mathbf{e}=\mathbf{e s p e s . t u b o} \\
\mathbf{( m )}\end{array}$ & Cordoalha & $\begin{array}{c}\mathbf{A} \\
\mathbf{m}^{\mathbf{2}} \mathbf{)}\end{array}$ \\
\hline $\mathbf{1}$ & 35,152 & 0,140 & 0,0054 & 19 & 0,00285 \\
\hline $\mathbf{2}$ & 38,857 & 0,140 & 0,0054 & 19 & 0,00285 \\
\hline $\mathbf{3}$ & 43,265 & 0,180 & 0,0070 & 21 & 0,00315 \\
\hline $\mathbf{4}$ & 48,175 & 0,180 & 0,0070 & 23 & 0,00345 \\
\hline $\mathbf{5}$ & 53,458 & 0,180 & 0,0070 & 24 & 0,00360 \\
\hline $\mathbf{6}$ & 59,007 & 0,180 & 0,0070 & 26 & 0,00390 \\
\hline $\mathbf{7}$ & 64,766 & 0,180 & 0,0070 & 28 & 0,00420 \\
\hline $\mathbf{8}$ & 70,673 & 0,180 & 0,0070 & 29 & 0,00435 \\
\hline $\mathbf{9}$ & 76,699 & 0,180 & 0,0070 & 31 & 0,00465 \\
\hline $\mathbf{1 0}$ & 82,814 & 0,200 & 0,0077 & 32 & 0,00480 \\
\hline $\mathbf{1 1}$ & 89,004 & 0,200 & 0,0077 & 34 & 0,00510 \\
\hline $\mathbf{1 2}$ & 95,255 & 0,250 & 0,0097 & 36 & 0,00540 \\
\hline $\mathbf{1 3}$ & 101,557 & 0,250 & 0,0097 & 38 & 0,00570 \\
\hline $\mathbf{1 4}$ & 107,895 & 0,250 & 0,0097 & 39 & 0,00585 \\
\hline
\end{tabular}

Os estais constam de 4 partes principais:

- tubo-forma;

- tubo antivandalismo;

- bainha;

- ancoragem. 


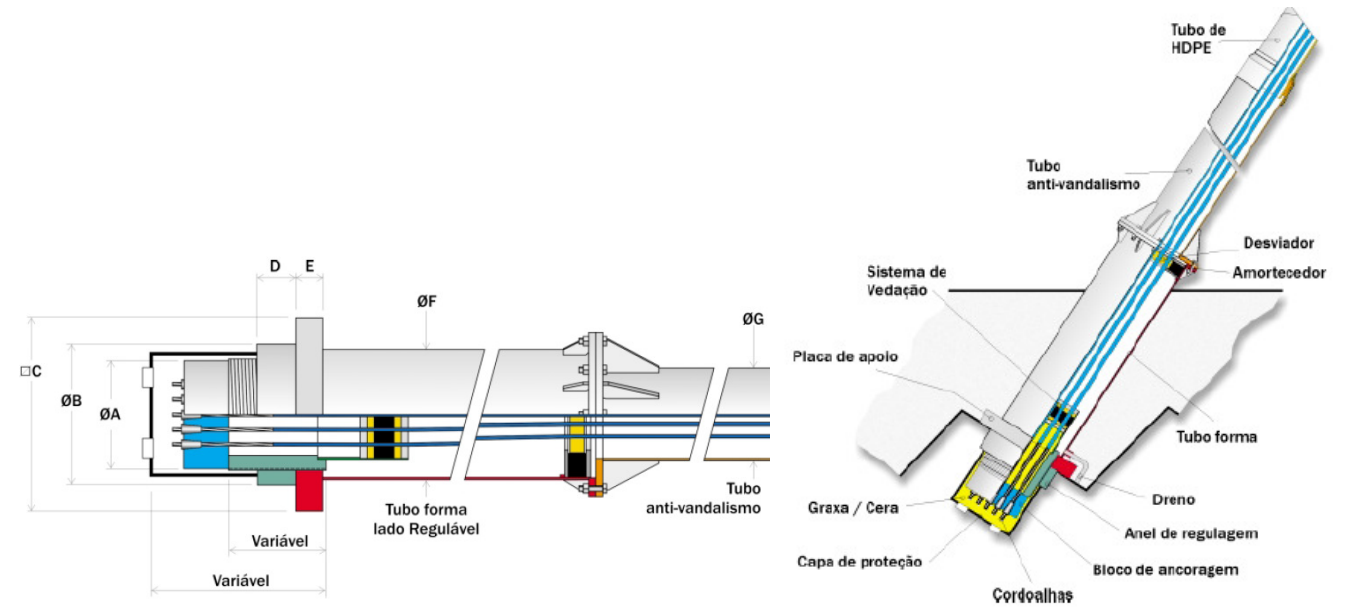

Figura 3.13: Esquema de elementos de um estai sistema "TSR” (Catalogo Protende)

- Tubo-forma

Geralmente, o tubo-forma tem uma dimensão de $50 \mathrm{~cm}$ a partir da cota do tabuleiro e $50 \mathrm{~cm}$ a partir da lateral concluída do mastro Esse tubo, como diz a palavra, é aquele que vai gerar um espaço para a futura colocação do estai, tanto na parte superior como na inferior.

- Tubo antivandalismo

Logo após o tubo-forma, vem o tubo antivandalismo. $\mathrm{O}$ objetivo desse tubo é proteger o cabo de agressões externas que podem danificar a estrutura.

- Bainha

O tubo do estai é feito de PAD (polietileno de alta densidade), sua função é proteger da corrosão os cabos de sustentação da ponte.

- Ancoragem

A ancoragem é um aparelho mecânico cuja função é manter a tensão no estai e transmitir esse carregamento à estrutura estaiada.

Um detalhe importante é que as cordoalhas são galvanizadas e estão dentro da bainha imersa em cera, mas na placa de ancoragem, logo após ser feita a protensão, as cordoalhas são cortadas, deixando, assim, a ancoragem menos protegida.

O processo de protensão que geralmente se utiliza é chamado de issoalongamento. Esse tipo de protensão consiste em dar a cada nova cordoalha protendida o mesmo alongamento de todas as demais cordoalhas já protendidas no mesmo estai. O alongamento de uma dada cordoalha muda conforme se protendem outras cordoalhas 
do mesmo estai, pois, ao aumentar a força no estai gradativamente, protende-se cordoalha por cordoalha. (ALMEIDA, et. all)

Para a execução do issoalongamento, mede-se a distância entre os dois pontos de ancoragem do estai (no mastro e no tabuleiro) numa temperatura de referência e marca-se todas as cordoalhas do estai com essa medida. Na montagem do estai, alinha-se a marca superior na ancoragem do mastro e a marca inferior na ancoragem do tabuleiro. Depois disso, inicia-se a protensão da primeira cordoalha até a outra marca se alinhar com a ancoragem do tabuleiro. O esforço de protensão da primeira cordoalha é dado por:

$$
F_{i}=\frac{F+\delta F_{i s o}}{1+\frac{\delta F_{i s o}}{F}}
$$

Onde:

$F_{i}$ : força na primeira cordoalha;

$F:$ força total no estai após a protensão;

$\delta F_{\text {iso }}=E \times A \times \frac{\Delta L}{L} ;$

$E$ : modulo de elasticidade

$A$ : área transversal do estai

$\Delta L$ : variação de comprimento

$L$ :comprimento do estai

$n$ : número de cordoalhas no estai.

Recomenda-se colocar uma célula de carga na primeira cordoalha de todos os estais para realizar operações de monitoração. Para a protensão das demais cordoalhas, deve-se protender até que a marca inferior fique alinhada com a marca inferior da primeira cordoalha protendida, de modo que tenham o mesmo alongamento. Assim por diante são protendidas as demais cordoalhas.

No estágio final, ajusta-se os esforços mediante um macaco; onde se protende o estai inteiro com ajuste da porca para não interferir nas cunhas. 


\subsubsection{Pilares secundários}

Os pilares secundários possuem duas seções: uma seção única na parte superior e uma seção dupla na parte inferior. Estes estão engastados no tabuleiro. A variação das barras está apresentada na Tabela 3.5.

Tabela 3.5: Seções detalhadas

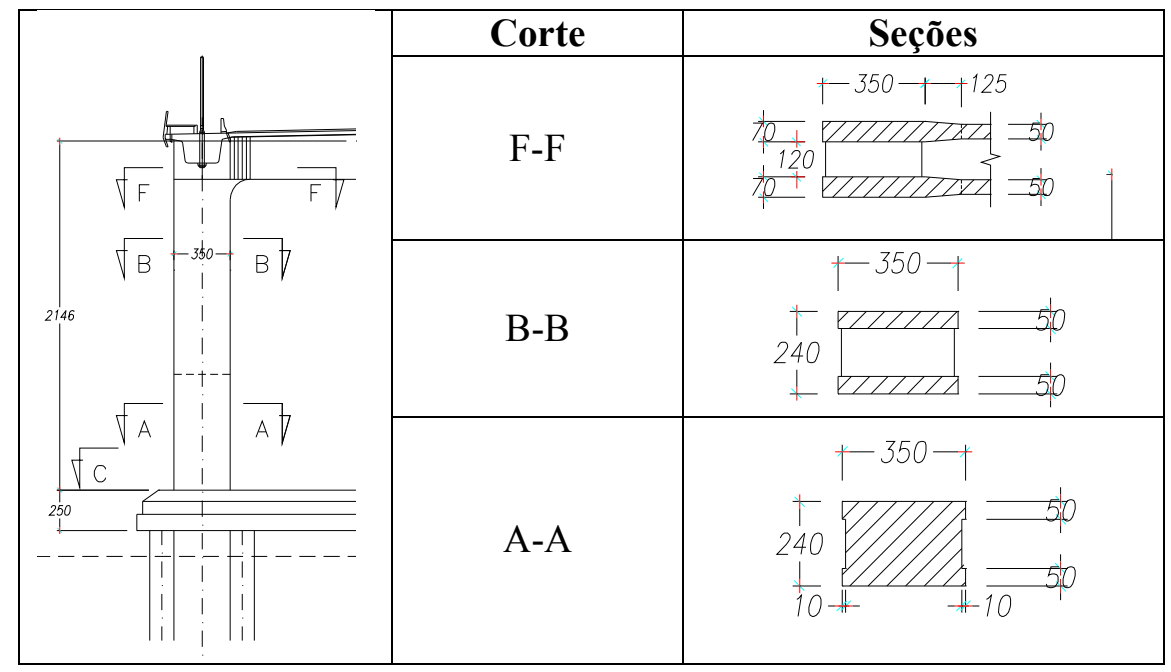

\subsubsection{Descrição das fases construtivas}

O método construtivo é de vital importância, não só pelo arranjo estrutural, mas também porque nessa etapa se avaliam os esforços estruturais. Consequentemente, cada fase deve ser respeitada e analisada para a obtenção de um bom resultado.

O comportamento desse tipo de ponte pode ser facilmente entendido quando se considera o processo construtivo. Quando se trata de balanços sucessivos, pode-se assumir que cada estai colocado suporta, aproximadamente, o peso de cada trecho, correspondendo, geralmente, à distância que há entre dois estais. Esse elemento é protendido e deve suportar o peso da próxima aduela.

Nesse caso, o método construtivo adotado foi o de consolos sucessivos e está detalhado a seguir. É importante destacar que em cada fase estão estabelecidas determinadas durações aproximadas para cada tarefa, estas dependem do tipo de solução a ser adotada. Os dados dos tempos foram obtidos a partir do projeto da Ponte Construtor João Alves. 


\section{Estacas}

A primeira fase de construção consiste na execução das estacas a sua duração dependendo do tipo de solução adotado. (Figura 3.14)

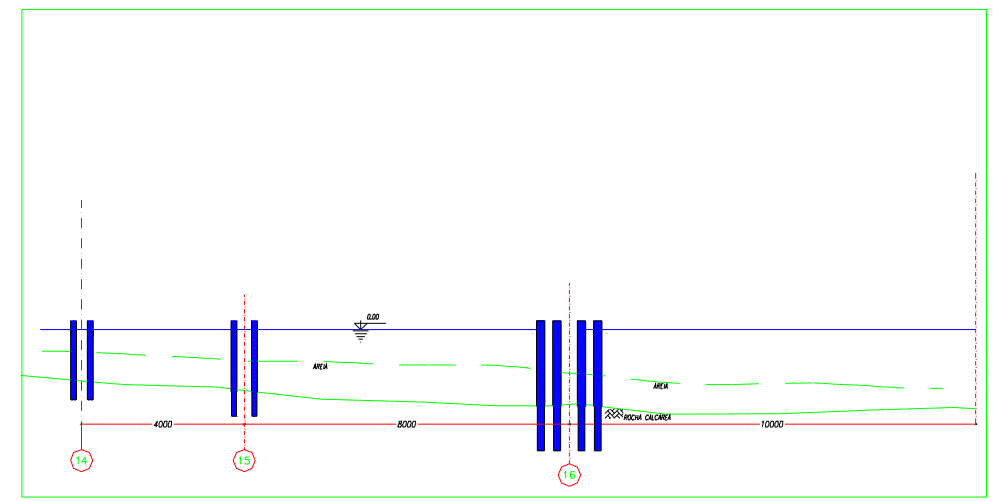

Figura 3.14: Primeira fase construtiva

\section{Fundação e pilares}

A segunda fase consiste a construção das fundações e dos pilares. A fundação, composta de estacas e blocos (Figura 3.15)

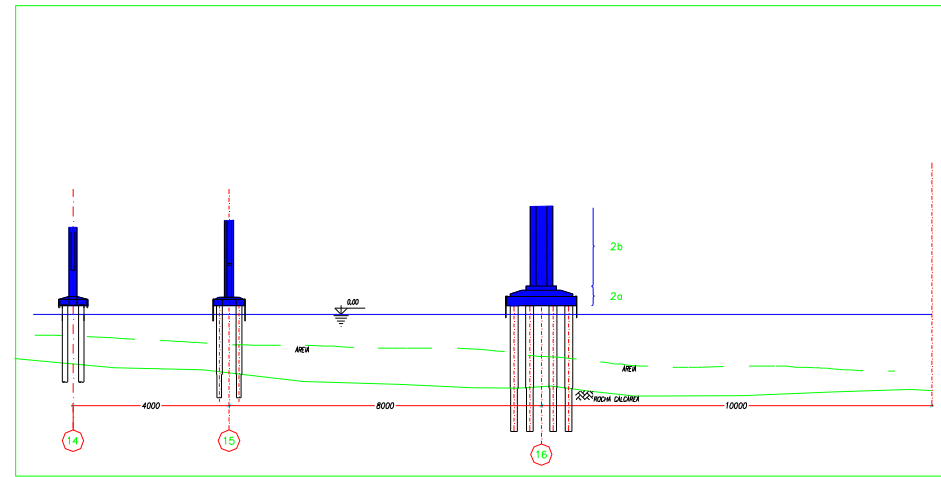

Figura 3.15: Segunda fase construtiva

\section{Construção do mastro}

A terceira fase consiste na construção do mastro. (Figura 3.16) 


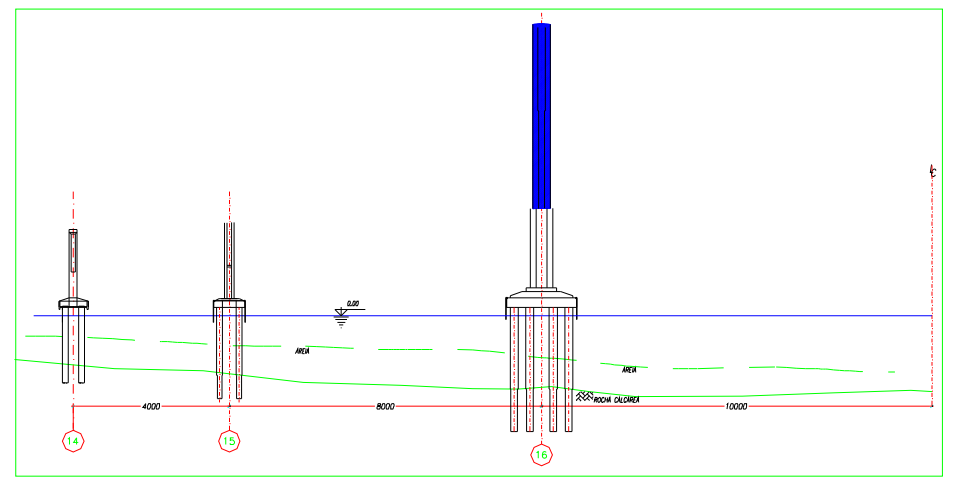

Figura 3.16: Terceira fase construtiva

\section{Montagem das aduelas de disparo e protensão do mastro}

A quarta fase construtiva é a montagem das aduelas em balanço dos pilares e a protensão transversal no topo do mastro. Essa protensão deve ser feita antes de começar a construir as aduelas, já que o mastro deve estar comprimido para suportar as altas trações provenientes da protensão dos estais (Figura 3.17).

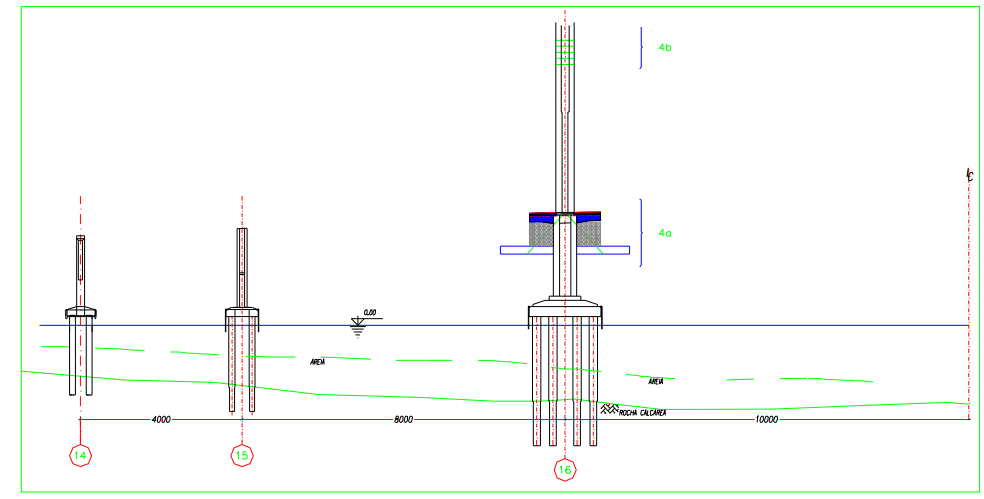

Figura 3.17: Quarta fase construtiva

\section{Montagem das aduelas e dos estais números 1 a 10}

A quinta etapa consiste na montagem das aduelas e seus correspondentes estais, desde o número 1 até o 10. As fases de montagem de uma aduela típica são: avanço da treliça, colocação das armaduras e dos tubos de antivandalismo, colocação das vigas transversais de aço, concretagem das vigas, protensão das vigas, concretagem da laje, protensão da laje e, finalmente, protensão dos estais. (Figura 3.18) 


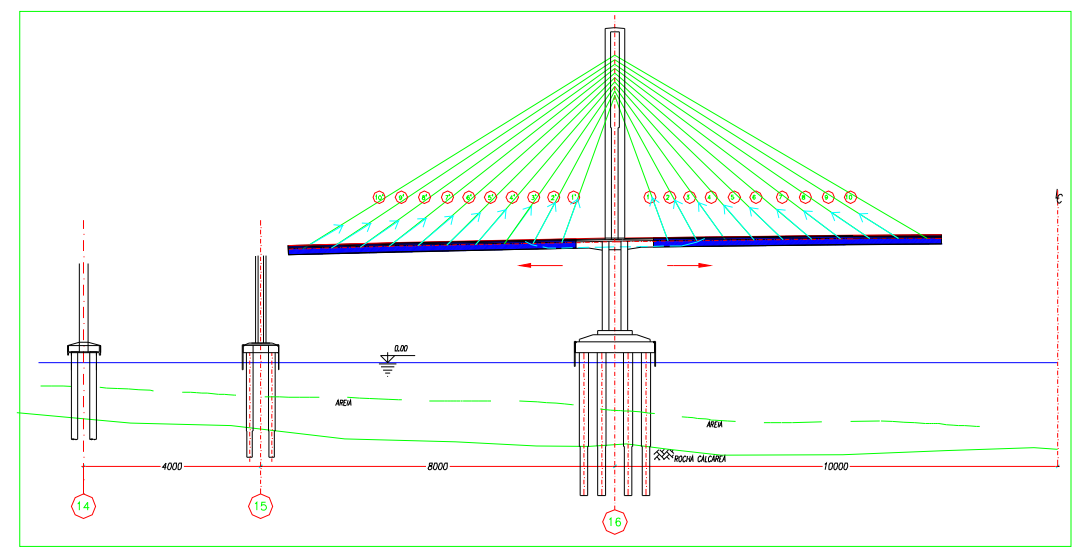

Figura 3.18: Quinta fase construtiva

\section{Vão lateral.}

A sexta fase é a fase de construção do tabuleiro do vão lateral. Primeiro, monta-se um apoio provisório centrado, logo após se protende o vão lateral e, por último, desmonta-se a treliça de cimbramento. (Figura 3.19)

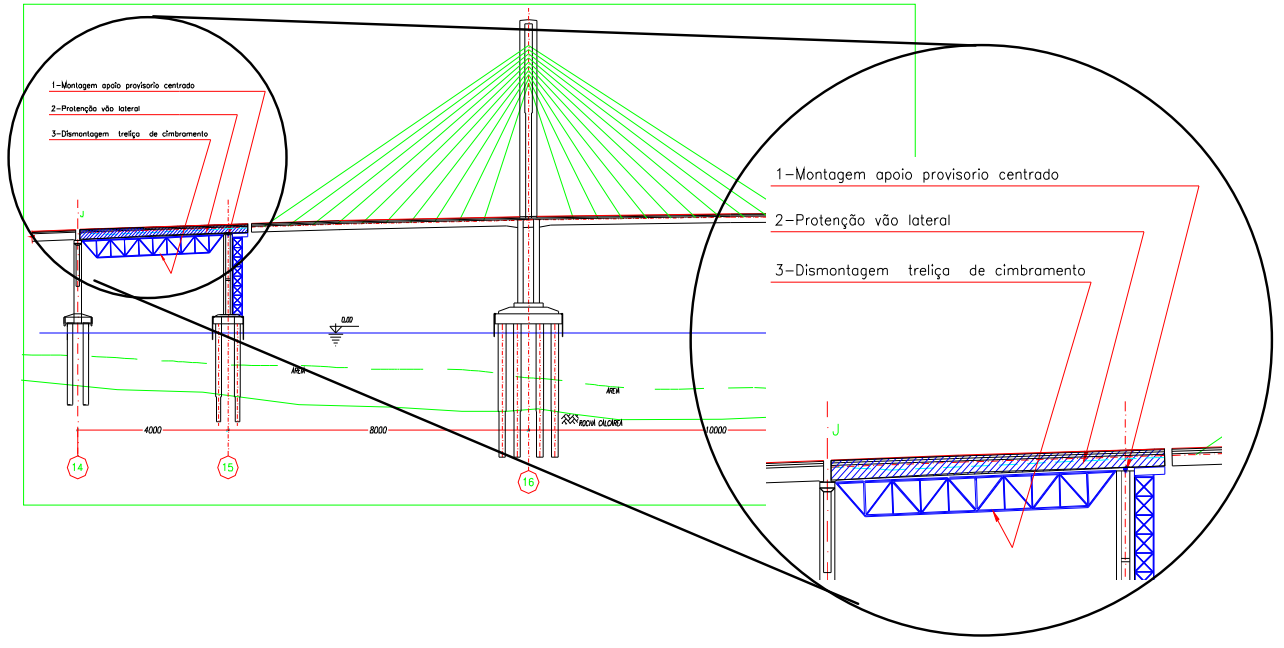

Figura 3.19: Sexta fase construtiva

\section{Fechamento}

A sétima fase corresponde ao fechamento do vão lateral. Para essa etapa é preciso fazer a ligação entre pilares e vigas. Posteriormente, se levanta o tabuleiro estaiado $3,4 \mathrm{~cm}$ sobre o nível anterior; essa fase é chamada "macaqueamento" já que para realizar essa operação precisa-se de um macaco hidráulico. Depois, é feito o fechamento e, por último, se protendem os pilares externos (pilar 15 e 18). (Figura $3.20)$ 


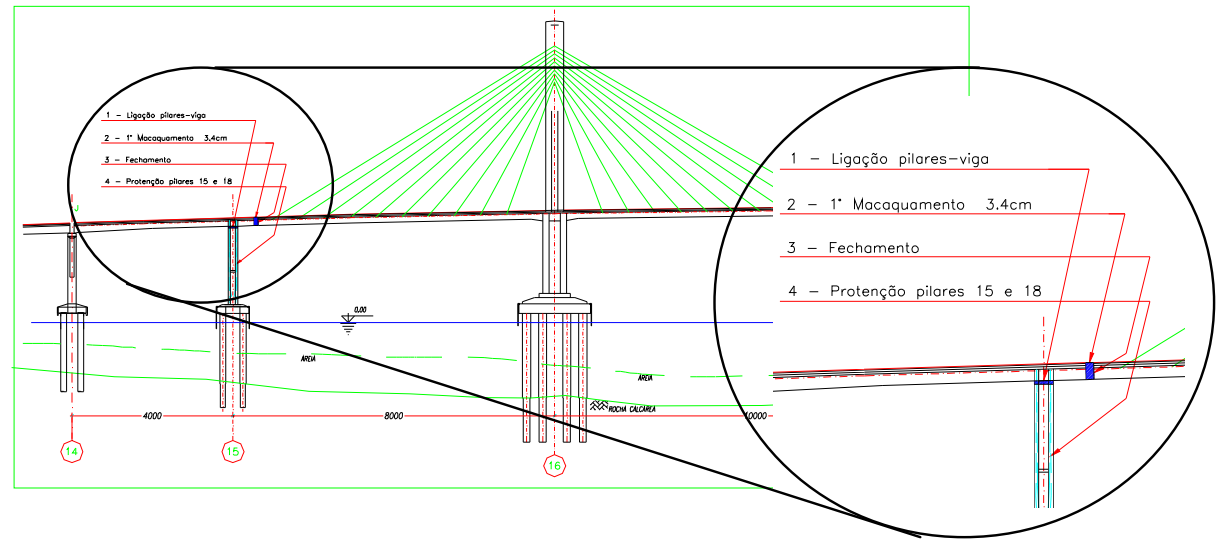

Figura 3.20: Sétima fase construtiva

8. Montagem das aduelas e dos estais números 11 ao 14 e do 11'ao 14'

A oitava etapa consiste na montagem em balanço de quatro aduelas e quatro estais no tramo central e no tramo lateral, correspondentes aos estais 11 ao 14 e 11 ' ao 14 '. (Figura 3.21)

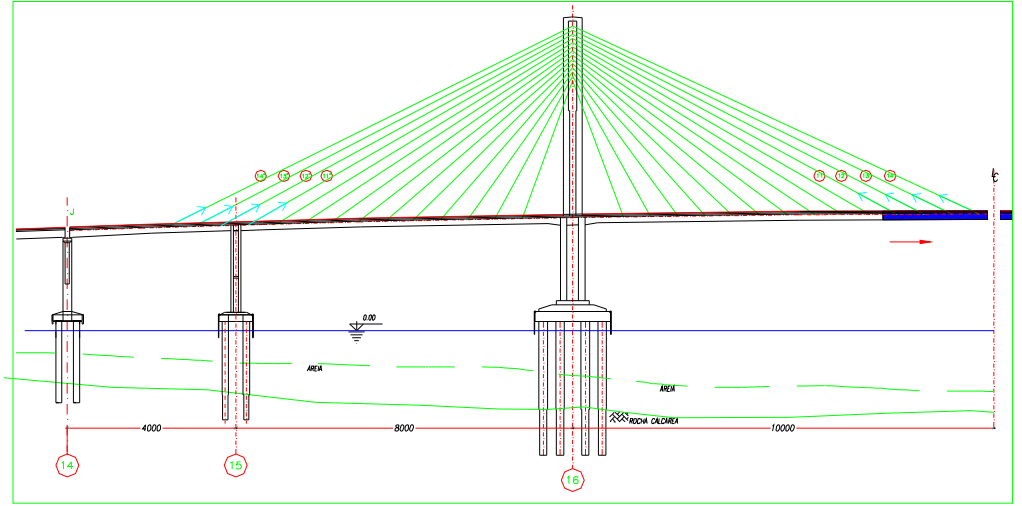

Figura 3.21: Oitava fase construtiva

\section{Fechamento}

A nona etapa consiste no fechamento do vão central. Para realizar essa tarefa, se constrói uma laje onde anteriormente encontrava-se o macaco hidráulico. (Figura 3.22) 


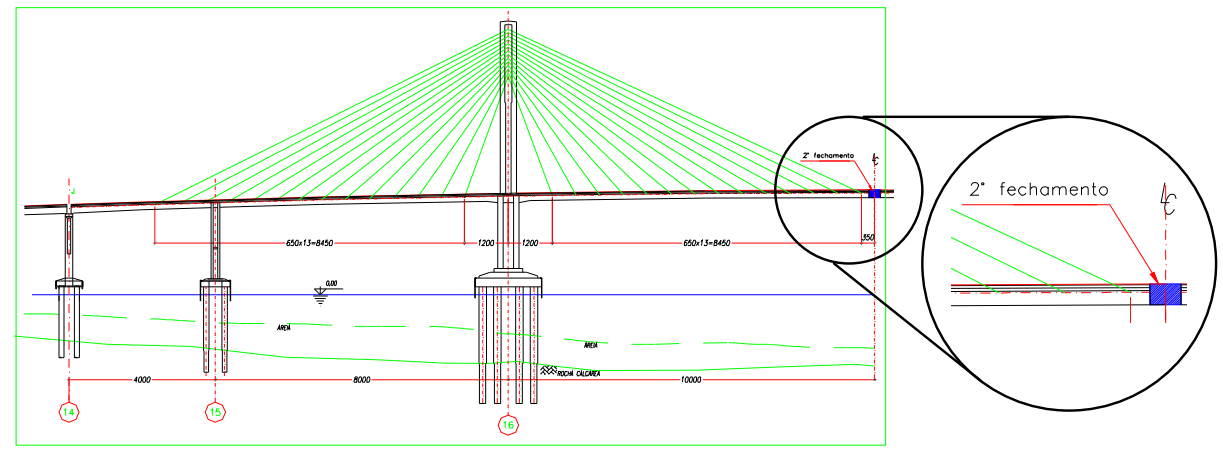

Figura 3.22: Nona fase construtiva

\section{Protensão final}

A décima fase consiste na protensão longitudinal que dá continuidade ao tabuleiro

\section{Acabamento}

Finalmente, a décima-primeira fase é o acabamento. Este consiste na colocação da carga permanente: pavimentação, guarda-rodas, guarda-corpo e iluminação. 


\section{Modelagem dos EXemplos}

\subsection{Tipos de modelos}

O modelo de uma estrutura consiste na sua idealização através da escolha de um conjunto de elementos apropriados que permita que o comportamento da estrutura real seja bem representado e o cálculo razoavelmente preciso (WALTHER, 1999).

Dependendo da complexidade da estrutura e do grau de confiança desejados, o modelo pode ser um conjunto de barras ou uma combinação de barras e elementos de placas.

Nas figuras, são apresentados exemplos de duas pontes. A primeira ponte, chamada Düsseldorf - Flehe, atravessa o Rio Rhin e está localizada na Alemanha (Figura 4.1). Como essa estrutura tem a particularidade de ter um mastro em forma de $\mathrm{Y}$ invertido, o modelo tem que representar essa característica, levando em conta também o comportamento do tabuleiro. Portanto, o sistema escolhido para essa ponte é um sistema de pórtico espacial, composto inteiramente de barras, onde o tabuleiro é representado por uma série de barras transversais.

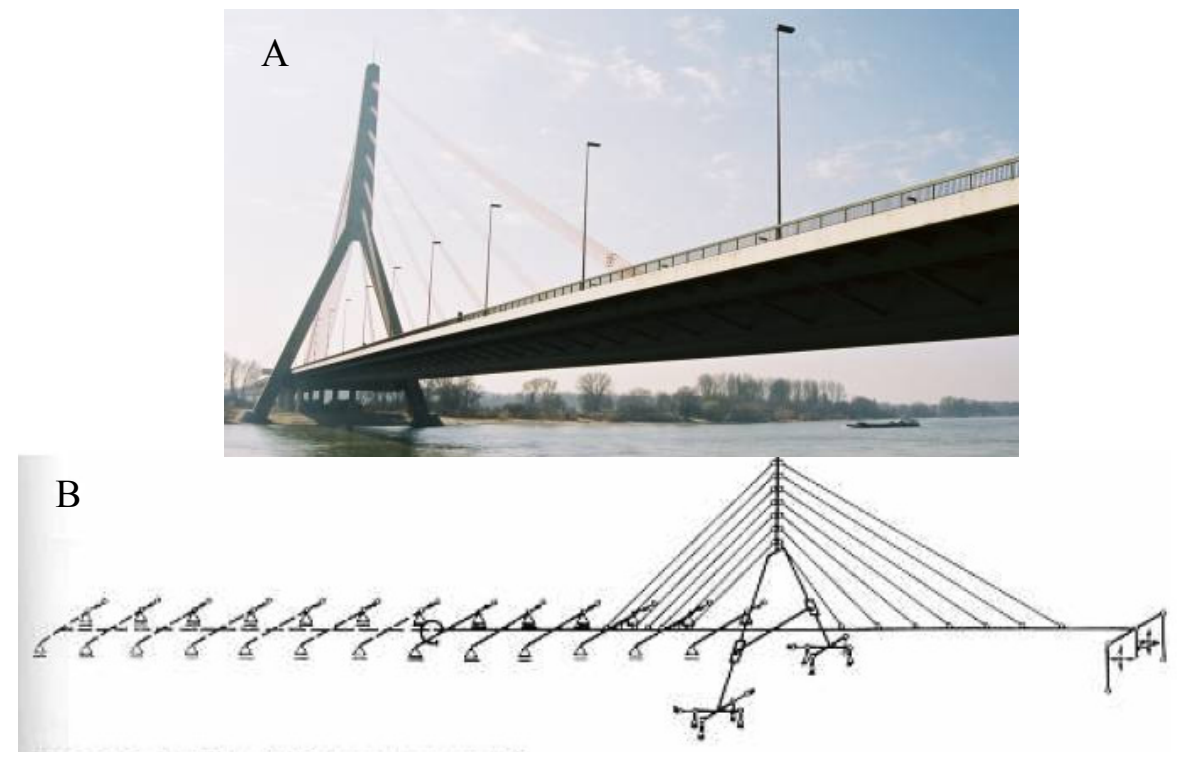

Figura 4.1: A) Ponte Düsseldorf-Flehe sobre o Rio Rhin na Alemanha (http://en.structurae.de), B) Modelo da Ponte (WALTHER, 1999)

No caso da ponte Diepoldsau, localizada na Suíça que atravessa o Rio Alpenrhein (Figura 4.2), o sistema utilizado incorpora um modelo de elementos finitos para a 
laje, que consiste em uma seção de concreto de aproximadamente $50 \mathrm{~cm}$ de espessura e 14,5m de largura. Dessa forma, foi possível calcular o momento transversal no mastro, as forças nos estais e o momento transversal e longitudinal do tabuleiro.

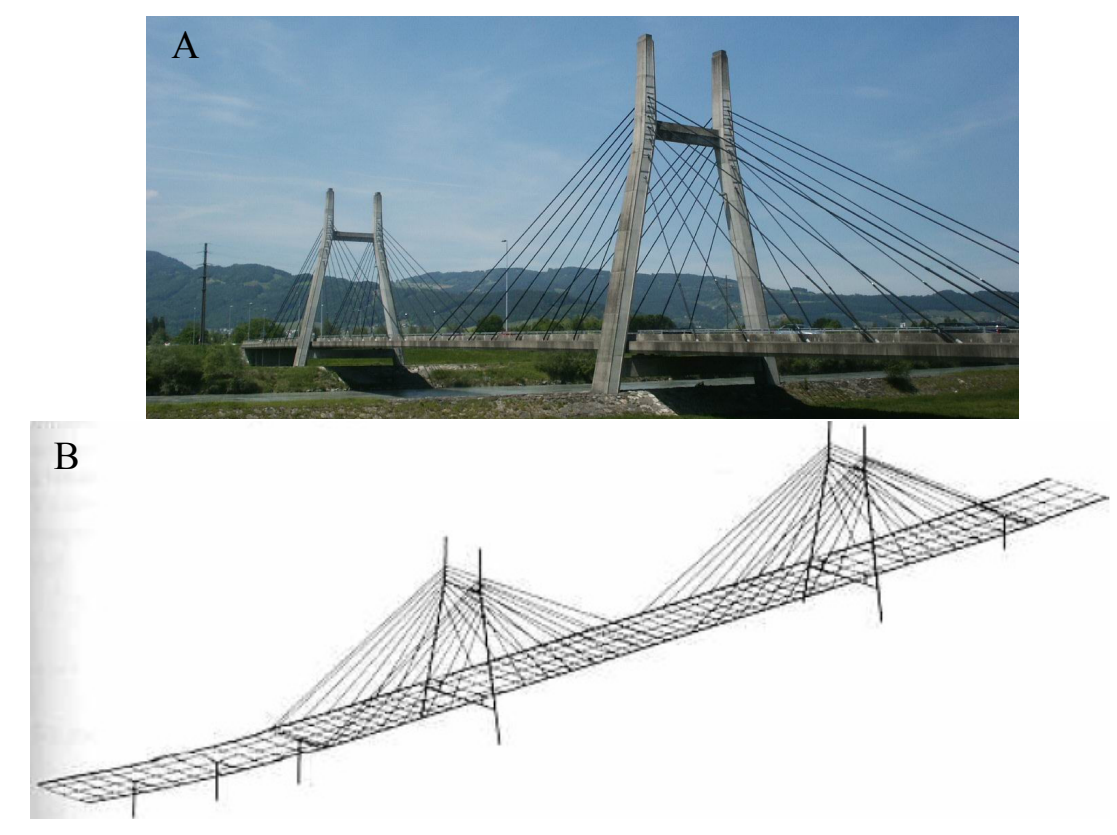

Figura 4.2:A) Ponte Diepoldsau sobre o Rio Alpenrhein na Suiça (http://en.structurae.de), B) Modelo da Ponte (WALTHER, 1999)

Outro aspecto importante da concepção do modelo é definir quais elementos da ponte devem ser considerados. Por exemplo, no caso da fundação, se o objetivo é chegar a um modelo mais representativo da realidade, pode-se modelar o bloco e as estacas. Entretanto, para um primeiro modelo, a fundação pode ser representada por um engastamento, simplificando este elemento e dando importância a outras partes do modelo.

Uma ferramenta muito importante é a utilização dos modelos parciais. O desenvolvimento do processo construtivo é um exemplo desses modelos. Antigamente, empregavam-se sistemas planos para obter resultados simplificados, já que devem ser analisadas várias partes da estrutura. Recentemente, os programas de cálculo estrutural permitem incorporar interfaces que permitem fazer essa análise com modelos mais complexos. Porém, modelos muito complexos devem ser evitados 
para diminuir erros. Se for estritamente necessário usá-los, esses modelos devem ser comparados com modelos mais simples.

Os modelos escolhidos para as pontes desta pesquisa são inteiramente de barras. Essa decisão foi tomada, pois um modelo desse tipo simplifica a geometria da estrutura, além de ajudar a modelagem na etapa do processo construtivo. Para cada elemento da ponte, foram adotadas determinadas características geométricas dos materiais que são apresentadas na descrição de cada modelo.

O programa escolhido para o modelo da ponte é o SAP 2000 V10.0.8 (COMPUTERS AND STRUCTURES INC).

Para um melhor entendimento do comportamento estrutural, foram realizados dois modelos. O primeiro tenta representar, de forma mais fielmente possível, as características geométricas do modelo, levando em conta todas as propriedades estruturais (mudanças e variação de seções, variações de materiais). O segundo consiste em um modelo plano. Este não só facilita a geometria do problema, mas também apresenta uma simplificação na escolha das seções transversais.

\subsection{Modelo do primeiro exemplo}

O objetivo desse modelo é a aplicação dos métodos apresentados nesta pesquisa para a obtenção da distribuição de esforços nos estais, por tal razão foi escolhido um modelo plano simples representado por barras (Figura 4.3). Os elementos representados são:

- Tabuleiro;

- Mastros;

- Estais.

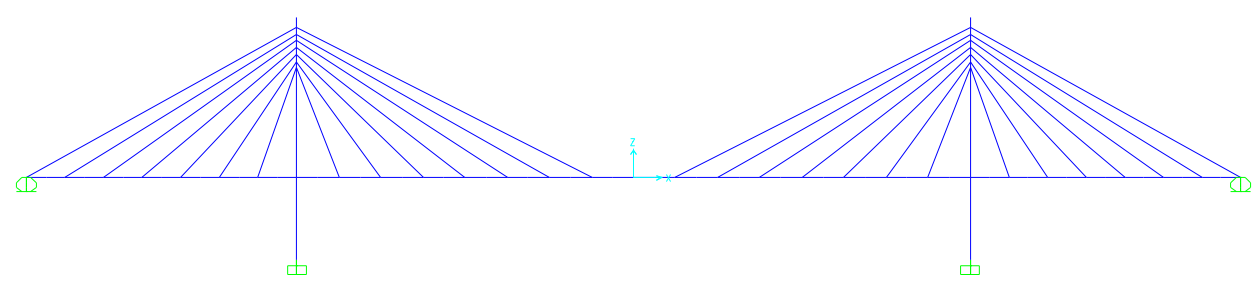

Figura 4.3:Modelo plano do primeiro exemplo 
As condições de contorno da ponte são: dois apoios deslizantes nas extremidades do tabuleiro e um engastamento para cada mastro. As propriedades geométricas desse exemplo estão descritas no item 3.1.1 da presente pesquisa.

Os estais foram modelados como barras de treliça com rigidez axial modificada.

Uma propriedade principal é o módulo de elasticidade equivalente ou Módulo de Dischinger. Quando os cabos são modelados com elementos lineares, o seu módulo de elasticidade deve ser modificado. Isso é feito para respeitar a perda de rigidez do cabo submetido a seu peso-próprio. A rigidez dos estais depende não só do módulo de deformação e da área de aço, mas também do comprimento projetado na direção horizontal e da tensão aplicada. A obtenção desse módulo de elasticidade está detalhada em: TORNERI, P., 2003, VARGAS, L.A.V., 2007.

De acordo com a formulação proposta por Dischinger, tem-se:

$$
E^{*}=\frac{E}{1+\frac{\gamma^{2} \cdot L^{2} \cdot E}{12 \cdot \sigma^{3}}}
$$

Onde:

$E^{*}:$ módulo de elasticidade de Dischinger;

$E$ : modulo de elasticidade do aço do estai;

$\gamma:$ peso específico do aço do estai;

$L$ : projeção horizontal do comprimento do estai;

$\sigma$ : tensão média no estai,

A nova rigidez do estai é calculada levando em conta os seguintes valores:

$E$ : módulo de elasticidade do aço $=195000 \mathrm{Mpa}$;

$\gamma$ : peso específico do aço do estai $=78,5 \mathrm{kN} / \mathrm{m}^{3}$;

$\sigma:$ tensão média no estai $=25 \%$ de $1850 \mathrm{MPa}$

Considerando a numeração dos estais estabelecida na Figura 3.3, os resultados obtidos se apresentam na Tabela 4.1 
Tabela 4.1: Determinação do módulo de elasticidade corrigido (Módulo de Dischinger)

\begin{tabular}{|c|c|c|c|c|c|}
\hline Estai & $\mathbf{L}(\mathbf{m})$ & $\begin{array}{c}\boldsymbol{\gamma}^{*} \\
\left(\mathbf{k N} / \mathbf{m}^{3}\right)\end{array}$ & $\begin{array}{c}\mathbf{E} \\
\left(\mathbf{k N} / \mathbf{m}^{2}\right)\end{array}$ & $\begin{array}{c}\boldsymbol{\sigma} \\
\left(\mathbf{k N} / \mathbf{m}^{\mathbf{2}}\right)\end{array}$ & $\begin{array}{c}\mathbf{E}^{*} \\
\left(\mathbf{k N} / \mathbf{m}^{2}\right)\end{array}$ \\
\hline E1 & 80,000 & 78,5 & $1,95 \times 10^{8}$ & 462500 & $1,937 \times 10^{8}$ \\
\hline E2 & 68,470 & 78,5 & $1,95 \times 10^{8}$ & 462500 & $1,941 \times 10^{8}$ \\
\hline E3 & 57,140 & 78,5 & $1,95 \times 10^{8}$ & 462500 & $1,943 \times 10^{8}$ \\
\hline E4 & 45,640 & 78,5 & $1,95 \times 10^{8}$ & 462500 & $1,946 \times 10^{8}$ \\
\hline E5 & 34,230 & 78,5 & $1,95 \times 10^{8}$ & 462500 & $1,948 \times 10^{8}$ \\
\hline E6 & 22,820 & 78,5 & $1,95 \times 10^{8}$ & 462500 & $1,949 \times 10^{8}$ \\
\hline E7 & 11,430 & 78,5 & $1,95 \times 10^{8}$ & 462500 & $1,9497 \times 10^{8}$ \\
\hline E8 & 12,44 & 78,5 & $1,95 \times 10^{8}$ & 462500 & $1,9497 \times 10^{8}$ \\
\hline E9 & 24,88 & 78,5 & $1,95 \times 10^{8}$ & 462500 & $1,9488 \times 10^{8}$ \\
\hline E10 & 37,31 & 78,5 & $1,95 \times 10^{8}$ & 462500 & $1,947 \times 10^{8}$ \\
\hline E11 & 49,75 & 78,5 & $1,95 \times 10^{8}$ & 462500 & $1,945 \times 10^{8}$ \\
\hline E12 & 62,19 & 78,5 & $1,95 \times 10^{8}$ & 462500 & $1,942 \times 10^{8}$ \\
\hline E13 & 74,63 & 78,5 & $1,95 \times 10^{8}$ & 462500 & $1,939 \times 10^{8}$ \\
\hline E14 & 87,06 & 78,5 & $1,95 \times 10^{8}$ & 462500 & $1,935 \times 10^{8}$ \\
\hline
\end{tabular}

\subsection{Modelo para a Ponte Construtor João Alves}

O primeiro modelo da ponte é um modelo plano (Figura 4.4). O tabuleiro e a torre são de concreto, com módulo de elasticidade igual a $30000 \mathrm{MPa}$. Os estais estão formados por cabos com cordoalhas de aço CP190RB, de 15,7mm de diâmetro. O módulo de elasticidade do aço foi considerado como $195000 \mathrm{MPa}$, sendo corrigido pela perda de rigidez devido à curvatura do estai, conforme a formulação proposta por Dischinger.

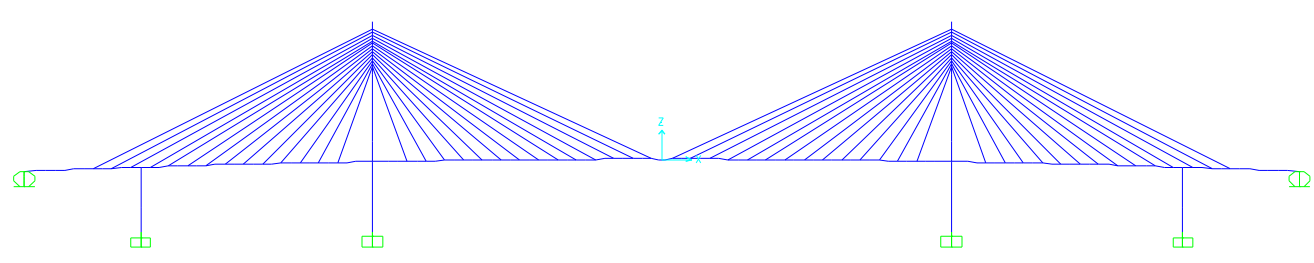

Figura 4.4: Segundo modelo da Ponte Constritor João Alves- modelo plano 


\subsubsection{Tabuleiro}

A modo de simplificação, a laje e as longarinas apresentam uma seção constante (aquela que predomina no tabuleiro). Além disso, por ser um modelo plano, o tabuleiro (laje, longarinas e transversinas) estão representados por uma única barra, cuja seção se apresenta na Figura 4.5.

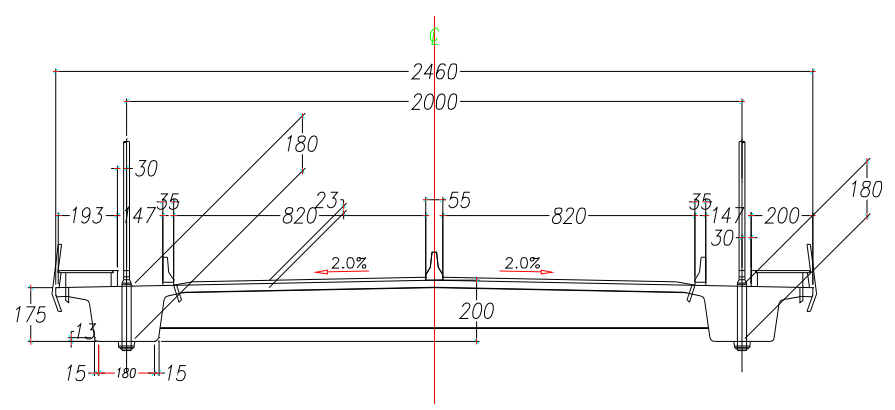

Figura 4.5: Seção do tabuleiro (medidas em centímetros)

\subsubsection{Mastros}

Os mastros também possuem uma geometria simplificada apresentada na Tabela 4.2. Estes estão engastados no tabuleiro, assim como também os pilares secundários.

Tabela 4.2: Seç̃̃es do mastro

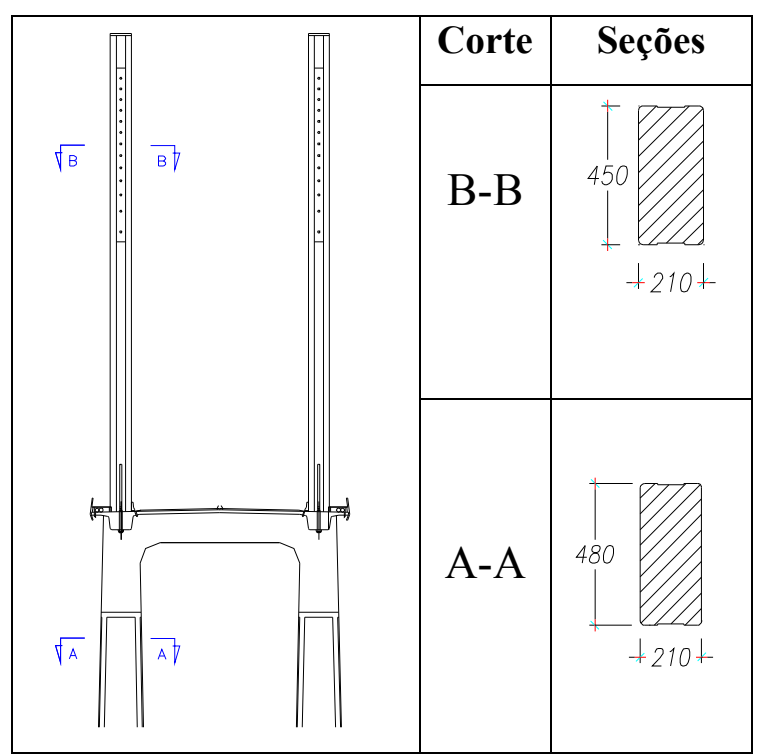




\subsubsection{Estais}

A ponte possui 28 estais por mastro, constituindo um total de 112 estais.

O arranjo dos estais é de semi-harpa e estão divididos em 8 grupos de 14 cabos. Cada grupo tem um diâmetro variável dependendo da localização do estai, os estais com maior dimensão são os mais afastados da base do mastro, e os de menor dimensão são os que estão mais perto da base do mastro. Essa conclusão é intuitiva, já que os cabos mais afastados são aqueles que recebem uma força maior que aqueles perto do mastro.

Os estais foram modelados como barras de treliça, considerando módulo de elasticidade equivalente ou Módulo de Dischinger. Foi realizado o mesmo procedimento descrito no item 3.1.1.3, obtendo-se o resultado apresentado na Tabela 4.3 .

Tabela 4.3: Determinação do módulo de elasticidade corrigido (Módulo de Dischinger)

\begin{tabular}{|c|c|c|c|c|c|}
\hline Estai & $\mathbf{L}_{\mathbf{H}}(\mathbf{m})$ & $\begin{array}{c}\gamma^{*} \\
\left(k N / m^{3}\right)\end{array}$ & $\begin{array}{c}E \\
\left(k N / m^{2}\right)\end{array}$ & $\begin{array}{c}\sigma \\
\left(k N / m^{2}\right)\end{array}$ & $\begin{array}{c}\mathrm{E}^{*} \\
\left(\mathrm{kNm}^{2}\right)\end{array}$ \\
\hline 1 & 12,0 & 78,5 & $1,95 \times 10^{8}$ & 462500 & $1,9497 \times 10^{8}$ \\
\hline 2 & 18,5 & 78,5 & $1,95 \times 10^{8}$ & 462500 & $1,9493 \times 10^{8}$ \\
\hline 3 & 25,0 & 78,5 & $1,95 \times 10^{8}$ & 462500 & $1,9488 \times 10^{8}$ \\
\hline 4 & 31,5 & 78,5 & $1,95 \times 10^{8}$ & 462500 & $1,9480 \times 10^{8}$ \\
\hline 5 & 38,0 & 78,5 & $1,95 \times 10^{8}$ & 462500 & $1,9471 \times 10^{8}$ \\
\hline 6 & 44,5 & 78,5 & $1,95 \times 10^{8}$ & 462500 & $1,9461 \times 10^{8}$ \\
\hline 7 & 51,0 & 78,5 & $1,95 \times 10^{8}$ & 462500 & $1,945 \times 10^{8}$ \\
\hline 8 & 57,5 & 78,5 & $1,95 \times 10^{8}$ & 462500 & $1,9435 \times 10^{8}$ \\
\hline 9 & 64,0 & 78,5 & $1,95 \times 10^{8}$ & 462500 & $1,9419 \times 10^{8}$ \\
\hline 10 & 70,5 & 78,5 & $1,95 \times 10^{8}$ & 462500 & $1,9402 \times 10^{8}$ \\
\hline 11 & 77,0 & 78,5 & $1,95 \times 10^{8}$ & 462500 & $1,9381 \times 10^{8}$ \\
\hline 12 & 83,5 & 78,5 & $1,95 \times 10^{8}$ & 462500 & $1,9363 \times 10^{8}$ \\
\hline 13 & 90,0 & 78,5 & $1,95 \times 10^{8}$ & 462500 & $1,9341 \times 10^{8}$ \\
\hline 14 & 96,5 & 78,5 & $1,95 \times 10^{8}$ & 462500 & $1,9318 \times 10^{8}$ \\
\hline
\end{tabular}


Onde:

$E^{*}:$ módulo de elasticidade de Dischinger;

$E$ : modulo de elasticidade do aço dos estais.

$\gamma:$ peso específico do aço dos estais;

$L_{H}$ : projeção horizontal do comprimento dos estais;

$\sigma$ : tensão media nos estais.

Por se tratar de um modelo plano, os estais possuem o dobro da área transversal que está estabelecida no projeto. Conforme a numeração adotada na Figura 3.11, as propriedades dos estais se apresentam na Tabela 4.4 .

Tabela 4.4: Seções dos estais

\begin{tabular}{|c|c|c|}
\hline Estai & $\mathbf{L}(\mathbf{m})$ & $\mathbf{A} \mathbf{( m}^{\mathbf{2}} \mathbf{~}$ \\
\hline E1 & 35,15 & 0,0057 \\
\hline E2 & 38,86 & 0,0057 \\
\hline E3 & 43,26 & 0,0063 \\
\hline E4 & 48,18 & 0,0069 \\
\hline E5 & 53,46 & 0,0072 \\
\hline E6 & 59,01 & 0,0078 \\
\hline E7 & 64,77 & 0,0084 \\
\hline E8 & 70,67 & 0,0087 \\
\hline E9 & 76,70 & 0,0093 \\
\hline E10 & 82,81 & 0,0096 \\
\hline E11 & 89,00 & 0,0102 \\
\hline E12 & 95,26 & 0,0108 \\
\hline E13 & 101,56 & 0,0114 \\
\hline E14 & 107,89 & 0,0117 \\
\hline & &
\end{tabular}

Onde:

$L$ : comprimento dos estais;

$A$ : área dos estais;

$\theta$ : diâmetro dos estais. 


\section{DETERMINAÇÃO DAS FORÇAS DE INSTALAÇÃO DOS ESTAIS}

As pontes estaiadas são uma forma moderna de ponte que não só apresenta atrativo estético, mas também podem apresentar vantagens econômicas. Estas têm sido amplamente empregadas na construção de longos vãos nas ultimas décadas. No entanto, é uma estrutura altamente hiperestática; por esta razão, vários esquemas de forças de implantação podem ser possíveis (D.W.CHEN, et. all., 2000) .

$\mathrm{Na}$ construção de pontes estaiadas, a protensão é aplicada aos estais à medida que as aduelas são içadas e é feito o controle de flechas, ou seja, os cabos são protendidos e se necessário reprotendidos para garantia da flecha nula no final da execução da obra. (TORNERI, 2002).

Ao longo dos anos foram estabelecidos vários métodos para definir estas forças. A escolha destes métodos está fortemente ligada à etapa de projeto e a preferência do projetista.

Basicamente podem-se citar cinco métodos:

- Método do tabuleiro articulado em todos os estais (MTA)

- Método de anulação dos deslocamentos (MAD)

- Método de anulação das reações em apoios fictícios (MAR)

- Método de anulação dos deslocamentos ao longo do processo construtivo (MAD evolutivo)

Para todos estes métodos são estabelecidos dois objetivos claros: a anulação dos deslocamentos no tabuleiro e a obtenção de uma distribuição de esforços razoável.

\subsection{Método do tabuleiro articulado em todos os estais (MTA)}

Este método estabelece que cada estai suporta aproximadamente o peso do trecho entre dois tirantes (aduela). Por tanto, se for considerado o peso-próprio de cada aduela, pode-se obter a força inicial e a área dos estais. É um método simples usado pelos projetistas como primeira aproximação do problema.

No caso das pontes simétricas, as forças nos estais são distribuídas simetricamente. No entanto, no caso de pontes assimétricas, estas forças podem acarretar momentos altos nos mastros. 
Primeiro é implementado o modelo com articulações em todos os estais, para isto os modelos planos dos exemplos são reutilizados adicionando-se as respectivas articulações na união entre os estais e o tabuleiro.

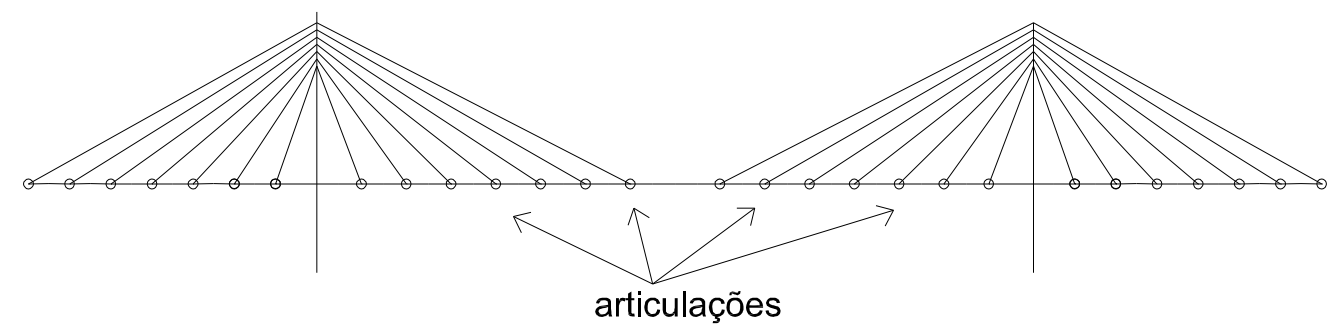

Figura 5.1: Exemplo de modelo para o MTA

Desta forma são obtidas as forças nos estais devidas ao peso próprio. A força será obtida a traves de uma queda de temperatura, levando em conta as propriedades de cada estai são determinadas as variações de temperaturas necessárias para protendêlos e assim suportar os seus respectivos carregamentos. Por tanto, estas temperaturas que serão o objetivo do estudo são temperaturas fictícias que simulam a protensão dos estais.

Para o cálculo da temperatura fictícia são consideradas as seguintes variáveis:

- $F$ : força no estai devido ao carregamento de peso-próprio

- $E^{*}$ : módulo de elasticidade de Dischinger

- $A$ : área da seção transversal do estai

- $\quad l$ : comprimento do estai

- $\Delta l$ : variação de comprimento do estai

- $\Delta T$ : variação de temperatura fíctícia

- $\alpha$ : coeficiente de expansão térmica, adotado como $1,17 \times 10^{-5}$

A variação de comprimento de uma barra devido à variação de temperatura é:

$$
\Delta l=\alpha \cdot l \cdot \Delta T
$$

Portanto, 


$$
\frac{\Delta l}{l}=\alpha . \Delta T
$$

A variação de comprimento de uma barra devido a um esforço axial F é:

$$
\Delta l=\frac{F \cdot l}{E \cdot A}
$$

Por conseguinte,

$$
\frac{\Delta l}{l}=\frac{F}{E \cdot A}
$$

Então, igualando as equações (5.2) e (5.4):

$$
\alpha . \Delta T=\frac{F}{E \cdot A}
$$

Logo, a variação de temperatura de um estai referente a uma força $F$ é:

$$
\Delta T=\frac{F}{\alpha \cdot E \cdot A}
$$

\subsection{Método de anulação dos deslocamentos (MAD)}

A primeira publicação que trata deste método foi no 1993, WANG et al.; onde determinam-se os esforços dos estais para atingir a geometria desejada da ponte depois da construção. Este método está baseado no conceito de que o tabuleiro se comporta como uma viga continua. Entretanto, BEHIN e CHEN et. al. (2000) estabeleciam que a geometria final da ponte deveria ser independente das tensões dos estais e devia ser definido levando em conta a contra-flecha do tabuleiro.

Neste método o objetivo é anular os deslocamentos verticais ( $\delta$ ) quando o tabuleiro está submetido à carga permanente (peso-próprio). Esta é uma tarefa difícil já que a estrutura é hiperestática e, deste modo, se um estai for protendido, os esforços dos estais vizinhos se vem modificados. 
A metodologia esta baseada em determinar o conjunto de forças $[\mathrm{F}]$ nos estais tal que a flecha de peso próprio, na união dos estais com o tabuleiro, seja nula (ALMEIDA, et all., 2003). Então a equação de equilíbrio (ALMEIDA et. all)é:

$$
[F g]=[F]+[K] x[\delta]
$$

Onde:

$\left[\mathrm{F}_{\mathrm{g}}\right]$ : vetor das forças nos estais devido ao carregamento de peso próprio (unidade: $\mathrm{kN}$ )

[F]: vetor das forças nos estais devido a sua protensão (unidade: $\mathrm{kN}$ )

$[\mathrm{K}]$ : matriz de rigidez condensada porque considera apenas os graus de liberdade correspondentes aos deslocamentos verticais nos encontros tabuleiro/estai (unidade: $\mathrm{kN} / \mathrm{m})$

$[\delta]$ : deslocamentos verticais da estrutura nos pontos de união entre os estais e o tabuleiro (unidade:m)

$\mathrm{O}$ vetor das forças dos estais [F] (estado inicial de esforços de protensão ), pode ser calculado de forma tal que $[\delta]$ de $\left(F+F_{g}\right)$ seja nulo. Como neste método as protensões são simuladas por temperatura, é mais pratico escrever a seguinte equação de compatibilidade:

$$
\left.[\delta]=[D] x\left[F_{g}\right]+[D] x\left[F_{0}\right]=[D] x \mid F_{g}\right]+\left[D_{T}\right] x[T]
$$

Onde:

[D]: matriz de flexibilidade condensada porque considera apenas como incógnitas as forças nos estais (unidade: $\mathrm{m} / \mathrm{kN}$ ), é a inversa da matriz [K]

$\left[\mathrm{D}_{\mathrm{T}}\right]$ : matriz de flexibilidade condensada em termos de temperatura (unidade: $\mathrm{m} /{ }^{\circ} \mathrm{C}$ )

[T]: vetor de temperatura nos estais (unidade ${ }^{\circ} \mathrm{C}$ )

O objetivo é calcular $[\mathrm{T}]$ tal que $[\delta]$ seja nulo, isto equivale a escrever:

$$
\left[D_{T}\right] x[T]=-\left\lfloor\delta_{g}\right\rfloor
$$

O método consiste em aplicar a cada estai um carregamento de temperatura unitária $\left(\mathrm{T}_{\mathrm{i}}\right)$. Para cada um, tabelam-se os resultados de deslocamentos verticais $(\delta)$ de todos os nós que correspondem à interseção dos estais com o tabuleiro. É importante destacar que no caso dos estais de estabilidade o deslocamento utilizado para a matriz $\left[\mathrm{D}_{\mathrm{T}}\right]$ é aquele que está na união do estai com o mastro. Isto é devido a que o 
deslocamento correspondente à interseção entre o estai e o tabuleiro pode ser zero (apoio no estai) ou muito próximo de zero.

Depois de tabelados os resultados, monta-se a matriz contendo os deslocamentos do tabuleiro em função da temperatura aplicada. Nesta matriz chamada $\left[\mathrm{D}_{\mathrm{T}}\right]$, cada coluna representa os deslocamentos de todos os nós do tabuleiro para o carregamento $\mathrm{T}_{\mathrm{i}}$. Então, a primeira coluna representa os deslocamentos de todos os nós para o carregamento $\mathrm{T}_{1}$. $\mathrm{O}$ formato da matriz é o seguinte:

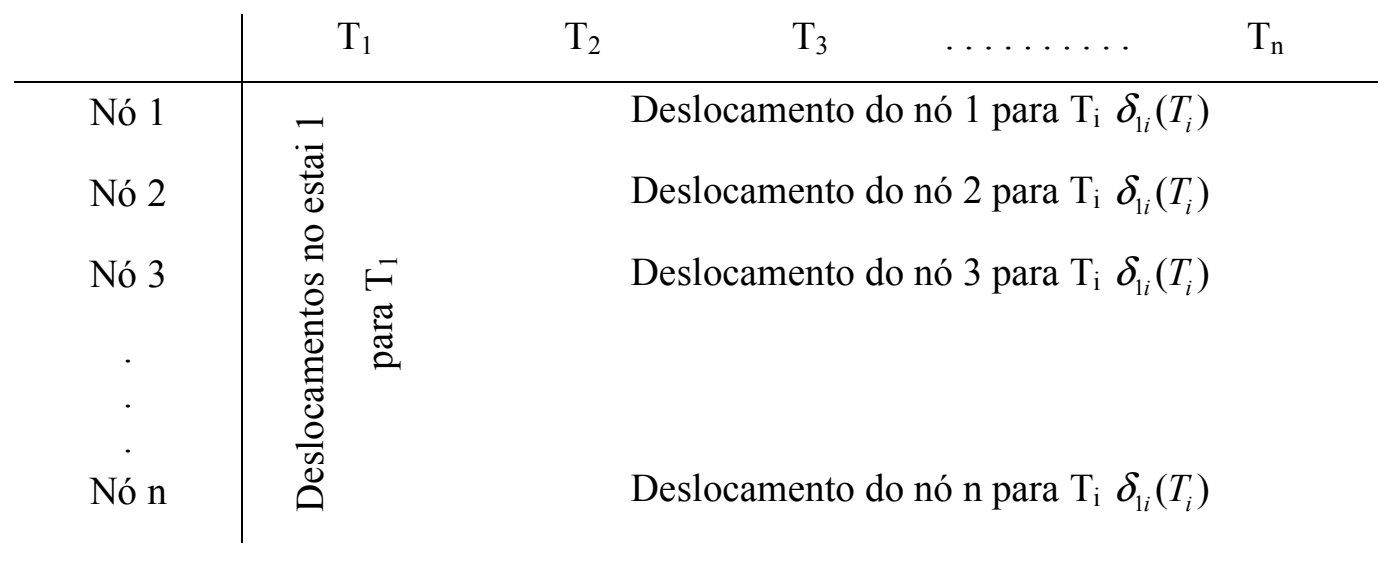

Cada elemento da matriz representa um deslocamento vertical correspondente a um estai devido a um carregamento de temperatura. Portanto, $\delta_{i j}$ é o deslocamento do nó $i$ devido ao carregamento de temperatura no estai $j$.

$$
\left[D_{T}\right]=\left(\begin{array}{ccc}
\delta_{11} & \cdots & \delta_{1 n} \\
\vdots & \ddots & \vdots \\
\delta_{n 1} & \cdots & \delta_{n n}
\end{array}\right)
$$

Os deslocamentos obtidos quando cada um dos estais é carregado, são pequenos e conduzem a um sistema de equações relativamente mal condicionado. O numero de cifras significativas é muito importante na hora da resolução deste problema. Segundo pesquisas realizadas pelo ISHITANI, H., acredita-se que utilizando versões mais atualizadas do SAP, pode-se conseguir um numero maior de cifras significativas e assim soluções exatas poderiam ser obtidas.

No caso desta pesquisa a quantidade de cifras significativas foi de 12. Para esta quantidade de valores, se tentarmos resolver a equação ( 5.9) diretamente, invertendo a matriz $\left[\mathrm{D}_{\mathrm{T}}\right]$, o resultado é ruim. Por conseguinte, para a resolução deste problema, se consideram os seguintes procedimentos: 
1. O método para determinar o vetor de temperaturas [T é o dos Mínimos Quadrados (MMQ). Esta é uma técnica de otimização matemática que procura encontrar o melhor ajuste para um conjunto de dados tentando minimizar a soma dos quadrados das diferenças entre a curva ajustada e os dados (tais diferenças são chamadas resíduos). Para realizar as iterações do problema, estabelecu-se que o resíduo seja menor que $1 \times 10^{-5}$.

2. A partir do primeiro método (avaliação isostática das forças nos estais), são obtidos os valores da primeira iteração para a resolução.

Os resultados obtidos no SAP foram analisados no programa EXCEL. Para a obtenção dos esforços finais foi utilizado o recurso chamado Solver para a obtenção do resultado.

Apresenta-se a seguir um fluxograma (Figura 5.2) onde se explicam todos os passos a serem cumpridos para a utilização deste método.

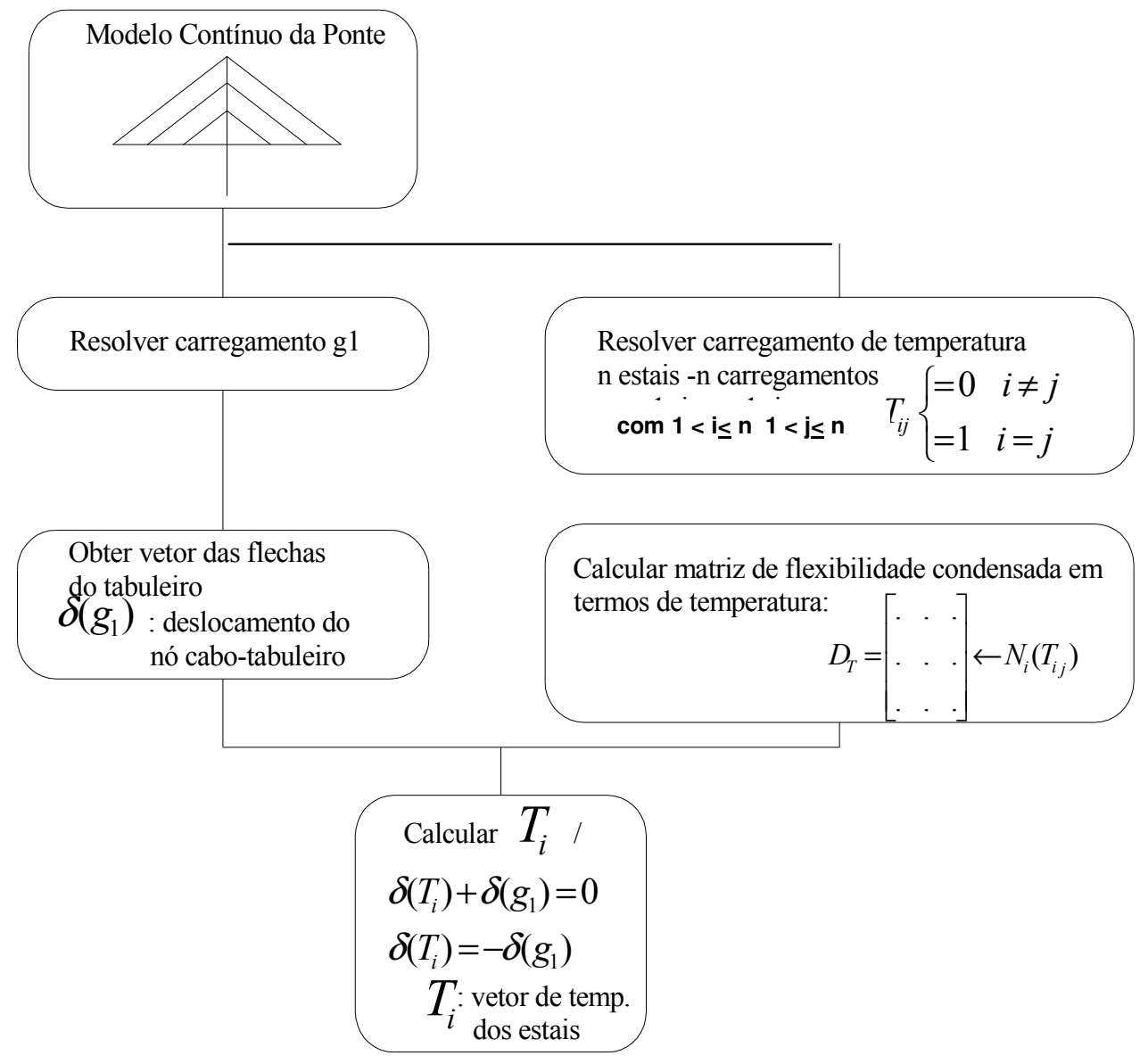

Figura 5.2: Fluxograma do Método de anulação dos deslocamentos 


\subsection{Método de anulação das reações em apoios fictícios (MAR)}

Em 1972 LAZAR et. al. desenvolveram, pela primeira vez, um método para alterar a distribuição de momento no tabuleiro mediante um ajuste nas tensões aplicadas nos estais. O mesmo procedimento foi utilizado por TROITSKY, 1988 e GIMNSING, 1997; enquanto um método mais simples para obter a tensões dos estais foi desenvolvido pelo AGRAWAL, 1997.

O método de anulação das reações em apoios fictícios foi proposto pelo CHEN et. al. (2000); este se baseia na idéia de obter uma boa distribuição de momentos zerando os deslocamentos do tabuleiro.

Pode-se assumir que uma ponte estaiada, quando submetidas a carregamento de peso-próprio, se comporta como uma viga contínua apoiada nos estais. Portanto, com o carregamento anterior, cada estai (representado por um apoio), terá uma reação associada. O método de anulação das reações em apoios fictícios está baseado na mesma idéia do método de anulação dos deslocamentos.

A idéia então, é estabelecer o modelo da ponte estaiada submetido ao seu pesopróprio com apoios fictícios em todos os pontos de ligação dos estais com o tabuleiro. Novamente é aplicado a cada estai um carregamento de temperatura unitária $\left[\mathrm{T}_{\mathrm{i}}\right]$. Para cada um destes, se tabelam os resultados das reações em apoios fictícios $\left[\mathrm{R}_{\mathrm{g}}\right]$. Depois de tabelados os resultados, monta-se a matriz de rigidez condensada em função da temperatura. Esta matriz é designada por $[\mathrm{K}]$ onde cada coluna representa as reações de todos os apoios fictícios. Chama-se matriz de rigidez condensada, já que representa parte da matriz de rigidez da estrutura correspondente aos graus de liberdade dos encontros estai/tabuleiro e no caso dos estais de estabilidade Estai/mastro (como no MAD).

A reação nos apoios fictícios $[\mathrm{R}]$ resultante dos efeitos de temperatura $\left[\mathrm{T}_{0}\right]$ é dado por:

$$
\left[K_{R}\right] \cdot[T]=[R]
$$

Designando o vetor das reações devido ao peso-próprio da estrutura por $\left[\mathrm{R}_{\mathrm{g} 1}\right]$; o vetor $[R]$ deverá ser igual a $-\left[R_{g}\right]$.

Assim como no MAD, neste método são consideradas as mesmas restrições e são analisadas as mesmas hipóteses. 
Apresenta-se a seguir um fluxograma onde são explicados todos os passos a serem cumpridos para a utilização deste método (Figura 5.3).

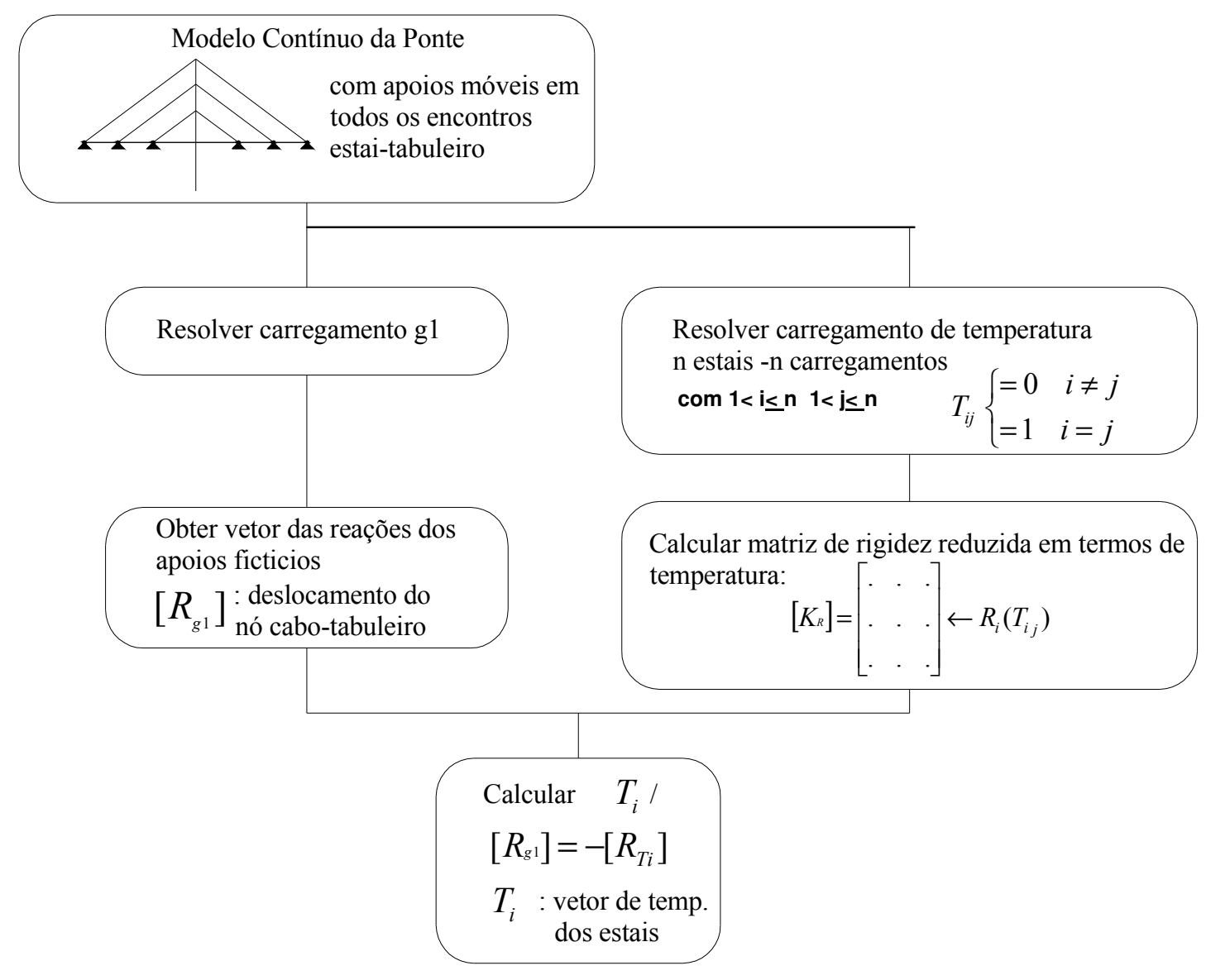

Figura 5.3: Fluxograma do Método de anulação das reações em apoios ficticios

\subsection{Método de anulação dos deslocamentos ao longo do processo construtivo}

As soluções anteriores estão baseadas na configuração final da estrutura e não levam em conta o processo construtivo. Isto é bastante problemático já que o processo construtivo ou faseamento influencia consideravelmente na distribuição interna de esforços na estrutura completa (JANJIC et. al. 2003). O presente método anula os deslocamentos na última aduela em cada fase da construção (Figura 5.4).

O método dos consolos sucessivos consiste na montagem de módulos nas laterais dos mastros; estes módulos estão formados pelo tabuleiro com seus respectivos estais. Geralmente, estas estruturas parciais que estão sendo montadas são mais flexíveis 
que a estrutura final e estão submetidas a carregamentos de construção que são diferentes dos esforços da ponte na fase final. Surge a dificuldade de projetar um processo construtivo que assegure que não existam tensões muito altas em nenhuma das estruturas parciais da seqüência. A fim de prevenir estas tensões podem-se utilizar apoios temporários, contra-pesos ou ajustes transitórios nos estais para garantir que as tolerâncias não acumulem a tal ponto que a ponte não atinja sua configuração final.

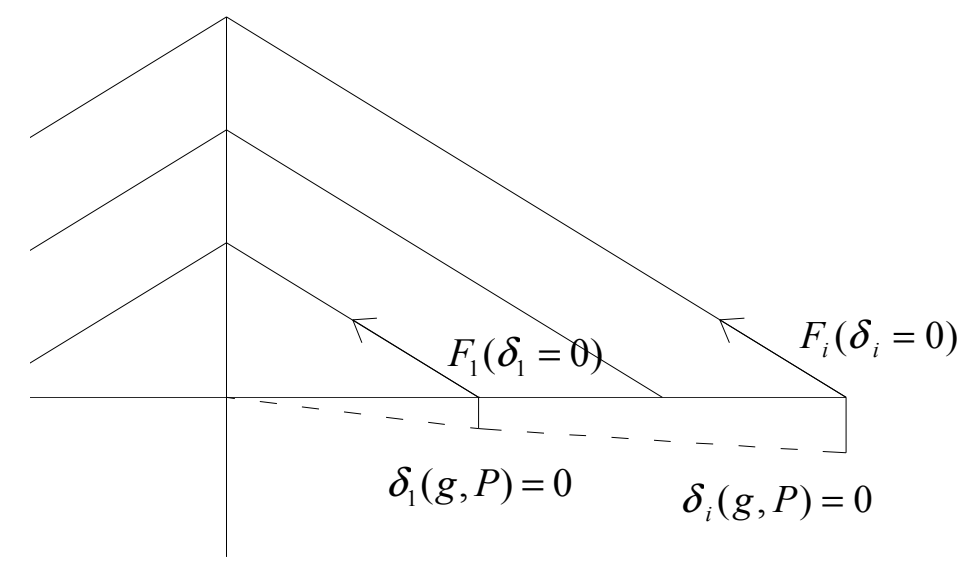

Figura 5.4: Diagrama de esforços no estai i na fase construtiva

Para cada fase construtiva ( $i$ ) é obtido o deslocamento na última aduela devido ao peso-próprio $\delta_{i}\left(g_{i}\right)$. A seguir, calcula-se a protensão, $P_{i}$ que deve ser aplicada para anular esse deslocamento, assim $\delta_{i}\left(g_{i}\right)+\delta_{i}\left(R_{i}\right)=0$. Dessa forma, são determinadas as forças de protensão dos estais para cada fase construtiva da ponte.

O programa utilizado, SAP, apresenta o aplicativo chamado Non-linear stage construction que permite ao usuário estabelecer o processo construtivo e calcular os resultados de cada fase, facilitando a implementação deste processo.

Para este método é necessário levar em conta as sobrecargas de construção, assim como também, as possíveis assimetrias da ponte. Quando o vão lateral tem um comprimento maior ou menor que metade do vão central, apresenta-se uma assimetria. Para estes casos, existem vários tipos de solução para realizar o processo construtivo; uma delas é o uso de contrapeso na extremidade de menor vão (Figura $5.5)$. 


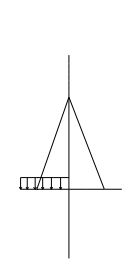

1 Etapa
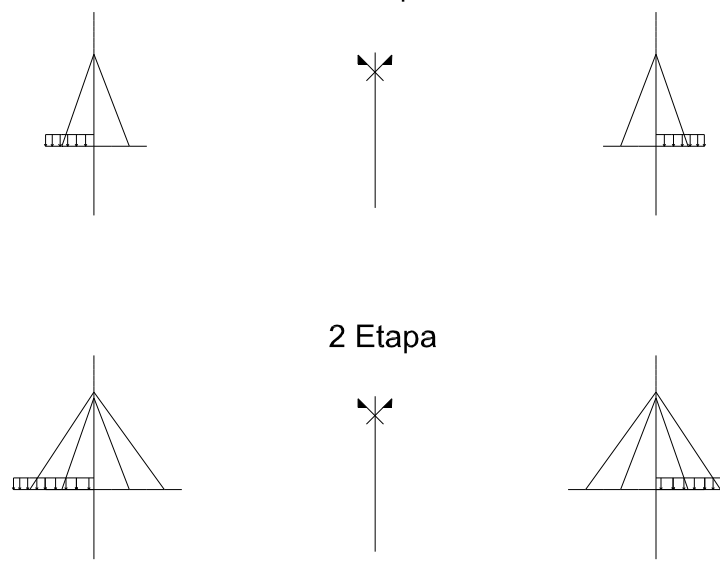

2 Etapa

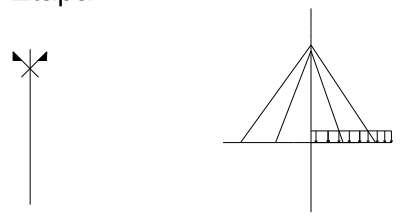

Penultima Etapa
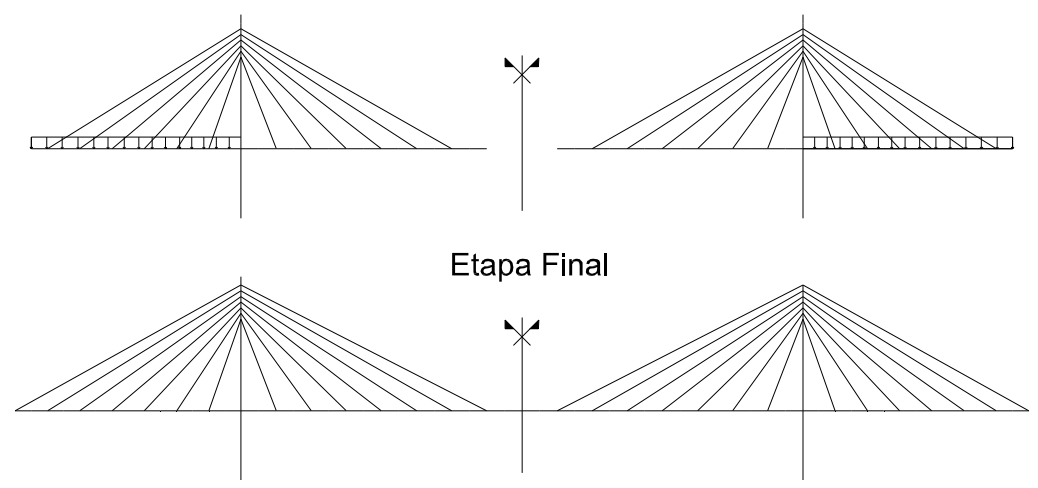

Figura 5.5: Solução de contrapeso para processo construtivo

Para a construção de cada aduela, utiliza-se um contrapeso que representa a diferença de pesos entre os dois vãos a serem construídos. No final da construção os contrapesos são retirados e os estais de estabilidade são protendidos.

Outra solução é a utilização de cabos de protensão (Figura 5.6) que ancoram a aduela de arranque do vão de menor comprimento, desta forma, estes cabos podes ser protendidos a medida que o vão central esta sendo construído para evitar desequilíbrios. 

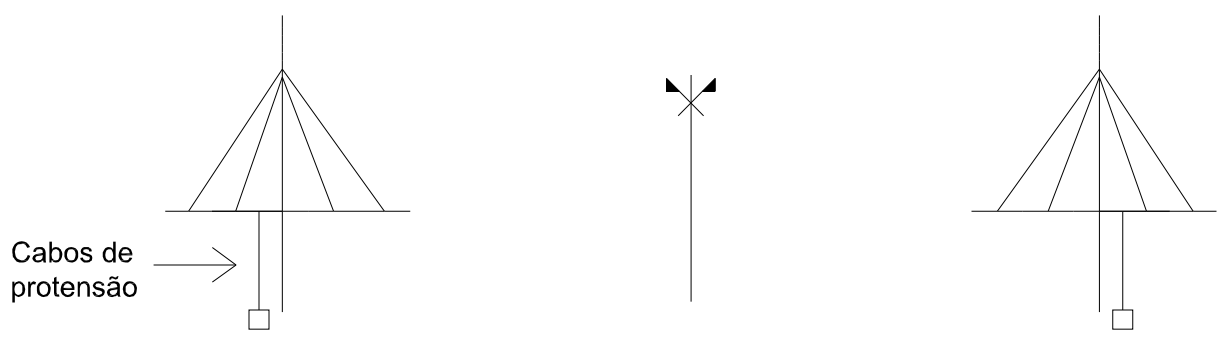

Figura 5.6: Solução de cabos de protensão para processo construtivo

A solução a ser adotada depende de cada caso; para o primeiro exemplo foi adotada a utilização de contrapeso de um lado da estrutura devido à facilidade de implementação no modelo estrutural escolhido. 


\section{RESULTADOS DOS MÉTODOS}

\subsection{Primeiro exemplo}

Para este exemplo foram implementados todos os métodos apresentados no capitulo anterior. A seguir, são apresentados os resultados e as comparações realizadas.

\subsubsection{Método do tabuleiro articulado em todos os estais (MTA)}

A partir do peso-próprio da ponte, foram obtidas as forças correspondentes a cada estai. Com esses resultados, aplicou-se o método em questão e se alcançaram as temperaturas. Para o primeiro exemplo, os resultados (Tabela 6.1) apresentam os esforços de cada estai assim como também as temperaturas equivalentes.

Tabela 6.1: Avaliação isostática do primeiro exemplo(MTA)

\begin{tabular}{|c|c|c|c|}
\hline Estai & $\left.\Delta \mathrm{T}\left({ }^{\circ} \mathrm{C}\right)\right)$ & Força (kN) & Deslocamento (m) \\
\hline $\mathrm{E} 1$ & $-351,39$ & 12769,9 & 0 \\
\hline E2 & $-350,77$ & 6519,8 & 0,014 \\
\hline E3 & $-350,27$ & 5730,2 & 0,024 \\
\hline E4 & $-349,85$ & 4888,8 & 0,027 \\
\hline E5 & $-349,53$ & 4195,2 & 0,025 \\
\hline E6 & $-349,30$ & 3820,8 & 0,017 \\
\hline E7 & $-349,16$ & 3845,2 & 0,007 \\
\hline E8 & $-349,17$ & 4840,7 & 0,028 \\
\hline E9 & $-349,33$ & 4664,3 & 0,087 \\
\hline E10 & $-349,60$ & 4837,9 & 0,158 \\
\hline E11 & $-349,99$ & 5254,8 & 0,233 \\
\hline E12 & $-350,48$ & 6043,2 & 0,303 \\
\hline E13 & $-351,08$ & 6965,8 & 0,360 \\
\hline E14 & $-351,79$ & 8342,2 & 0,394 \\
\hline E15 & $-351,79$ & 8345,5 & 0,394 \\
\hline E16 & $-351,08$ & 6967,7 & 0,361 \\
\hline E17 & $-350,48$ & 6044,1 & 0,303 \\
\hline E18 & $-349,99$ & 5255,1 & 0,233 \\
\hline E19 & $-349,60$ & 4837,9 & 0,158 \\
\hline E20 & $-349,33$ & 4664,4 & 0,087 \\
\hline E21 & $-349,17$ & 4841 & 0,028 \\
\hline E22 & $-349,16$ & 3846,1 & 0,007 \\
\hline E23 & $-349,30$ & 3829,1 & 0,016 \\
\hline E24 & $-349,53$ & 4202,3 & 0,024 \\
\hline E25 & $-349,85$ & 4890,5 & 0,027 \\
\hline E26 & $-350,27$ & 5733,6 & 0,024 \\
\hline E27 & $-350,77$ & 6522,8 & 0,014 \\
\hline E28 & $-351,39$ & 12763,7 & 0 \\
\hline
\end{tabular}


Na Figura 6.1, apresenta-se o gráfico de forças nos estais. Pode-se observar que quanto mais afastados os cabos do mastro, maior a força de tração; isto é coerente já que estes possuem um carregamento maior a aqueles próximos ao mastro. O maior esforço ocorre nos estais de estabilidade, já que estes são os que suportam a torre. É importante destacar que desta primeira aproximação resulta uma contraflecha no centro do tabuleiro de $39 \mathrm{~cm}$ Figura 6.3.

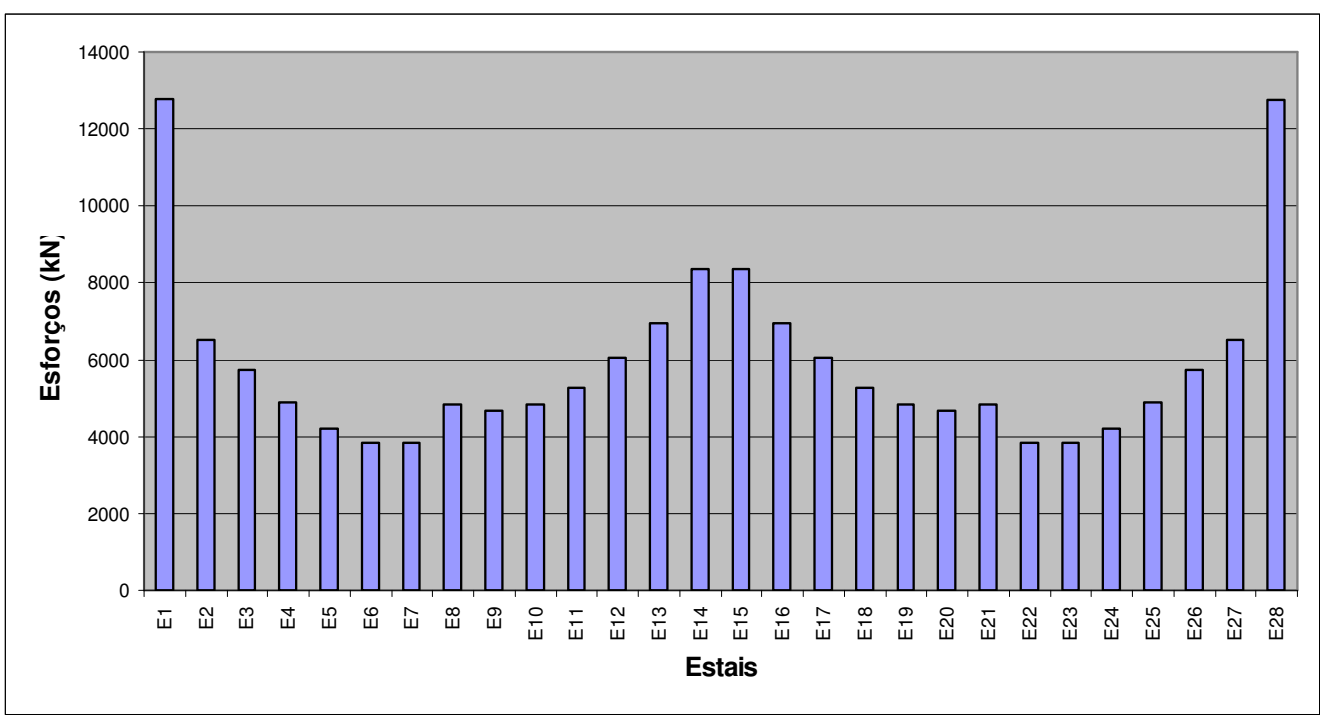

Figura 6.1: Distribuição de esforços dos estais do primeiro exemplo(MTA)

A)

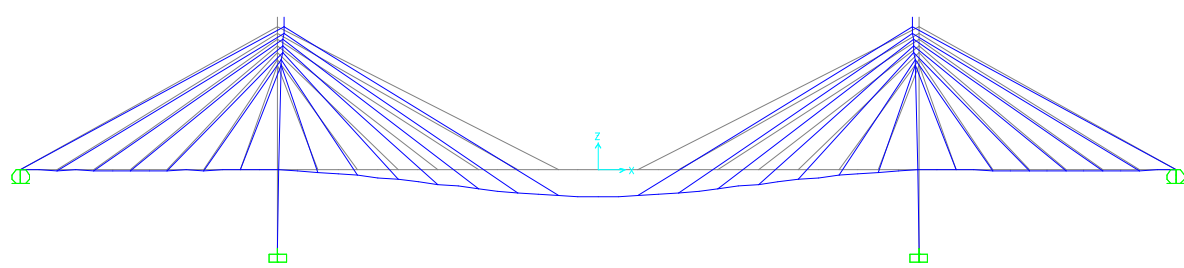

B)

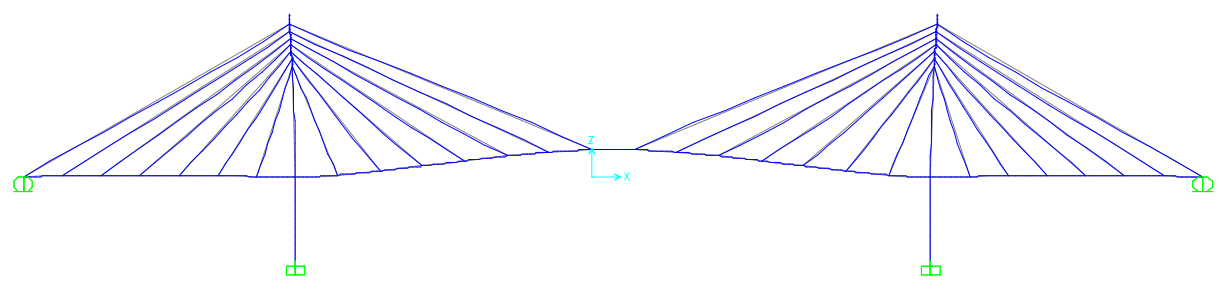

Figura 6.2: A) Deformada da ponte devida ao peso-próprio sem protensão dos estais, B) Deformada da ponte com forças do MTA 


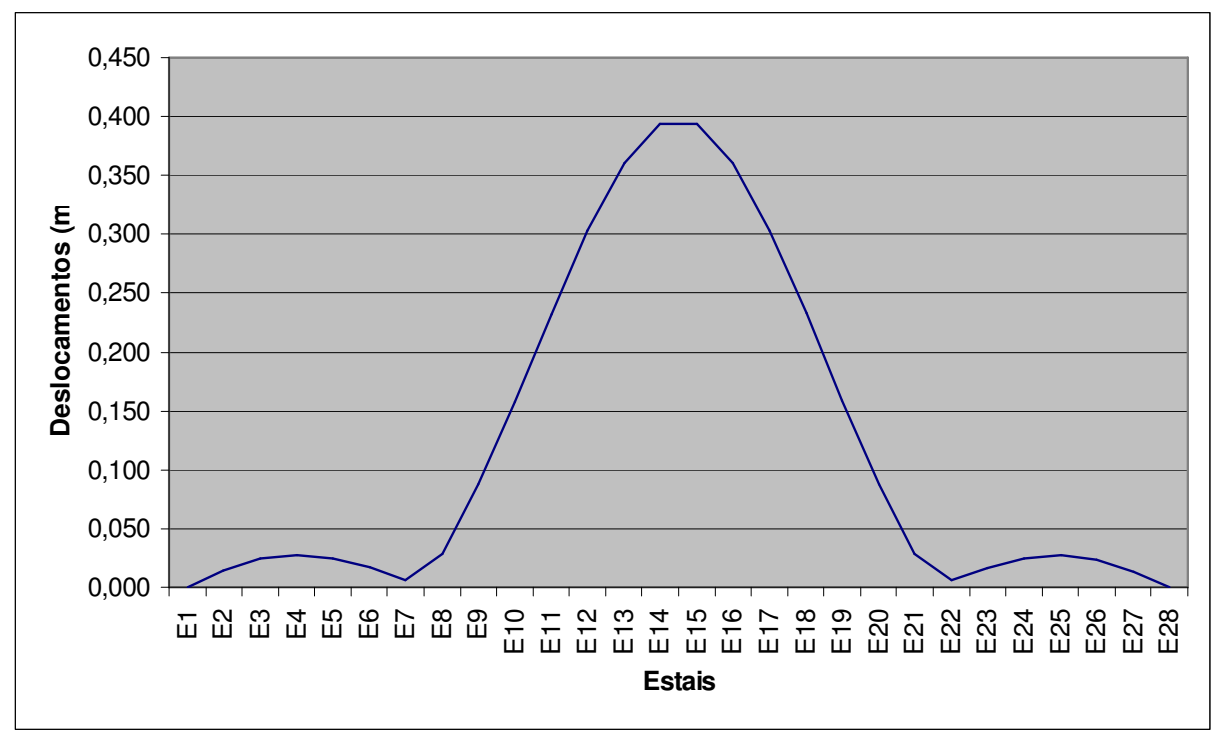

Figura 6.3: Deformada da ponte do primeiro exemplo (MTA)

O diagrama de momentos no tabuleiro e no mastro para as temperaturas impostas nos estais, apresenta uma diagramação contraria ao momento resultante do peso-próprio Figura 6.4 e Figura 6.5.

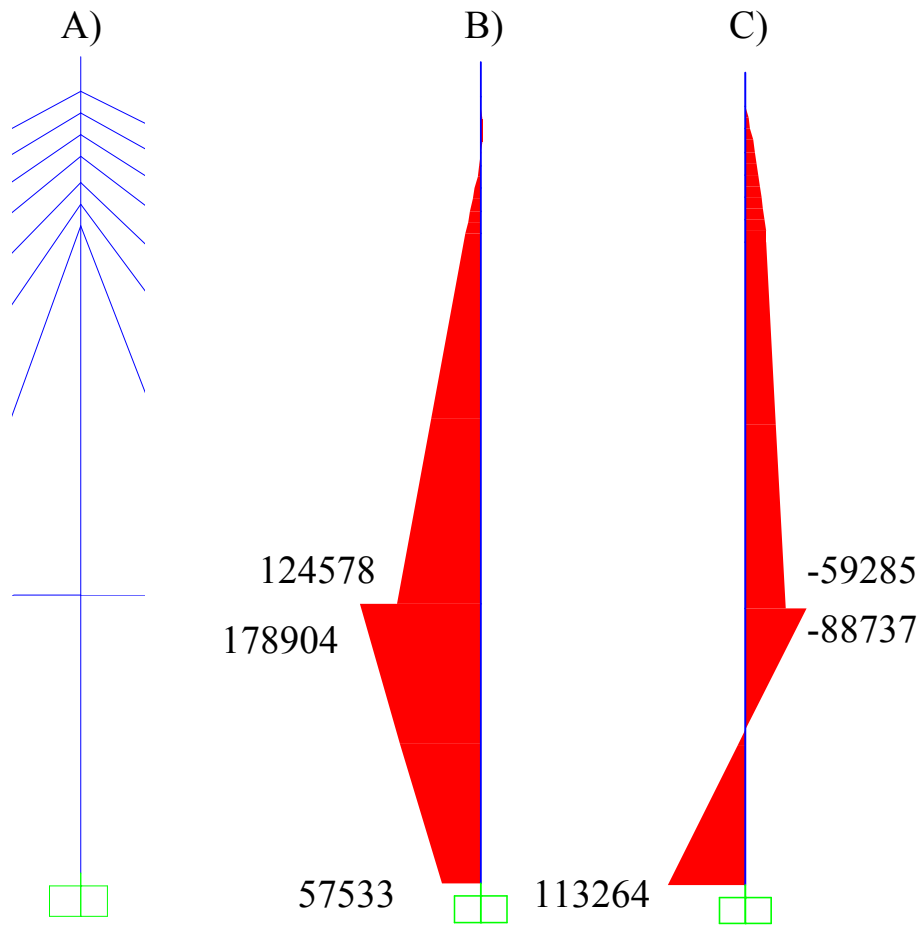

Figura 6.4: A)Forma do mastro, B) Momento no mastro devido ao peso-próprio sem protensão nos estais, C) Momento no mastro com forças do MTA (unidades: $k N, m$ ) 
A)

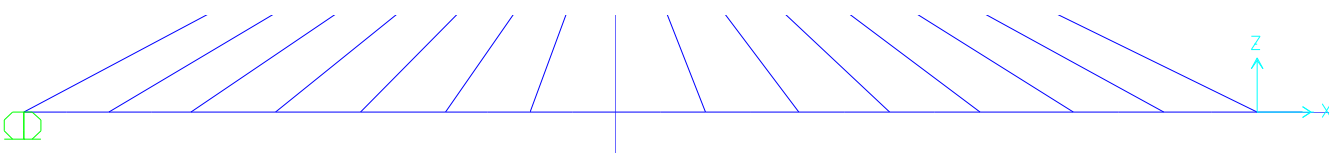

B)

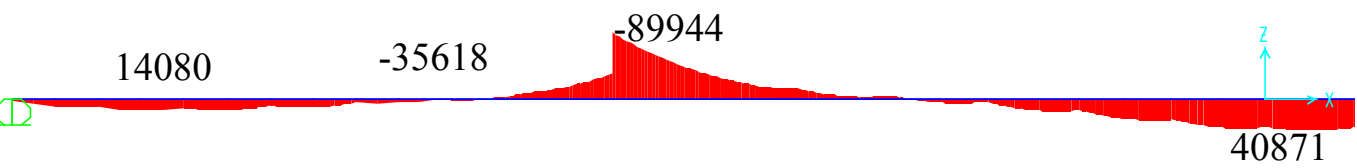

C)

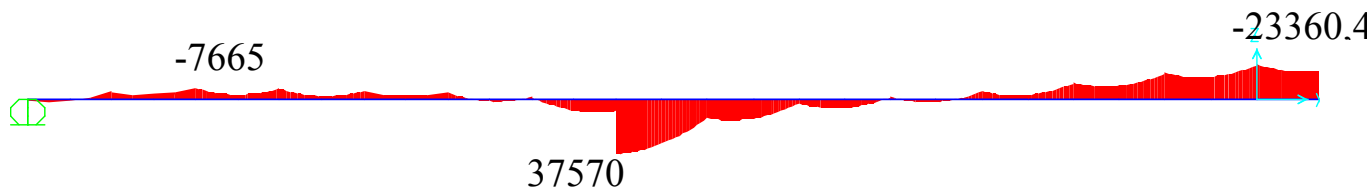

Figura 6.5: A) Forma do tabuleiro (metade), B) Momento no tabuleiro devido ao peso-próprio sem protensão nos estais, C) Momento no tabuleiro com forças do MTA(unidades: $k N, m$ ) 


\subsubsection{Método de anulação dos deslocamentos (MAD)}

No primeiro exemplo, criaram-se 28 carregamentos, correspondendo a aplicação de queda de temperatura de $100^{\circ} \mathrm{C}$ em cada estai, individualmente. A partir destes foram obtidos os deslocamentos do tabuleiro e foi criada a matriz $\left[\mathrm{D}_{\mathrm{T}}\right]$. Além disso, foram determinados os deslocamentos correspondentes ao peso-próprio da estrutura $\left[\delta_{P}\right]$. Com estes resultados foi aplicado o método dos Mínimos Quadrados, levando em conta que a primeira iteração deste método é o vetor de temperaturas [T], resultado do MAT (item 6.1.1). Devido a dificuldades de convergência do método foram estabelecidos seis intervalos limitando as temperaturas: $[\mathrm{T} \pm 10 \%]$ até $[\Delta T \pm 50 \%]$. Estes intervalos representam temperaturas que variem entre $10 \%$ e $50 \%$ em torno do vetor $[\mathrm{T}]$. O melhor resultado é atingido com intervalo de $[\mathrm{T}+40 \%]$.

Tabela 6.2: Distribuição de temperaturas dos estais do primeiro exemplo (MAD) (unidades: ${ }^{\circ} \mathrm{C}$ )

\begin{tabular}{|c|r|r|r|r|r|r|}
\hline ESTAIS & DES(10\%) & DES(20\%) & DES(30\%) & DES(40\%) & DES(50\%) & DES(livre) \\
\hline E1 & $-316,25$ & $-281,11$ & $-245,97$ & $-238,72$ & $-238,50$ & $-245,28$ \\
\hline E2 & $-315,69$ & $-280,62$ & $-245,54$ & $-269,95$ & $-271,41$ & $-275,26$ \\
\hline E3 & $-315,24$ & $-280,21$ & $-245,19$ & $-235,96$ & $-237,38$ & $-241,22$ \\
\hline E4 & $-314,86$ & $-279,88$ & $-244,89$ & $-247,88$ & $-249,70$ & $-253,54$ \\
\hline E5 & $-314,57$ & $-279,62$ & $-244,67$ & $-240,08$ & $-241,79$ & $-245,51$ \\
\hline E6 & $-314,37$ & $-279,44$ & $-244,51$ & $-238,18$ & $-238,64$ & $-242,59$ \\
\hline E7 & $-314,24$ & $-279,33$ & $-244,41$ & $-222,81$ & $-234,76$ & $-230,94$ \\
\hline E8 & $-384,08$ & $-419,00$ & $-453,92$ & $-305,59$ & $-295,15$ & $-298,02$ \\
\hline E9 & $-314,40$ & $-279,46$ & $-244,53$ & $-233,25$ & $-233,15$ & $-228,85$ \\
\hline E10 & $-314,64$ & $-279,68$ & $-244,72$ & $-241,99$ & $-240,04$ & $-236,46$ \\
\hline E11 & $-314,99$ & $-279,99$ & $-244,99$ & $-240,54$ & $-239,13$ & $-235,06$ \\
\hline E12 & $-315,43$ & $-280,38$ & $-245,34$ & $-236,87$ & $-235,75$ & $-231,97$ \\
\hline E13 & $-315,97$ & $-280,86$ & $-245,76$ & $-239,68$ & $-238,29$ & $-234,34$ \\
\hline E14 & $-316,61$ & $-281,43$ & $-246,25$ & $-228,80$ & $-228,17$ & $-224,40$ \\
\hline E15 & $-316,61$ & $-281,43$ & $-246,25$ & $-228,80$ & $-268,86$ & $-224,35$ \\
\hline E16 & $-315,97$ & $-280,86$ & $-245,76$ & $-239,68$ & $-280,97$ & $-234,30$ \\
\hline E17 & $-315,43$ & $-280,38$ & $-245,34$ & $-236,87$ & $-280,00$ & $-231,90$ \\
\hline E18 & $-314,99$ & $-279,99$ & $-244,99$ & $-240,54$ & $-284,76$ & $-234,95$ \\
\hline E19 & $-314,64$ & $-279,68$ & $-244,72$ & $-241,99$ & $-286,88$ & $-236,41$ \\
\hline E20 & $-314,40$ & $-279,46$ & $-244,53$ & $-233,25$ & $-271,84$ & $-228,81$ \\
\hline E21 & $-384,08$ & $-419,00$ & $-453,92$ & $-305,59$ & $-348,59$ & $-297,80$ \\
\hline E22 & $-314,24$ & $-279,33$ & $-244,41$ & $-222,81$ & $-174,58$ & $-227,34$ \\
\hline E23 & $-314,37$ & $-279,44$ & $-244,51$ & $-238,18$ & $-203,76$ & $-245,96$ \\
\hline E24 & $-314,57$ & $-279,62$ & $-244,67$ & $-240,08$ & $-199,06$ & $-249,15$ \\
\hline E25 & $-314,86$ & $-279,88$ & $-244,89$ & $-247,88$ & $-196,94$ & $-247,90$ \\
\hline E26 & $-315,24$ & $-280,21$ & $-245,19$ & $-235,96$ & $-192,50$ & $-242,19$ \\
\hline E27 & $-315,69$ & $-280,62$ & $-245,54$ & $-269,95$ & $-231,02$ & $-279,51$ \\
\hline E28 & $-316,25$ & $-281,11$ & $-245,97$ & $-238,72$ & $-179,00$ & $-243,73$ \\
\hline & & & & & & \\
\hline
\end{tabular}


A distribuição alcançada a partir deste método está dentro das expectativas (Figura 6.6).

Tabela 6.3: Distribuição de esforços dos estais do primeiro exemplo (MAD) (unidades: $k N)$

\begin{tabular}{|c|c|c|c|c|c|c|}
\hline ESTAIS & DES(10\%) & DES(20\%) & DES(30\%) & DES(40\%) & DES(50\%) & DES(livre) \\
\hline E1 & 12251,5 & 11732,9 & 11214,3 & $\mathbf{1 0 7 5 1 , 6}$ & 10689,9 & 10833,6 \\
\hline E2 & 6332,6 & 6145,3 & 5958 & $\mathbf{6 5 1 0 , 7}$ & 6515,9 & 6516,5 \\
\hline E3 & 5642,1 & 5553,9 & 5465,6 & $\mathbf{5 2 0 6 , 4}$ & 5205,7 & 5205 \\
\hline E4 & 4869,2 & 4849,5 & 4829,9 & $\mathbf{4 8 8 5}$ & 4888,6 & 4887,9 \\
\hline E5 & 4193,7 & 4192,2 & 4190,7 & $\mathbf{4 1 3 4 , 2}$ & 4132,5 & 4132,4 \\
\hline E6 & 3763 & 3705,1 & 3647,2 & $\mathbf{3 5 9 1 , 6}$ & 3570 & 3581,1 \\
\hline E7 & 3624,7 & 3404,1 & 3183,5 & $\mathbf{2 9 0 9 , 5}$ & 3060,5 & 2976,4 \\
\hline E8 & 5376,9 & 5913 & 6449,2 & $\mathbf{4 4 5 5 , 3}$ & 4314,1 & 4393,4 \\
\hline E9 & 4362,2 & 4060 & 3757,9 & $\mathbf{3 9 1 0}$ & 3939,2 & 3923,2 \\
\hline E10 & 4755 & 4672 & 4589,1 & $\mathbf{4 8 2 0 , 8}$ & 4814,3 & 4819,5 \\
\hline E11 & 5281,7 & 5308,5 & 5335,2 & $\mathbf{5 4 8 3 , 4}$ & 5484,1 & 5480,9 \\
\hline E12 & 6073,9 & 6104,5 & 6135,1 & $\mathbf{6 1 7 2 , 4}$ & 6176 & 6179,3 \\
\hline E13 & 6899,2 & 6832,6 & 6766 & $\mathbf{6 8 7 0 , 3}$ & 6861,7 & 6858,6 \\
\hline E14 & 8075,6 & 7808,9 & 7542,2 & $\mathbf{7 2 7 5 , 8}$ & 7286,5 & 7286,5 \\
\hline E15 & 8078,7 & 7811,7 & 7544,8 & $\mathbf{7 2 7 8 , 4}$ & 7281,4 & 7286,3 \\
\hline E16 & 6901 & 6834,3 & 6767,5 & $\mathbf{6 8 7 1 , 9}$ & 6865,7 & 6859 \\
\hline E17 & 6074,7 & 6105,3 & 6135,9 & $\mathbf{6 1 7 3 , 1}$ & 6174,8 & 6179,3 \\
\hline E18 & 5281,9 & 5308,7 & 5335,4 & $\mathbf{5 4 8 3 , 6}$ & 5480,3 & 5480,1 \\
\hline E19 & 4755 & 4672,1 & 4589,1 & $\mathbf{4 8 2 0 , 8}$ & 4829,8 & 4820,1 \\
\hline E20 & 4362,3 & 4060,2 & 3758 & $\mathbf{3 9 1 0 , 1}$ & 3870,8 & 3924 \\
\hline E21 & 5377,2 & 5913,3 & 6449,5 & $\mathbf{4 4 5 5 , 6}$ & 4696,2 & 4391 \\
\hline E22 & 3625,6 & 3405,1 & 3184,5 & $\mathbf{2 9 1 0 , 4}$ & 2593,6 & 2924,3 \\
\hline E23 & 3771,1 & 3713 & 3655 & $\mathbf{3 5 9 9 , 4}$ & 3676,9 & 3634,3 \\
\hline E24 & 4200,6 & 4198,9 & 4197,3 & $\mathbf{4 1 4 0 , 6}$ & 4196,9 & 4197,6 \\
\hline E25 & 4870,9 & 4851,1 & 4831,4 & $\mathbf{4 8 8 6 , 5}$ & 4764,4 & 4768,2 \\
\hline E26 & 5645,3 & 5557 & 5468,6 & $\mathbf{5 2 0 9 , 3}$ & 5229,7 & 5226,2 \\
\hline E27 & 6335,4 & 6147,8 & 5960,3 & $\mathbf{6 5 1 2 , 9}$ & 6620,1 & 6622,8 \\
\hline E28 & 12245,2 & 11726,6 & 11208 & $\mathbf{1 0 7 4 5 , 4}$ & 9905,2 & 10756,2 \\
\hline
\end{tabular}




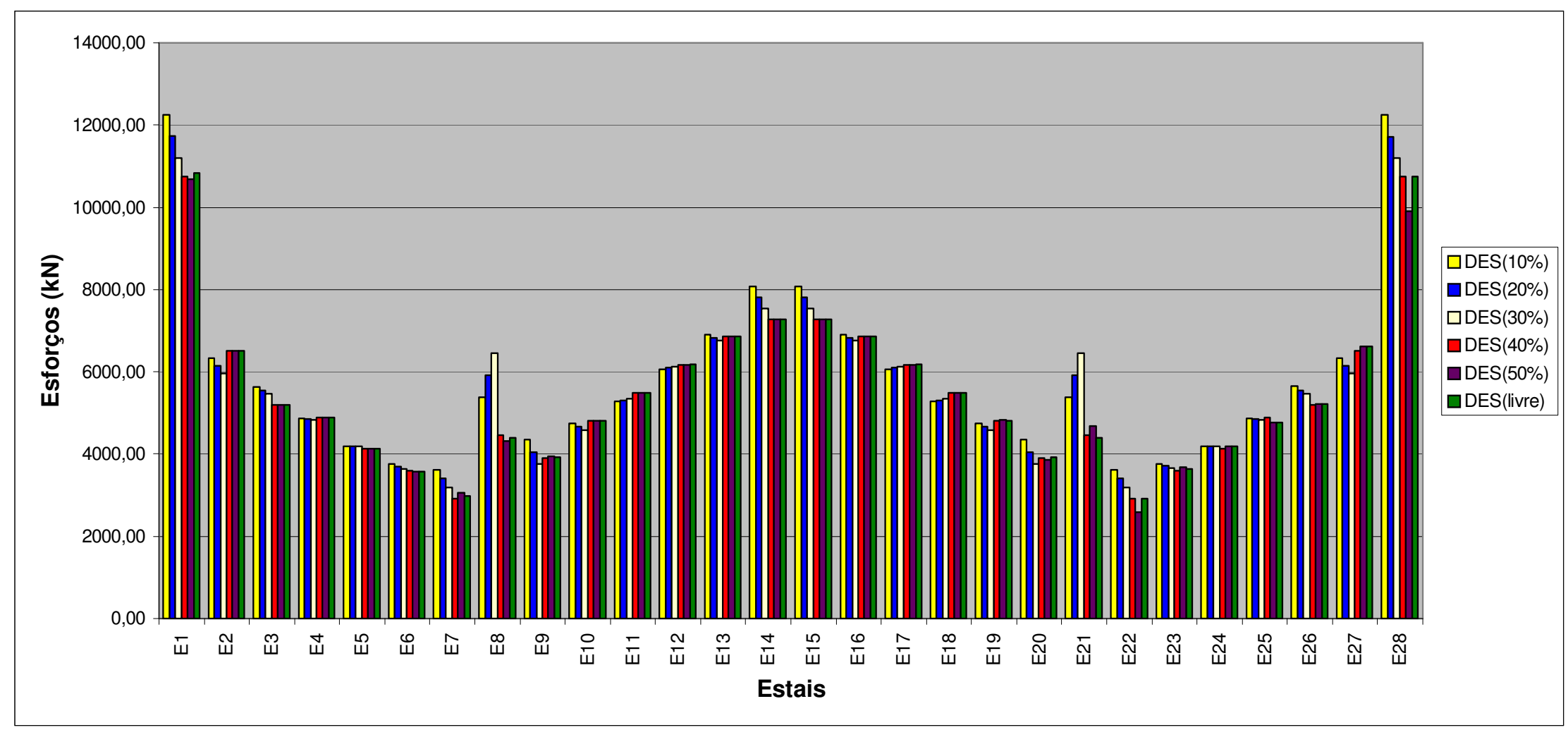

Figura 6.6: Distribuição de esforços dos estais do primeiro exemplo (MAD) 


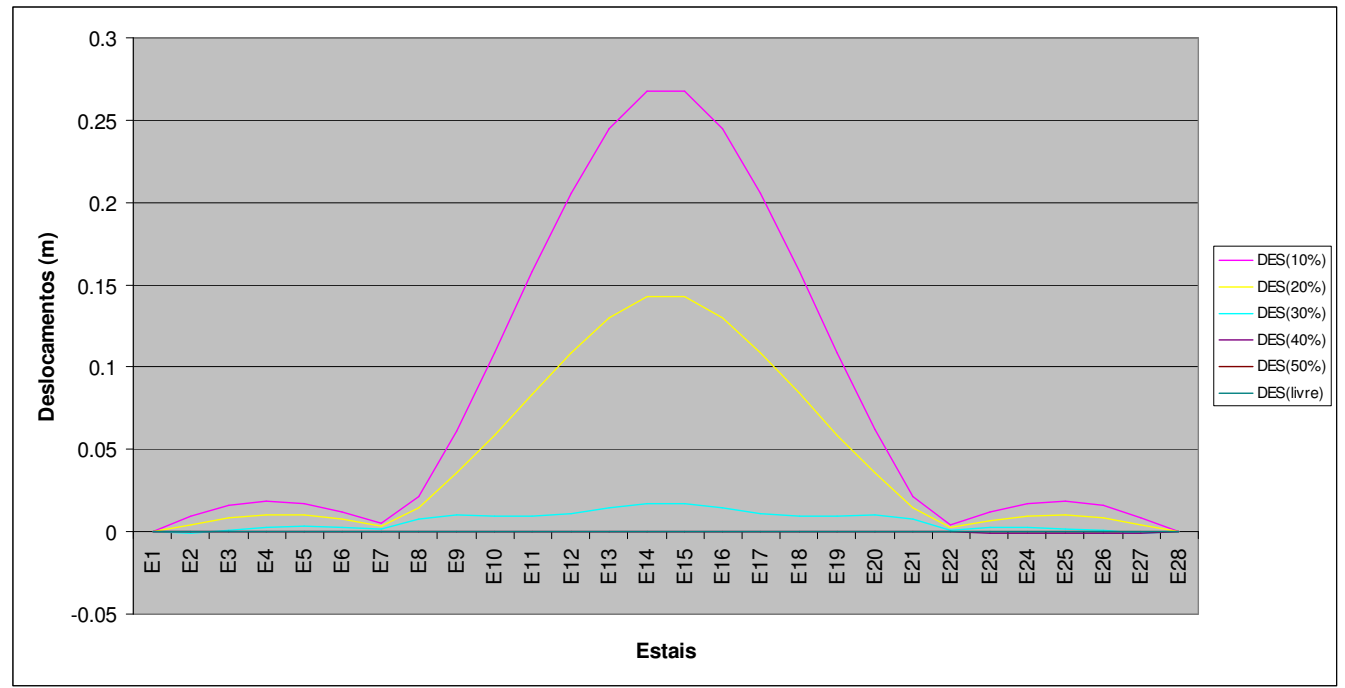

Figura 6. 7: Deformada do tabuleiro do primeiro exemplo (MAD)

É importante destacar que o deslocamento do vão central da ponte devido ao pesopróprio é de $84 \mathrm{~cm}$. Após de aplicadas as temperaturas obtidas anteriormente, a ponte apresenta uma deformação máxima muito próxima de zero (Figura 6.8).

A)
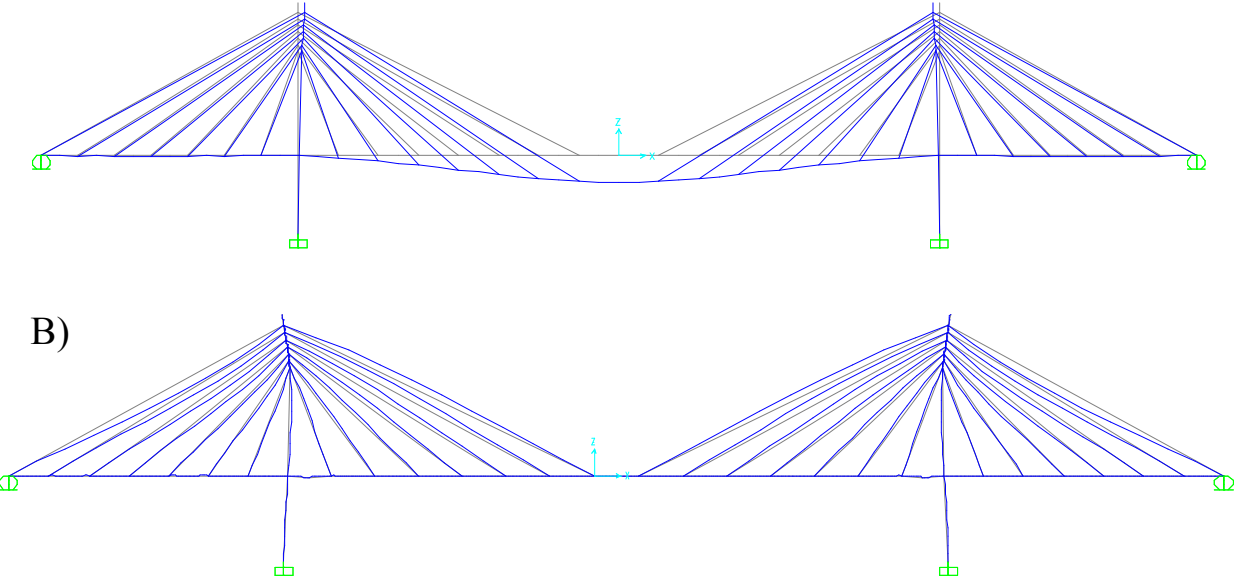

Figura 6.8: A) Deformada da ponte devida ao peso-próprio sem protensão dos estais, B) Deformada da ponte com forças do MAD 
As Figura 6.9 e Figura 6.10 apresentam os diagramas de momento na torre e o tabuleiro.

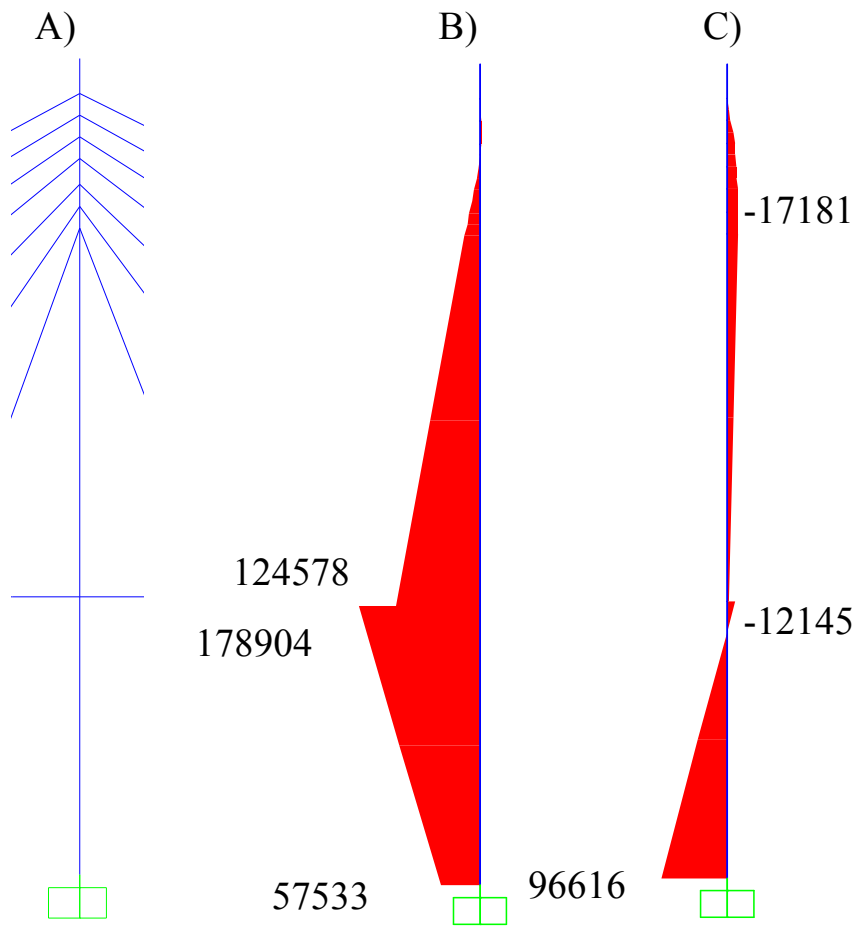

Figura 6.9: A)Forma do mastro, B) Momento no mastro devido ao peso-próprio sem protensão dos estais, C) Momento no mastro com forças do MAD (unidades: $k N, m$ )

A)

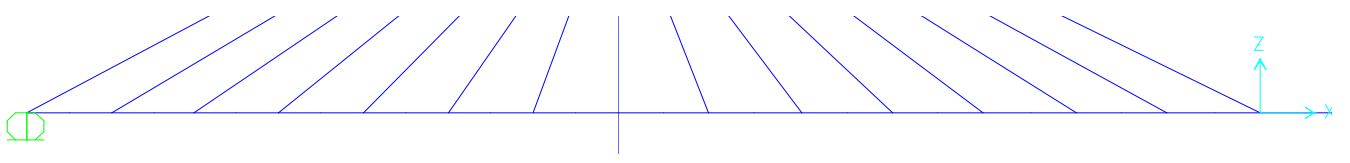

B)

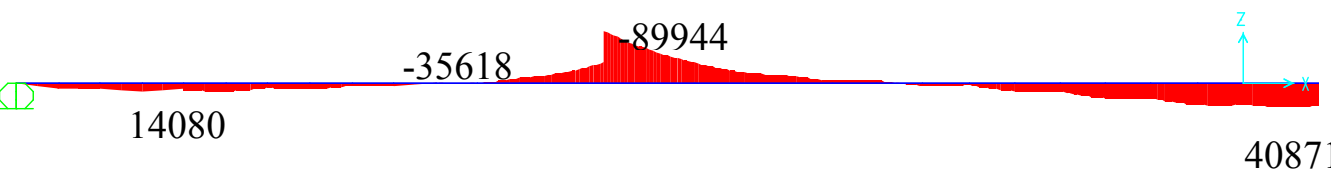

C)

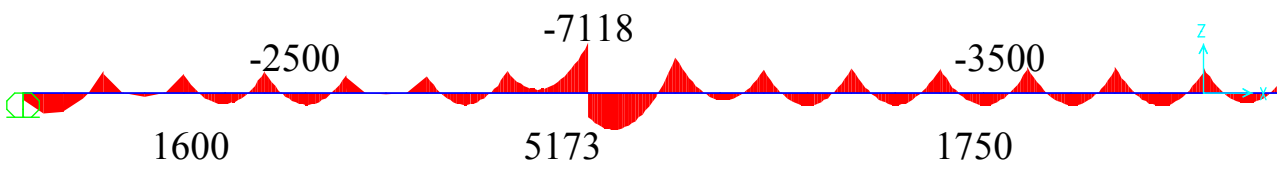

Figura 6.10: A)Forma do tabuleiro (metade), B) Momento no tabuleiro devido ao peso-próprio sem protensão dos estais, $C$ ) Momento no tabuleiro com forças do MAD (unidades: $k N, m$ ) 


\subsubsection{Método de anulação das reações em apoios fictícios (MAR)}

Este método é similar ao método de anulação dos deslocamentos, mas neste caso foram criados apoios fictícios em todos os estais.

A partir dos carregamentos de temperatura, foram determinadas as reações de todos os apoios, formando assim a matriz $\left[K_{R}\right]$. Além disso, foram determinados as reações de todos os apoios fictícios que correspondem ao peso-próprio da estrutura. Com estes resultados foi aplicado o método dos Mínimos Quadrados, levando em conta que a primeira iteração deste método é o vetor de temperaturas [T] obtido no primeiro método MTA (item 6.1.1).

Tabela 6.4: Distribuição de esforços e temperaturas dos estais e deslocamentos dos nós do primeiro exemplo (MAR)

\begin{tabular}{|c|c|c|c|}
\hline Estai & $\boldsymbol{\Delta} \mathbf{T}\left({ }^{\circ} \mathbf{C}\right) \mathbf{)}$ & Força $\mathbf{( k N})$ & Deslocamento $(\mathbf{m})$ \\
\hline E1 & $-237,73$ & 10728,7 & 0 \\
\hline E2 & $-269,67$ & 6514,8 & $-1,57 \mathrm{E}-07$ \\
\hline E3 & $-235,63$ & 5206,9 & $-2,09 \mathrm{E}-07$ \\
\hline E4 & $-247,75$ & 4887,6 & $-1,65 \mathrm{E}-07$ \\
\hline E5 & $-239,76$ & 4131 & $-8,47 \mathrm{E}-08$ \\
\hline E6 & $-237,80$ & 3585,9 & $-3,98 \mathrm{E}-08$ \\
\hline E7 & $-225,71$ & 2949,5 & $-5,7 \mathrm{E}-09$ \\
\hline E8 & $-303,10$ & 4417,5 & $-1,75 \mathrm{E}-08$ \\
\hline E9 & $-233,79$ & 3918,2 & $-1,81 \mathrm{E}-08$ \\
\hline E10 & $-242,22$ & 4821 & $5,538 \mathrm{E}-08$ \\
\hline E11 & $-240,80$ & 5482,4 & $9,491 \mathrm{E}-08$ \\
\hline E12 & $-237,30$ & 6174,6 & $1,883 \mathrm{E}-09$ \\
\hline E13 & $-239,84$ & 6864,1 & $-1,96 \mathrm{E}-07$ \\
\hline E14 & $-229,44$ & 7284 & $-3,77 \mathrm{E}-07$ \\
\hline E15 & $-229,45$ & 7284 & $-3,99 \mathrm{E}-07$ \\
\hline E16 & $-239,84$ & 6864,1 & $-2,71 \mathrm{E}-07$ \\
\hline E17 & $-237,30$ & 6174,6 & $-1,06 \mathrm{E}-07$ \\
\hline E18 & $-240,79$ & 5482,4 & $3,107 \mathrm{E}-08$ \\
\hline E19 & $-242,20$ & 4820,9 & $1,198 \mathrm{E}-07$ \\
\hline E20 & $-233,78$ & 3918,4 & $1,227 \mathrm{E}-07$ \\
\hline E21 & $-303,03$ & 4416,7 & $5,958 \mathrm{E}-08$ \\
\hline E22 & $-221,97$ & 2896,1 & $1,94 \mathrm{E}-09$ \\
\hline E23 & $-241,10$ & 3638,9 & $-3,19 \mathrm{E}-08$ \\
\hline E24 & $-243,36$ & 4196,8 & $-1,11 \mathrm{E}-07$ \\
\hline E25 & $-242,06$ & 4768,1 & $-1,95 \mathrm{E}-07$ \\
\hline E26 & $-236,53$ & 5227,8 & $-2,11 \mathrm{E}-07$ \\
\hline E27 & $-273,83$ & 6620,4 & $-1,39 \mathrm{E}-07$ \\
\hline E28 & $-236,12$ & 10651,1 & 0 \\
\hline & & & \\
\hline
\end{tabular}




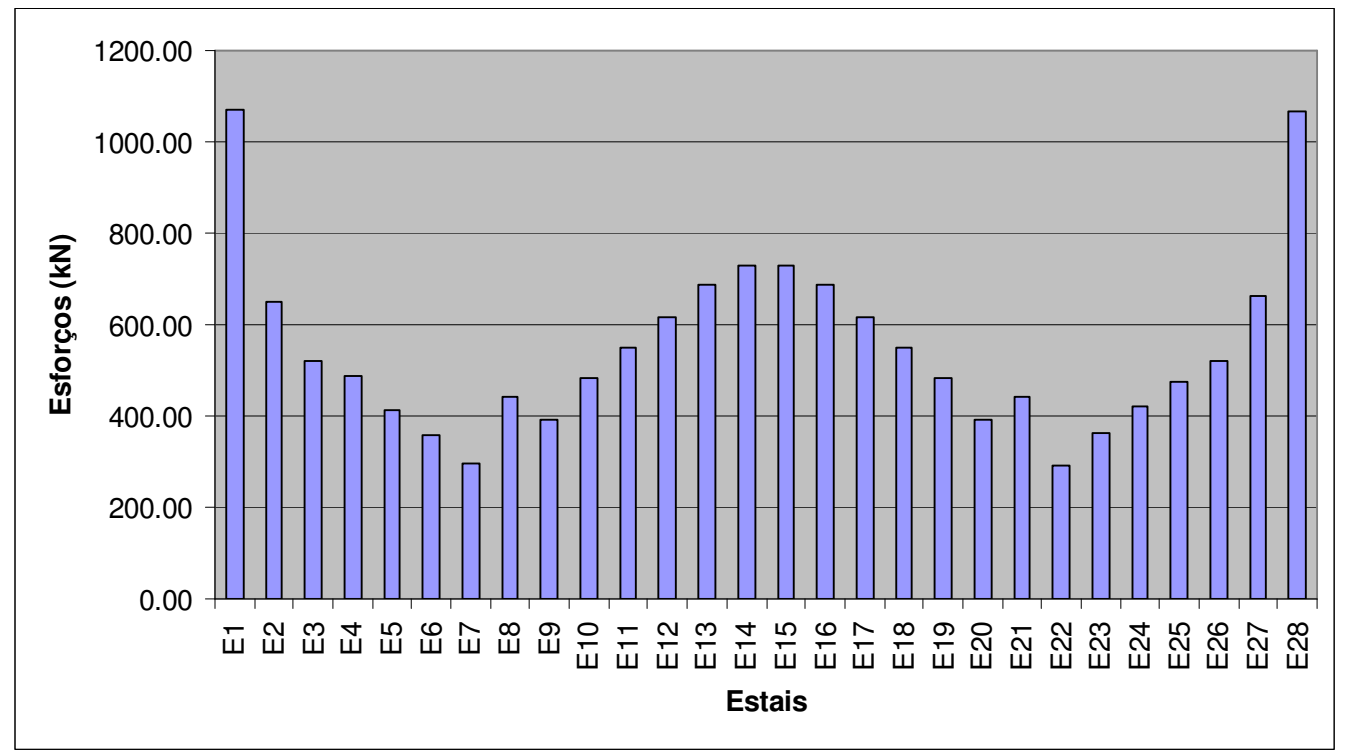

Figura 6.11: Distribuição de esforços dos estais do primeiro exemplo (MAR)

Aplicando as temperaturas obtidas anteriormente, pode se afirmar que o tabuleiro da ponte não apresenta deformação alguma, já que o resultado do deslocamento obtido no meio da ponte é de $4 \times 10^{-7} \mathrm{~m}$ (Figura 6.12).

\section{A)}
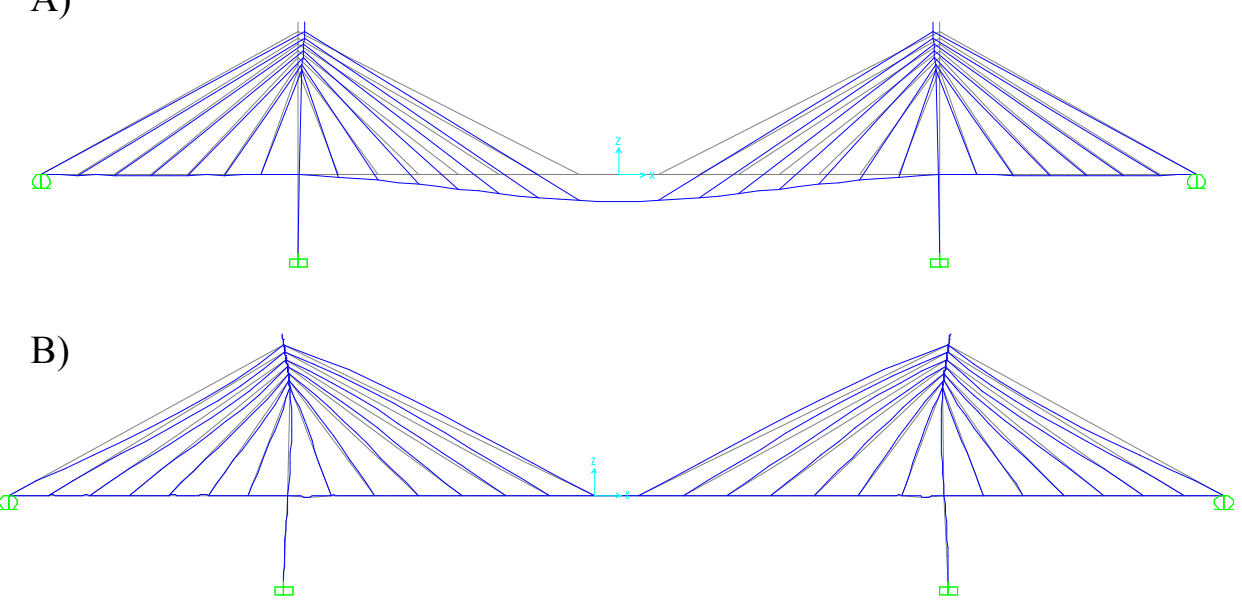

Figura 6.12: A) Deformada da ponte sem protensão dos estais, B) Deformada da ponte com forças do $M A R$

Para o MAR o diagrama de momentos para as temperaturas impostas nos estais, apresenta uma diagramação próxima ao resultado obtido no MAD Figura 6.13. Os diagramas do mastro são apresentados na figura Figura 6.14. 


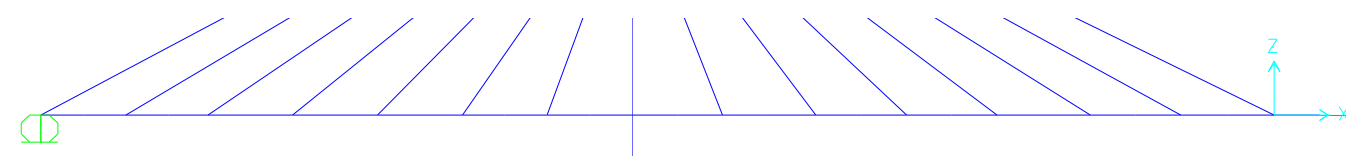

B)

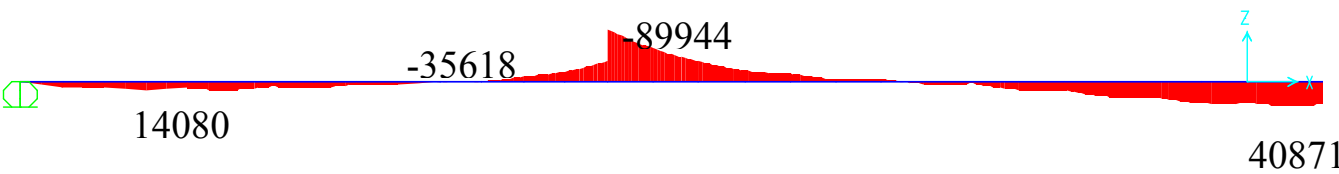

C)

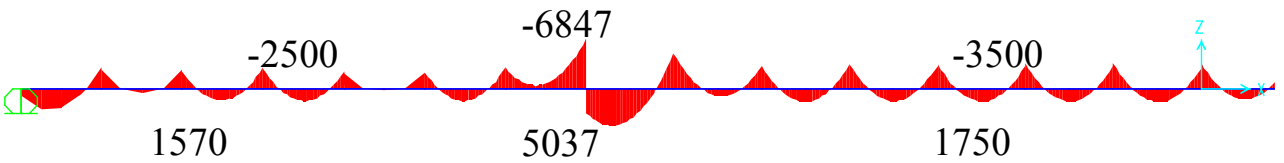

Figura 6.13: A)Forma do tabuleiro (metade), B) Momento no tabuleiro devido ao peso-próprio sem protensão dos estais, C) Momento no tabuleiro com forças do MAR (unidades: $k N$, m)

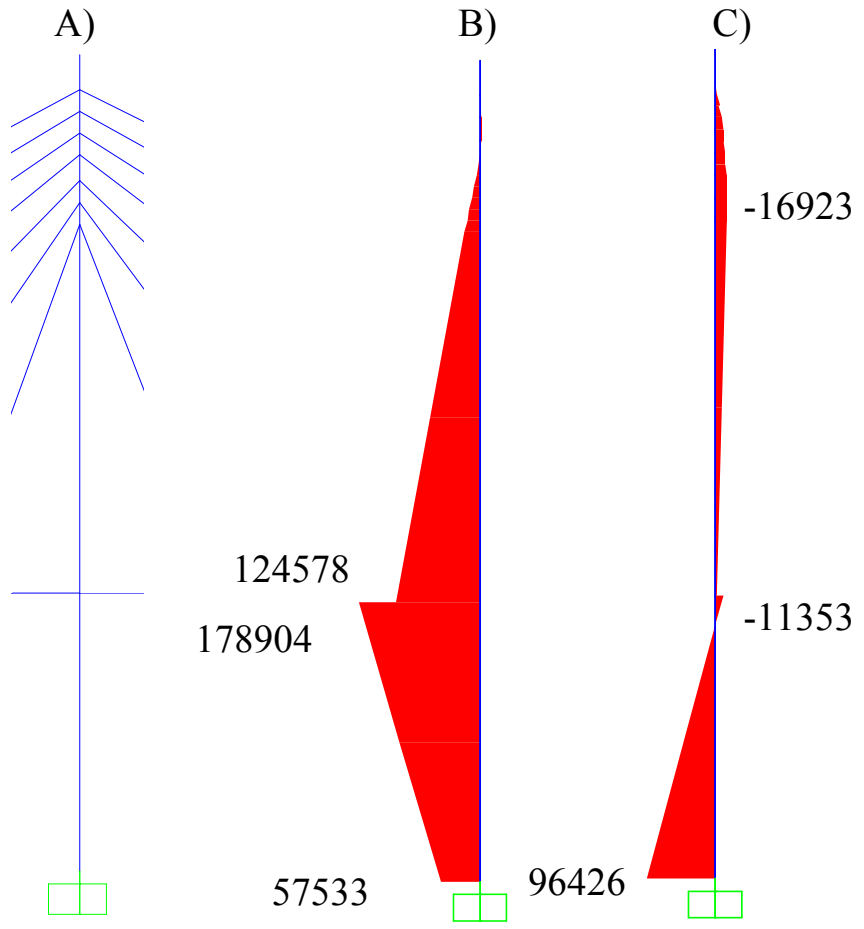

Figura 6.14: A)Forma do mastro, B) Momento no mastro devido ao peso-próprio sem protensão dos estais, C) Momento no mastro com forças do MAR(unidades: $k N, m$ ) 
6.1.4. Método de anulação dos deslocamentos no processo construtivo (MAD evolutivo)

No ultimo método foram aplicadas todas as temperaturas necessárias para anular os deslocamentos da estrutura devido ao peso próprio. Este procedimento deve ser feito passo a passo e a partir dos deslocamentos resultantes nas aduelas, são obtidas as temperaturas como foi explicado anteriormente.

Tabela 6.5: Distribuição de esforços e temperaturas dos estais e deslocamentos dos nós do primeiro exemplo (MAD evolutivo)

\begin{tabular}{|c|c|c|c|}
\hline Estai & $\left.\boldsymbol{\Delta} \mathbf{T}\left({ }^{\circ} \mathbf{C}\right)\right)$ & Força $(\mathbf{k N})$ & Deslocamento $(\mathbf{m})$ \\
\hline E1 & -196.18 & 8353,9 & 0.0000 \\
\hline E2 & -217.13 & 5608 & -0.0075 \\
\hline E3 & -220.81 & 5660,2 & 0.0040 \\
\hline E4 & -229.36 & 5390,6 & 0.0223 \\
\hline E5 & -237.64 & 4881 & 0.0344 \\
\hline E6 & -242.85 & 4270,3 & 0.0318 \\
\hline E7 & -272.69 & 3934 & 0.0162 \\
\hline E8 & -262.36 & 3516,3 & -0.0215 \\
\hline E9 & -243.83 & 3768 & -0.0450 \\
\hline E10 & -247.17 & 4486,7 & -0.0540 \\
\hline E11 & -255.32 & 5320,1 & -0.0440 \\
\hline E12 & -259.07 & 6329,8 & -0.0224 \\
\hline E13 & -268.01 & 7620,3 & -0.0034 \\
\hline E14 & -196.40 & 6847,3 & 0.0013 \\
\hline E15 & -196.40 & 6848,2 & 0.0013 \\
\hline E16 & -268.01 & 7620,9 & -0.0034 \\
\hline E17 & -259.07 & 6330,1 & -0.0225 \\
\hline E18 & -255.32 & 5320,2 & -0.0440 \\
\hline E19 & -247.17 & 4486,6 & -0.0540 \\
\hline E20 & -243.83 & 3767,8 & -0.0450 \\
\hline E21 & -262.36 & 3516,2 & -0.0215 \\
\hline E22 & -272.69 & 3935,5 & 0.0162 \\
\hline E23 & -242.85 & 4277,3 & 0.0316 \\
\hline E24 & -237.64 & 4885,2 & 0.0342 \\
\hline E25 & -229.36 & 5389,4 & 0.0224 \\
\hline E26 & -220.81 & 5660,1 & 0.0041 \\
\hline E27 & -217.13 & 5607,5 & -0.0075 \\
\hline E28 & -196.18 & 8350,2 & 0.0000 \\
\hline & & & \\
\hline
\end{tabular}




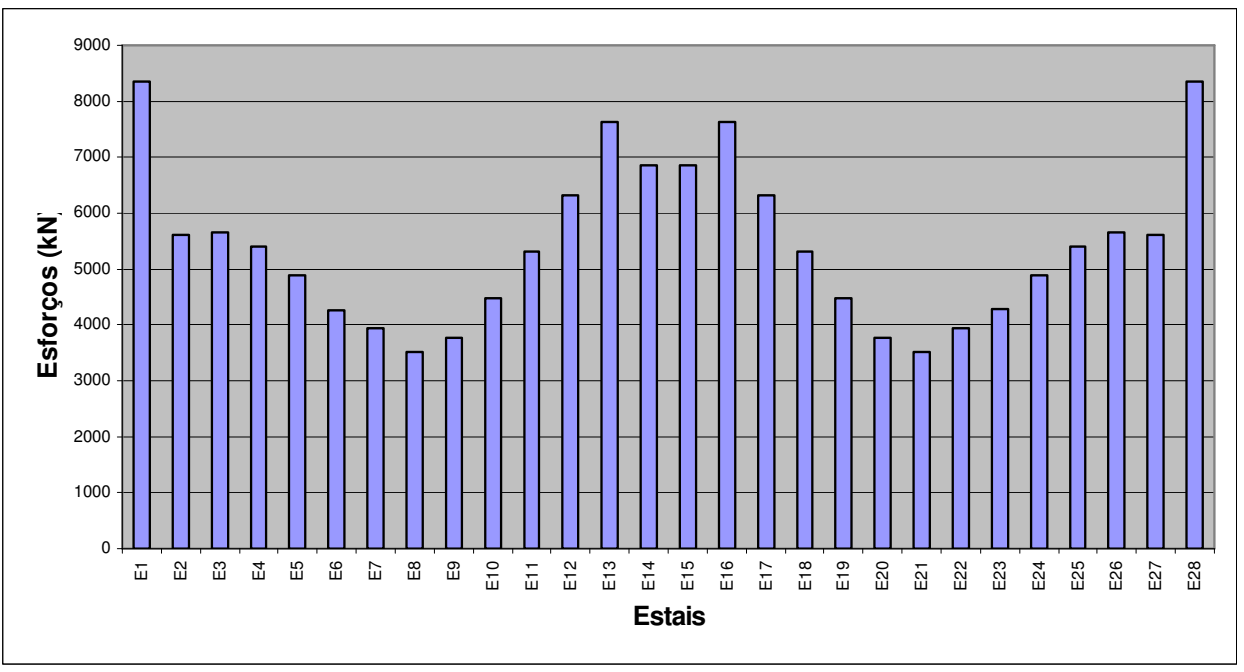

Figura 6.15: Distribuição de esforços dos estais do primeiro exemplo (MAD evolutivo)

Pode-se observar na Figura 6.15 que a distribuição de esforços é similar a obtida nos métodos anteriores. Porém, os esforços referentes aos estais localizados no meio do vão têm aos seus valores acrescentados, já que quanto mais avançada esta a construção maiores são os esforços que devem ser aplicados.

Com respeito aos deslocamentos, estes se vem modificados na medida que a ponte esta sendo construída. Depois que foi aplicada uma tensão no estai, nenhum outro esforço é imposto para corrigir os possíveis desvios no deslocamento produzidos pela construção das aduelas seguintes. Na Figura 6.16, apresenta-se a comparação entre o deslocamento da ponte sob carregamento de peso próprio na fase final e o deslocamento depois do processo construtivo. 
A)

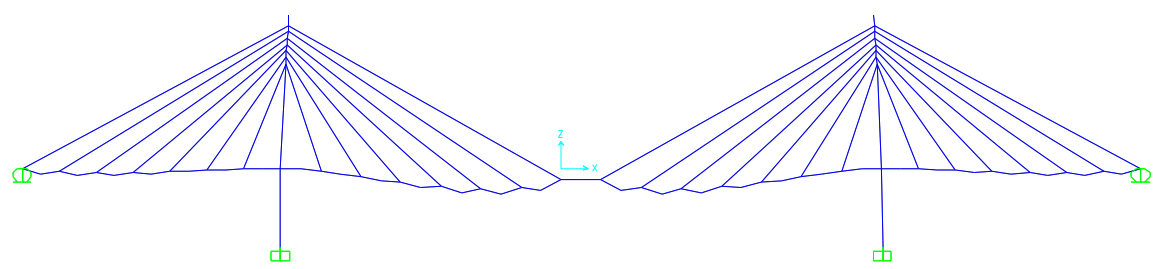

B)

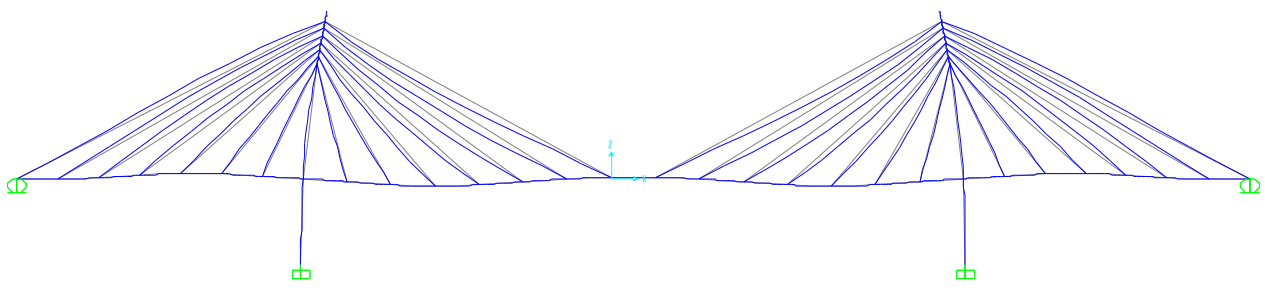

Figura 6.16: A) Deformada da ponte sob carregamento de peso próprio sem protensão dos estais, B) Deformada da ponte com forças do MAD evolutivo

O mesmo ocorre com o momento, obtendo-se assim um diagrama de momento não otimizado para o tabuleiro (Figura 6.18). O diagrama de momento do mastro, apresenta-se na Figura 2.7.

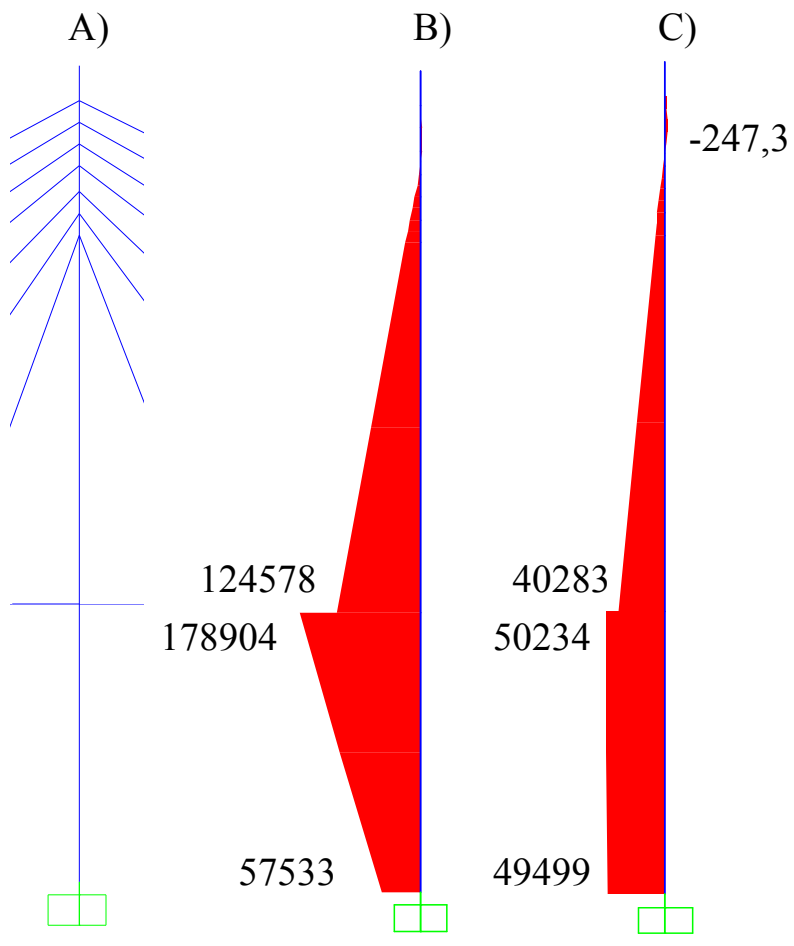

Figura 6.17: A)Forma do mastro, B) Momento no mastro devido ao peso-próprio sem protensão dos estais, C) Momento do mastro com forças do MAD evolutivo (unidades: $\mathrm{kN}, \mathrm{m}$ ) 
A)

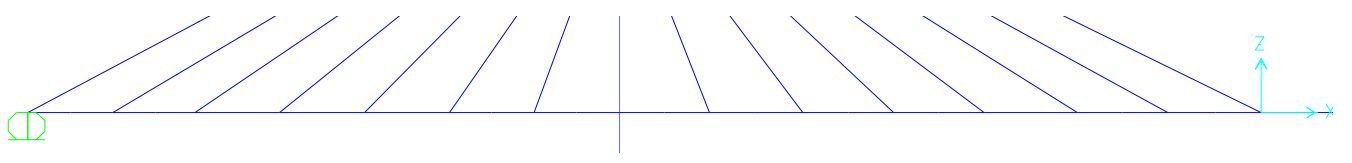

B)

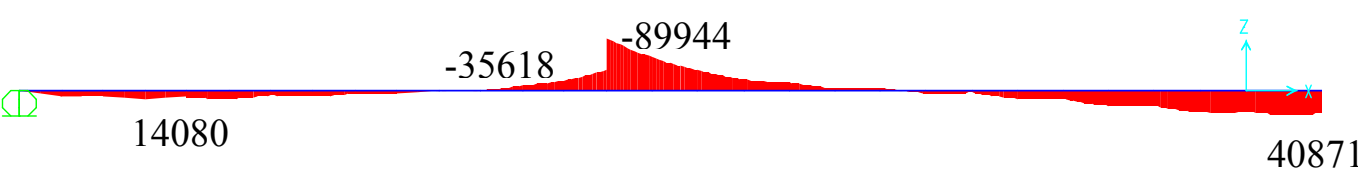

C)

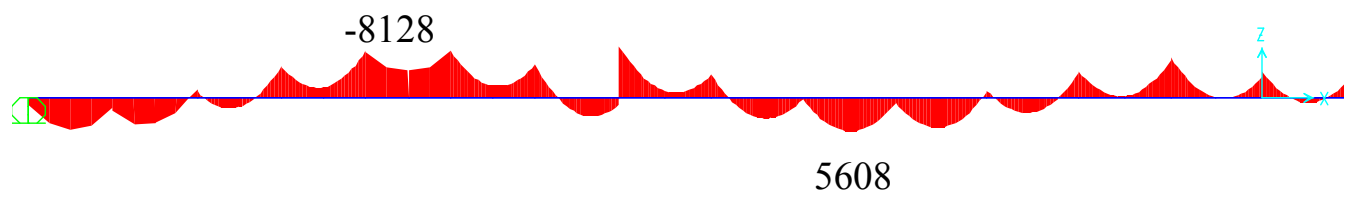

Figura 6.18: A)Forma do tabuleiro (metade), B) Momento no tabuleiro devido ao peso-próprio sem protensão dos estais, $C$ ) Momento do tabuleiro com forças do MAD evolutivo (unidades: $k N, m$ ) 


\subsubsection{Comparação dos métodos}

\subsubsection{Fase final}

Estabelece-se primeiro uma comparação entre o MTA, o MAD e o MAR, já que esses métodos foram realizados com o modelo da estrutura na configuração final, e não se levaram em consideração as fases do processo construtivo.

Nesta primeira comparação, obtem-se que as temperaturas do MAD e o MAR são similares, por tanto, os resultados de deslocamento, esforços e momento são próximos (Tabela 6.6).

Tabela 6.6: Comparação das temperaturas do MTA, MAD e MAR para o primeiro exemplo (unidades: ${ }^{\circ} \mathrm{C}$ )

\begin{tabular}{|c|c|c|c|c|}
\hline ESTAIS & MTA & MAD(40\%) & MAR & $\begin{array}{c}\text { ( (MAD(40\%)- } \\
\text { MAR) (\%) }\end{array}$ \\
\hline E1 & -351.39 & -238.72 & -237.73 & 0,41 \\
\hline E2 & -350.77 & -269.95 & -269.67 & 0,10 \\
\hline E3 & -350.27 & -235.96 & -235.63 & 0,14 \\
\hline E4 & -349.85 & -247.88 & -247.75 & 0,05 \\
\hline E5 & -349.53 & -240.08 & -239.76 & 0,13 \\
\hline E6 & -349.30 & -238.18 & -237.80 & 0,16 \\
\hline E7 & -349.16 & -222.81 & -225.71 & 1,28 \\
\hline E8 & -349.17 & -305.59 & -303.10 & 0,81 \\
\hline E9 & -349.33 & -233.25 & -233.79 & 0,23 \\
\hline E10 & -349.60 & -241.99 & -242.22 & 0,09 \\
\hline E11 & -349.99 & -240.54 & -240.80 & 0,11 \\
\hline E12 & -350.48 & -236.87 & -237.30 & 0,18 \\
\hline E13 & -351.08 & -239.68 & -239.84 & 0,07 \\
\hline E14 & -351.79 & -228.80 & -229.44 & 0,28 \\
\hline E15 & -351.79 & -228.80 & -229.45 & 0,28 \\
\hline E16 & -351.08 & -239.68 & -239.84 & 0,07 \\
\hline E17 & -350.48 & -236.87 & -237.30 & 0,18 \\
\hline E18 & -349.99 & -240.54 & -240.79 & 0,10 \\
\hline E19 & -349.60 & -241.99 & -242.20 & 0,09 \\
\hline E20 & -349.33 & -233.25 & -233.78 & 0,23 \\
\hline E21 & -349.17 & -305.59 & -303.03 & 0,84 \\
\hline E22 & -349.16 & -222.81 & -221.97 & 0,38 \\
\hline E23 & -349.30 & -238.18 & -241.10 & 1,21 \\
\hline E24 & -349.53 & -240.08 & -243.36 & 1,35 \\
\hline E25 & -349.85 & -247.88 & -242.06 & 2,35 \\
\hline E26 & -350.27 & -235.96 & -236.53 & 0,24 \\
\hline E27 & -350.77 & -269.95 & -273.83 & 1,42 \\
\hline E28 & -351.39 & -238.72 & -236.12 & 1,09 \\
\hline & & & & \\
\hline
\end{tabular}

No caso dos esforços, observa-se o mesmo resultado decorrente das temperaturas aplicadas nos estais (Tabela 6.7). 
Tabela 6.7: Comparação dos esforços do MTA, MAD e MAR para o primeiro exemplo(unidades: kN)

\begin{tabular}{|c|c|c|c|c|}
\hline ESTAIS & MTA & MAD(40\%) & MAR & $\begin{array}{c}\boldsymbol{\delta} \text { (MAD(40\%)- } \\
\text { MAR) (\%) }\end{array}$ \\
\hline E1 & 12769,9 & 10761,1 & 10728,7 & 12770 \\
\hline E2 & 6519,8 & 6514,3 & 6514,8 & 6519,9 \\
\hline E3 & 5730,2 & 5208,3 & 5206,9 & 5730,3 \\
\hline E4 & 4888,8 & 4885,2 & 4887,6 & 4888,9 \\
\hline E5 & 4195,2 & 4133,1 & 4131 & 4195,2 \\
\hline E6 & 3820,8 & 3589,5 & 3585,9 & 3820,9 \\
\hline E7 & 3845,2 & 2907,1 & 2949,5 & 3845,2 \\
\hline E8 & 4840,7 & 4457,7 & 4417,5 & 4840,7 \\
\hline E9 & 4664,3 & 3911,8 & 3918,2 & 4664,3 \\
\hline E10 & 4837,9 & 4821,6 & 4821 & 4837,9 \\
\hline E11 & 5254,8 & 5483,4 & 5482,4 & 5254,9 \\
\hline E12 & 6043,2 & 6171,9 & 6174,6 & 6043,2 \\
\hline E13 & 6965,8 & 6869,6 & 6864,1 & 6965,8 \\
\hline E14 & 8342,2 & 7275,2 & 7284 & 8342,3 \\
\hline E15 & 8345,5 & 7293,8 & 7284 & 8345,6 \\
\hline E16 & 6967,7 & 6856,4 & 6864,1 & 6967,8 \\
\hline E17 & 6044,1 & 6179,1 & 6174,6 & 6044,1 \\
\hline E18 & 5255,1 & 5481 & 5482,4 & 5255,1 \\
\hline E19 & 4837,9 & 4817,8 & 4820,9 & 4837,9 \\
\hline E20 & 4664,4 & 3940 & 3918,4 & 4664,4 \\
\hline E21 & 4841 & 4287,3 & 4416,7 & 4841,1 \\
\hline E22 & 3846,1 & 3036,8 & 2896,1 & 3846,2 \\
\hline E23 & 3829,1 & 3622,2 & 3638,9 & 3829,1 \\
\hline E24 & 4202,3 & 4193,9 & 4196,8 & 4202,3 \\
\hline E25 & 4890,5 & 4775 & 4768,1 & 4890,6 \\
\hline E26 & 5733,6 & 5220,4 & 5227,8 & 5733,6 \\
\hline E27 & 6522,8 & 6625,6 & 6620,4 & 6522,9 \\
\hline E28 & 12763,7 & 11008,6 & 10651,1 & 12763,8 \\
\hline & & & & \\
\hline
\end{tabular}

Na Figura 6.19 apresentam-se um diagrama de comparação de esforços onde podese observar o aumento de esforço nos estais que estão mais afastados do mastro, sendo o estai de estabilidade aquele com o maior esforço. 


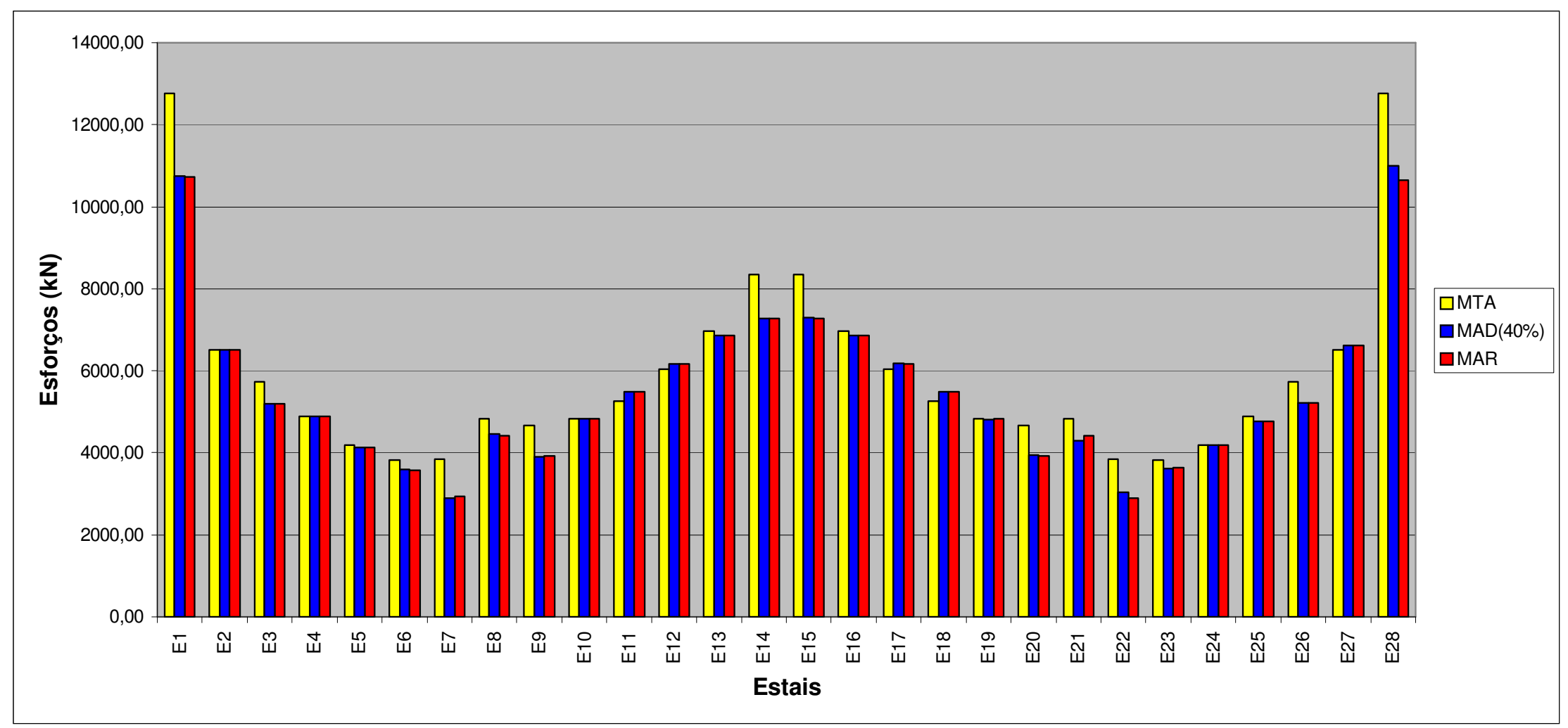

Figura 6.19: Comparação dos esforços do MTA, MAD e MAR para o primeiro exemplo 
Para os deslocamentos do tabuleiro, os valores mais próximos de zero foram os valores obtidos com o MAR. Isto é devido a uma melhor convergência do processo iterativo porque anular as flechas ou trabalhar com as reações fictícias é teoricamente o mesmo (Tabela 6.8).

Tabela 6.8: Comparação das deslocamentos do MTA, MAD e MAR para o primeiro exemplo (unidades: $m$ )

\begin{tabular}{|c|r|c|c|c|}
\hline ESTAIS & $\begin{array}{c}\text { Peso- } \\
\text { próprio } \\
\text { sem } \\
\text { protensão }\end{array}$ & MTA & MAD(40\%) & MAR \\
\hline E1 & 0 & 0 & 0 & 0 \\
\hline E2 & $-0,0392$ & 0.0140 & $5.664 \mathrm{E}-07$ & $-1.57 \mathrm{E}-07$ \\
\hline E3 & $-0,0618$ & 0.0242 & $3.184 \mathrm{E}-07$ & $-2.09 \mathrm{E}-07$ \\
\hline E4 & $-0,0657$ & 0.0275 & $-1.45 \mathrm{E}-06$ & $-1.65 \mathrm{E}-07$ \\
\hline E5 & $-0,0546$ & 0.0246 & $1.673 \mathrm{E}-06$ & $-8.47 \mathrm{E}-08$ \\
\hline E6 & $-0,0344$ & 0.0169 & $-1.25 \mathrm{E}-06$ & $-3.98 \mathrm{E}-08$ \\
\hline E7 & $-0,0118$ & 0.0066 & $1.609 \mathrm{E}-06$ & $-5.7 \mathrm{E}-09$ \\
\hline E8 & $-0,0725$ & 0.0282 & $-6.82 \mathrm{E}-07$ & $-1.75 \mathrm{E}-08$ \\
\hline E9 & $-0,2041$ & 0.0874 & $-2.43 \mathrm{E}-07$ & $-1.81 \mathrm{E}-08$ \\
\hline E10 & $-0,3563$ & 0.1583 & $-3.03 \mathrm{E}-07$ & $5.538 \mathrm{E}-08$ \\
\hline E11 & $-0,5119$ & 0.2325 & $4.213 \mathrm{E}-07$ & $9.491 \mathrm{E}-08$ \\
\hline E12 & $-0,6563$ & 0.3031 & $-5.47 \mathrm{E}-07$ & $1.883 \mathrm{E}-09$ \\
\hline E13 & $-0,7711$ & 0.3604 & $1.68 \mathrm{E}-06$ & $-1.96 \mathrm{E}-07$ \\
\hline E14 & $-0,8358$ & 0.3937 & $-3.95 \mathrm{E}-06$ & $-3.77 \mathrm{E}-07$ \\
\hline E15 & $-0,8358$ & 0.3937 & $3.571 \mathrm{E}-06$ & $-3.99 \mathrm{E}-07$ \\
\hline E16 & $-0,7711$ & 0.3606 & $-3.57 \mathrm{E}-06$ & $-2.71 \mathrm{E}-07$ \\
\hline E17 & $-0,6563$ & 0.3033 & $1.434 \mathrm{E}-06$ & $-1.06 \mathrm{E}-07$ \\
\hline E18 & $-0,5118$ & 0.2327 & $-7.27 \mathrm{E}-07$ & $3.107 \mathrm{E}-08$ \\
\hline E19 & $-0,3562$ & 0.1584 & $7.686 \mathrm{E}-08$ & $1.198 \mathrm{E}-07$ \\
\hline E20 & $-0,2041$ & 0.0874 & $3.858 \mathrm{E}-07$ & $1.227 \mathrm{E}-07$ \\
\hline E21 & $-0,0725$ & 0.0282 & $-7.69 \mathrm{E}-07$ & $5.958 \mathrm{E}-08$ \\
\hline E22 & $-0,0119$ & 0.0065 & $-7.3 \mathrm{E}-07$ & $1.94 \mathrm{E}-09$ \\
\hline E23 & $-0,0347$ & 0.0165 & $2.976 \mathrm{E}-06$ & $-3.19 \mathrm{E}-08$ \\
\hline E24 & $-0,0549$ & 0.0242 & $-2.7 \mathrm{E}-06$ & $-1.11 \mathrm{E}-07$ \\
\hline E25 & $-0,0658$ & 0.0272 & $2.651 \mathrm{E}-06$ & $-1.95 \mathrm{E}-07$ \\
\hline E26 & $-0,0620$ & 0.0238 & $-3.65 \mathrm{E}-06$ & $-2.11 \mathrm{E}-07$ \\
\hline E27 & $-0,0395$ & 0.0135 & $2.244 \mathrm{E}-06$ & $-1.39 \mathrm{E}-07$ \\
\hline E28 & 0 & 0 & 0 & 0 \\
\hline & & & & \\
\hline
\end{tabular}




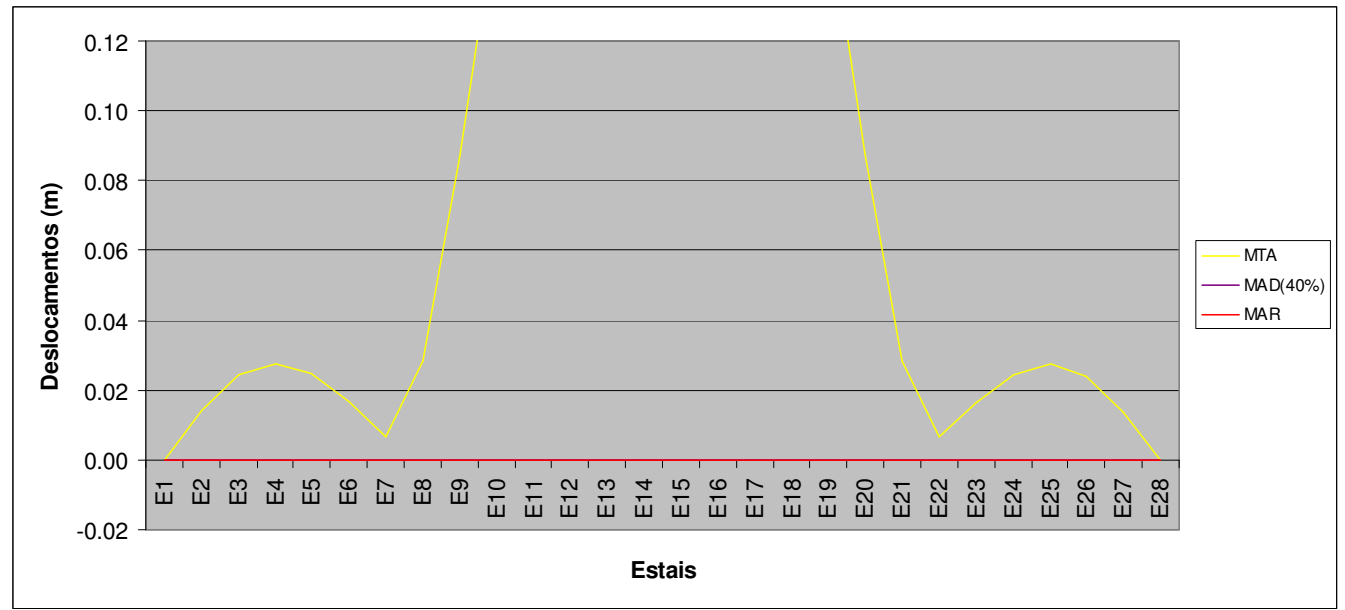

Figura 6.20: Comparação dos deslocamentos do MTA, MAD e MAR para o primeiro exemplo

Com respeito à distribuição de momentos os métodos dos deslocamentos (MAD) e o método das reações (MAR) apresentam as melhores distribuições dos três métodos comparados (Figura 6.21 e Figura 6.22).

A)

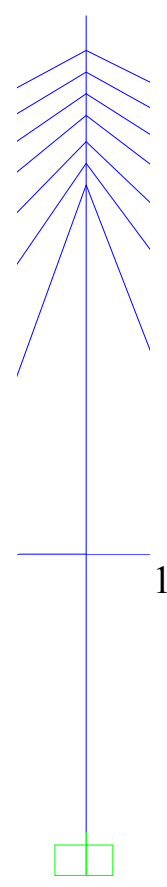

B)

124578 178904

57533
C)

D)

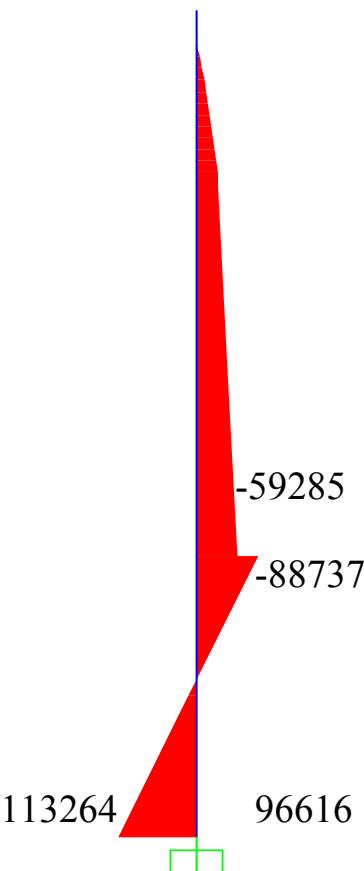

E)

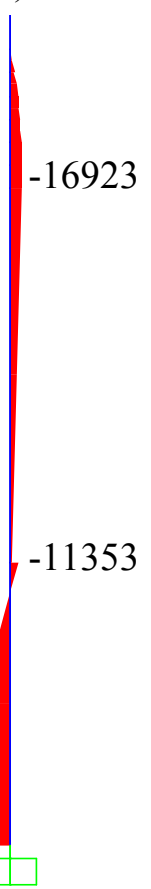

Figura 6.21: A)Forma do mastro, B) Momento no mastro devido ao peso-próprio sem protensão dos estais, C) Momento no mastro para o MTA, D) Momento no mastro para o MAD, E) Momento no mastro para o MAR (unidades: $k N, m$ ) 
A)

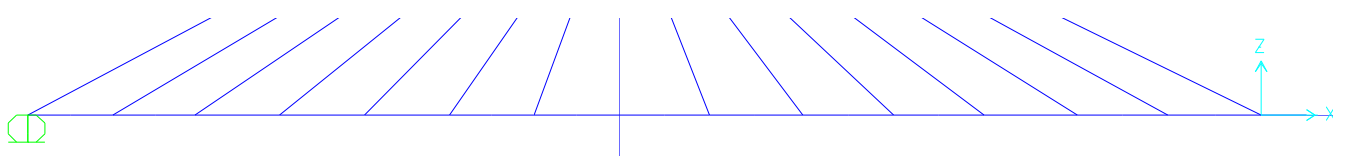

B)

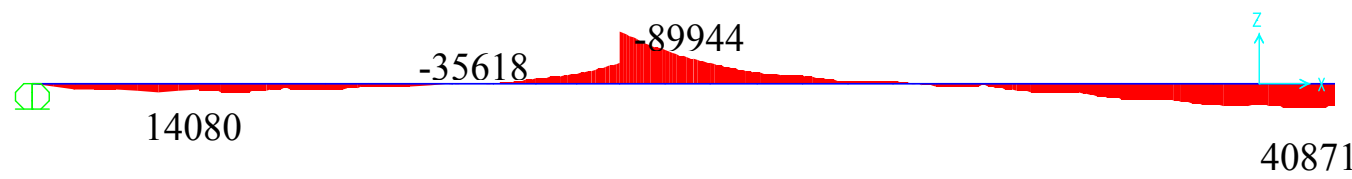

C)

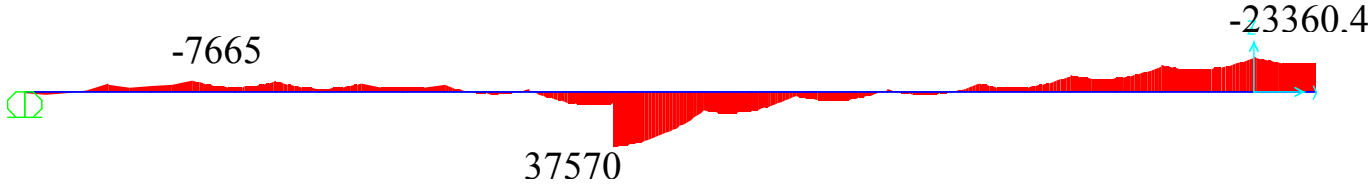

D)

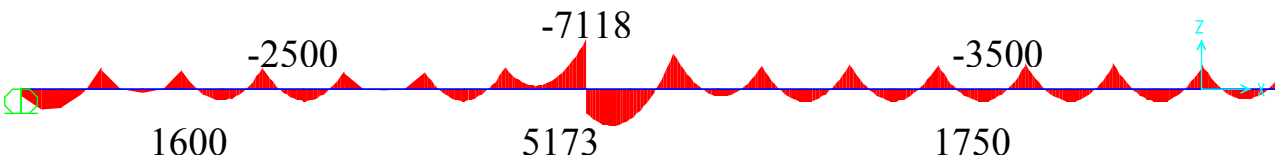

E)

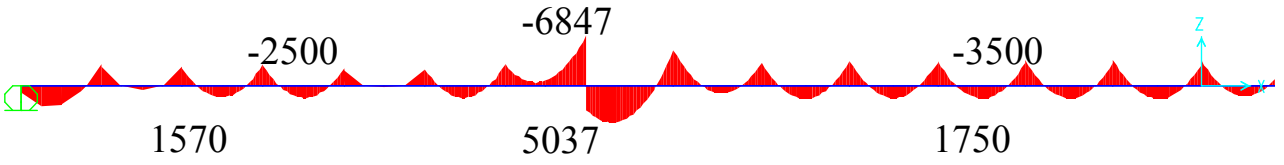

Figura 6.22: A) Forma do tabuleiro (metade), B) Momento do tabuleiro para o peso-próprio sem protensão dos estais, C) Momento no tabuleiro para o MTA, D) Momento no tabuleiro para o MAD, E) Momento no tabuleiro para o MAR (unidades: $k N, m$ ) 


\subsubsection{Evolutivos}

Considera-se importante uma comparação entre os evolutivos de todos os métodos inclusive aquele que controla as flechas na construção. Neste caso foi realizado o processo construtivo com os valores de temperatura obtidos com cada um deles. (Tabela 6.9)

Observa-se na Tabela 6.10 e a Figura 6.23 que os esforços são bastante próximos, salvo os estais de estabilidade e aqueles que estão no meio do vão.

Tabela 6.9: Comparação das temperaturas nos estais dos evolutivos dos métodos (unidades: ${ }^{\circ} \mathrm{C}$ )

\begin{tabular}{|c|c|c|c|c|}
\hline ESTAIS & MTA & $\begin{array}{c}\text { MAD } \\
\text { (EVOLUTIVO) }\end{array}$ & MAD(40\%) & MAR \\
\hline E1 & -351.39 & -196.18 & -238.72 & -237.73 \\
\hline E2 & -350.77 & -217.13 & -269.95 & -269.67 \\
\hline E3 & -350.27 & -220.81 & -235.96 & -235.63 \\
\hline E4 & -349.85 & -229.36 & -247.88 & -247.75 \\
\hline E5 & -349.53 & -237.64 & -240.08 & -239.76 \\
\hline E6 & -349.30 & -242.85 & -238.18 & -237.80 \\
\hline E7 & -349.16 & -272.69 & -222.81 & -225.71 \\
\hline E8 & -349.17 & -262.36 & -305.59 & -303.10 \\
\hline E9 & -349.33 & -243.83 & -233.25 & -233.79 \\
\hline E10 & -349.60 & -247.17 & -241.99 & -242.22 \\
\hline E11 & -349.99 & -255.32 & -240.54 & -240.80 \\
\hline E12 & -350.48 & -259.07 & -236.87 & -237.30 \\
\hline E13 & -351.08 & -268.01 & -239.68 & -239.84 \\
\hline E14 & -351.79 & -196.40 & -228.80 & -229.44 \\
\hline E15 & -351.79 & -196.40 & -228.80 & -229.45 \\
\hline E16 & -351.08 & -268.01 & -239.68 & -239.84 \\
\hline E17 & -350.48 & -259.07 & -236.87 & -237.30 \\
\hline E18 & -349.99 & -255.32 & -240.54 & -240.79 \\
\hline E19 & -349.60 & -247.17 & -241.99 & -242.20 \\
\hline E20 & -349.33 & -243.83 & -233.25 & -233.78 \\
\hline E21 & -349.17 & -262.36 & -305.59 & -303.03 \\
\hline E22 & -349.16 & -272.69 & -222.81 & -221.97 \\
\hline E23 & -349.30 & -242.85 & -238.18 & -241.10 \\
\hline E24 & -349.53 & -237.64 & -240.08 & -243.36 \\
\hline E25 & -349.85 & -229.36 & -247.88 & -242.06 \\
\hline E26 & -350.27 & -220.81 & -235.96 & -236.53 \\
\hline E27 & -350.77 & -217.13 & -269.95 & -273.83 \\
\hline E28 & -351.39 & -196.18 & -238.72 & -236.12 \\
\hline & & & & \\
\hline
\end{tabular}


Tabela 6.10: Comparação dos esforços nos estais para dos evolutivos dos métodos (unidades: $k N$ )

\begin{tabular}{|c|c|c|c|c|}
\hline ESTAIS & MTA & $\begin{array}{c}\text { MAD } \\
\text { (EVOLUTIVO) }\end{array}$ & MAD(40\%) & MAR \\
\hline E1 & 12221,3 & 8353,9 & 9409,3 & 9384,8 \\
\hline E2 & 5603,1 & 5608 & 5607,1 & 5612,5 \\
\hline E3 & 4667,7 & 5660,2 & 4706,8 & 4710,7 \\
\hline E4 & 4029,5 & 5390,6 & 4633,1 & 4638 \\
\hline E5 & 3656,8 & 4881 & 4200,7 & 4201,7 \\
\hline E6 & 3628,1 & 4270,3 & 3899,6 & 3900,6 \\
\hline E7 & 4149,3 & 3934 & 3421,6 & 3454,8 \\
\hline E8 & 4118,9 & 3516,3 & 3882,3 & 3852,3 \\
\hline E9 & 3730 & 3768 & 3698,7 & 3699 \\
\hline E10 & 4117,2 & 4486,7 & 4655,9 & 4653 \\
\hline E11 & 4736,9 & 5320,1 & 5441,6 & 5437,9 \\
\hline E12 & 5681,5 & 6329,8 & 6166,3 & 6166 \\
\hline E13 & 7047,5 & 7620,3 & 6882,2 & 6877,4 \\
\hline E14 & 9229,4 & 6847,3 & 7344,3 & 7354,1 \\
\hline E15 & 9230,3 & 6848,2 & 7345,2 & 7355 \\
\hline E16 & 7048,1 & 7620,9 & 6882,8 & 6877,9 \\
\hline E17 & 5681,7 & 6330,1 & 6166,5 & 6166,1 \\
\hline E18 & 4737 & 5320,2 & 5441,6 & 5437,3 \\
\hline E19 & 4117,1 & 4486,6 & 4655,8 & 4652 \\
\hline E20 & 3729,7 & 3767,8 & 3698,6 & 3699 \\
\hline E21 & 4118,6 & 3516,2 & 3882,2 & 3847,7 \\
\hline E22 & 4151,2 & 3935,5 & 3423,1 & 3404,7 \\
\hline E23 & 3636,5 & 4277,3 & 3906,8 & 3930,5 \\
\hline E24 & 3660 & 4885,2 & 4204,5 & 4266,2 \\
\hline E25 & 4028,6 & 5389,4 & 4632,1 & 4561,6 \\
\hline E26 & 4669,3 & 5660,1 & 4707,4 & 4692,4 \\
\hline E27 & 5602,6 & 5607,5 & 5606,7 & 5677,7 \\
\hline E28 & 12215,3 & 8350,2 & 9405 & 9340,4 \\
\hline
\end{tabular}




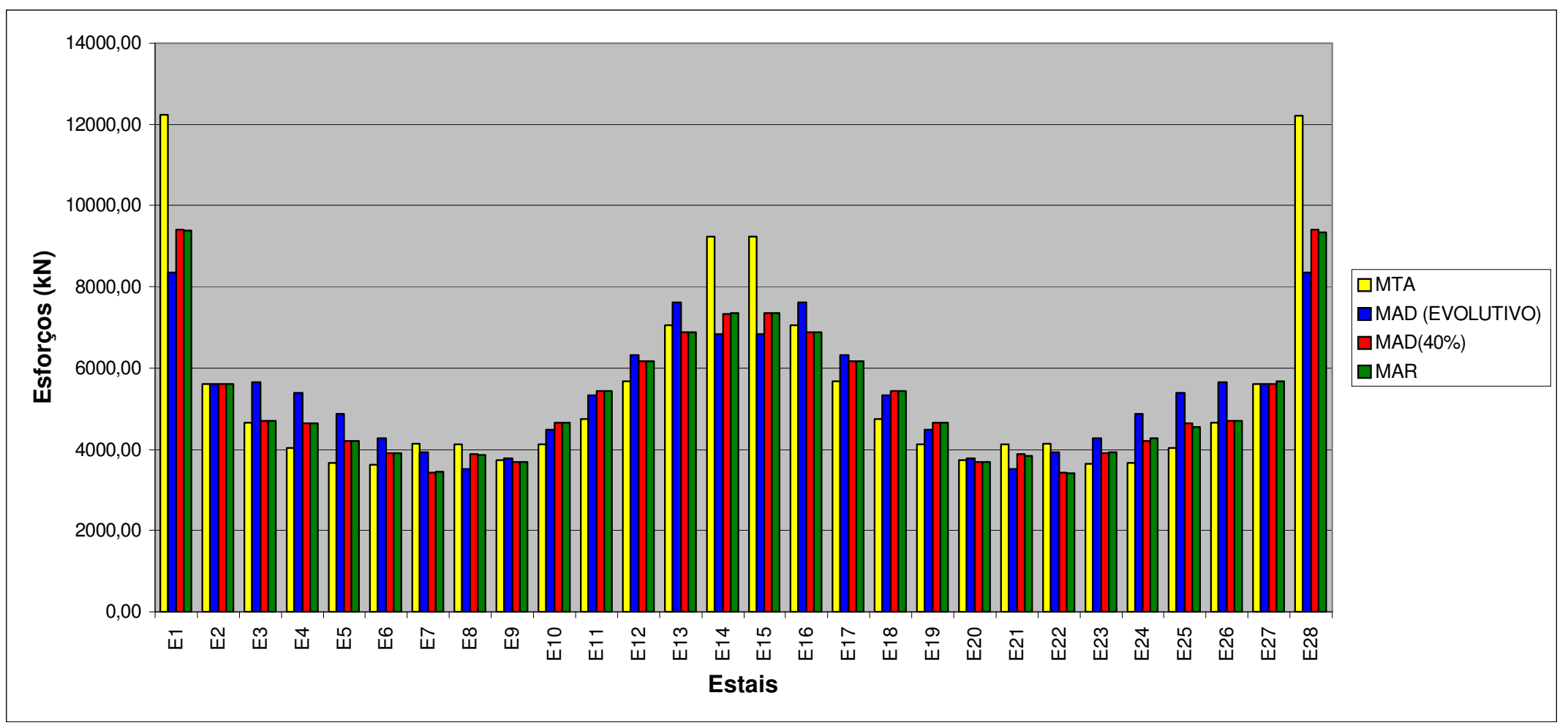

Figura 6.23: Comparação dos esforços dos evolutivos dos métodos e o processo construtivo para o primeiro exemplo 
Os deslocamentos não apresentam valores tão próximos a zero quando se consideram as fases construtivas. É importante destacar que os valores de temperaturas usados foram obtidos a partir da configuração final da ponte. Quando estas são aplicadas ao processo construtivo da ponte, obtem-se deslocamentos maiores que os anteriores. Na Figura 6.24, apresenta-se a comparação entre os deslocamentos obtidos com os evolutivos dos métodos anteriores e o MAD evolutivo.

O mesmo ocorre com o momento, obtendo-se assim um diagrama não otimizado para o tabuleiro (Figura 6.27). O diagrama de momento do mastro, apresenta-se na Figura 6.26.

Tabela 6.11: Comparação dos deslocamentos nos estais para dos evolutivos dos métodos (unidades:m)

\begin{tabular}{|c|c|c|c|c|c|}
\hline ESTAIS & \begin{tabular}{|c|} 
Peso- \\
próprio \\
sem \\
protensão
\end{tabular} & MTA & $\begin{array}{c}\text { MAD } \\
\text { (EVOLUTIVO) }\end{array}$ & MAD(40\%) & MAR \\
\hline $\mathrm{E} 1$ & 0 & 0 & 0 & 0 & 0 \\
\hline E2 & $-0,0392$ & 0,1267 & -0.0075 & 0,0809 & 0,0808 \\
\hline E3 & $-0,0618$ & 0,1729 & 0.0040 & 0,0902 & 0,0902 \\
\hline E4 & $-0,0657$ & 0,1653 & 0.0223 & 0,0876 & 0,0878 \\
\hline E5 & $-0,0546$ & 0,1309 & 0.0344 & 0,0668 & 0,0669 \\
\hline E6 & $-0,0344$ & 0,0838 & 0.0318 & 0,0404 & 0,0405 \\
\hline E7 & $-0,0118$ & 0,0277 & 0.0162 & 0,0129 & 0,0131 \\
\hline E8 & $-0,0725$ & 0,0165 & -0.0215 & $-0,0143$ & $-0,0146$ \\
\hline E9 & $-0,2041$ & 0,0599 & -0.0450 & $-0,0439$ & $-0,0439$ \\
\hline E10 & $-0,3563$ & 0,1068 & -0.0540 & $-0,0618$ & $-0,0619$ \\
\hline E11 & $-0,5119$ & 0,1689 & -0.0440 & $-0,0687$ & $-0,0688$ \\
\hline E12 & $-0,6563$ & 0,2481 & -0.0224 & $-0,0502$ & $-0,0503$ \\
\hline E13 & $-0,7711$ & 0,3237 & -0.0034 & 0,0014 & 0,0011 \\
\hline E14 & $-0,8358$ & 0,3813 & 0.0013 & 0,0919 & 0,0916 \\
\hline E15 & $-0,8358$ & 0,3812 & 0.0013 & 0,0919 & 0,0898 \\
\hline E16 & $-0,7711$ & 0,3236 & -0.0034 & 0,0014 & $-0,0004$ \\
\hline E17 & $-0,6563$ & 0,2480 & -0.0225 & $-0,0503$ & $-0,0516$ \\
\hline E18 & $-0,5118$ & 0,1688 & -0.0440 & $-0,0687$ & $-0,0700$ \\
\hline E19 & $-0,3562$ & 0,1068 & -0.0540 & $-0,0618$ & $-0,0625$ \\
\hline E20 & $-0,2041$ & 0,0599 & -0.0450 & $-0,0439$ & $-0,0442$ \\
\hline E21 & $-0,0725$ & 0,0165 & -0.0215 & $-0,0143$ & $-0,0147$ \\
\hline E22 & $-0,0119$ & 0,0277 & 0.0162 & 0,0129 & 0,0133 \\
\hline E23 & $-0,0347$ & 0,0836 & 0.0316 & 0,0401 & 0,0415 \\
\hline E24 & $-0,0549$ & 0,1307 & 0.0342 & 0,0666 & 0,0676 \\
\hline E25 & $-0,0658$ & 0,1652 & 0.0224 & 0,0877 & 0,0866 \\
\hline E26 & $-0,0620$ & 0,1727 & 0.0041 & 0,0901 & 0,0937 \\
\hline E27 & $-0,0395$ & 0,1265 & -0.0075 & 0,0808 & 0,0850 \\
\hline E28 & 0 & 0 & 0 & 0 & 0 \\
\hline
\end{tabular}


A)

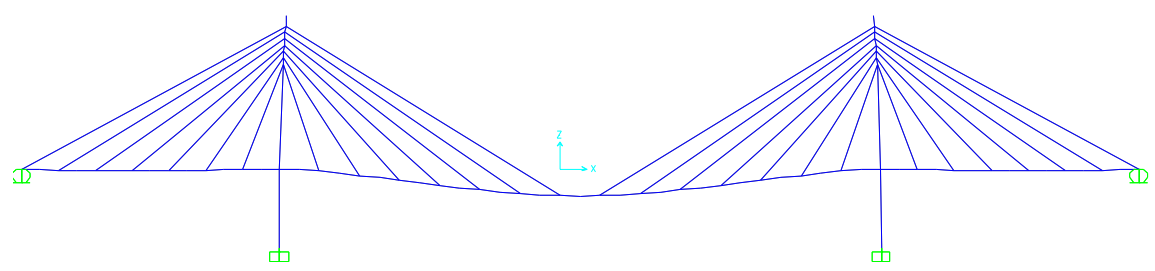

B)

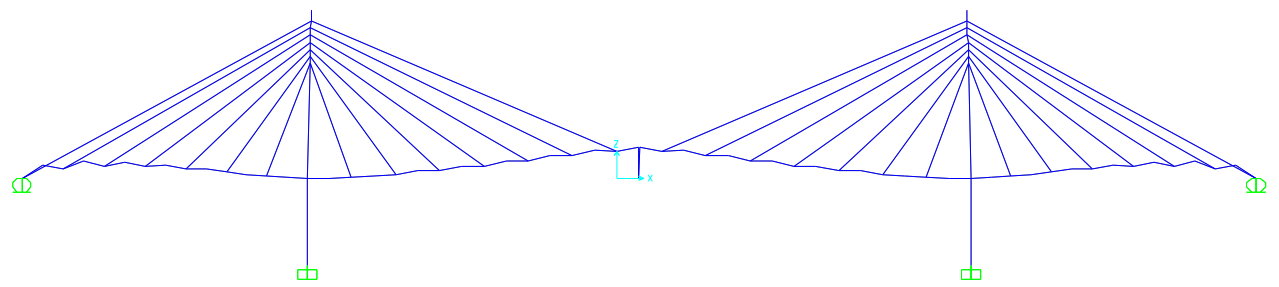

C)

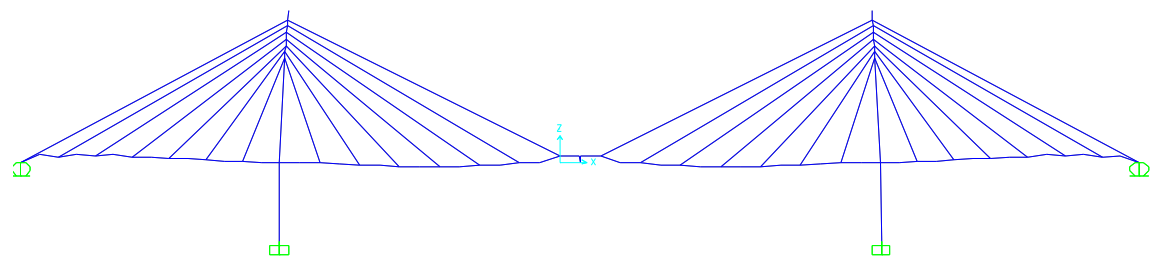

D)

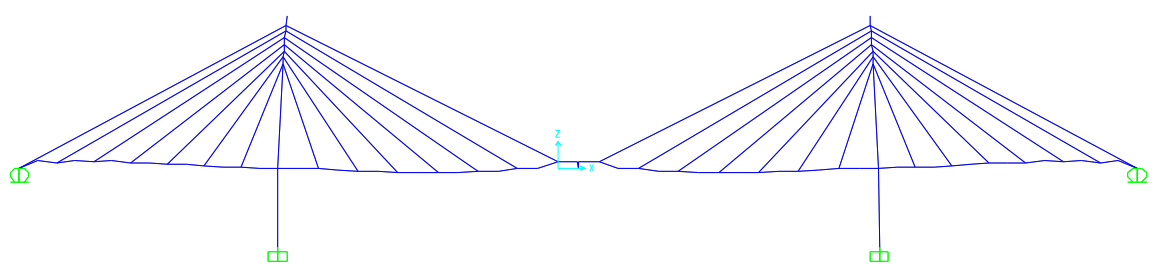

E)

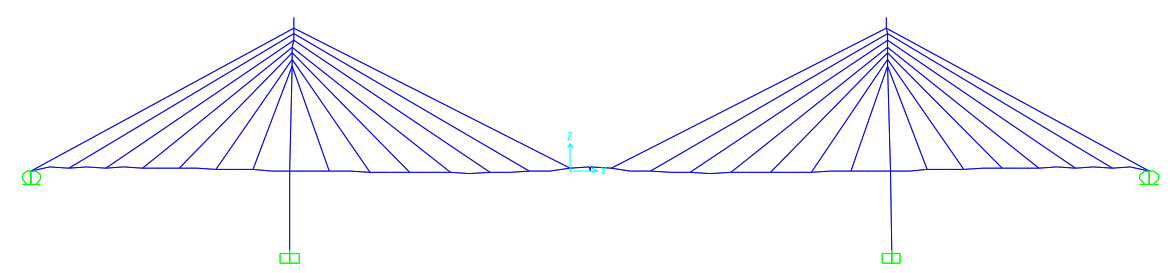

Figura 6.24: A) Deformada da ponte ao final do evolutivo sem protensão dos estais, B) Deformada da ponte com forças do MTA, C) Deformada da ponte com forças do MAD, D) Deformada da ponte com forças do MAR, E) Deformada da ponte com forças do MAD evolutivo 


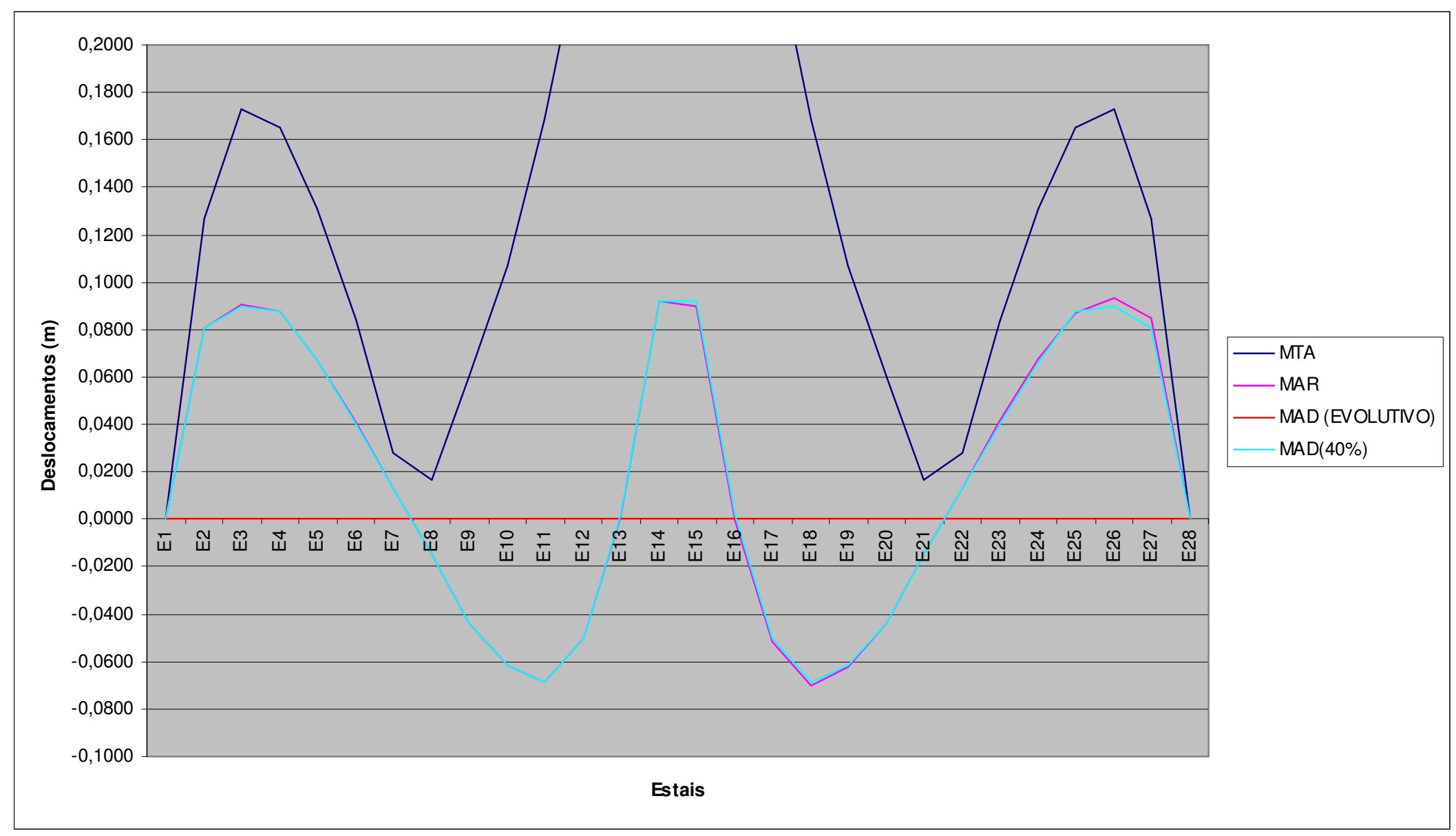

Figura 6.25: Diagrama dos deslocamentos dos evolutivos dos métodos e o processo construtivo para o primeiro exemplo 
A)

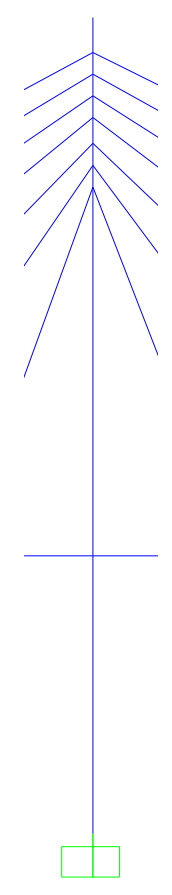

B)

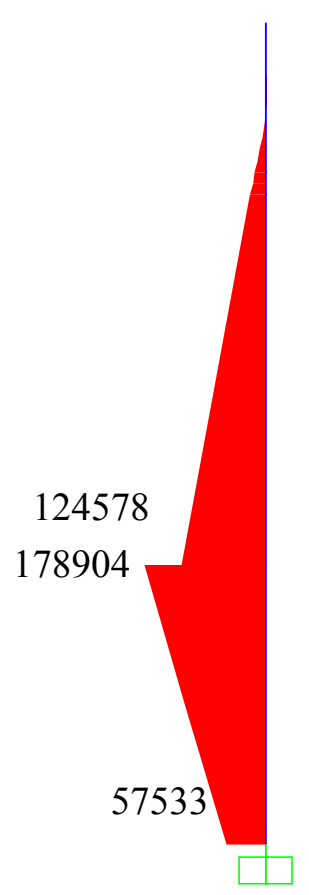

C)

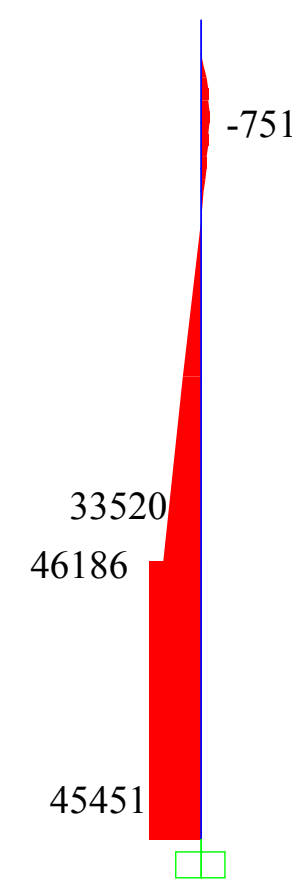

D)

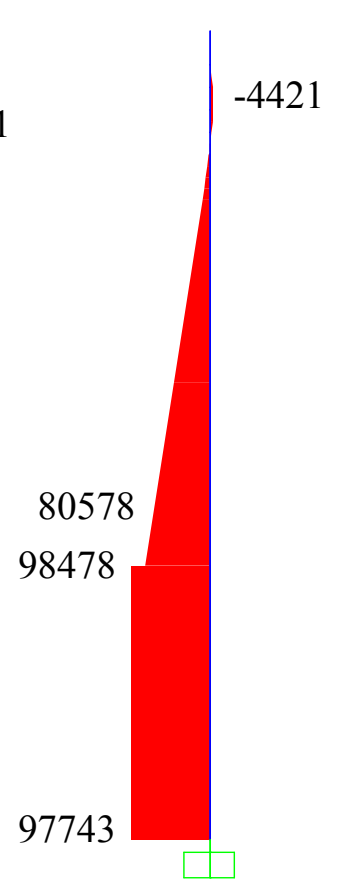

E)

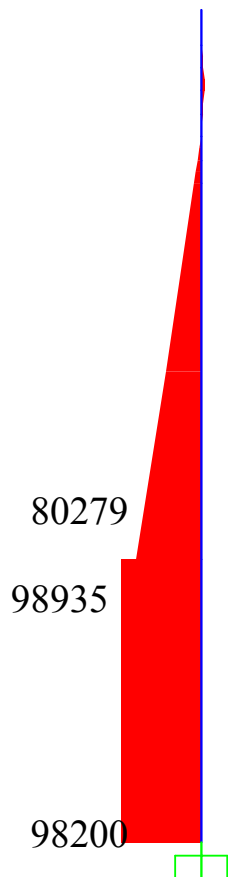

F)

40283

50234

49499

Figura 6.26: A) Forma do mastro, B) Momento no mastro devido ao peso-próprio sem protensão dos estais(fase final), C) Momento no mastro com forças do MTA, D) Momento no mastro com forças do MAD, E) Momento no mastro com forças do MAR, F) Momento do mastro com forças do MAD evolutivo (unidades: $k N$, m) 
A)

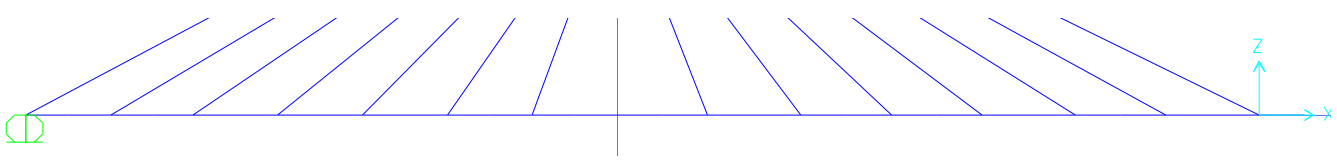

B)

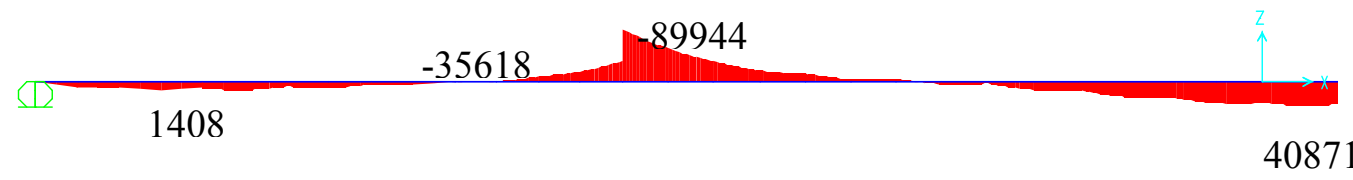

C)

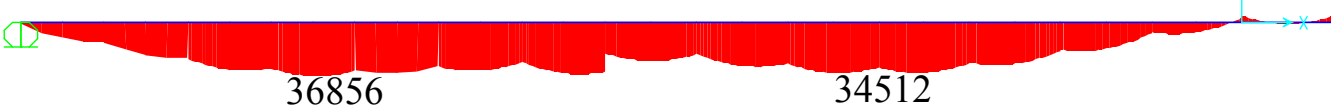

D)
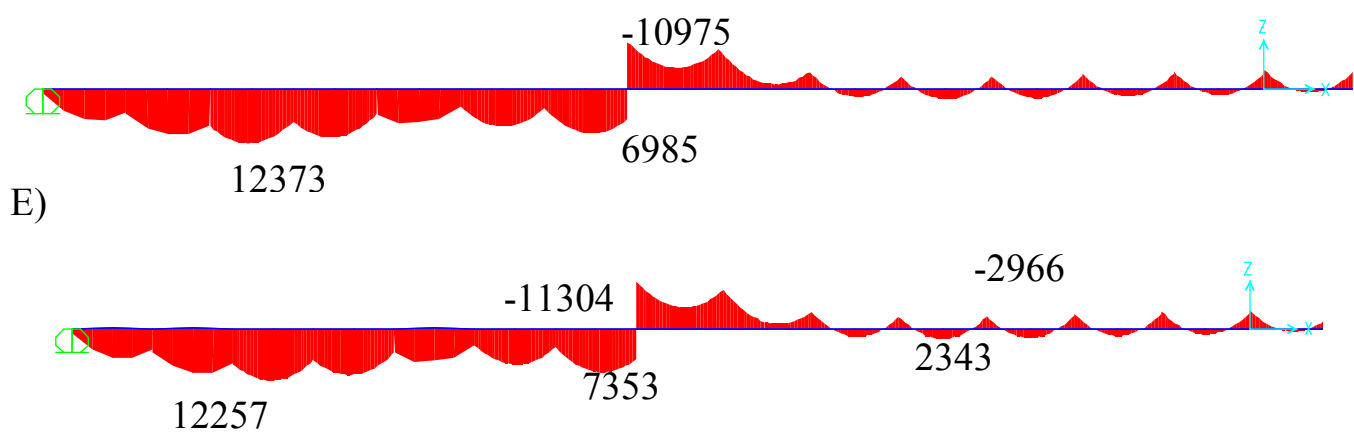

F)

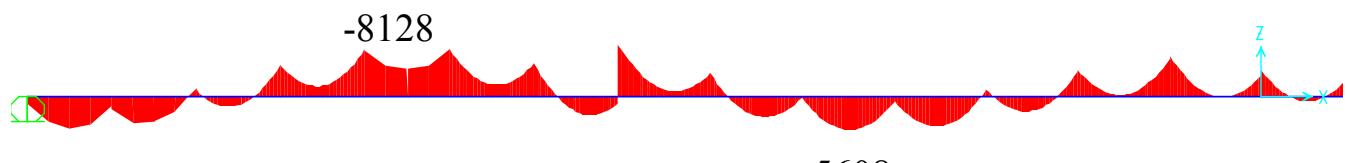

5608

Figura 6.27: A) Forma do tabuleiro (metade), B) Momento do tabuleiro devido ao peso-próprio sem protensão dos estais, C) Momento no tabuleiro com forças do MTA, D) Momento no tabuleiro com forçaso do MAD, E) Momento no tabuleiro com forças do MAR, F) Momento do tabuleiro com forças do MAD evolutivo (unidades: $k N, m$ )

Desses exemplos se conclui que nenhum dos métodos estudados fornecem flechas próximas ou diagramas de momentos próximos de zero no evolutivo. O melhor método é o MAD evolutivo para as flechas e o MAR para os momentos.

Uma solução mais complexa que melhoraria estes resultados é um método que a cada fase construtiva realizasse o MAD. Este método poderia se chamar MAD evolutivo com correção fase a fase. 


\subsection{Segundo exemplo: Ponte Construtor João Alves}

Da mesma forma que no primeiro exemplo, são apresentados os resultados e as comparações realizadas para os quatro métodos analisados.

\subsubsection{Método do tabuleiro articulado em todos os estais (MTA)}

Da mesma forma que no exemplo anterior, obtem-se os seguintes resultados (Tabela $6.12)$.

Tabela 6.12: Avaliação isostática das forças nos estais para a Ponte Construtor João Alves

\begin{tabular}{|c|c|c|c|c|c|c|c|}
\hline Estai & $\mathbf{\Delta} \mathbf{T}(\mathbf{}(\mathbf{C}) \mathbf{)}$ & $\begin{array}{c}\text { Força } \\
(\mathbf{k N})\end{array}$ & $\begin{array}{c}\text { Deslocamento } \\
(\mathbf{m})\end{array}$ & Estai & $\mathbf{\Delta} \mathbf{T}(\mathbf{-} \mathbf{C}) \mathbf{)}$ & $\begin{array}{c}\text { Força } \\
(\mathbf{k N})\end{array}$ & $\begin{array}{c}\text { Deslocamento } \\
(\mathbf{m})\end{array}$ \\
\hline E1 & -228.68 & 7006,7 & $-0,0241$ & E29 & -231.76 & 7602,1 & 0,5228 \\
\hline E2 & -225.33 & 6282,1 & $-0,0103$ & E30 & -217.97 & 6138,6 & 0,5096 \\
\hline E3 & -221.75 & 5446 & $-0,0007$ & E31 & -221.23 & 5563,7 & 0,4856 \\
\hline E4 & -224.46 & 5128,6 & $-0,0013$ & E32 & -203.44 & 4166,4 & 0,4531 \\
\hline E5 & -225.65 & 4826,2 & $-0,0056$ & E33 & -240.39 & 5378,2 & 0,4151 \\
\hline E6 & -223.22 & 4549,7 & $-0,0103$ & E34 & -219.78 & 4270,7 & 0,3733 \\
\hline E7 & -221.24 & 4198,8 & $-0,0148$ & E35 & -217.73 & 3931 & 0,3299 \\
\hline E8 & -218.68 & 4009 & $-0,0186$ & E36 & -210.86 & 3608,4 & 0,2865 \\
\hline E9 & -210.62 & 3536,9 & $-0,0214$ & E37 & -216.04 & 3669,3 & 0,2439 \\
\hline E10 & -220.99 & 3759,5 & $-0,0233$ & E38 & -207.56 & 3300,9 & 0,2024 \\
\hline E11 & -208.3 & 3481,7 & $-0,0247$ & E39 & -214.81 & 3703,5 & 0,1618 \\
\hline E12 & -215.69 & 3821,5 & $-0,0259$ & E40 & -201.62 & 3462,4 & 0,1217 \\
\hline E13 & -214.56 & 4054,4 & $-0,0267$ & E41 & -211.33 & 4027,3 & 0,0826 \\
\hline E14 & -67.807 & 1065,1 & $-0,0250$ & E42 & -69.146 & 1154,6 & 0,0460 \\
\hline E15 & -69.146 & 1154,6 & 0,0460 & E43 & -67.807 & 1065,1 & $-0,0250$ \\
\hline E16 & -211.33 & 4027,3 & 0,0826 & E44 & -214.56 & 4054,4 & $-0,0267$ \\
\hline E17 & -201.62 & 3462,4 & 0,1217 & E45 & -215.69 & 3821,5 & $-0,0259$ \\
\hline E18 & -214.81 & 3703,5 & 0,1618 & E46 & -208.3 & 3481,7 & $-0,0247$ \\
\hline E19 & -207.56 & 3300,9 & 0,2024 & E47 & -220.99 & 3759,5 & $-0,0233$ \\
\hline E20 & -216.04 & 3669,3 & 0,2439 & E48 & -210.62 & 3536,9 & $-0,0214$ \\
\hline E21 & -210.86 & 3608,4 & 0,2865 & E49 & -218.68 & 4009 & $-0,0186$ \\
\hline E22 & -217.73 & 3931 & 0,3299 & E50 & -221.24 & 4198,8 & $-0,0148$ \\
\hline E23 & -219.78 & 4270,7 & 0,3733 & E51 & -223.22 & 4549,7 & $-0,0103$ \\
\hline E24 & -240.39 & 5378,2 & 0,4151 & E52 & -225.65 & 4826,2 & $-0,0056$ \\
\hline E25 & -203.44 & 4166,4 & 0,4531 & E53 & -224.46 & 5128,7 & $-0,0013$ \\
\hline E26 & -221.23 & 5563,7 & 0,4856 & E54 & -221.75 & 5446 & $-0,0007$ \\
\hline E27 & -217.97 & 6138,6 & 0,5096 & E55 & -225.33 & 6282,1 & $-0,0103$ \\
\hline E28 & -231.76 & 7602,1 & 0,5228 & E56 & -228.68 & 7006,6 & $-0,0241$ \\
\hline & & & & & & & \\
\hline
\end{tabular}

Observa-se que neste segundo exemplo as forças nos estais apresentam o mesmo comportamento que no exemplo anterior (Figura 6.28). Nota-se uma diferença importante nos esforços dos estais próximos ao mastro com respeito aos demais. 
Neste caso a extensão do tabuleiro não acaba junto com os estais no apoio extremo. O tabuleiro se prolonga até os pilares secundários. Existe um engastamento entre o tabuleiro e o mastro, portanto, os estais E14 e E15 assim como o E42 e E43 suportam apenas parte de uma aduela. Assim, estes apresentam esforços menores que os estais vizinhos. Outro engastamento está presente na união do tabuleiro com o pilar secundário.

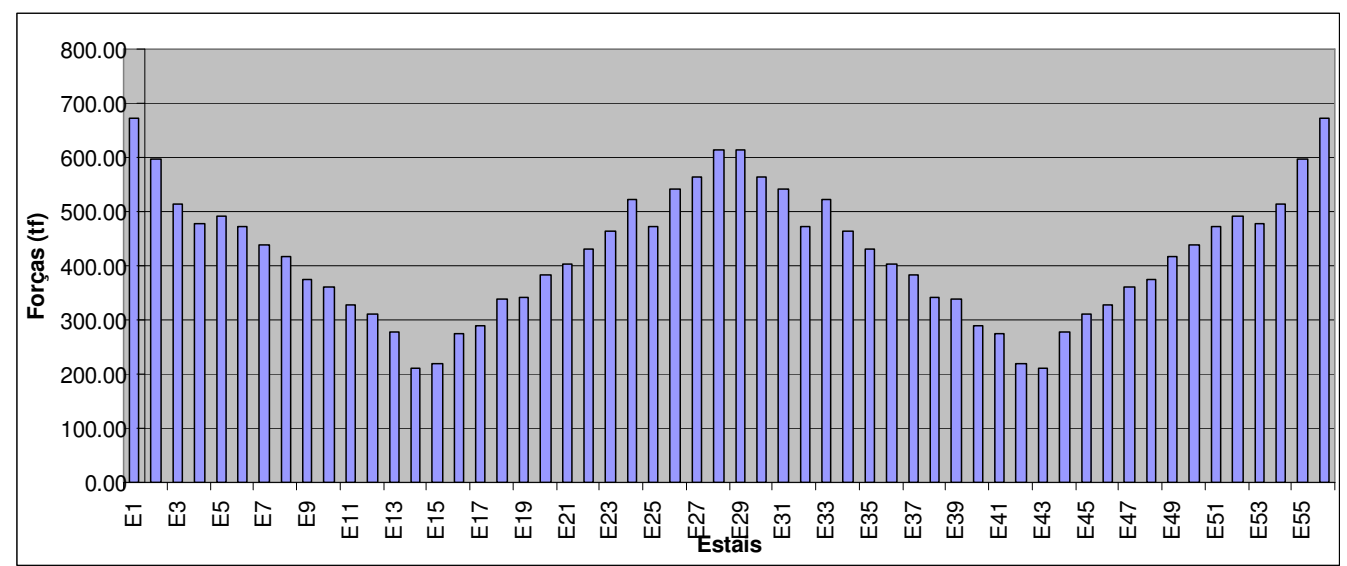

Figura 6.28: Distribuição de esforços dos estais do segundo exemplo (MTA)

Os deslocamentos obtidos com este método não são nulos obtendo-se assim uma contra-flecha no meio do vão (Figura 6.29).

A)

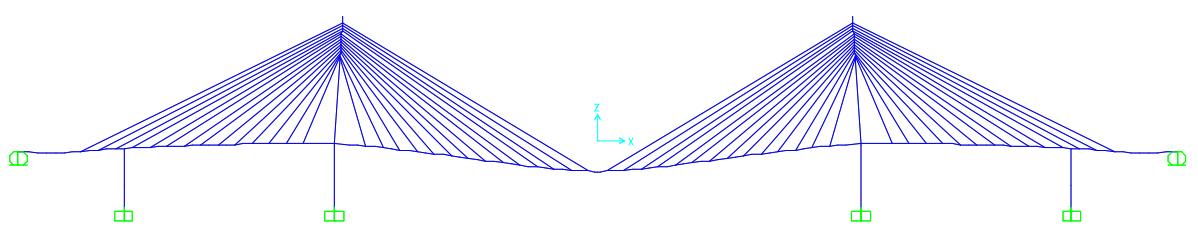

B)

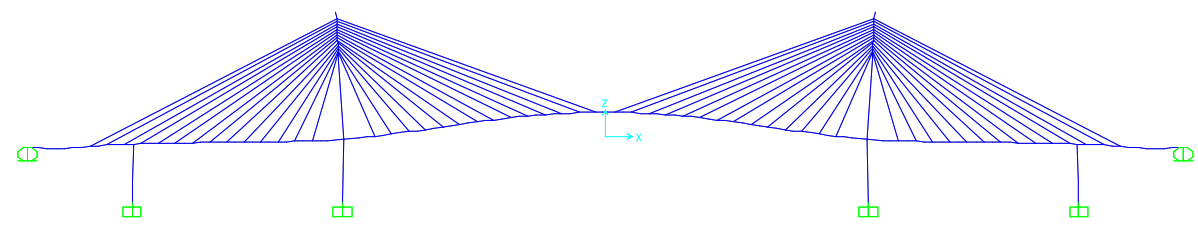

Figura 6.29: A) Deformada da ponte sem protensão dos estais, B) Deformada da ponte com forças do $M T A$

Como aconteceu no primeiro exemplo o diagrama de momentos é contraria ao momento resultante do peso-próprio Figura 6.30 e Figura 6.31. 
A)

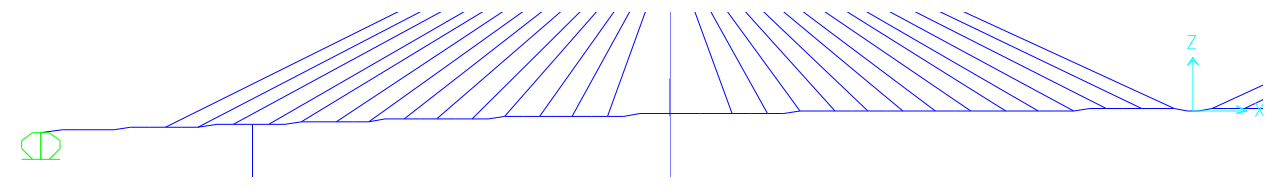

B)

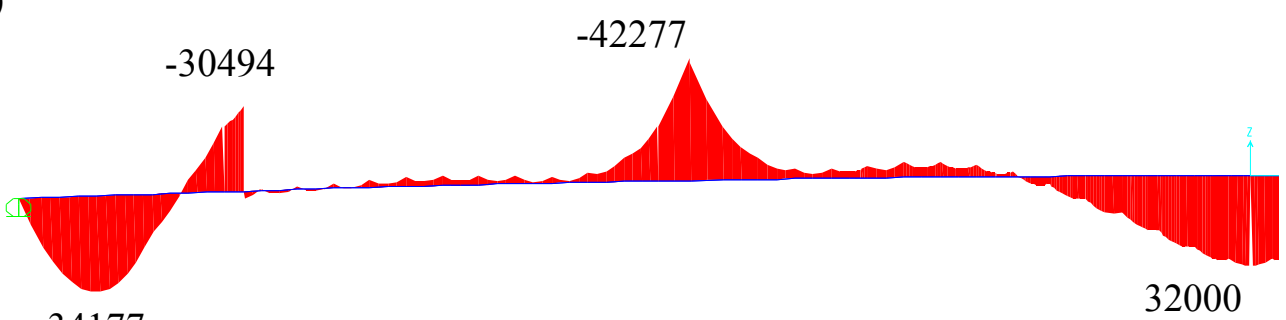

34177

C)

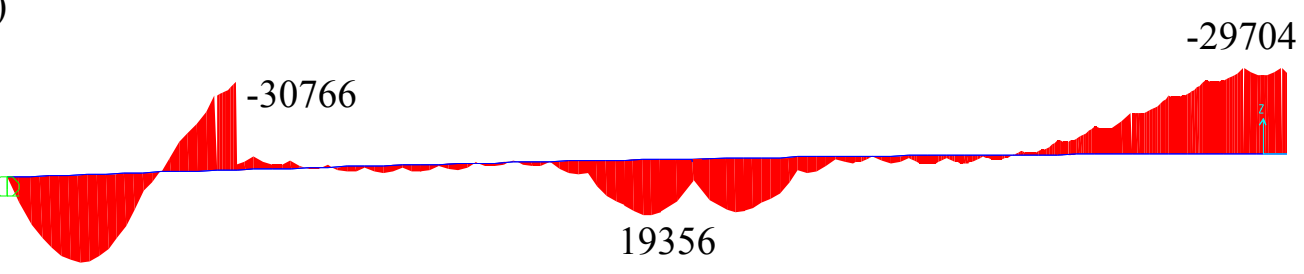

30028

Figura 6.30: A) Forma do tabuleiro (metade), B) Momento no tabuleiro devido ao peso próprio sem protensão dos estais, C)Momento no tabuleiro com forças do MTA(unidades: $k N, m$ ) 
A)

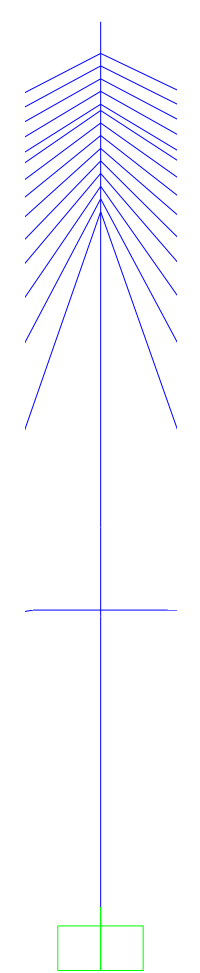

B)

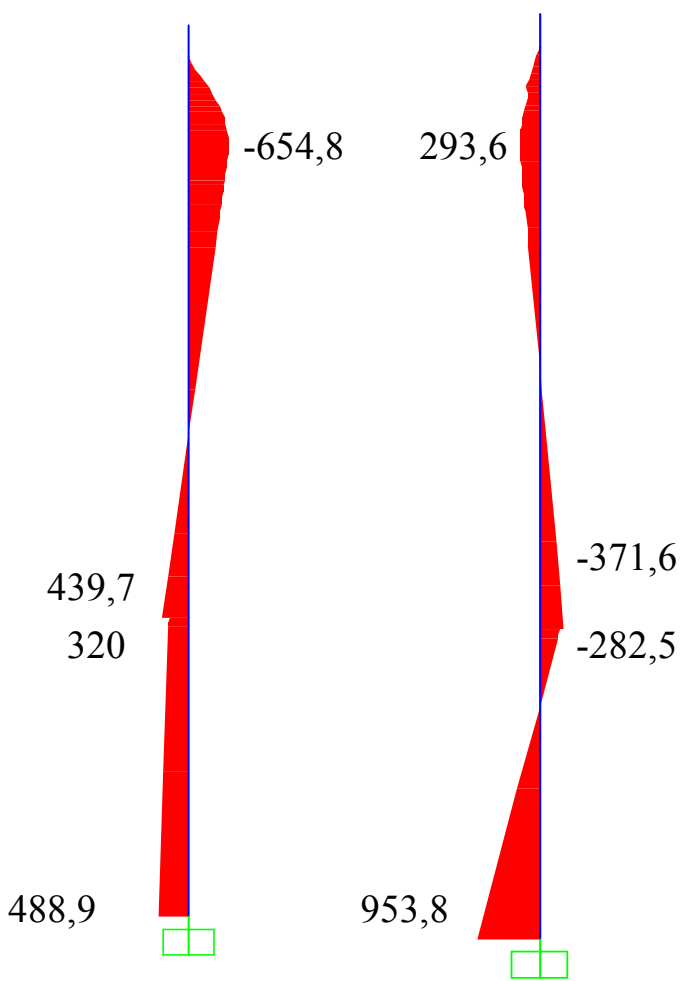

C)

$-371,6$

$-282,5$

Figura 6.31: A) Forma do mastro, B) Momento no mastro devido ao peso-próprio sem protensão dos estais, $C$ ) Momento no mastro com forças do MTA(unidades: $k N, m$ ) 


\subsubsection{Método de anulação dos deslocamentos (MAD)}

Para este método, criaram-se 56 carregamentos. Foram realizados todos os cálculos pertinentes ao método, tendo como resultado os valores apresentados na Tabela 6.13.

Tabela 6.13: Distribuição de esforços e temperaturas dos estais e deslocamentos da Ponte Construtor João Alves (MAD)

\begin{tabular}{|c|c|c|c|c|c|c|c|}
\hline Estai & $\mathbf{\Delta} \mathbf{T}\left({ }^{\circ} \mathbf{C}\right) \mathbf{)}$ & $\begin{array}{c}\text { Força } \\
(\mathbf{k N})\end{array}$ & $\begin{array}{c}\text { Deslocamento } \\
(\mathbf{m})\end{array}$ & Estai & $\mathbf{\Delta} \mathbf{T}(\mathbf{} \mathbf{C}))$ & $\begin{array}{c}\text { Força } \\
(\mathbf{k N})\end{array}$ & $\begin{array}{c}\text { Deslocamento } \\
(\mathbf{m})\end{array}$ \\
\hline E1 & $-115,83$ & 6342,9 & $-0,0297$ & E29 & $-131,14$ & 6522,8 & $-0,0007$ \\
\hline E2 & $-115,76$ & 5941,2 & $-0,0146$ & E30 & $-112,36$ & 5391,2 & $-0,0014$ \\
\hline E3 & $-114,64$ & 5355,5 & $-0,0024$ & E31 & $-117,33$ & 5356,9 & $-0,0022$ \\
\hline E4 & $-119,80$ & 5251,9 & 0,0002 & E32 & $-102,30$ & 4383,9 & $-0,0030$ \\
\hline E5 & $-122,40$ & 5077,9 & $-0,0006$ & E33 & $-140,77$ & 5821,8 & $-0,0035$ \\
\hline E6 & $-115,30$ & 4646,1 & $-0,0017$ & E34 & $-116,71$ & 4646,1 & $-0,0042$ \\
\hline E7 & $-110,51$ & 4192,4 & $-0,0023$ & E35 & $-112,52$ & 4215,9 & $-0,0047$ \\
\hline E8 & $-102,68$ & 3758,6 & $-0,0018$ & E36 & $-100,06$ & 3612,8 & $-0,0043$ \\
\hline E9 & $-97,41$ & 3275,6 & 0,0000 & E37 & $-106,33$ & 3566,5 & $-0,0027$ \\
\hline E10 & $-117,42$ & 3596 & 0,0029 & E38 & $-105,32$ & 3202,8 & $-0,0003$ \\
\hline E11 & $-117,46$ & 3352,1 & 0,0055 & E39 & $-123,36$ & 3567,6 & 0,0021 \\
\hline E12 & $-148,15$ & 3881,2 & 0,0064 & E40 & $-132,34$ & 3481,5 & 0,0031 \\
\hline E13 & $-172,64$ & 4215,6 & 0,0046 & E41 & $-167,53$ & 4141,7 & 0,0018 \\
\hline E14 & $-46,48$ & 1164,4 & 0,0005 & E42 & $-46,41$ & 1212,1 & $-0,0013$ \\
\hline E15 & $-46,41$ & 1212,1 & $-0,0013$ & E43 & $-46,48$ & 1164,4 & 0,0005 \\
\hline E16 & $-167,53$ & 4141,7 & 0,0018 & E44 & $-172,64$ & 4215,6 & 0,0046 \\
\hline E17 & $-132,34$ & 3481,6 & 0,0031 & E45 & $-148,15$ & 3881,2 & 0,0064 \\
\hline E18 & $-123,35$ & 3567,6 & 0,0021 & E46 & $-117,45$ & 3352 & 0,0055 \\
\hline E19 & $-105,32$ & 3202,9 & $-0,0003$ & E47 & $-117,41$ & 3596 & 0,0029 \\
\hline E20 & $-106,32$ & 3566,5 & $-0,0027$ & E48 & $-97,41$ & 3275,6 & 0,0000 \\
\hline E21 & $-100,05$ & 3612,8 & $-0,0043$ & E49 & $-102,68$ & 3758,5 & $-0,0018$ \\
\hline E22 & $-112,51$ & 4215,9 & $-0,0047$ & E50 & $-110,51$ & 4192,3 & $-0,0023$ \\
\hline E23 & $-116,70$ & 4646 & $-0,0043$ & E51 & $-115,30$ & 4646 & $-0,0017$ \\
\hline E24 & $-140,77$ & 5821,6 & $-0,0035$ & E52 & $-122,41$ & 5077,9 & $-0,0006$ \\
\hline E25 & $-102,30$ & 4383,7 & $-0,0030$ & E53 & $-119,80$ & 5251,8 & 0,0002 \\
\hline E26 & $-117,33$ & 5356,7 & $-0,0022$ & E54 & $-114,65$ & 5355,4 & $-0,0024$ \\
\hline E27 & $-112,36$ & 5391,1 & $-0,0014$ & E55 & $-115,77$ & 5941,1 & $-0,0145$ \\
\hline E28 & $-131,15$ & 6522,8 & $-0,0007$ & E56 & $-115,86$ & 6343,8 & $-0,0297$ \\
\hline
\end{tabular}

A distribuição de esforços não é harmoniosa, obtendo-se assim uma variação nas proximidades do pilar secundário e o mastro. Os resultados indicam um aumento na tensão do estai a medida que atinge o meio do vão (Figura 6.32). 


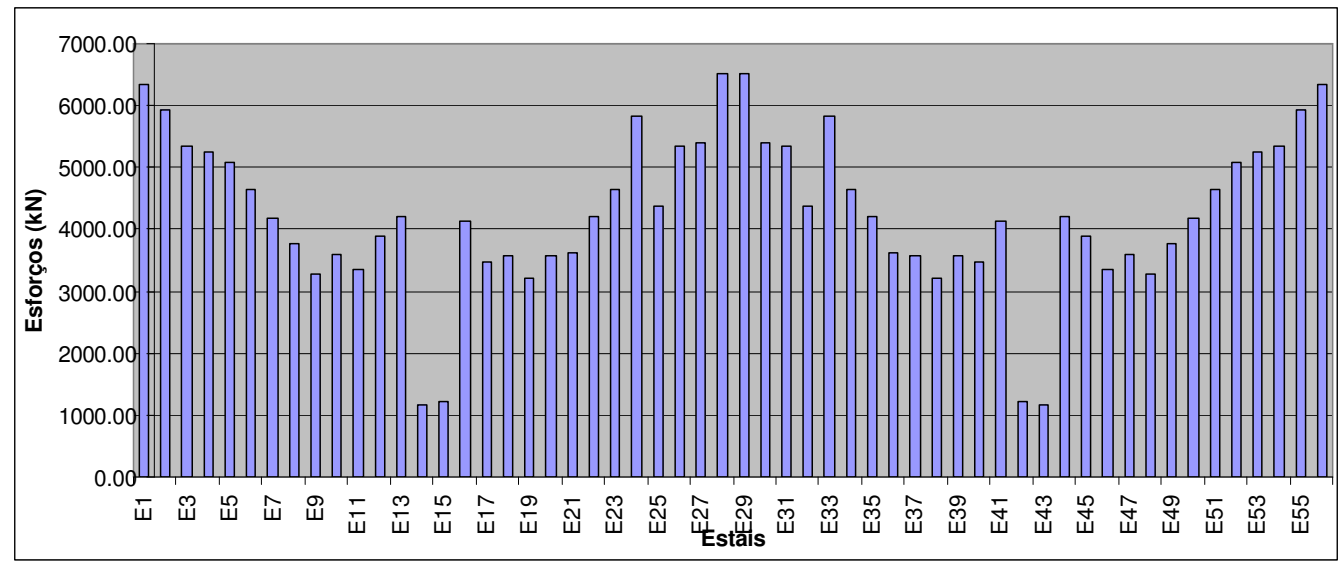

Figura 6.32: Distribuição de esforços dos estais da Ponte Construtor João Alves (MAD)

O deslocamento central da ponte devido ao peso-próprio é de 0,58m (Figura 6.33-A). Após de aplicadas as temperaturas, a ponte apresenta uma deformação máxima no meio do vão de 0,0006m (Figura 6.33-B).

A)

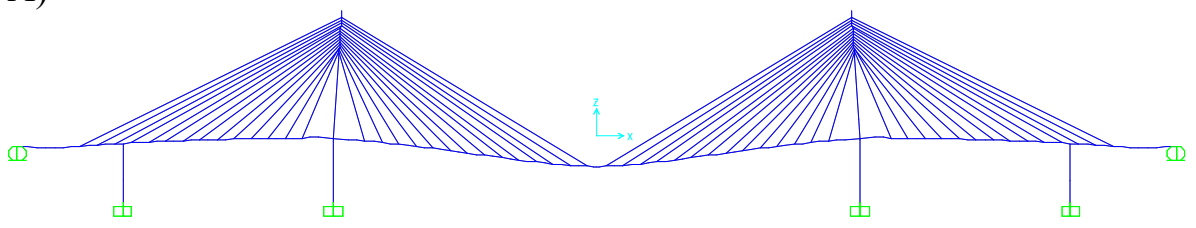

B)

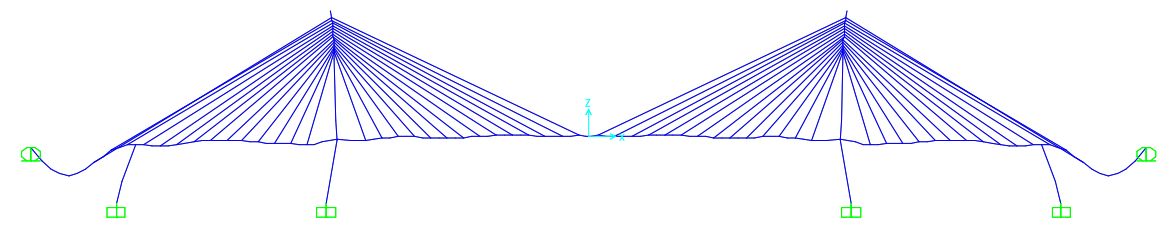

Figura 6.33: A) Deformada da ponte sem porotensão dos estais, B) Deformada da ponte com forças do $M A D$

O diagrama de momentos não apresenta um formato de viga continua esperado. No meio do vão, observa-se uma distribuição de momentos similar, mas com valores menores, a do MTA Figura 6.34. O diagrama de momentos do mastro, apresenta-se na Figura 6.35. 
A)

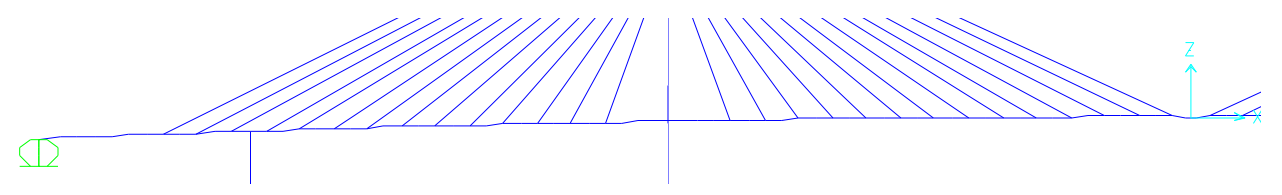

B)

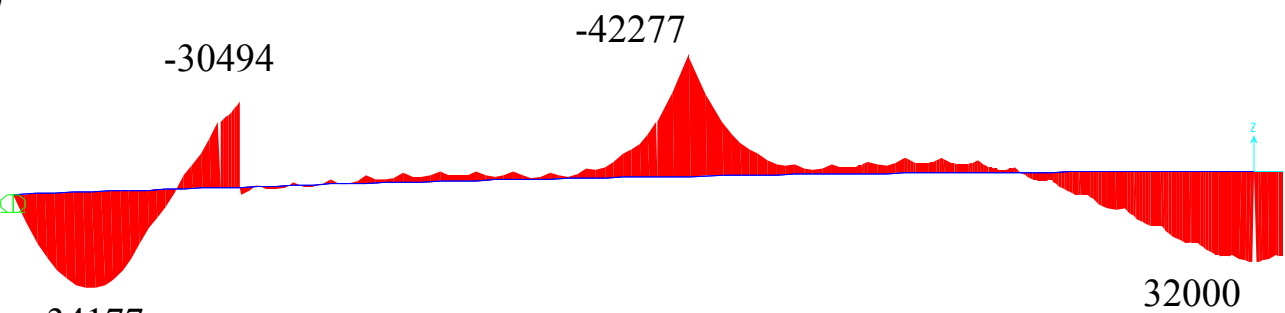

34177

C)

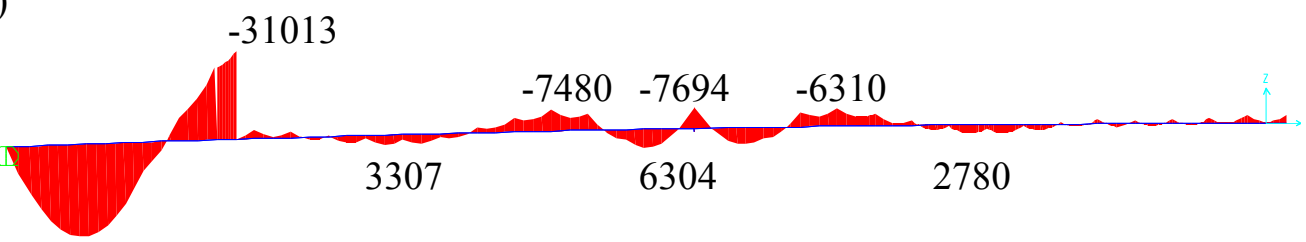

32134

Figura 6.34: A) Forma do tabuleiro (metade), B) Momento no tabuleiro devido ao peso próprio sem protensão dos estais, C)Momento no tabuleiro com forças do MAD(unidades: $k N, m$ ) 
A)

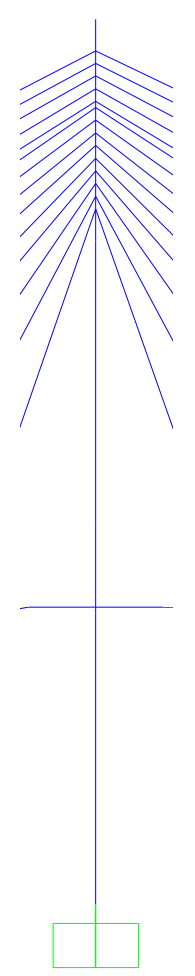

B)

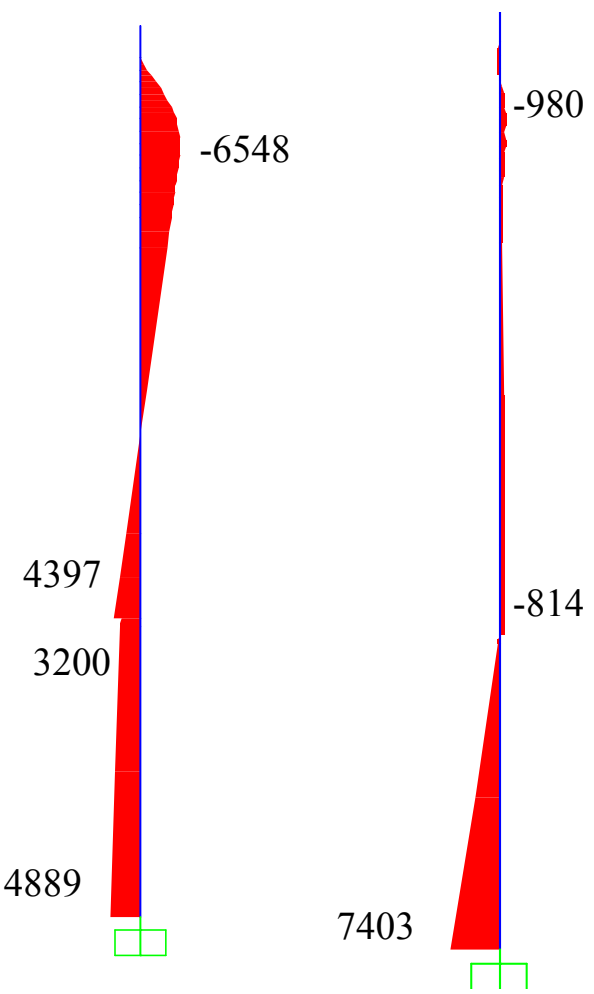

C)

980

Figura 6.35: A) Forma do mastro, B) Momento no mastro devido ao peso-próprio sem protensão dos estais, $C$ ) Momento no mastro com forças do MAD(unidades: $k N, m$ ) 


\subsubsection{Método de anulação das reações em apoios fictícios (MAR)}

Assim como no MAD, foram criados 56 carregamentos. Realizaram-se todos os cálculos pertinentes ao método, tendo como resultado os valores apresentados na Tabela 6.14.

Tabela 6.14: Distribuição de esforços e temperaturas dos estais da Ponte Construtor João Alves (MAR)

\begin{tabular}{|c|c|c|c|c|c|c|c|}
\hline Estai & $\left.\Delta \mathrm{T}\left({ }^{\circ} \mathrm{C}\right)\right)$ & $\begin{array}{l}\text { Força } \\
(\mathrm{kN})\end{array}$ & $\begin{array}{c}\text { Deslocamento } \\
(\mathrm{m})\end{array}$ & Estai & $\left.\Delta \mathrm{T}\left({ }^{\circ} \mathrm{C}\right)\right)$ & $\begin{array}{l}\text { Força } \\
(\mathbf{k N})\end{array}$ & $\begin{array}{c}\text { Deslocamento } \\
(\mathrm{m})\end{array}$ \\
\hline E1 & -54.31 & 2758,4 & -8.56E-06 & E29 & -116.30 & 6173,6 & 5.34E-07 \\
\hline E2 & -102.68 & 4852,9 & $-8.54 \mathrm{E}-06$ & E30 & -108.50 & 5615,9 & 3.54E-07 \\
\hline E3 & -175.39 & 7801,1 & $-8.51 E-06$ & E31 & -109.53 & 5373,1 & 1.02E-07 \\
\hline E4 & -173.23 & 7127,6 & $9.11 \mathrm{E}-08$ & E32 & -102.24 & 4753 & $-1.66 \mathrm{E}-07$ \\
\hline E5 & -155.60 & 5879,8 & 2.83E-07 & E33 & -120.24 & 5274,4 & $-3.88 \mathrm{E}-07$ \\
\hline E6 & -129.36 & 4560,1 & 4.34E-07 & E34 & -108.22 & 4614,6 & $-5.21 E-07$ \\
\hline E7 & -127.59 & 4208,7 & $5.18 \mathrm{E}-07$ & E35 & -106.91 & 4293,2 & $-5.78 \mathrm{E}-07$ \\
\hline E8 & -126.19 & 4039,3 & $5.40 \mathrm{E}-07$ & E36 & -102.85 & 4019,1 & $-5.61 E-07$ \\
\hline E9 & -122.10 & 3651,7 & 4.93E-07 & E37 & -104.85 & 3841,7 & $-4.90 \mathrm{E}-07$ \\
\hline E10 & -126.70 & 3564,6 & 4.19E-07 & E38 & -99.98 & 3415,7 & $-3.87 E-07$ \\
\hline E11 & -119.75 & 3252,9 & 3.65E-07 & E39 & -101.56 & 3357,4 & $-2.80 \mathrm{E}-07$ \\
\hline E12 & -121.58 & 3077,2 & 3.39E-07 & E40 & -94.89 & 2893,6 & $-1.73 \mathrm{E}-07$ \\
\hline E13 & -103.78 & 2390 & 3.04E-07 & E41 & -94.11 & 2606,4 & $-1.29 E-07$ \\
\hline E14 & -176.85 & 4377,6 & 2.27E-07 & E42 & -120.87 & 3285 & $-8.56 \mathrm{E}-08$ \\
\hline E15 & -120.87 & 3285 & $-3.01 E-07$ & E43 & -176.85 & 4377,6 & $-4.48 E-08$ \\
\hline E16 & -94.11 & 2606,4 & $-4.38 \mathrm{E}-07$ & E44 & -103.78 & 2390 & $-1.08 \mathrm{E}-07$ \\
\hline E17 & -94.89 & 2893,6 & $-5.73 E-07$ & E45 & -121.58 & 3077,2 & $-1.88 \mathrm{E}-07$ \\
\hline E18 & -101.56 & 3357,4 & $-7.49 \mathrm{E}-07$ & E46 & -119.75 & 3252,9 & $-2.61 E-07$ \\
\hline E19 & -99.98 & 3415,7 & $-8.89 E-07$ & E47 & -126.70 & 3564,6 & $-2.92 \mathrm{E}-07$ \\
\hline E20 & -104.85 & 3841,7 & $-9.74 \mathrm{E}-07$ & E48 & -122.10 & 3651,7 & $-2.76 \mathrm{E}-07$ \\
\hline E21 & -102.85 & 4019 & $-9.72 \mathrm{E}-07$ & E49 & -126.19 & 4039,3 & $-2.45 \mathrm{E}-07$ \\
\hline E22 & -106.91 & 4293,2 & $-8.71 E-07$ & E50 & -127.59 & 4208,7 & $-2.21 \mathrm{E}-07$ \\
\hline E23 & -108.22 & 4614,6 & $-6.83 E-07$ & E51 & -129.36 & 4560,1 & $-1.82 \mathrm{E}-07$ \\
\hline E24 & -120.24 & 5274,4 & $-4.08 \mathrm{E}-07$ & E52 & -155.60 & 5879,7 & $-1.29 \mathrm{E}-07$ \\
\hline E25 & -102.24 & 4753 & $-7.26 \mathrm{E}-08$ & E53 & -173.23 & 7127,5 & $-5.50 \mathrm{E}-08$ \\
\hline E26 & -109.53 & 5373,2 & $2.52 \mathrm{E}-07$ & E54 & -175.39 & 7801,1 & $-8.51 \mathrm{E}-06$ \\
\hline E27 & -108.50 & 5615,8 & 4.94E-07 & E55 & -102.68 & 4852,8 & $-8.54 \mathrm{E}-06$ \\
\hline E28 & -116.30 & 6173,6 & $6.01 \mathrm{E}-07$ & E56 & -54.31 & 2758,4 & $-8.56 \mathrm{E}-06$ \\
\hline
\end{tabular}

A distribuição de esforços resultante apresenta valores maiores no meio do vão, perto do pilar secundário e logo depois do mastro. Os estais de estabilidade dos extremos (E1 e E56) tem como resultado tensões menores devido a que neste caso o método atinge a convergência com valores de temperatura maiores na região próxima ao pilar secundário (Figura 6.36). 


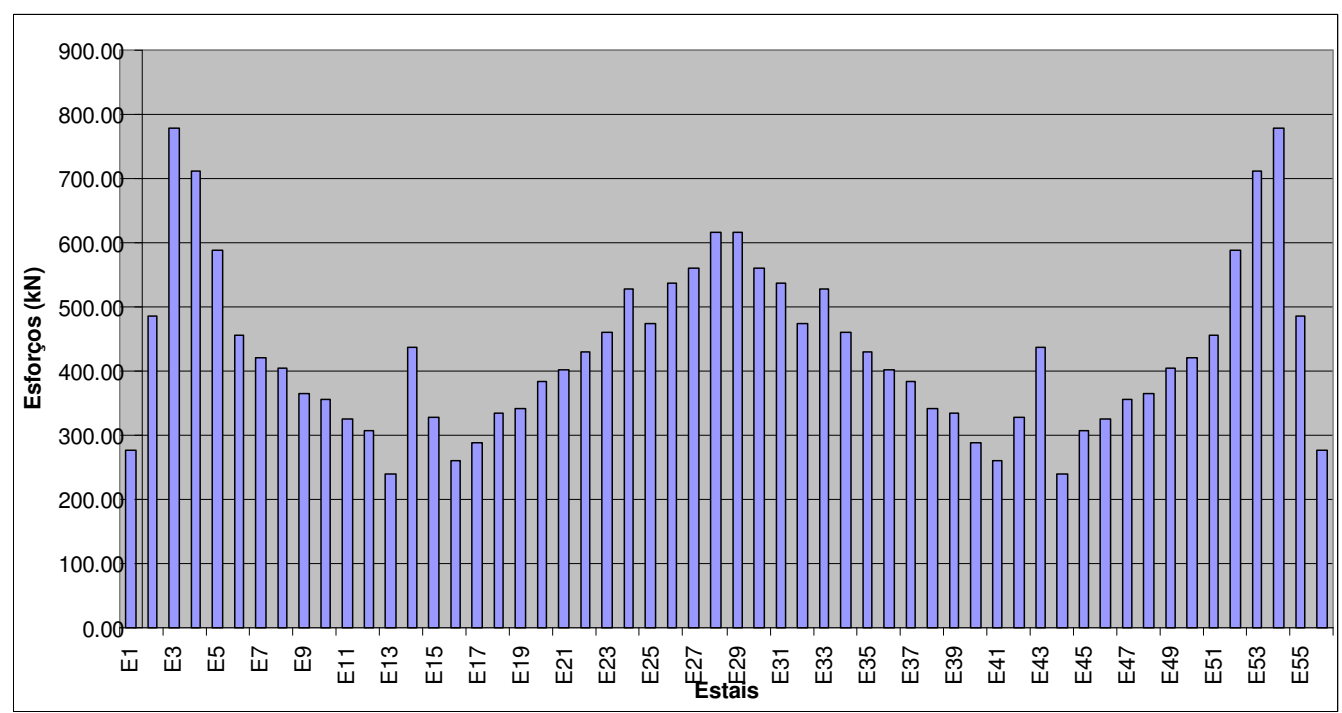

Figura 6.36: Distribuição de esforços dos estais da Ponte Construtor João Alves (MAR)

O deslocamento central da ponte devido ao peso-próprio é de 0,58m (Figura 6.37A). Após de aplicadas as temperaturas, a ponte apresenta uma deformação máxima no meio do vão de 0,008 m (Figura 6.37-B).

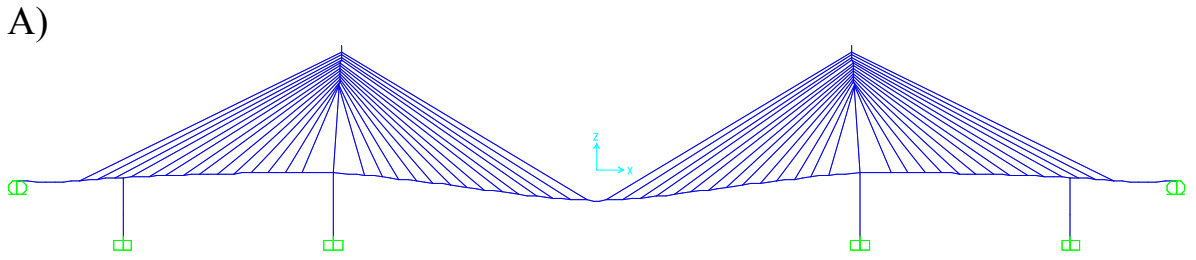

B)

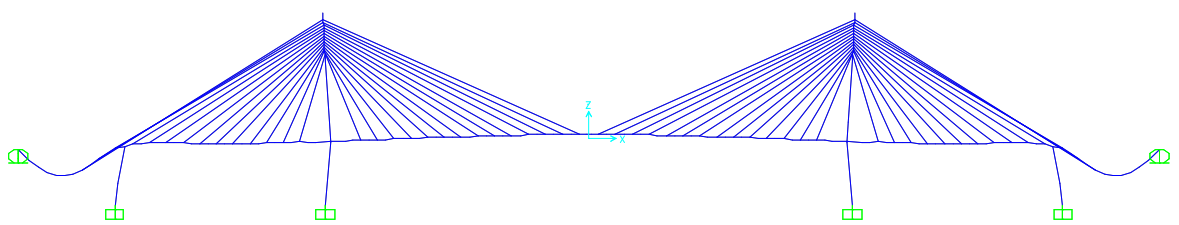

Figura 6.37: A) Deformada da ponte sem protensão dos estais, B) Deformada da ponte com forças do MAR

Observa-se que o diagrama de momentos deste método apresentam um resultado otimizado Figura 6.38. Nota-se que a distribuição de momentos é similar à de uma viga continua. O diagrama de momentos do mastro se apresenta na Figura 6.39 
A)

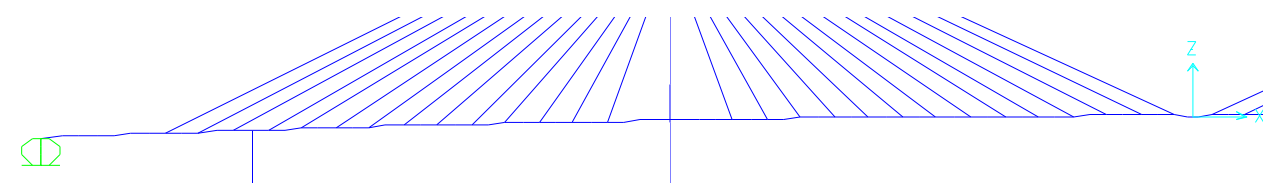

B)

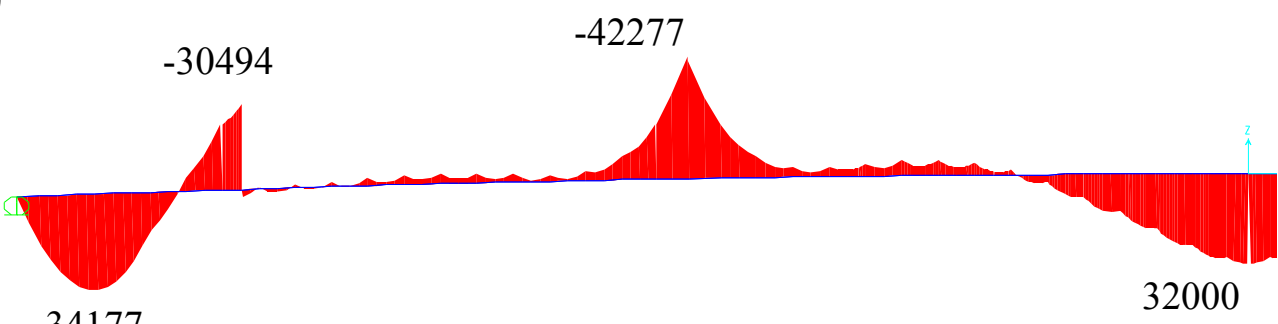

C)

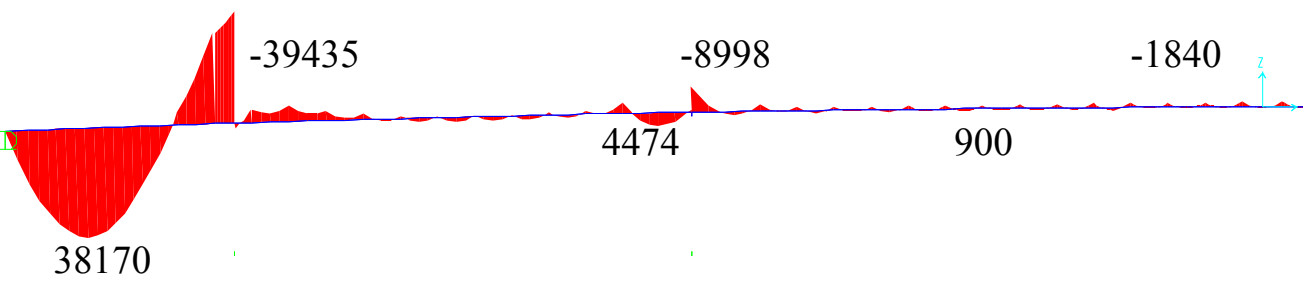

Figura 6.38: A) Forma do tabuleiro (metade), B) Momento no tabuleiro devido ao peso próprio sem protensão dos estais, C)Momento no tabuleiro com forças do MAR(unidades: $\mathrm{kN}, \mathrm{m}$ ) 
A)

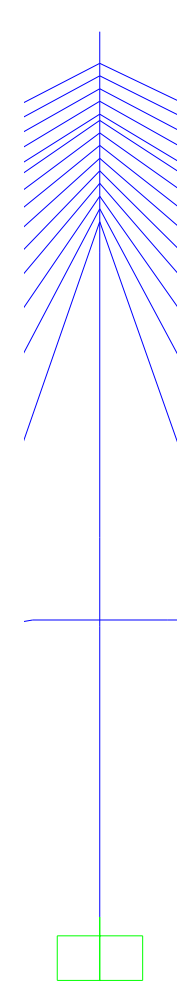

B)

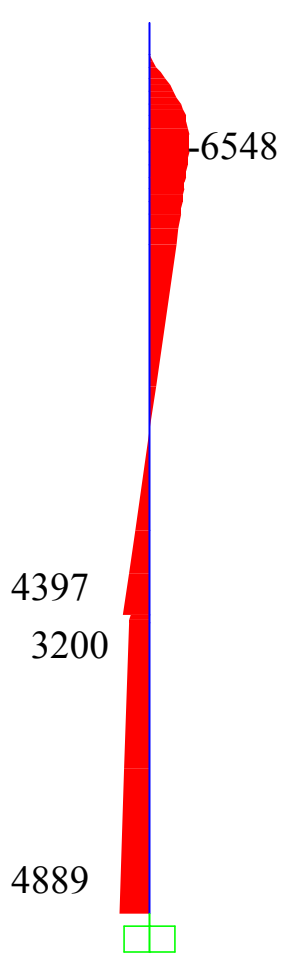

C)

8824

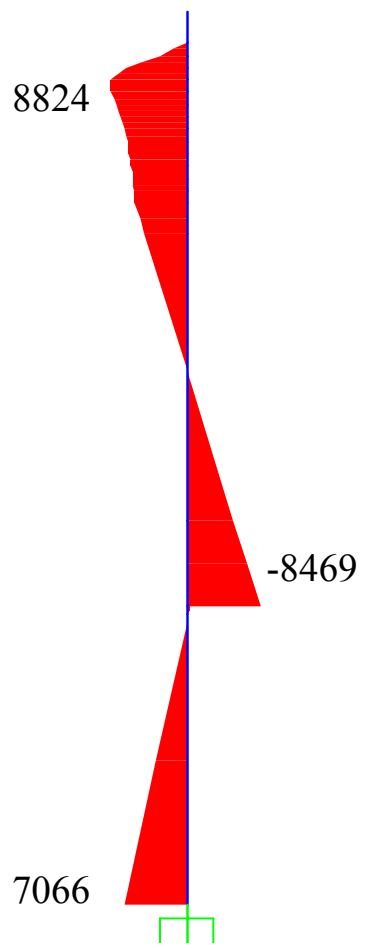

Figura 6.39: A) Forma do mastro, B) Momento no mastro devido ao peso-próprio sem protensão dos estais, C) Momento no mastro com forças do MAR(unidades: $k N, m$ ) 
6.2.4. Método de anulação dos deslocamentos no processo construtivo (MAD evolutivo)

Neste método conforme o explicado anteriormente foram anulados os deslocamentos de todas as aduelas no processo construtivo. Obtendo-se assim o resultado apresentado na Tabela 6.15 .

Tabela 6.15: Distribuição de esforços e temperaturas dos estais da Ponte Construtor João Alves (MAD evolutivo)

\begin{tabular}{|c|c|c|c|c|c|c|c|}
\hline Estai & $\left.\Delta \mathbf{T}\left({ }^{\circ} \mathbf{C}\right)\right)$ & $\begin{array}{c}\text { Força } \\
(\mathbf{k N})\end{array}$ & $\begin{array}{c}\text { Deslocamento } \\
(\mathbf{m})\end{array}$ & Estai & $\Delta \mathbf{T}\left({ }^{\circ} \mathbf{C}\right) \mathbf{)}$ & $\begin{array}{c}\text { Força } \\
(\mathbf{k N})\end{array}$ & $\begin{array}{c}\text { Deslocamento } \\
(\mathbf{m})\end{array}$ \\
\hline E1 & $-115,55$ & 6579,3 & $-0,0349$ & E29 & $-89,08$ & 5053 & $-0,0167$ \\
\hline E2 & $-110,62$ & 5920,4 & $-0,0190$ & E30 & $-108,36$ & 5908,1 & $-0,0198$ \\
\hline E3 & $-112,13$ & 5424,3 & $-0,0044$ & E31 & $-113,31$ & 5720,1 & $-0,0165$ \\
\hline E4 & $-110,49$ & 4961,4 & 0,0021 & E32 & $-116,27$ & 5397,3 & $-0,0133$ \\
\hline E5 & $-121,82$ & 4986,1 & 0,0035 & E33 & $-108,33$ & 4798,6 & $-0,0109$ \\
\hline E6 & $-118,11$ & 4569,8 & 0,0024 & E34 & $-106,84$ & 4605,6 & $-0,0078$ \\
\hline E7 & $-118,28$ & 4246,2 & $-0,0001$ & E35 & $-107,78$ & 4356,1 & $-0,0046$ \\
\hline E8 & $-113,89$ & 3944 & $-0,0027$ & E36 & $-105,79$ & 4108,3 & $-0,0014$ \\
\hline E9 & $-113,18$ & 3698,9 & $-0,0046$ & E37 & $-106,55$ & 3821,1 & 0,0011 \\
\hline E10 & $-113,31$ & 3455,1 & $-0,0061$ & E38 & $-107,99$ & 3536,7 & 0,0029 \\
\hline E11 & $-108,43$ & 3226,2 & $-0,0065$ & E39 & $-104,63$ & 3257,6 & 0,0040 \\
\hline E12 & $-109,37$ & 3021,2 & $-0,0059$ & E40 & $-107,03$ & 3005,8 & 0,0045 \\
\hline E13 & $-110,69$ & 2811,2 & $-0,0046$ & E41 & $-108,55$ & 2763,2 & 0,0039 \\
\hline E14 & $-135,19$ & 3481,8 & $-0,0031$ & E42 & $-131,76$ & 3405,1 & 0,0025 \\
\hline E15 & $-131,76$ & 3405,1 & 0,0025 & E43 & $-135,19$ & 3481,8 & $-0,0031$ \\
\hline E16 & $-108,55$ & 2763,2 & 0,0039 & E44 & $-110,69$ & 2811,2 & $-0,0046$ \\
\hline E17 & $-107,03$ & 3005,8 & 0,0045 & E45 & $-109,37$ & 3021,2 & $-0,0059$ \\
\hline E18 & $-104,63$ & 3257,6 & 0,0040 & E46 & $-108,43$ & 3226,2 & $-0,0065$ \\
\hline E19 & $-107,99$ & 3536,7 & 0,0029 & E47 & $-113,31$ & 3455,1 & $-0,0061$ \\
\hline E20 & $-106,55$ & 3821,1 & 0,0011 & E48 & $-113,18$ & 3698,9 & $-0,0046$ \\
\hline E21 & $-105,79$ & 4108,3 & $-0,0014$ & E49 & $-113,89$ & 3944 & $-0,0027$ \\
\hline E22 & $-107,78$ & 4356,1 & $-0,0046$ & E50 & $-118,28$ & 4246,2 & $-0,0001$ \\
\hline E23 & $-106,84$ & 4605,6 & $-0,0078$ & E51 & $-118,11$ & 4569,8 & 0,0024 \\
\hline E24 & $-108,33$ & 4798,6 & $-0,0109$ & E52 & $-121,82$ & 4986,1 & 0,0035 \\
\hline E25 & $-116,27$ & 5397,3 & $-0,0133$ & E53 & $-110,49$ & 4961,4 & 0,0021 \\
\hline E26 & $-113,31$ & 5720,1 & $-0,0165$ & E54 & $-112,13$ & 5424,3 & $-0,0044$ \\
\hline E27 & $-108,36$ & 5908,1 & $-0,0198$ & E55 & $-110,62$ & 5920,3 & $-0,0190$ \\
\hline E28 & $-89,08$ & 5053 & $-0,0167$ & E56 & $-115,55$ & 6579,3 & $-0,0349$ \\
\hline
\end{tabular}

A distribuição de esforços resultante apresenta valores maiores no meio do vão e nos estais de estabilidade. A distribuição harmoniosa similar a obtida no exemplo anterior é devida à anulação dos deslocamentos das aduelas passo a passo (Figura 6.40). 


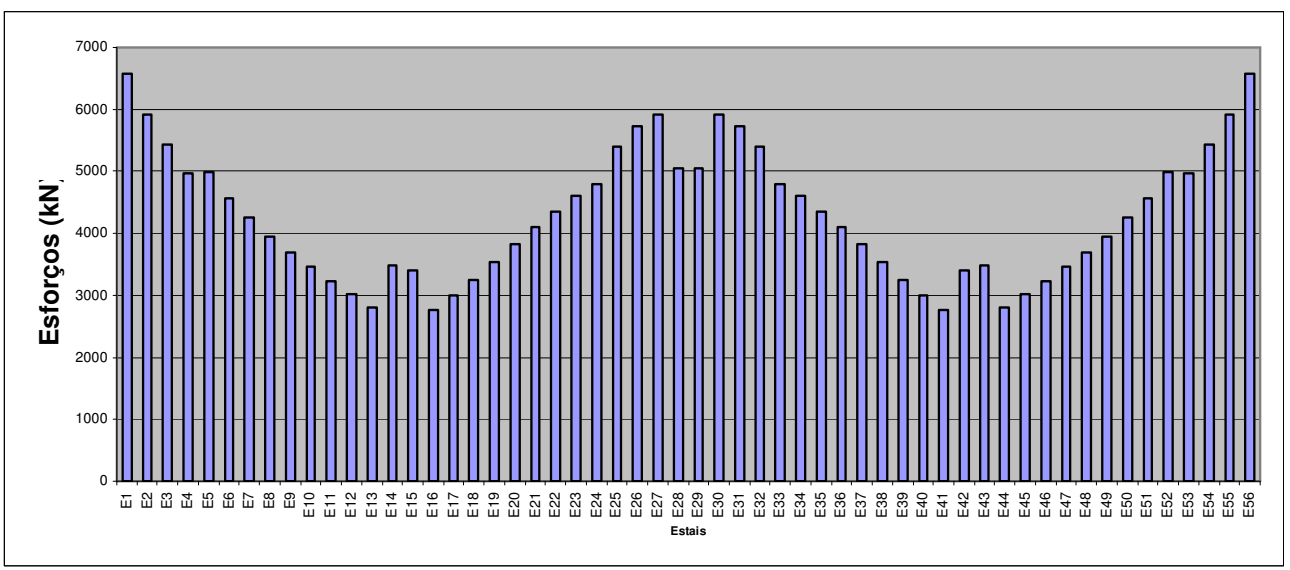

Figura 6.40: Distribuição de esforços dos estais da Ponte Construtor João Alves (Processo Construtivo)

O deslocamento central da ponte devido ao peso-próprio é de $0,58 \mathrm{~m}$ (Figura 6.41A). Após aplicadas às temperaturas, a ponte apresenta uma deformação máxima no estai E27 e E55 de 0,02m (Figura 6.41-C). Na mesma figura também são apresentadas as deformadas dos evolutivos de cada um dos métodos.

A)

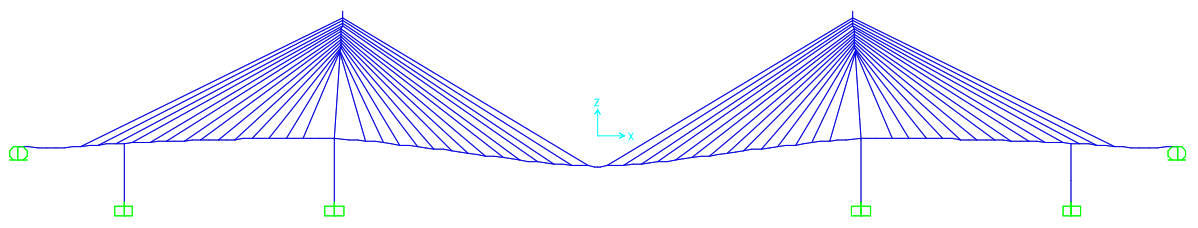

B)

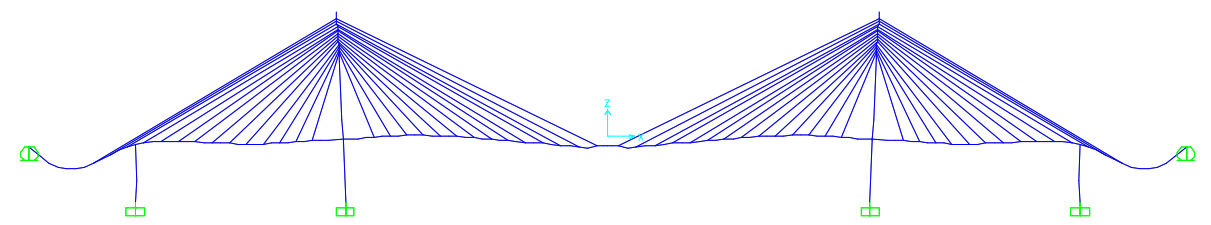

Figura 6.41: A) Deformada da ponte sem protesão dos estais, B) Deformada da ponte com forças do MAD evolutivo

Embora a distribuição de momentos do tabuleiro pareça à de uma viga continua, o fato é que este diagrama não apresenta um resultado otimizado como foi obtido nos métodos MAD e MAR (Figura 6.42). O diagrama de momentos no mastro está apresentado na Figura 6.43 . 
A)

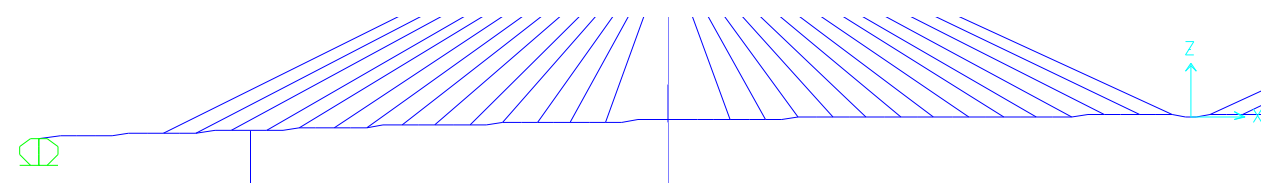

B)

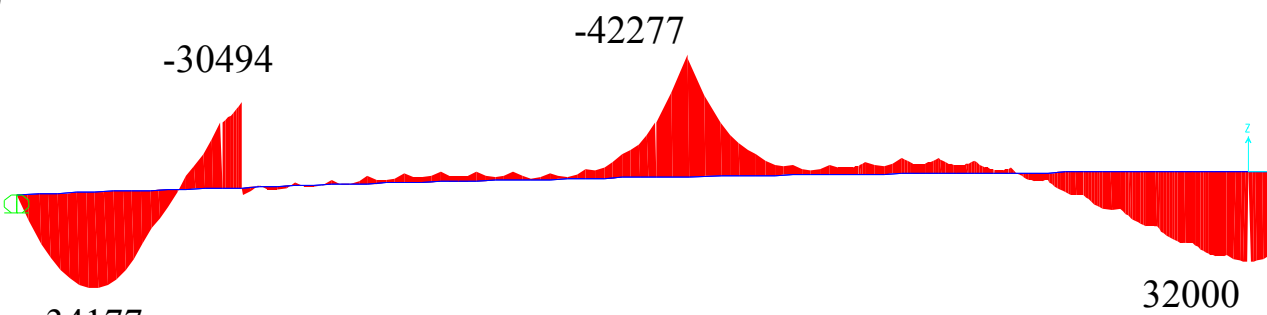

34177

C)

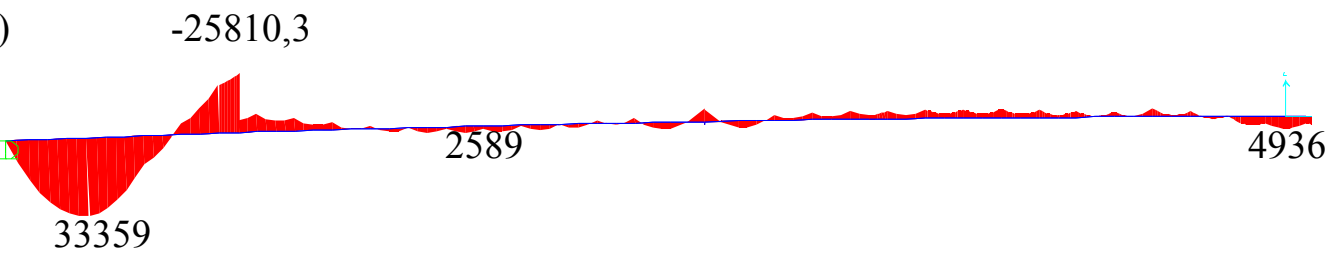

Figura 6.42: A) Forma do tabuleiro (metade), B) Momento no tabuleiro devido ao peso próprio sem protensão dos estais, C)Momento no tabuleiro com forças do MAD evolutivo(unidades: $k N, m$ ) 
A)

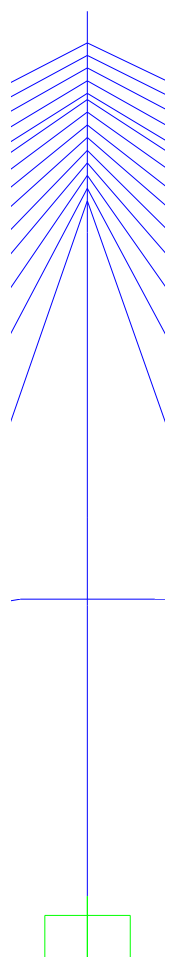

B)

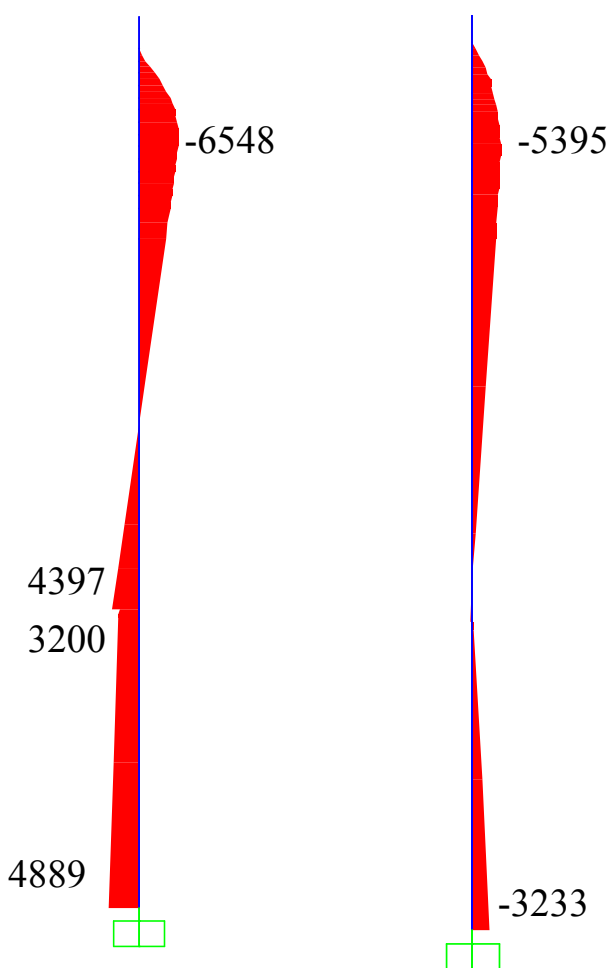

Figura 6.43: A) Forma do mastro, B) Momento no mastro devido ao peso-próprio sem protensão dos estais, C) Momento no mastro com forças do MAD evolutivo(unidades: $k N, m$ ) 


\subsubsection{Comparação dos métodos.}

\subsubsection{Fase final}

Assim como no exemplo anterior, é feita uma comparação entre os primeiros métodos. Neste caso as temperaturas dos estais não possuem uma similaridade como no exemplo anterior. A presença de um pilar secundário repercute na distribuição de esforços impedindo uma boa convergência dos métodos (Tabela 6.16).

Tabela 6.16: Comparação das temperaturas dos métodos (unidades: ${ }^{\circ} \mathrm{C}$ )

\begin{tabular}{|c|c|c|c|c|c|c|c|c|c|}
\hline ESTAIS & MTA & MAD & MAR & $\begin{array}{c}\delta \text { (MAD } \\
- \text { MAR) } \\
(\%)\end{array}$ & ESTAIS & MTA & MAD & MAR & $\begin{array}{c}\delta \text { (MAD- } \\
\text { MAR) } \\
(\%)\end{array}$ \\
\hline E1 & $-228,68$ & $-115,83$ & $-54,31$ & 53,11 & E29 & $-231,76$ & $-131,14$ & $-116,30$ & 11,32 \\
\hline E2 & $-225,33$ & 15,76 & $-102,68$ & 11,30 & E30 & $-217,97$ & $-112,36$ & $-108,50$ & 3,44 \\
\hline E3 & $-221,75$ & $-114,64$ & $-175,39$ & 34,64 & E31 & $-221,23$ & $-117,33$ & $-109,53$ & 65 \\
\hline E4 & $-224,46$ & $-119,80$ & $-173,23$ & 30,84 & E32 & $-203,44$ & $-102,30$ & $-102,24$ & 0,06 \\
\hline E5 & $-225,65$ & $-122,40$ & $-155,60$ & 21,34 & E33 & $-240,39$ & $-140,77$ & $-120,24$ & 14,58 \\
\hline E6 & $-223,22$ & $-115,30$ & $-129,36$ & 10,87 & E34 & $-219,78$ & $-116,71$ & $-108,22$ & 7,27 \\
\hline E7 & $-221,24$ & $-110,51$ & $-127,59$ & 13,39 & E35 & $-217,73$ & $-112,52$ & $-106,91$ & 4,99 \\
\hline E8 & $-218,68$ & $-102,68$ & $-126,19$ & 18,63 & E36 & $-210,86$ & $-100,06$ & $-102,85$ & 2,71 \\
\hline E9 & $-210,62$ & $-97,41$ & $-122,10$ & 20,22 & E37 & $-216,04$ & $-106,33$ & $-104,85$ & 1,39 \\
\hline E10 & $-220,99$ & $-117,42$ & -12 & 32 & E38 & $-207,56$ & $-105,32$ & \begin{tabular}{|c|}
$-99,98$ \\
\end{tabular} & 5,07 \\
\hline E11 & $-208,3$ & & & & E39 & $-214,81$ & $-123,36$ & $-101,56$ & 17,67 \\
\hline E12 & $-215,69$ & $-148,15$ & -12 & 17,93 & E40 & $-201,62$ & $-132,34$ & $-94,89$ & 28,30 \\
\hline E13 & $-214,56$ & $-172,64$ & -10 & 39,89 & E41 & $-211,33$ & $-167,53$ & $-94,11$ & 43,82 \\
\hline E14 & $-67,807$ & $-46,48$ & $-176,85$ & 73,72 & E42 & $-69,146$ & $-46,41$ & $-120,87$ & 61,60 \\
\hline E15 & $-69,146$ & $-46,41$ & $-120,87$ & 61,60 & E43 & $-67,807$ & $-46,48$ & $-176,85$ & 73,72 \\
\hline E16 & $-211,33$ & $-167,53$ & $-94,11$ & 43,82 & E44 & $-214,56$ & $-172,64$ & $-103,78$ & 39,89 \\
\hline E17 & $-201,62$ & $-132,34$ & $-94,89$ & 28,30 & E45 & $-215,69$ & $-148,15$ & $-121,58$ & 17,93 \\
\hline E18 & $-214,81$ & $-123,35$ & $-101,56$ & 17,67 & E46 & $-208,3$ & $-117,45$ & $-119,75$ & 1,92 \\
\hline E19 & $-207,56$ & $-105,32$ & $-99,98$ & 5,07 & E47 & $-220,99$ & $-117,41$ & $-126,70$ & 7,33 \\
\hline E20 & $-216,04$ & $-106,32$ & & & E48 & $-210,62$ & $-97,41$ & $-122,10$ & 20,22 \\
\hline E21 & $-210,86$ & & & & E49 & & & & \\
\hline E22 & $-217,73$ & $-112,51$ & $-106,91$ & 4,98 & E50 & $-221,24$ & $-110,51$ & $-127,59$ & 13,39 \\
\hline E23 & $-219,78$ & $-116,70$ & $-108,22$ & 7,27 & E51 & $-223,22$ & $-115,30$ & $-129,36$ & 10,87 \\
\hline E24 & $-240,39$ & $-140,77$ & $-120,24$ & 14,58 & E52 & $-225,65$ & $-122,41$ & $-155,60$ & 21,33 \\
\hline E25 & $-203,44$ & $-102,30$ & $-102,24$ & 0,06 & E53 & $-224,46$ & $-119,80$ & $-173,23$ & 30,84 \\
\hline E26 & $-221,23$ & $-117,33$ & $-109,53$ & 6,65 & E54 & $-221,75$ & $-114,65$ & $-175,39$ & 34,63 \\
\hline E27 & $-217,97$ & $-112,36$ & $-108,50$ & 3,44 & E55 & $-225,33$ & $-115,77$ & $-102,68$ & 11,31 \\
\hline E28 & $-231,76$ & $-131,15$ & $-116,30$ & 11,32 & E56 & $-228,68$ & $-115,86$ & $-54,31$ & 53,12 \\
\hline
\end{tabular}

Na Tabela 6.17 se apresenta a comparação dos esforços dos métodos estudados.

Pode-se observar que o MAD dá resultados maiores nos estais de estabilidade e nos estais do meio do vão. Na Figura 6.44 pode-se observar a falta de homogeneização 
dos resultados, a melhor distribuição de valores é o do MTA. Enquanto o MAD e MAR apresentam esforços menores nas proximidades dos apoios e esforços maiores no meio do vão e nos estais de estabilidade. Observa-se que a distribuição de esforços do MTA e o MAD é similar, enquanto a distribuição apresentada pelo MAR é diferente devido à convergência do método.

Tabela 6.17: Comparação dos esforços dos métodos (unidades:kN)

\begin{tabular}{|c|c|c|c|c|c|c|c|c|c|}
\hline ESTAIS & MTA & MAD & MAR & $\begin{array}{c}\delta \text { (MAD } \\
\text {-MAR) } \\
(\%) \\
\end{array}$ & ESTAIS & MTA & MAD & MAR & $\begin{array}{c}\delta \text { (MAD- } \\
\text { MAR) } \\
(\%)\end{array}$ \\
\hline E1 & 7006,7 & 6342,9 & 2758,4 & 56,51 & E29 & 7602,1 & 6522,8 & 6173,6 & 5,35 \\
\hline E2 & 6282,1 & 5941,2 & 4852,9 & 18,32 & E30 & 6138,6 & 5391,2 & 5615,9 & 4,00 \\
\hline E3 & 5446 & 5355,5 & 7801,1 & 31,35 & E31 & & & 5373,1 & 0,30 \\
\hline E4 & 5128,6 & 5251,9 & 712 & 26,32 & E32 & 4166,4 & & 4753 & 7,77 \\
\hline E5 & 826,2 & 5077,9 & 5879,8 & 13,64 & E33 & 5378,2 & 5821,8 & 5274,4 & 40 \\
\hline E6 & 4549,7 & 4646,1 & 4560,1 & 85 & E34 & 4270,7 & 4646,1 & 4614,6 & 0,68 \\
\hline E7 & 4198,8 & 4192,4 & 4208,7 & 39 & E35 & 3931 & 4215,9 & 4293,2 & 1,80 \\
\hline E8 & 4009 & 3758,6 & 4039,3 & 6,95 & E36 & 3608,4 & 3612,8 & 4019,1 & 10,11 \\
\hline E9 & 3536,9 & 3275,6 & 3651,7 & 10,30 & E37 & 3669,3 & 3566,5 & 3841,7 & 7,16 \\
\hline E10 & 3759,5 & 3596 & 3564,6 & 0,87 & E38 & 3300,9 & 3202,8 & 3415,7 & 6,23 \\
\hline E11 & 3481,7 & 3352,1 & 3252,9 & 2,96 & E39 & 3703,5 & 3567,6 & 3357,4 & 5,89 \\
\hline E12 & 3821,5 & & & 20,72 & E40 & & & & 16,89 \\
\hline E13 & 4054,4 & & 390 & 3,31 & E41 & 4027,3 & & 2606,4 & 37,07 \\
\hline E14 & 1065,1 & 116 & 4377,6 & 73,40 & E42 & 4,6 & 2,1 & 3285 & 63,10 \\
\hline E15 & 1154,6 & 1212,1 & 3285 & 63,10 & E43 & 1065,1 & 1164,4 & 4377,6 & 73,40 \\
\hline E16 & 4027,3 & 4141,7 & 2606,4 & 37,07 & E44 & 4054,4 & 4215,6 & 2390 & 43,31 \\
\hline E17 & 3462,4 & 3481,6 & 2893,6 & 16,89 & E45 & 3821,5 & 3881,2 & 3077,2 & 20,72 \\
\hline E18 & 3703,5 & 3567,6 & 3357,4 & 5,89 & E46 & 3481,7 & 3352 & 3252,9 & 2,96 \\
\hline E19 & 3300,9 & 3202,9 & 3415,7 & 23 & E47 & 3759,5 & 3596 & 3564,6 & 0,87 \\
\hline E20 & 3669,3 & 3566,5 & 3841,7 & 7,16 & E48 & 3536,9 & 3275,6 & 3651,7 & 10,30 \\
\hline E21 & 3608,4 & & & & E49 & & & & 6,95 \\
\hline E22 & & & 4293,2 & & E50 & & 4192,3 & 4208,7 & 0,39 \\
\hline E23 & 4270,7 & 4646 & 4614,6 & 68 & E51 & 4549,7 & 4646 & 4560,1 & 1,85 \\
\hline E24 & 5378,2 & 5821,6 & 5274,4 & 40 & E52 & 4826,2 & 5077,9 & 5879,7 & 13,64 \\
\hline E25 & 4166,4 & 4383,7 & 4753 & 77 & E53 & 5128,7 & 5251,8 & 7127,5 & 26,32 \\
\hline E26 & 5563,7 & 5356,7 & 5373,2 & 0,31 & E54 & 5446 & 5355,4 & 7801,1 & 31,35 \\
\hline E27 & 6138,6 & 5391,1 & 5615,8 & 4,00 & E55 & 6282,1 & 5941,1 & 4852,8 & 18,32 \\
\hline E28 & 7602,1 & 6522,8 & 6173,6 & 5,35 & E56 & 7006,6 & 6343,8 & 2758,4 & 56,52 \\
\hline
\end{tabular}




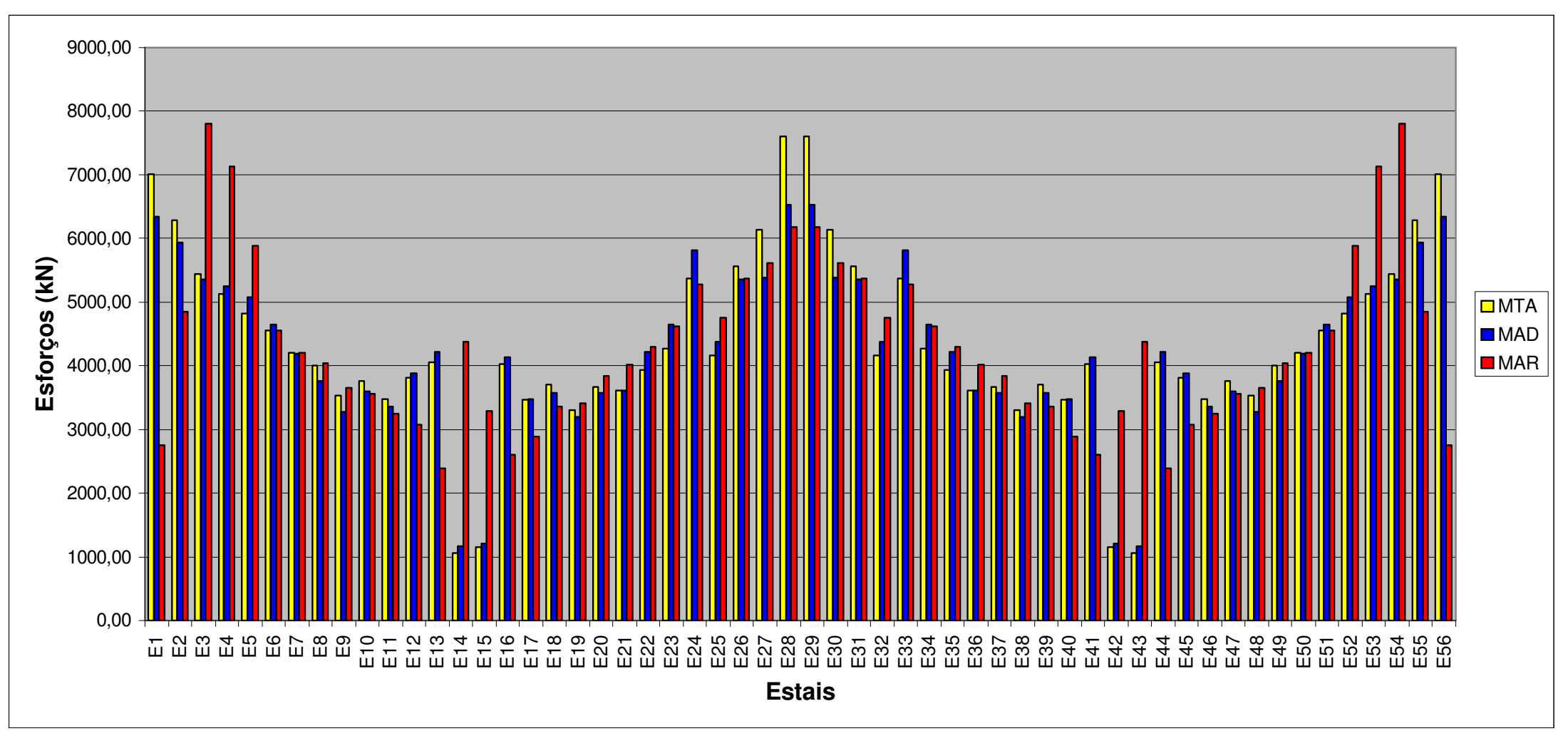

Figura 6.44: Comparação da distribuição de esforços do segundo exemplo 
Como é de esperar devido as observações anteriores, os deslocamentos do tabuleiro, os valores mais próximos de zero, assim como no exemplo anterior, foram os valores obtidos com o MAR. (Tabela 6.18)

Tabela 6.18: Comparação dos deslocamentos dos métodos (unidades: m)

\begin{tabular}{|c|c|c|c|c|c|c|c|c|c|}
\hline ESTAIS & \begin{tabular}{|c|} 
Peso \\
próprio \\
sem \\
prot.
\end{tabular} & MTA & MAD & MAR & ESTAIS & $\begin{array}{c}\text { Peso } \\
\text { próprio } \\
\text { sem } \\
\text { prot. }\end{array}$ & MTA & MAD & MAR \\
\hline E1 & $-0,0353$ & $-0,0241$ & \begin{tabular}{|l|}
$-0,0297$ \\
\end{tabular} & $-8,56 \mathrm{E}-06$ & E29 & $-0,5810$ & 0,5228 & $-0,0007$ & $5,34 \mathrm{E}-07$ \\
\hline E2 & $-0,0189$ & $-0,0103$ & $-0,0146$ & $-8,54 E-06$ & E30 & $-0,5665$ & 0,5096 & & \\
\hline E3 & $-0,0041$ & $-0,0007$ & $-0,0024$ & $-8,51 \mathrm{E}-06$ & E31 & & 0,4856 & & \\
\hline E4 & 018 & $-0,0013$ & 0,0002 & $9,11 \mathrm{E}-08$ & E32 & $-0,5039$ & 0,4531 & & $-1,6$ \\
\hline E5 & & $-0,0 \mathrm{C}$ & & & E33 & & & & \\
\hline E6 & & $-0,0$ & & 4,34 & & & & & \\
\hline E7 & & $-0,0$ & $-0,0$ & 5,1 & & & & & \\
\hline $\mathrm{E}$ & & $-0,0$ & $-0,0$ & 5,4 & & & & & \\
\hline E9 & & $-0,0$ & & 4,93 & E37 & & & & \\
\hline E10 & 189 & $-0,0233$ & 0,0029 & 4,19E-07 & E38 & $-0,2271$ & & & \\
\hline E11 & & $-0,0247$ & 0,00 & & E39 & & & & \\
\hline E12 & & $-0,0259$ & & & E40 & & & & \\
\hline E13 & 171 & $-0,02$ & & & E41 & & & & \\
\hline E14 & 151 & $-0,0$ & 0,0005 & 2,27E-07 & & & & & \\
\hline$E$ & & & & $-3,01$ & E4 & & & & \\
\hline E1 & & & & $-4,3$ & 0 & & & & \\
\hline E17 & & 0,12 & & $-5,7$ & E45 & & & & \\
\hline E18 & & 0,1618 & 021 & $-7,49$ & E46 & & 247 & 055 & E-07 \\
\hline E19 & $-0,2271$ & 0,2024 & $-0,0003$ & -8,89E-07 & E47 & 0,0189 & $-0,0233$ & 0,0029 & $2 \mathrm{E}-07$ \\
\hline E20 & & 0,2439 & $-0,0027$ & $-9,74 \mathrm{E}-07$ & E48 & 179 & $-0,0214$ & 0,0000 & $-2,76 \mathrm{E}-07$ \\
\hline E21 & $-0,3186$ & 0,2865 & $-0,0043$ & $-9,72 E-07$ & E49 & 0,0158 & $-0,0186$ & $-0,0018$ & $-2,45 \mathrm{E}-07$ \\
\hline E22 & $-0,3667$ & 0,3299 & $-0,0047$ & $-8,71 \mathrm{E}-07$ & E50 & 0,0127 & $-0,0148$ & $-0,0023$ & E-07 \\
\hline E23 & & 0,37 & $-0,0043$ & \begin{tabular}{|l|}
$-6,83 E-07$ \\
\end{tabular} & & & & & \\
\hline E24 & & & & $-4,08 \mathrm{E}-07$ & & & & & \\
\hline E25 & & & & $-7,26 \mathrm{E}-08$ & & & & & \\
\hline E26 & & & $-0,0022$ & 2,52E-07 & & $-0,0041$ & & & \\
\hline E27 & & 0,5096 & $-0,0014$ & 4,94E-07 & E55 & $-0,0189$ & $-0,0103$ & $-0,0145$ & \\
\hline E28 & $-0,5810$ & 0,5228 & $-0,0007$ & 6,01E-07 & E56 & $-0,0353$ & $-0,0241$ & $-0,0297$ & $-8,56 \mathrm{E}-06$ \\
\hline
\end{tabular}

Com respeito à distribuição de momentos no tabuleiro dos métodos dos deslocamentos (MAD) e o método das reações (MAR) apresentam as melhores distribuições dos quatro métodos estudados. Pode-se observar que existe uma diminuição dos momentos logo de aplicadas as temperaturas nos estais (Figura 6.46 e Figura 6.47). 


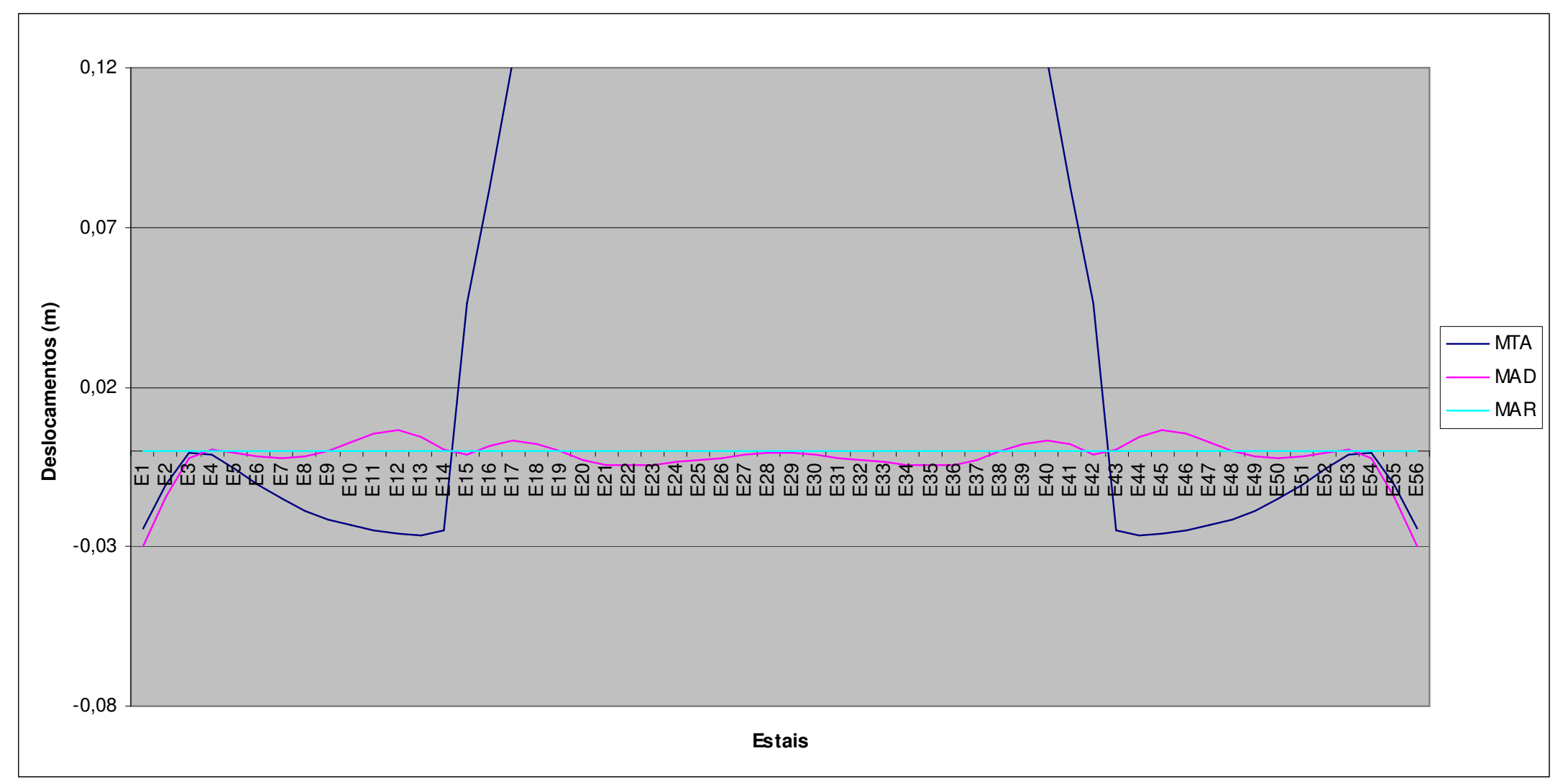

Figura 6.45: Comparação dos deslocamentos. 
A)

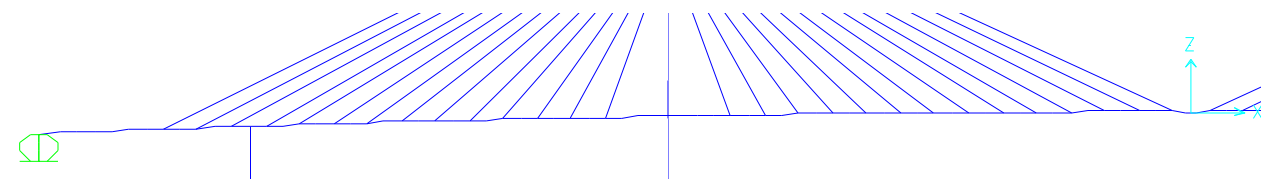

B)

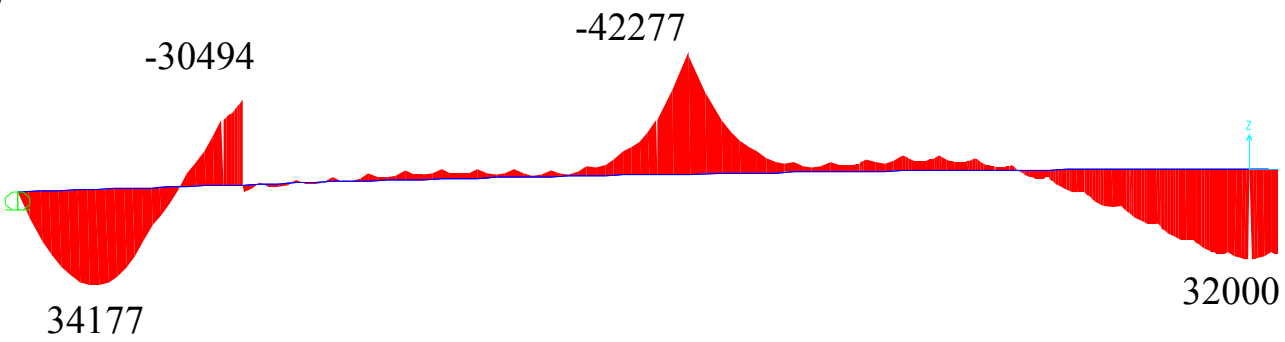

C)

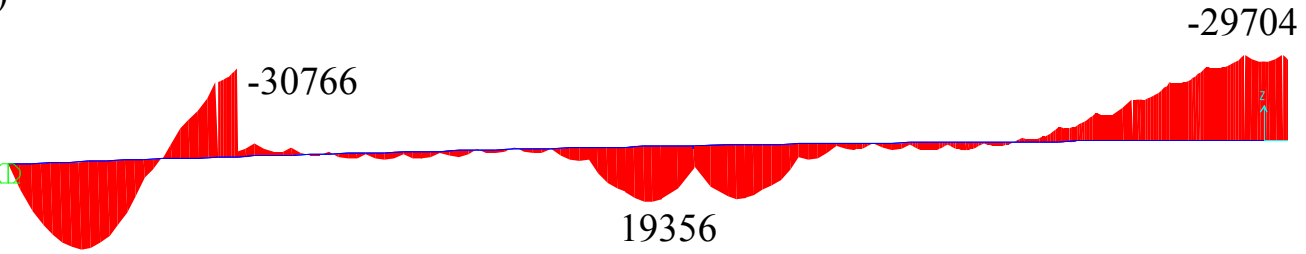

30028

D)

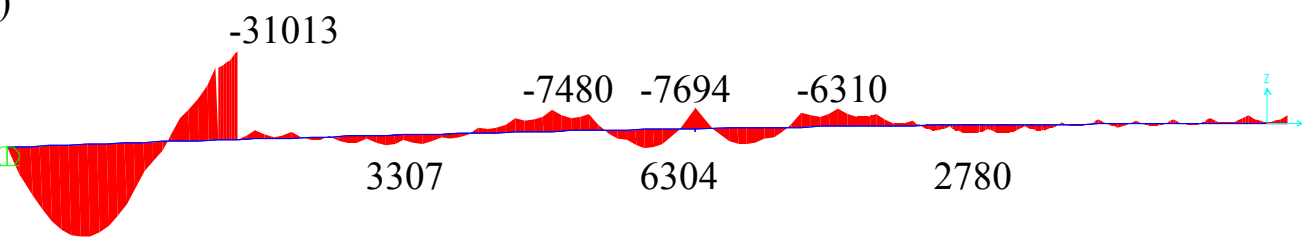

32134

E)

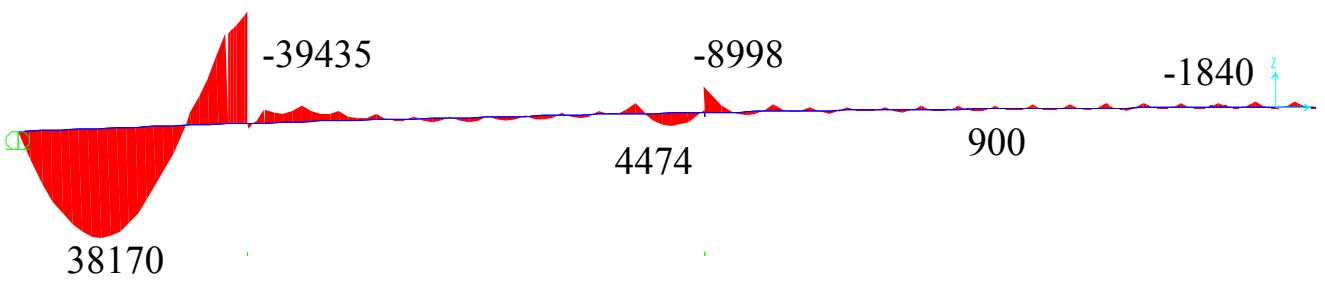

Figura 6.46: A) Forma do tabuleiro (metade), B) Momento no tabuleiro devido ao peso próprio sem protensão dos estais, C)Momento no tabuleiro com forças do MTA, D) Momento no tabuleiro com forças do MAD, E) Momento no tabuleiro com forças do MAR(unidades: $k N, m$ ) 
A)

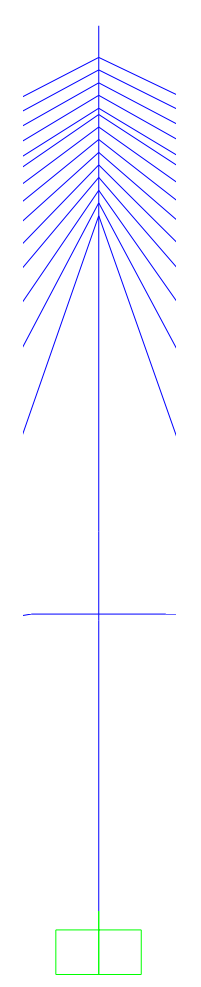

B)

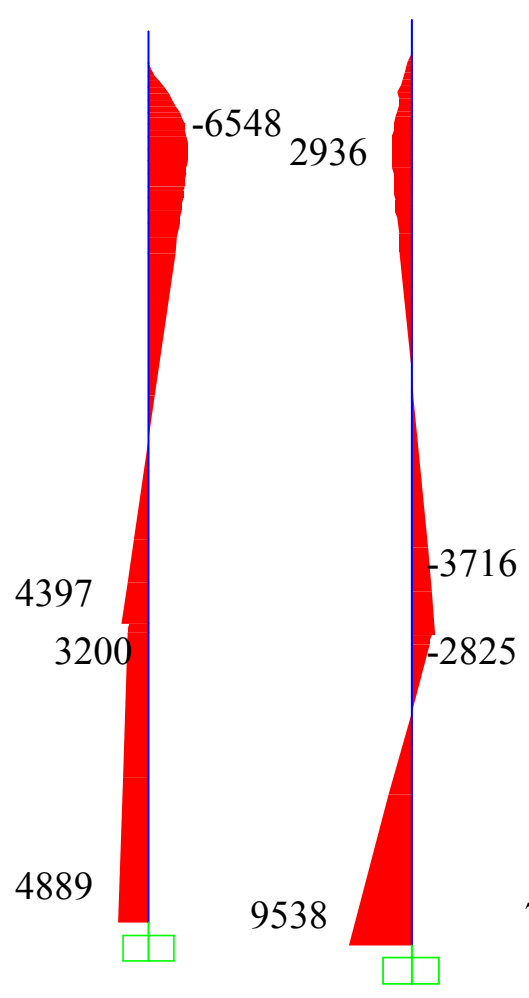

D)

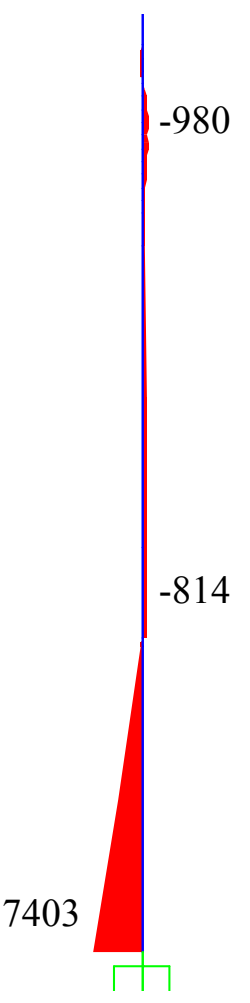

E)

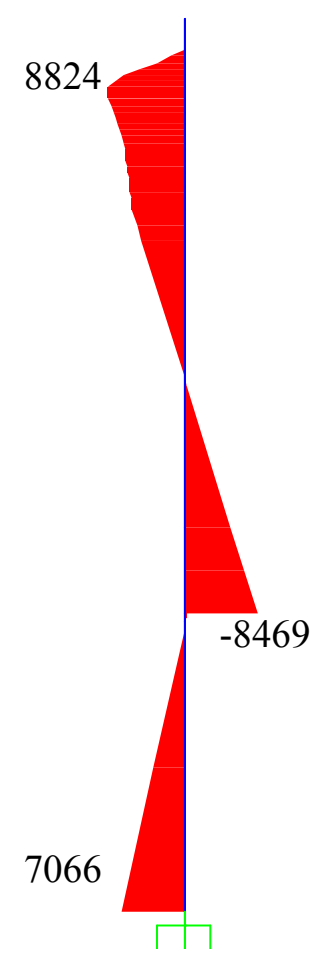

Figura 6.47: A) Forma do mastro, B) Momento no mastro devido ao peso-próprio sem protensão dos estais, C) Momento no mastro com forças do MTA,D) Momento no mastro com forças do MAD,E) Momento no mastro com forças do MAR(unidades: $k N, m$ ) 


\subsubsection{Evolutivos}

Da comparação dos evolutivos dos métodos obtem-se resultados similares aos do primeiro exemplo, no sentido de que os deslocamentos originados não são tão próximos de zero como nos estudos estáticos. Os valores de temperatura estão apresentados na Tabela 6.19

Tabela 6.19: Comparação das temperaturas dos métodos (unidades: ${ }^{\circ} \mathrm{C}$ )

\begin{tabular}{|c|c|c|c|c|c|c|c|c|c|}
\hline ESTAIS & MTA & MAD & $\begin{array}{c}\text { MAD } \\
\text { (EVOL.) }\end{array}$ & MAR & ESTAIS & MTA & MAD & $\begin{array}{c}\text { MAD } \\
\text { (EVOL.) }\end{array}$ & MAR \\
\hline E1 & $-228,68$ & $-115,83$ & $-115,55$ & $-54,31$ & E29 & $-231,76$ & $-131,14$ & $-89,08$ & $-116,30$ \\
\hline E2 & $-225,33$ & $-115,76$ & $-110,62$ & $-102,68$ & E30 & $-217,97$ & $-112,36$ & $-108,36$ & 88,50 \\
\hline E3 & $-221,75$ & $-114,64$ & $-112,13$ & $-175,39$ & E31 & $-221,23$ & $-117,33$ & $-113,31$ & 109,53 \\
\hline E4 & $-224,46$ & $-119,80$ & $-110,49$ & $-173,23$ & E32 & $-203,44$ & $-102,30$ & $-116,27$ & $-102,24$ \\
\hline E5 & $-225,65$ & $-122,40$ & $-121,82$ & $-155,60$ & E33 & $-240,39$ & $-140,77$ & $-108,33$ & $-120,24$ \\
\hline E6 & $-223,22$ & $-115,30$ & $-118,11$ & $-129,36$ & E34 & $-219,78$ & $-116,71$ & $-106,84$ & $-108,22$ \\
\hline E7 & $-221,24$ & $-110,51$ & $-118,28$ & $-127,59$ & E35 & $-217,73$ & $-112,52$ & $-107,78$ & $-106,91$ \\
\hline E8 & $-218,68$ & $-102,68$ & $-113,89$ & $-126,19$ & E36 & $-210,86$ & $-100,06$ & $-105,79$ & $-102,85$ \\
\hline E9 & $-210,62$ & $-97,41$ & $-113,18$ & $-122,10$ & E37 & $-216,04$ & $-106,33$ & $-106,55$ & $-104,85$ \\
\hline E10 & $-220,99$ & $-117,42$ & $-113,31$ & $-126,70$ & E38 & $-207,56$ & $-105,32$ & $-107,99$ & $\begin{array}{l}-99,98 \\
\end{array}$ \\
\hline E11 & $-208,3$ & $-117,46$ & $-108,43$ & $-119,75$ & E39 & $-214,81$ & $-123,36$ & $-104,63$ & $-101,56$ \\
\hline E12 & $-215,69$ & $-148,15$ & $-109,37$ & $-121,58$ & E40 & $-201,62$ & $-132,34$ & $-107,03$ & $-94,89$ \\
\hline E13 & $-214,56$ & $-172,64$ & $-110,69$ & $-103,78$ & E41 & $-211,33$ & $-167,53$ & 3,55 & $-94,11$ \\
\hline E14 & $-67,807$ & $-46,48$ & $-135,19$ & $-176,85$ & E42 & $-69,146$ & $-46,41$ & $-131,76$ & $-120,87$ \\
\hline E15 & $-69,146$ & $-46,41$ & $-131,76$ & $-120,87$ & E43 & $-67,807$ & $-46,48$ & $-135,19$ & $-176,85$ \\
\hline E16 & $-211,33$ & $-167,53$ & $-108,55$ & $-94,11$ & E44 & $-214,56$ & $-172,64$ & $-110,69$ & $-103,78$ \\
\hline E17 & $-201,62$ & $-132,34$ & $-107,03$ & $-94,89$ & E45 & $-215,69$ & $-148,15$ & $-109,37$ & $-121,58$ \\
\hline E18 & $-214,81$ & $-123,35$ & $-104,63$ & $-101,56$ & E46 & $-208,3$ & $-117,45$ & $-108,43$ & $-119,75$ \\
\hline E19 & $-207,56$ & $-105,32$ & $-107,99$ & \begin{tabular}{|c|}
$-99,98$ \\
\end{tabular} & E47 & $-220,99$ & $-117,41$ & $-113,31$ & $-126,70$ \\
\hline E20 & $-216,04$ & $-106,32$ & $-106,55$ & $-104,85$ & E48 & $-210,62$ & $-97,41$ & $-113,18$ & $-122,10$ \\
\hline E21 & $-210,86$ & $-100,05$ & $-105,79$ & $-102,85$ & E49 & $-218,68$ & $-102,68$ & $-113,89$ & $-126,19$ \\
\hline E22 & $-217,73$ & $-112,51$ & $-107,78$ & $-106,91$ & E50 & $-221,24$ & $-110,51$ & $-118,28$ & $-127,59$ \\
\hline E23 & $-219,78$ & $-116,70$ & $-106,84$ & $-108,22$ & E51 & $-223,22$ & $-115,30$ & $-118,11$ & $-129,36$ \\
\hline E24 & $-240,39$ & $-140,77$ & $-108,33$ & $-120,24$ & E52 & $-225,65$ & $-122,41$ & $-121,82$ & $-155,60$ \\
\hline E25 & $-203,44$ & $-102,30$ & $-116,27$ & $-102,24$ & E53 & $-224,46$ & $-119,80$ & $-110,49$ & $-173,23$ \\
\hline E26 & $-221,23$ & $-117,33$ & $-113,31$ & $-109,53$ & E54 & $-221,75$ & $-114,65$ & $-112,13$ & $-175,39$ \\
\hline E27 & $-217,97$ & $-112,36$ & $-108,36$ & $-108,50$ & E55 & $-225,33$ & $-115,77$ & $-110,62$ & $-102,68$ \\
\hline E28 & $-231,76$ & $-131,15$ & $-89,08$ & $-116,30$ & E56 & $-228,68$ & $-115,86$ & $-115,55$ & $-54,31$ \\
\hline
\end{tabular}


Os esforços obtidos a partir da aplicação das tensões nos estais apresentam valores esperados, que correspondam às temperaturas aplicadas Tabela 6.20

Tabela 6.20: Comparação dos esforços dos métodos (unidades:kN)

\begin{tabular}{|c|c|c|c|c|c|c|c|c|c|}
\hline ESTAIS & MTA & MAD & $\begin{array}{c}\text { MAD } \\
\text { (EVOL.) }\end{array}$ & MAR & ESTAIS & MTA & MAD & $\begin{array}{c}\text { MAD } \\
\text { (EVOL.) }\end{array}$ & MAR \\
\hline E1 & 10640,8 & 6591,3 & 6579,3 & 4385,2 & E29 & 9635,7 & 6402,6 & 5053 & 5923,6 \\
\hline E2 & 8461,1 & 6099,4 & 5920,4 & 6463,5 & E30 & 6976 & 5353,4 & 5908,1 & 5472,5 \\
\hline E3 & 6459,3 & 5438,2 & 5424,3 & 8234,1 & E31 & 5517,2 & 5304,6 & 5720,1 & 5308 \\
\hline E4 & 4967,3 & 5153,8 & 4961,4 & 6550,5 & E32 & 3952,1 & 4628,8 & 5397,3 & 4891,3 \\
\hline E5 & 3616,2 & 4814,5 & 4986,1 & 4752,6 & E33 & 4597,5 & 5601,8 & 4798,6 & 5242,4 \\
\hline E6 & 2822,2 & 4357,6 & 4569,8 & 3530,3 & E34 & 3436,9 & 4440,5 & 4605,6 & 4601,5 \\
\hline E7 & 2485 & 4018,5 & 4246,2 & 3428,3 & E35 & 3245,4 & 4114,5 & 4356,1 & 4309,7 \\
\hline E8 & 2451,1 & 3784 & 3944 & 3456,9 & E36 & 3115,5 & 3759,1 & 4108,3 & 4055 \\
\hline E9 & 2424,3 & 3583,7 & 3698,9 & 3340,4 & E37 & 3270,1 & 3809,3 & 3821,1 & 3842,6 \\
\hline E10 & 2876,4 & 3838,5 & 3455,1 & 3396,7 & E38 & 3069,5 & 3552,7 & 3536,7 & 3461,3 \\
\hline E11 & 2726,3 & 3507,3 & 3226,2 & 3200,6 & E39 & 3223,2 & 3664,4 & 3257,6 & 3340,7 \\
\hline E12 & 2900,7 & 3533 & 3021,2 & 3061,1 & E40 & 2814,3 & 3263,7 & 3005,8 & 2943,6 \\
\hline E13 & 2955,5 & 3318,9 & 2811,2 & 2597,1 & E41 & 3059 & 3344,1 & 2763,2 & 2720,6 \\
\hline E14 & 1176,4 & 1225,6 & 3481,8 & 4234,9 & E42 & 1315,3 & 1327,6 & 3405,1 & 3424,5 \\
\hline E15 & 1315,3 & 1327,6 & 3405,1 & 3424,5 & E43 & 1176,4 & 1225,6 & 3481,8 & 4234,9 \\
\hline E16 & 3059 & 3344,1 & 2763,2 & 2720,7 & E44 & 2955,5 & 3318,9 & 2811,2 & 2597,1 \\
\hline E17 & 2814,3 & 3263,7 & 3005,8 & 2943,6 & E45 & 2900,7 & 3533 & 3021,2 & 3061,1 \\
\hline E18 & 3223,2 & 3664,4 & 3257,6 & 3340,7 & E46 & 2726,3 & 3507,3 & 3226,2 & 3200,6 \\
\hline E19 & 3069,5 & 3552,7 & 3536,7 & 3461,3 & E47 & 2876,4 & 3838,5 & 3455,1 & 3396,7 \\
\hline E20 & 3270,1 & 3809,4 & 3821,1 & 3842,6 & E48 & 2424,3 & 3583,7 & 3698,9 & 3340,4 \\
\hline E21 & 3115,5 & 3759,1 & 4108,3 & 4055 & E49 & 2451,1 & 3783,9 & 3944 & 3456,9 \\
\hline E22 & 3245,4 & 4114,5 & 4356,1 & 4309,7 & E50 & 2485 & 4018,3 & 4246,2 & 3428,3 \\
\hline E23 & 3436,9 & 4440,5 & 4605,6 & 4601,5 & E51 & 2822,2 & 4357,3 & 4569,8 & 3530,3 \\
\hline E24 & 4597,5 & 5601,7 & 4798,6 & 5242,4 & E52 & 3616,2 & 4814,3 & 4986,1 & 4752,6 \\
\hline E25 & 3952,1 & 4628,6 & 5397,3 & 4891,3 & E53 & 4967,3 & 5153,7 & 4961,4 & 6550,5 \\
\hline E26 & 5517,2 & 5304,5 & 5720,1 & 5308 & E54 & 6459,3 & 5438,1 & 5424,3 & 8234,2 \\
\hline E27 & 6976 & 5353,3 & 5908,1 & 5472,5 & E55 & 8461,1 & 6099,3 & 5920,3 & 6463,4 \\
\hline E28 & 9635,7 & 6402,8 & 5053 & 5923,6 & E56 & 10640,7 & 6592,2 & 6579,3 & 4385,2 \\
\hline
\end{tabular}




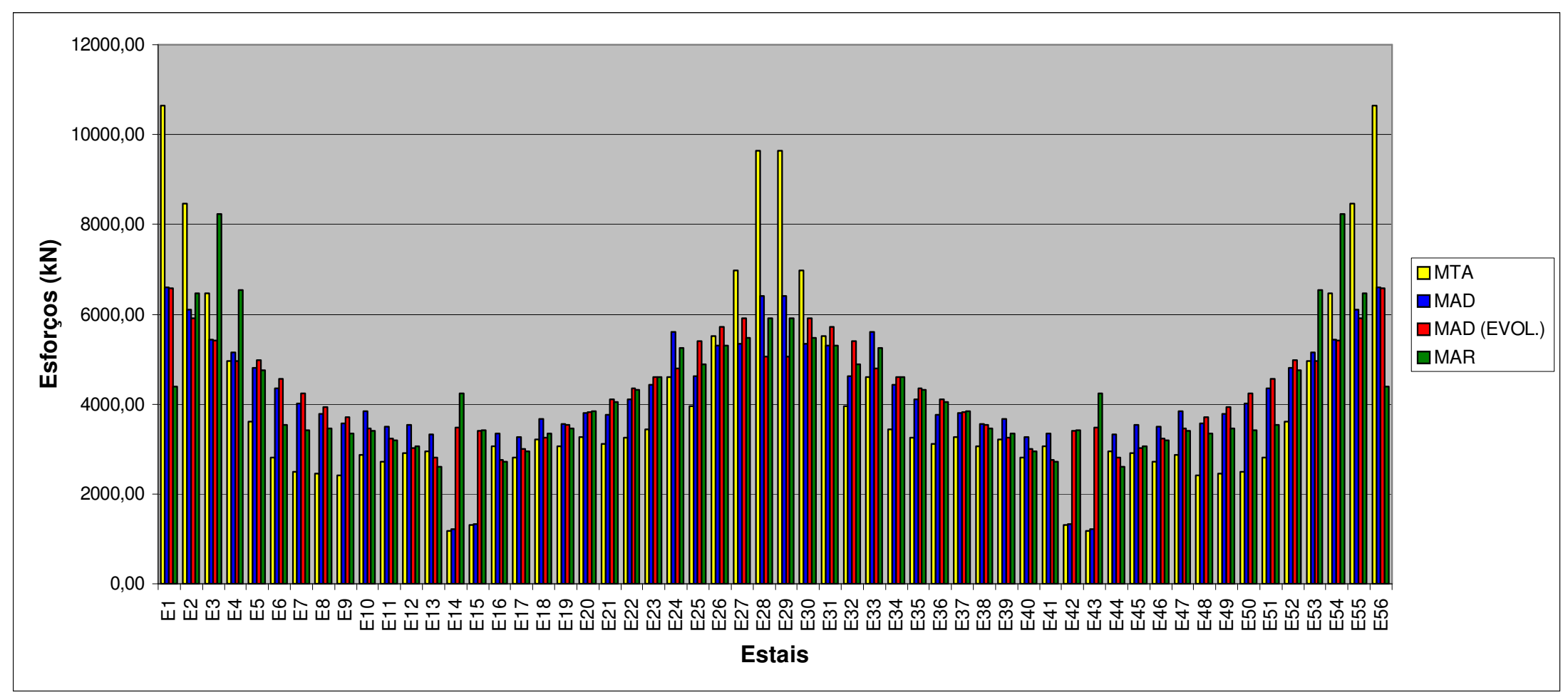

Figura 6.48: A) Momento no tabuleiro para o MTA, B) Momento no tabuleiro para o MAD, C) Momento no tabuleiro para o MAR 
Com respeito aos deslocamentos, os evolutivos dos métodos anteriormente estudados, apresentam resultados maiores que aqueles do Processo Construtivo. No MTA, MAD e MAR as tensões dos estais são calculadas com a estrutura integramente construída; enquanto no Processo Construtivo cada estai possui a tensão necessária para anular o deslocamento da aduela correspondente. (Tabela 6.21)

Tabela 6.21: Comparação dos deslocamentos dos métodos (unidades:m)

\begin{tabular}{|c|c|c|c|c|c|c|c|c|c|c|c|}
\hline EST. & $\begin{array}{c}\text { Peso } \\
\text { próprio } \\
\text { sem } \\
\text { prot. }\end{array}$ & MTA & MAD & $\begin{array}{c}\text { MAD } \\
\text { (EVOL.) }\end{array}$ & MAR & EST. & \begin{tabular}{|c|} 
Peso \\
próprio \\
sem \\
prot.
\end{tabular} & MTA & MAD & $\begin{array}{c}\text { MAD } \\
\text { (EVOL.) }\end{array}$ & MAR \\
\hline E1 & $-0,0353$ & 0,0182 & $-0,0347$ &, 0349 & $-0,0634$ & E29 & $-0,5810$ & 0,2025 & 0,0317 & $-0,0167$ & $-0,0157$ \\
\hline E2 & $-0,0189$ & 0345 & $-0,0178$ & $-0,0190$ & $-0,0358$ & E30 & $-0,5665$ & 0,3381 & 0,0224 & $-0,0198$ & $-0,0304$ \\
\hline E3 & $-0,0041$ & 0,0171 & $-0,0039$ & $-0,0044$ & $-0,0055$ & E31 & $-0,5399$ & 0,4421 & 0,0181 & $-0,0165$ & 0,0097 \\
\hline E4 & 0,0018 & $-0,0189$ & 0,0013 & 0,0021 & 0,0000 & E32 & $-0,5039$ & 0,5042 & 0,0043 & $-0,0133$ & \\
\hline E5 & 0,0053 & 0,0191 & 0,0014 & & & E33 & $-0,4616$ & & & & \\
\hline E6 & 0,0091 & 0285 & 0,00 & 0024 & 0,0 & E34 & $-0,4150$ & 0,4459 & 0,0248 & $-0,0078$ & \\
\hline E7 & 0,0127 & 181 & $-0,0$ & $-0,0001$ & $-0,0032$ & E35 & $-0,3667$ & 0,3921 & 0,0200 & $-0,0046$ & \\
\hline E8 & 0,0158 & 034 & & $-0,0027$ & $-0,0$ & E36 & $-0,3186$ & 0,3362 & & 14 & \\
\hline E9 & 0,0179 & $-0,0152$ & $-0,0258$ & $-0,0046$ & $-0,0213$ & E37 & $-0,2719$ & 0,2856 & 082 & & \\
\hline E10 & 0,0189 & $-0,0233$ & $-0,0190$ & $-0,0061$ & $-0,0235$ & E38 & $-0,2271$ & 0,2343 & 0,0062 & 0,0029 & \\
\hline E11 & 0,0189 & $-0,0273$ & $-0,0113$ & $-0,0065$ & $-0,0234$ & E39 & $-0,1841$ & 0,1943 & 0,0132 & 040 & \\
\hline E12 & 0182 & $-0,0227$ & 0,0031 & $-0,0059$ & $-0,0202$ & E40 & $-0,1425$ & 0,1526 & & & \\
\hline E13 & 0,0171 & $-0,0172$ & 0,01 & $-0,0046$ & $-0,0$ & E41 & 19 & 142 & 257 & & \\
\hline E14 & 0,0151 & $-0,0350$ & $-0,0059$ & $-0,0031$ & $-0,0089$ & E42 & $-0,0623$ & 0,0515 & 0,0022 & 0,0025 & 088 \\
\hline E15 & 0,0623 & 515 & 022 & & & E43 & 0,0151 & $-0,0350$ & 0059 & & \\
\hline E16 & 0,1019 & 142 & 0257 & 0,0039 & & E44 & 0,0171 & $-0,017$ & 143 & & \\
\hline E17 & $-0,1425$ & 526 & 187 & 0,0045 & & E45 & 0,0182 & $-0,0227$ & 031 & & \\
\hline E18 & $-0,1841$ & 1943 & 0,0131 & 0,0040 & 0,0259 & E46 & 0,0189 & $-0,0273$ & $-0,0114$ & $-0,0065$ & 234 \\
\hline E19 & $-0,2271$ & 2343 & 0,0062 & 0,0029 & & E47 & 0,0189 & $-0,0233$ & 190 & $-0,0061$ & 235 \\
\hline E20 & $-0,2719$ & 2856 & 0,0082 & 0,0011 & 0,0352 & E48 & 0,0179 & $-0,0152$ & $-0,0258$ & $-0,0046$ & 0213 \\
\hline E21 & $-0,3186$ & 3362 & 0,0108 & $-0,0014$ & 0,0386 & E49 & 0,0158 & 0,0034 & $-0,0196$ & $-0,0027$ & $-0,0128$ \\
\hline E22 & $-0,3667$ & 3921 & 0,0199 & $-0,0046$ & 0,0433 & E50 & 0,0127 & 0,0181 & 0120 & $-0,0001$ & $-0,0032$ \\
\hline E23 & $-0,4150$ & 0,4459 & & $-0,0$ & & E51 & 0,0091 & 0,0 & & & \\
\hline E24 & $-0,4615$ & 4908 & & $-0,0$ & & E52 & 0,0053 & 0,01 & & & \\
\hline E25 & $-0,5039$ & 5042 & 0,0042 & $-0,0133$ & & E53 & 0,0018 & $-0,0189$ & 0,0 & & \\
\hline E26 & $-0,5399$ & 4421 & 0,0181 & $-0,0165$ & & E54 & $-0,0041$ & 0,0171 & -0, & $-0,0$ & \\
\hline E27 & $-0,5665$ & 3381 & 0,0224 & $-0,0198$ & $-0,0$ & E55 & $-0,0189$ & 0,0345 & $-0,0178$ & $-0,0190$ & $-0,0358$ \\
\hline E28 & $-0,5810$ & 0,2025 & 0,0316 & $-0,0167$ & $-0,0157$ & E56 & $-0,0353$ & 0,0182 & $-0,0347$ & $-0,0349$ & $-0,0634$ \\
\hline
\end{tabular}




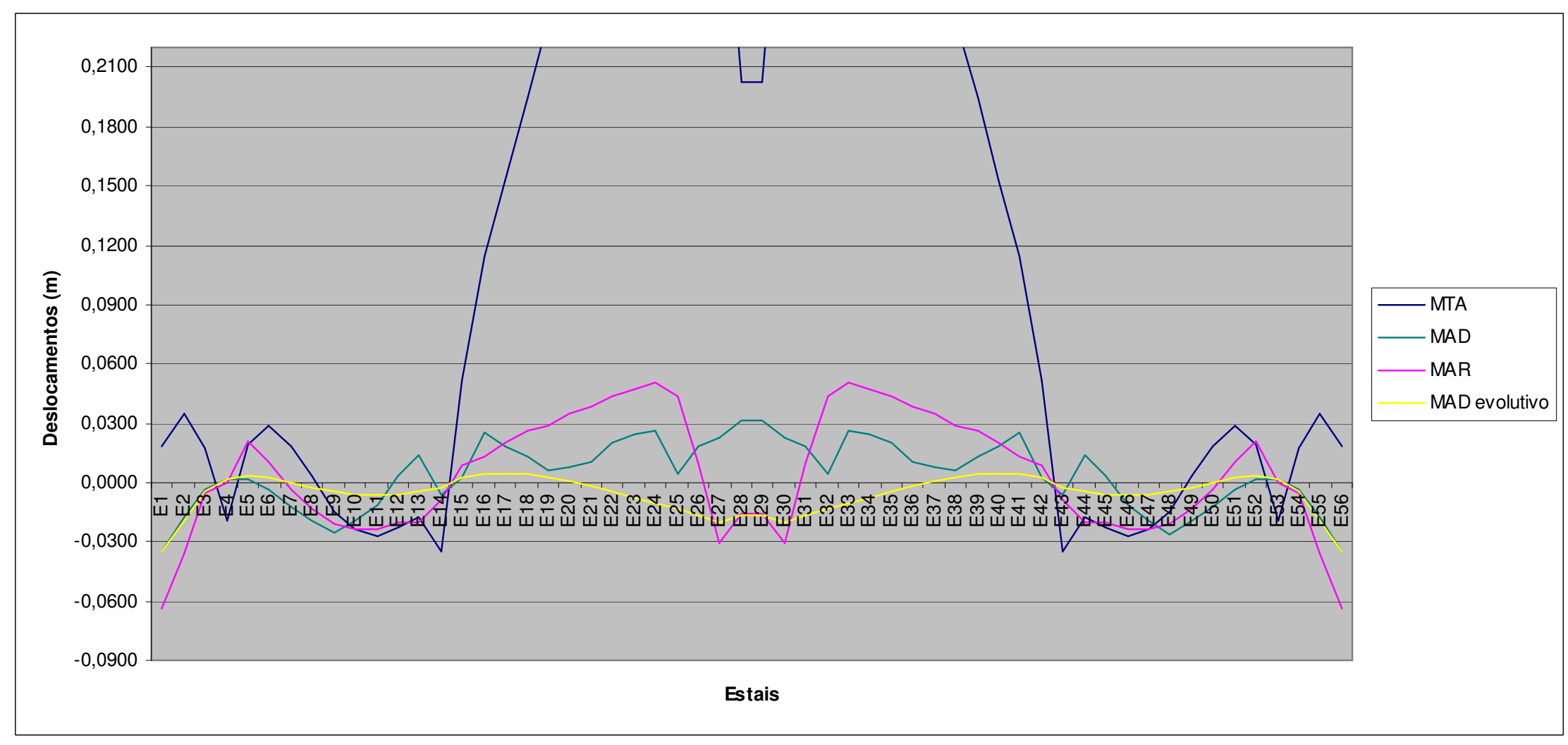

Figura 6.49: Comparação dos deslocamentos. 
A)

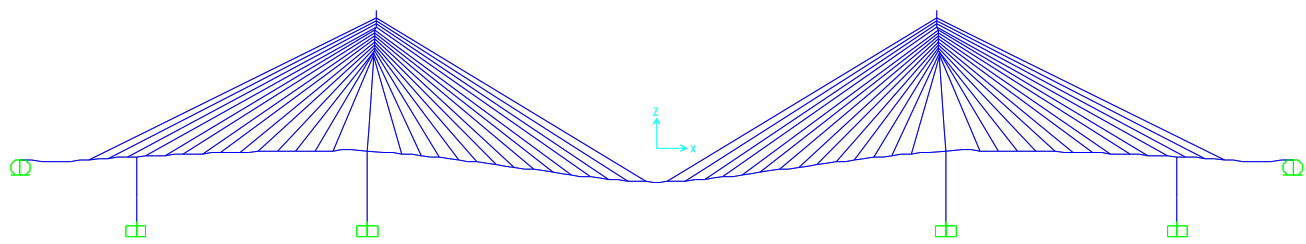

B)

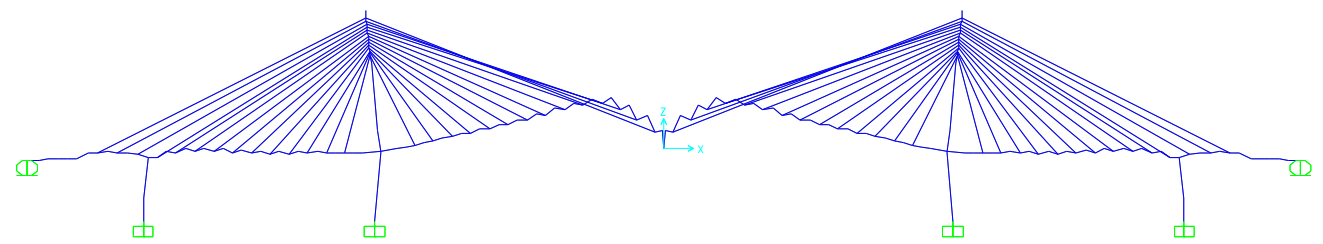

C)

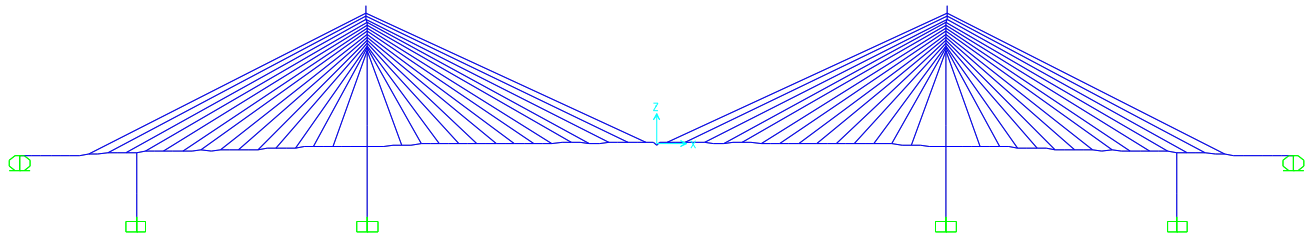

D)

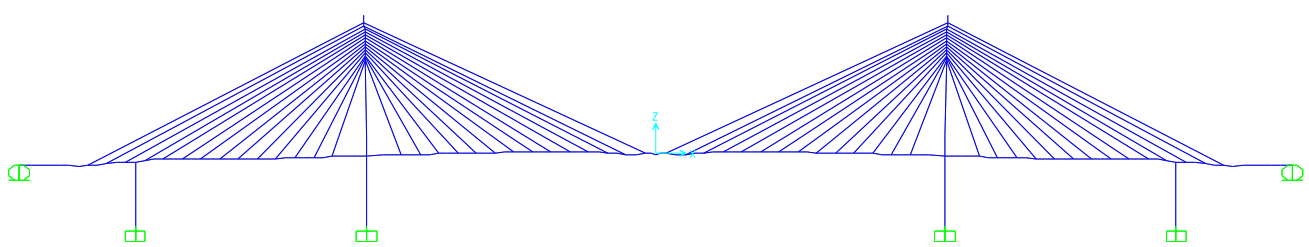

E)

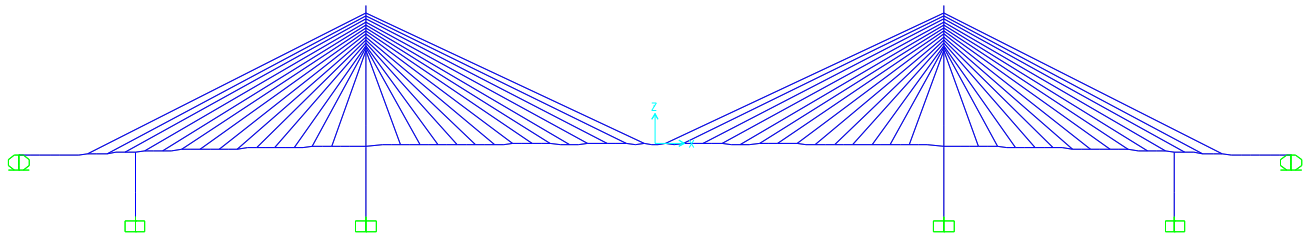

Figura 6.50: A) Deformada da ponte na fase final, B) Deformada da ponte com forças do MTA, C) Deformada da ponte com forças do MAD, D) Deformada a ponte com forças do MAR, E) Deformada da ponte com forças do MAD evolutivo

A distribuição de momentos no tabuleiro apresenta valores altos para o MTA e assim que o calculo vai sendo refinado com o MAD e o MAR os resultados começam a ser menores e se aproximar a um formato de momento de viga continua. O diagrama de momentos mais similar a uma viga continua é o do MAD evolutivo (Figura 6.51). O diagrama de momentos no mastro está apresentado na Figura 6.52. 
A)

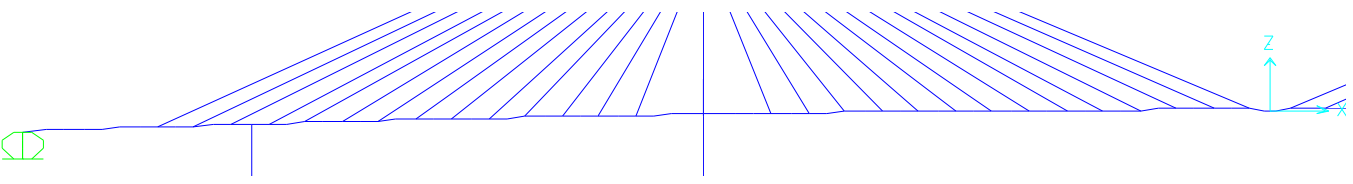

B)

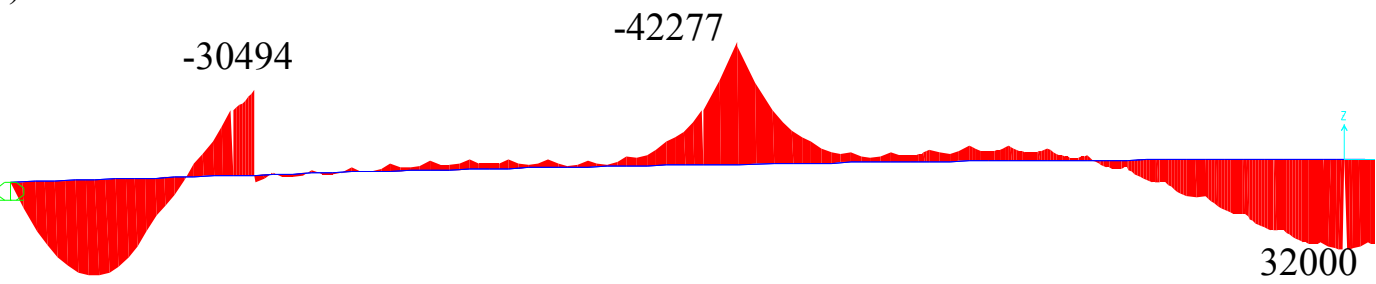

34177

C)

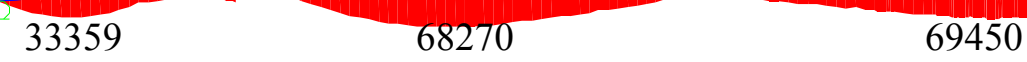

D)

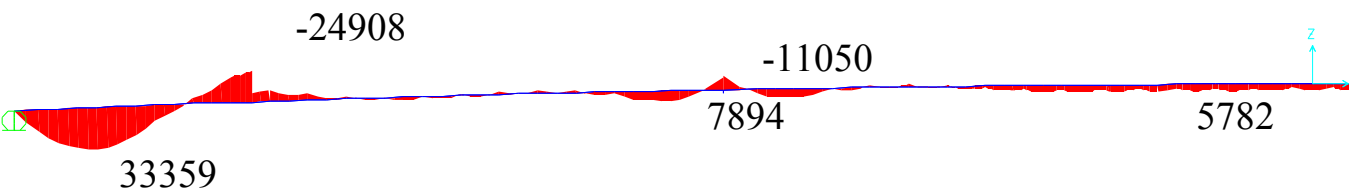

E)

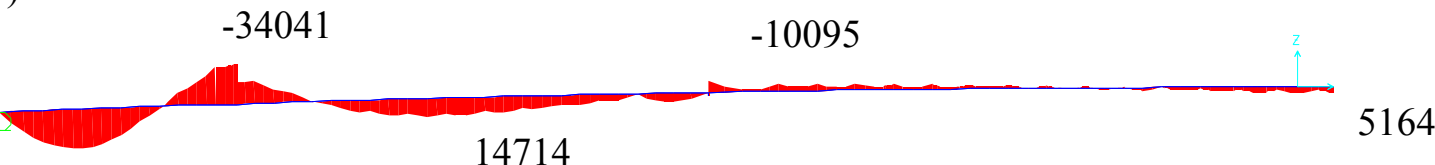

F)

33359

$-5943$

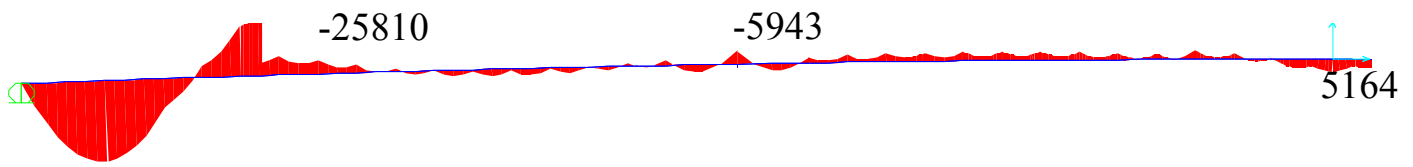

33359

Figura 6.51: A) Forma do tabuleiro (metade) na fase final, B) Momento no tabuleiro devido ao peso próprio sem protensão dos estais, C)Momento no tabuleiro com forças do MTA, D) Momento no tabuleiro com forças do MAD, E) Momento no tabuleiro com forças do MAR, F) Momento no tabuleiro com forças do MAD evolutivo(unidades: $k N, m$ ) 
A)

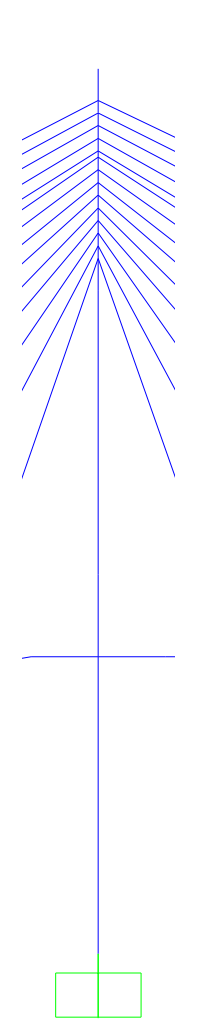

B)

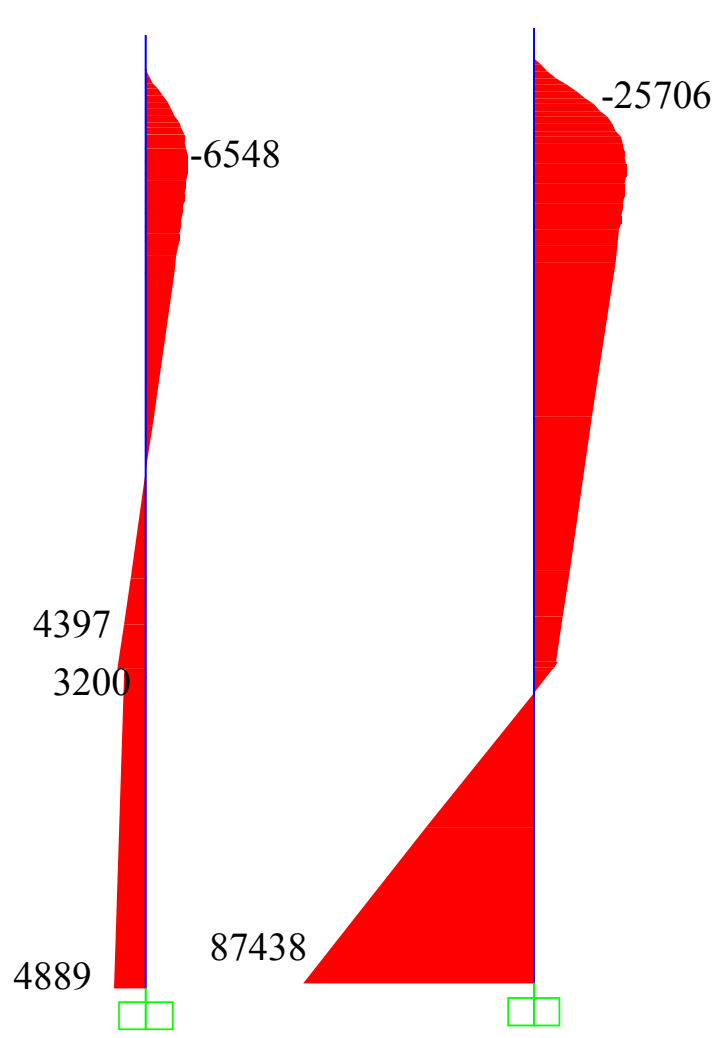

D)

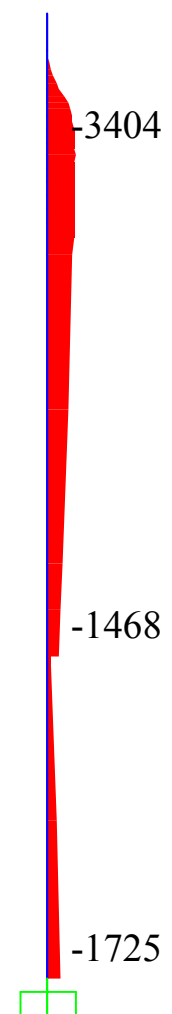

E)

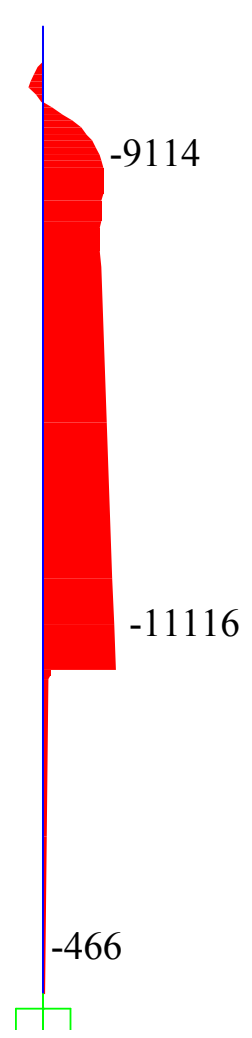

F)

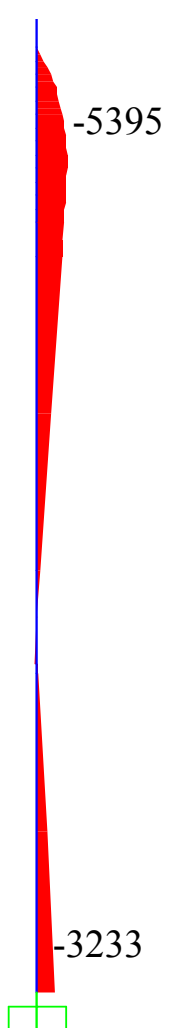

Figura 6.52: A) Forma do mastro, B) Momento no mastro devido ao peso-próprio sem protensão dos estais, C) Momento no mastro com forças do MTA,D) momento no mastro com forças do MAD, E) Momento no mastro com forças do MAR, F) Momento no mastro com forças do MAD evolutivo(unidades: $\boldsymbol{k} N$, $\boldsymbol{m}$ ) 


\section{CONCLUSÕES}

\subsection{Considerações gerais}

Do estudo dos métodos construtivos, conclui-se que o cimbramento geral apresenta várias dificuldades para estabelecer uma distribuição de esforços. Nesse caso, a ponte passa de uma configuração com apoios intermediários quase indeslocáveis a uma situação sem estes apoios. As protensões dos estais teriam de ser efetuadas com a ponte cimbrada e, portanto, o estudo a ser realizado teria de levar em conta a alta hiperestaticidade que se apresenta, misturando apoios flexíveis (cabos) com apoios rígidos (cimbre). Os outros métodos (lançamentos progressivos e consolos sucessivos) não apresentam essa dificuldade exacerbada pelas diferenças de rigidez. Nesta pesquisa, escolheu-se estudar o método de consolos sucessivos.

Para a obtenção dos esforços de instalação dos cabos, escolheu-se uma metodologia relativamente usual, mas que apresentou uma alta instabilidade numérica. Devido a esse fato, todas as tentativas de resolução direta não tiveram sucesso. Esse problema suscitou, então, uma outra forma de resolução, o Método dos Mínimos Quadrados (MMQ). Novamente o problema da convergência se apresentou. Ele só foi contornado com a consideração de resultados anteriormente conhecidos, correspondentes à solução isostática (articulada em todos os cruzamentos estaistabuleiro) como primeira iteração do método. Além disso, estabeleceram-se limites para que a solução não se afastasse muito desses primeiros valores.

No caso dos estais de estabilidade, chega-se à conclusão que, para os métodos MAD e MAR é necessário trabalhar com a anulação dos deslocamentos horizontais no mastro, já que os apoios laterais do tabuleiro, por terem deslocamentos efetivos nulos, não fornecem equações adicionais.

Com o uso de programas mais sofisticados e de um maior numero de cifras significativas o problema talvez pudesse ter tido uma solução direta.

\subsection{Conclusões dos estudos na configuração final}

No primeiro exemplo, da comparação do MAD e o MAR, conclui-se que as temperaturas fictícias empregadas nos métodos não são muito diferentes; o mesmo 
ocorre com os esforços. A maior diferença encontra-se nos estais de estabilidade (próximos ao apoio) e nos estais próximos ao mastro.

No segundo exemplo (Ponte Construtor João Alves), as diferenças entre as temperaturas e os esforços seguem o mesmo comportamento que no exemplo anterior, as maiores diferenças estão próximas aos pilares laterais e aos mastros. Porém, os valores de deslocamento são mais elevados que no exemplo anterior e os esforços apresentam uma distribuição não uniforme, causada pelo pilar secundário. Com respeito aos deslocamentos finais do tabuleiro, o MAR é o único método que apresenta valores nulos. Os demais métodos apresentam resultados próximos de zero. Os momentos nos mastros e nos tabuleiros de ambos os exemplos apresentam uma variação dos seus diagramas.

No primeiro exemplo, para o MTA ocorre uma inversão do diagrama com respeito ao do peso próprio sem protensão dos estais. $\mathrm{O}$ intervalo de valores dos momentos do tabuleiro no vão central devido ao peso próprio é [-89944 kN; 40871 kN] e devido ao MTA é [-23360,4 kN; 37570 kN]. Para o mastro, o intervalo de momentos acima do tabuleiro devido ao peso próprio é [-2479 kN; $124578 \mathrm{kN}$ ] e devido ao MTA é [-59285 kN; $0 \mathrm{kN}$ ]. Embora os valores de momento do tabuleiro tenham diminuído para o MTA, algum valor aumenta no mastro, mas também diminuem em media.

No caso do MAD e MAR os valores são similares e ambos apresentam valores mais próximos aos de uma viga contínua. Para o MAD, os valores do tabuleiro no vão central variam entre $[-3500 \mathrm{kN} ; 1750 \mathrm{kN}]$ e no mastro acima do tabuleiro [-17181 kN; -1641,3 kN], enquanto para o MAR os limite no tabuleiro são [-3500 kN; $1750 \mathrm{kN}]$ e no mastro [-16923 kN; -1366 kN].

No segundo exemplo, os intervalos de momento para o peso próprio sem protensão dos estais são: [-42277 kN; $32000 \mathrm{kN}$ ] no tabuleiro e [-6548 kN; $4397 \mathrm{kN}]$ no mastro. Para o MTA, [-29704 kN; 19356 kN] no tabuleiro e [-3716 kN; 2936 kN] no mastro. Para o MAD, os limites no tabuleiro são [-7694 kN; 6304 kN] e no mastro [-980 kN; -814 kN], enquanto para o MAR os limites no tabuleiro são [-8998 kN; $900 \mathrm{kN}]$ e no mastro [-8469 kN; $8824 \mathrm{kN}]$. Nesse caso, o MAD nos dá como resultado o melhor diagrama de momento no mastro e o MAR nos dá o melhor valor de momento no tabuleiro. Embora o MAD apresente uma boa distribuição de momento no tabuleiro e no mastro, o MAR apresenta uma boa distribuição de momento no tabuleiro e uma não tão boa no mastro. 
As diferenças entre o MAD e MAR estão ligadas a diferentes dificuldades de convergência e diferentes condições de contorno.

\subsection{Conclusões dos estudos evolutivos}

No caso dos evolutivos, as temperaturas empregadas foram as encontradas no estudo da ponte na configuração final. Os resultados obtidos nesse caso não apresentam valores de deslocamentos muito próximos de zero, os valores máximos localizam-se no meio do vão para ambos exemplos. Isso se deve ao fato de o MTA, MAD e MAR serem estudados na configuração final da ponte, cujos resultados são afetados pelo processo construtivo.

No caso dos evolutivos, os momentos não apresentam os diagramas desejados, pois os esforços dos estais não foram estudados para a construção da ponte. No primeiro exemplo, o intervalo de valores dos momentos do tabuleiro no vão central, devido ao evolutivo do MTA, é [-4465 kN; $34512 \mathrm{kN}$ ] e, para o mastro, o intervalo de momentos acima do tabuleiro é $[-7511 \mathrm{kN} ; 33520 \mathrm{kN}]$. No caso do evolutivo do MAD, os limites do tabuleiro são [-4465 kN; $2240 \mathrm{kN}$ ] e no mastro acima do tabuleiro [-44203 kN; $80518 \mathrm{kN}$ ]. Enquanto para o MAR os limites no tabuleiro são [-4465 kN; $2243 \mathrm{kN}$ ] e no mastro [-4317 kN; $80279 \mathrm{kN}$, para o MAD evolutivo o intervalo de momentos no tabuleiro no meio do vão é $[-8128 \mathrm{kN} ; 5608 \mathrm{kN}]$ e no mastro acima do tabuleiro [-2473 kN; $40283 \mathrm{kN}$ ]. Nota-se uma similaridade entre os valores do MAD e do MAR, mas a melhor distribuição de momentos é a apresentada no MAD evolutivo.

No segundo exemplo, os intervalos de momentos para o MTA são [0 kN; 69450 kN] no tabuleiro e [-25706 kN; -6105 kN] no mastro. Para o MAD, os limites no tabuleiro são [-11050 kN; 5782 kN] e no mastro [-3404 kN; 1468 kN], enquanto para o MAR os limites no tabuleiro são [-10095 kN; $5164 \mathrm{kN}$ ] e no mastro [-9114 kN; -11116 kN]. Para o MAD evolutivo o intervalo de momento no tabuleiro é [-5943 kN; $5164 \mathrm{kN}$ ] e no mastro é [-5395 kN; $579 \mathrm{kN}]$.

Nesse caso, a melhor distribuição de momentos também é a apresentada pelo MAD evolutivo.

Conclui-se então que, para uma melhor solução, é necessário controlar as flechas na fase construtiva utilizando o método do MAD ou MAR em todas as fases 
construtivas (inclusive na configuração final). Assim, poder-se-ia tomar uma decisão melhor se fosse usado um processo que contemple não só a fase final da ponte, mas também todas as fases da sua construção.

\subsection{Conclusões finais sobre os resultados}

De uma maneira geral pode-se dizer que os resultados obtidos são satisfatórios para MAD, MAR ou MAD evolutivo. Qualquer um deles pode ser usado.

Os desvios de obra gerarão alterações maiores que as aqui calculadas. As dificuldades de convergência foram contornadas com aproximação aceitável, mas não com precisão absoluta. O MAD e MAR deram sempre resultados diferentes.

\subsection{Sugestões para trabalhos futuros}

Como sugestão para trabalhos futuros podemos citar:

- Aplicação desses procedimentos usando programas que permitam considerações de mais cifras significativas para verificar se a convergência se resolve.

- Aplicação do MAD ou MAR a cada etapa do faseamento controlando flechas ou reações fictícias em todos os estais. O processo será bem mais trabalhoso, mas o resultado esperado é melhor.

- Aplicação desses procedimentos a outras configurações de obras estaiadas, especialmente arranjo de estais em leque.

- Aplicação desses procedimentos a outros métodos construtivos como lançamentos progressivos e cimbramento geral.

- Aplicação desses procedimentos a pontes curvas. 


\section{REFERENCIA BIBLIOGRAFICA}

AGRAWAL, T.P., Cable-stayed bridges - Parametric study, Journal of Bridge Engineering, vol. 2, pp. 61-67, 1997.

ALMEIDA, PEDRO AFONSO DE OLIVEIRA; STUCCHI, FERNANDO REBOUÇAS; RODRIGUES, JOSE FERNANDO SOUSA; WAIBERG, MARCELO; BERGUER, DANIEL Retroanálise de ensaios na $3^{\text {a }}$ ponte sobre o Lago Sul de Brasília, Simpósio EPUSP sobre estruturas de concreto, São Paulo, 2003.

ALMEIDA, SÉRGIO MARQUES FERREIRA DE, SOUZA, VICENTE CUSTÓDIO MOREIRA DE, CORDEIRO, THOMAS JOSÉ RIPPER, Processos construtivos de pontes e viadutos pré-moldados no Brasil, 1 Congresso Nacional da Indústria de Pré-fabricação em Betão, Porto-Portugal, v.1, p.139-154, 2000

BEHIN, Z. e MURRAY, D. W., T.P., A substructure - frontal technique for cantilever erection analysis of cable-stayed bridges, Computer and Structures, vol. 42, pp. 145-157, 1992

CHEN, D. W., AU, F. T. K., THAM, L. G. e LEE, P. K. K.., Determination of initial cable forces in prestressed concrete cable-stayed bridges for given design deck profiles using the force equilibrium method, Computer and Structures, vol. 74 , pp. $1-9,2000$

COMBAULT, JACQUES, Conceptual design of Bridges, $1^{\circ}$ Simpósio Internacional de Pontes e Grandes Estruturas, São Paulo-Brasil, 2008

EL DEBS, MOUNIR KHALIL. Introdução às pontes de concreto. 2007. Notas de Aula-Escola de Engenharia de São Carlos, Universidade de São Paulo. São Carlos 
Golebiewski, B., O Projeto e a Construção da Ponte Estaiada do Rio Paranaiba - Divisa MG-MS - BR 497, $1^{\circ}$ Simpósio Internacional de Pontes e Grandes Estruturas, São Paulo-Brasil, 2008

GIMNSING, N.J, Cable-supported bridges. Cichester, John Wiley. 1993. 400p.

JANJIC, D., PIRCHER, M., PIRCHER, M, Optimization of cable tensioning in cabled-stayed bridges, Journal of Bridges Engineering, vol. 8, pp. 131-137, MaioJunho ,2003.

PODOLNY, W.; SCALZI, J.B. Construction and design of cable-stayed bridges. New York. John While, 1976. 506p.

PONCE DELGADO; A. Puente Libertador Gereral San Martin. MontevideoUruguay, Amesur. 1992. 180p.

SCHMID, MANFRED THEODOR, Pontes estaiadas - um pouco de sua historia, Concreto - IBRACON (Instituto Brasileiro de Concreto), São Paulo, vol. 48, pp. 9092,Abril,2008.

SOUZA, SÉRGIO MARQUES DE, Pontes de Concreto Protendido Executadas por Empurramentos Sucessivos, Anais do Seminário sobre Concreto Protendido Associação Brasileira de Pontes e Estruturas, Rio de Janeiro, vol. 1, pp. 5-15,1983.

STUCCHI, F.R. Pontes e grandes estruturas. 1999. Notas de Aula-Escola Politécnica, Universidade de São Paulo. São Paulo.

TORNERI, P. Comportamento estrutural de pontes estaiadas: comparação de alternativas. 2002. 1v. Dissertação (Mestrado)-Escola Politécnica, Universidade de São Paulo. São Paulo.

TROITSKY,M.S., Cable-stayed bridges. William Clowes \& Sons, 1977. 385p. 
VARGAS, L.A.V. Comportamento estrutural de pontes estaiadas: efeitos de segunda ordem. 2007. 1v. Dissertação (Mestrado)-Escola Politécnica, Universidade de São Paulo. São Paulo.

WAIMBERG, M. O método dos lançamentos progressivos para a execução de pontes em concreto protendido. 2002. 1v. Dissertação (Mestrado)-Escola Politécnica, Universidade de São Paulo. São Paulo.

WALTHER, R., et al., Cable stayed bridges, Lausanne: Presses Polytechniques, 1999, 225 pag.

WANG, P. H., TSEN, T. C. e YANG, C. G., Initial shape of cable-stayed bridges, Computer and Structures, vol. 46, pp. 1095-1106, 1993 